Silvia Marengo

Exchange Rate Policy for MERCOSUR: Lessons from the European Union 


\section{Exchange Rate Policy for MERCOSUR: Lessons from the European Union}

In January 1995, four Latin American countries, Argentina, Brazil, Uruguay and Paraguay joined their destinies within a common and ambitious enterprise called MERCOSUR. MERCOSUR, the Common Market of the South, represents an important economic integration area that generates a GDP of \$US 600 billion, providing a market of 200 million people spread over an area of 12 million square $\mathrm{km}$. Initially, MERCOSUR performance has been more than successful, as intraMERCOSUR trade has increased significantly. However, the elimination of intraMERCOSUR tariffs will not be efficient if at the same time the sharp variability of nominal exchange rates artificially affects the relative prices of different products. The question as to the choice of the optimal exchange rate system to be adopted among MERCOSUR countries becomes critical if MERCOSUR states attempt to go further along the path of increasing their trade flows of goods and services. The study contributes to filling this gap by providing some alternative answers to this issue. The analysis has been based on three pillars: a theoretical review of exchange rate systems; a review of the European experience; and an analysis of the Latin American experience.

Silvia Marengo was born in Buenos Aires in 1963. After graduating in Economics, she joined the Research Department of the BCRA (Central Bank of Argentine Republic). In 1992, she received her Masters degree in Public Policies at the Di Tella Institute (Buenos Aires)-Inter-American Development Bank (Washington); and in 1993 she graduated from the Advanced Studies Program in International Economic Policy Research in Kiel. Afterwards, she joined the Institute of Economic Theory of the Universität der Bundeswehr Hamburg, as an Associate Researcher where she received her Ph.D. in Economics in 1997. Since January 1998 she works as a Senior Economist at Credit Suisse Private Banking (Zürich). 
Exchange Rate Policy for MERCOSUR:

Lessons from the European Union 


\section{SCHRIFTEN ZUR WIRTSCHAFTSTHEORIE UND WIRTSCHAFTSPOLITIK}

Herausgegeben von

Rolf Hasse, Wolf Schäfer, Thomas Straubhaar und Klaus W. Zimmermann

Band 9

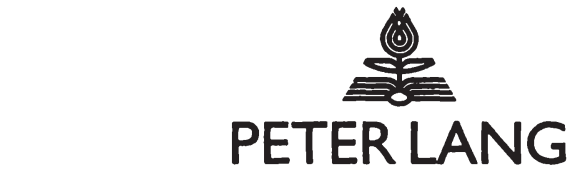

Frankfurt am Main - Berlin · Bern - New York · Paris · Wien 
Silvia Marengo

\section{Exchange Rate Policy for MERCOSUR: Lessons from the European Union}

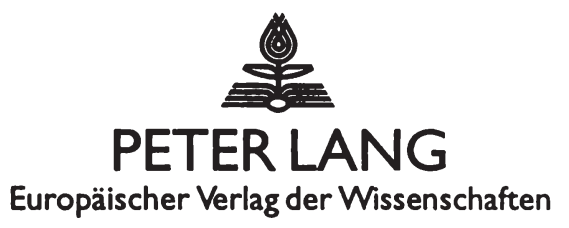

Silvia Marengo - 978-3-631-75137-4

Downloaded from PubFactory at 01/11/2019 07:53:19AM

via free access 
Die Deutsche Bibliothek - CIP-Einheitsaufnahme

Marengo, Silvia:

Exchange rate policy for MERCOSUR: lessons from the European Union / Silvia Marengo. - Frankfurt am Main ; Berlin ; Bern ; New York ; Paris ; Wien : Lang, 1998

(Schriften zur Wirtschaftstheorie und Wirtschaftspolitik ;

Bd. 9)

Zugl.: Hamburg, Univ. der Bundeswehr, Diss., 1997

ISBN 3-631-32791-9

Open Access: The online version of this publication is published on www.peterlang.com and www.econstor.eu under the international Creative Commons License CC-BY 4.0. Learn more on how you can use and share this work: http://creativecommons. org/licenses/by/4.0.

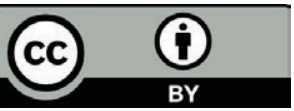

This book is available Open Access thanks to the kind support of ZBW - Leibniz-Informationszentrum Wirtschaft.

Gedruckt mit Unterstützung der UniBw Hamburg.

\author{
D 705 \\ ISSN 1433-1519 \\ ISBN 3-631-32791-9 \\ US-ISBN 0-8204-3555-4 \\ ISBN 978-3-631-75137-4 (eBook) \\ (c) Peter Lang $\mathrm{GmbH}$ \\ Europäischer Verlag der Wissenschaften \\ Frankfurt am Main 1998 \\ Alle Rechte vorbehalten.
}

Das Werk einschließlich aller seiner Teile ist urheberrechtlich geschützt. Jede Verwertung außerhalb der engen Grenzen des

Urheberrechtsgesetzes ist ohne Zustimmung des Verlages unzulässig und strafbar. Das gilt insbesondere für Vervielfältigungen, Übersetzungen, Mikroverfilmungen und die Einspeicherung und Verarbeitung in elektronischen Systemen.

Printed in Germany 124567 
A mis padres

Silvia Marengo - 978-3-631-75137-4

Downloaded from PubFactory at 01/11/2019 07:53:19AM

via free access 
Silvia Marengo - 978-3-631-75137-4

Downloaded from PubFactory at 01/11/2019 07:53:19AM

via free access 


\section{Acknowledgments}

This book is based on the research developed during my stay at the Institute of Economic Theory of the Universität der Bundeswehr Hamburg as well as during my participation in the Graduiertenkolleg of the Institut fur Integrationsforschung at the Europa-Kolleg Hamburg. It was submitted to the Universität der Bundeswehr Hamburg in March 1997 and accepted as Ph.D. dissertation.

I am specially indebted with Prof. Dr. Franco Reither, my Ph.D. supervisor, who provided invaluable advice, guidance and support throughout the preparation of this study. I am grateful for many afternoons that he set aside to assist me with my work.

I would like to thank Prof. Dr. Thomas Straubhaar for useful comments during the seminars at Europa-Kolleg Hamburg and for accepting my work as a second advisor. I am also grateful to Prof. Dr. Hasse, Prof. Dr. Uebe and Dr. Federico Foders for providing detailed comments on various part of this book. I thank the participants of the 22nd Annual Convention of the Eastern Economic Association held in Boston (March 1996) and 11th Annual Congress of the European Economic Association in Istanbul (August 1996) for useful comments. Mr. Andreas Barck has provided with valuable research assistance.

Last but not least, I wish to express my gratitude to my friend and colleague Christian Schmidt for his support and tolerance along difficult times.

Finally, I emphasize that I am exclusively responsible for any errors and omissions.

This book was printed with financial support of the Universität der Bundeswehr Hamburg. 
Silvia Marengo - 978-3-631-75137-4

Downloaded from PubFactory at 01/11/2019 07:53:19AM

via free access 


\section{Table of Contents}

LIST OF TABLES XIII

LIST OF FIGURES $\quad$ XV

$\begin{array}{ll}\text { LIST OF CHARTS } & \text { XVI }\end{array}$

1. CHAPTER 1: OVERVIEW 1

2. CHAPTER 2: A THEORETICAL APPROACH 5

2.1 Introduction 5

2.2 The Mundell-Fleming Model 10

2.2.1 Flexible Exchange Rate $\quad 12$

$\begin{array}{ll}\text { The Model } & 12\end{array}$

The Goods Market $\quad 12$

$\begin{array}{ll}\text { The Money Market } & 13\end{array}$

$\begin{array}{lr}\text { Interest Parity Condition } & 14\end{array}$

$\begin{array}{ll}\text { Comparative Statics } & 14\end{array}$

Fiscal Shock 15

Monetary Shock $\quad 16$

2.2.2 Fixed Exchange Rate 17

$\begin{array}{ll}\text { The Goods Market } & 17\end{array}$

The Money Market $\quad 17$

Fiscal Shock $\quad 19$

$\begin{array}{ll}\text { Monetary Shock } & 20\end{array}$

Distribution of Money Supply Across Countries $\quad 20$

Effect of the Monetary Policy on Output and Interest Rates 21

2.2.3 Concluding Remarks 22

2.3 Dynamic Effects: The Dombusch Model 26

2.3.1 Flexible Exchange Rates 26

$\begin{array}{ll}\text { The Model } & 26\end{array}$

The Goods Market $\quad 26$

The Money Market $\quad 28$

Uncovered Interest Parity Condition $\quad 29$

$\begin{array}{ll}\text { Monetary and Fiscal Shocks } & 29\end{array}$

The Long Run Comparative Statics $\quad 29$

$\begin{array}{ll}\text { Monetary Shock } & 30\end{array}$

$\begin{array}{ll}\text { Fiscal Shock } & 31\end{array}$

Dynamic Analysis 31

$\begin{array}{lr}\text { Monetary Shock } & 32\end{array}$

Fiscal shock $\quad 32$

2.3.2 Fixed Exchange Rates 33

$\begin{array}{ll}\text { The Model } & 33\end{array}$

The Goods market $\quad 33$ 
The Money Market $\quad 33$

Fisher Condition $\quad 35$

Uncovered Interest Parity $\quad 35$

$\begin{array}{ll}\text { Solving the Model } & 36\end{array}$

Comparative Statics $\quad 36$

The Long Run Effect $\quad 36$

$\begin{array}{ll}\text { Monetary Shock } & 36\end{array}$

$\begin{array}{ll}\text { Distribution of Money Supply across the Countries } & 37\end{array}$

$\begin{array}{ll}\text { Short Run Adjustment } & 38\end{array}$

$\begin{array}{ll}\text { Fiscal Shock } & 39\end{array}$

$\begin{array}{ll}\text { Short Run Adjustment } & 39\end{array}$

2.3.3 Concluding Remarks 40

2.4 The N-1 Problem in a Fixed Exchange Rate System 46

2.4.1 The asymmetric or Hegemonic Solution 47

2.4.2 Symmetric or Cooperative Solution 48

Intervention Rules $\quad 48$

2.4.3 Concluding Remarks 49

$2.5 \quad$ Time Inconsistency and Credibility Problem 52

2.5.1 Introduction $\quad 52$

2.5.2 Social Losses under Discretionary Policy as Commitment 53

2.5.3 The Model 54

2.5.4 Rules versus Discretion and the Presence of Stochastic Shocks 59

$\begin{array}{lll}2.5 .5 & \text { Multiple Period Horizon } & 62\end{array}$

2.5.6 Dealing with the Time Inconsistency Problem 63

2.5.7 Concluding Remarks 65

$\begin{array}{lll}2.6 & \text { Summary and Conclusions } & 67\end{array}$

$\begin{array}{ll}\text { Appendix } & 70\end{array}$

3. CHAPTER 3: LESSONS FROM THE EUROPEAN EXPERIENCE:

THE EMS AS AN INSTRUMENT TO ACHIEVE PRICE AND

$\begin{array}{ll}\text { EXCHANGE RATE STABILITY } & 72\end{array}$

$3.1 \quad$ Introduction $\quad 72$

3.2 Review of the European Exchange Rate Agreements 73

$\begin{array}{ll}\text { The Origins } & 73\end{array}$

The EMS: the Quest for Stability $\quad 76$

The Institutional Arrangements $\quad 77$

The Turbulent EMS: 1979- $1987 \quad 79$

The EMS without Realignments 1987- $1992 \quad 80$

1992 The Crisis $\quad 84$

Some Explanations of the Crisis of $1992 \quad 85$

$\begin{array}{lll}3.3 & \text { Effect of the EMS on Price Stability } & 87\end{array}$

$\begin{array}{ll}\text { Credibility and Inertia Inflation } & 87\end{array}$

$\begin{array}{ll}\text { Review of the Empirical Literature } & 87\end{array}$

$\begin{array}{lr}\text { Stylized Facts } & 89\end{array}$

The Unemployment-Inflation Trade - Off 96

3.4 The Effect of the EMS on the Dynamic Exchange Rate 102

Responses to Nominal and Real Shocks: An Econometric Analysis 102 
Stylized Facts

Variability of Nominal and Real Exchange Rates 104

3.4.1 Model Specification Analysis 108

Univariate and Bivariate Analysis $\quad 108$

Unit Root Tests

108

Test for Cointegration $\quad 110$

Granger Causality Test 111

3.4.2 VAR Analysis $\quad 112$

The Methodology $\quad 112$

Empirical Results $\quad 115$

Impulse Response Analysis $\quad 115$

$\begin{array}{ll}\text { Snake 1973.03-1979.03 } & 117\end{array}$

$\begin{array}{ll}\text { Hard EMS 1987.03-1992.09 } & 117\end{array}$

$\begin{array}{ll}\text { EMS Wide Bands 1993.07-1994.04 } & 118\end{array}$

$\begin{array}{ll}\text { Forecast Error Variance Decomposition } & 118\end{array}$

Concluding Remarks 119

Summary and Conclusions $\quad 120$

$\begin{array}{ll}\text { Appendix 3.1 } & 138\end{array}$

$\begin{array}{ll}\text { Appendix } 3.2 & 139\end{array}$

4. I CHAPTER 4: THE LATIN AMERICAN EXPERIENCE 140

4.1 Introduction 140

4.2. Review of Economic integration in Latin America from the Import-Substitution to the

Washington Consensus

4.2.1 Regional Integration within a Protectionist Framework 142

$\begin{array}{ll}\text { LAFTA } & 142\end{array}$

New attempt of integration: LAIA $\quad 145$

Other Free Trade Agreements among Latin American Countries $\quad 147$

$\begin{array}{ll}\text { The Andean Pact } & 147\end{array}$

Economic Integration in Central America $\quad 149$

4.2.2 The New Integration Approach 150

The Integration between Argentina and Brazil 152

The Enlargement of the Agreement to Paraguay and Uruguay 155

MERCOSUR: The Asuncion Treaty 155

Institutional Aspects of MERCOSUR $\quad 157$

The Transition Period 158

4.3 Macroeconomic Profile of MERCOSUR 161

$\begin{array}{ll}\text { Stylized Facts } & 161\end{array}$

Structure and Evolution of Regional GDP 161

$\begin{array}{ll}\text { Fiscal Sector } & 168\end{array}$

$\begin{array}{ll}\text { Monetary Sector } & 168\end{array}$

Exchange Rates and Capital Inflows $\quad 169$

$\begin{array}{ll}\text { Foreign Sector } & 171\end{array}$

4.4. Recent MERCOSUR Relevant Experiences with Fixed
Exchange Rates

Stabilization Plans Anchored on Fixed Exchange Rates 175 
4.4.1 The Argentinian Currency Board System

The Effect of the Currency Board on the Argentinian

Economy

Recent Developments and Evaluation $\quad 185$

4.4.2 The Brazilian Real Plan 186

Recent Developments $\quad 188$

4.5 Summary and Conclusions $\quad 189$

$\begin{array}{ll}\text { Appendix } 4.1 & 196\end{array}$

5. CHAPTER 5: CONCLUSIONS AND ECONOMIC POLICY

$\begin{array}{ll}\text { RECOMMENDATIONS } & 198\end{array}$

6 REFERENCES 203 


\section{List of Tables}

Table 2.2

Table 2.3

Table 3.2.

Table 3.2.2

Table 3.2.3

Table 3.2.4

Table 3.2 .5

Table 3.2 .6

Table 3.2 .7

Table 3.2.8

Table 3.2.9

Table 3.3.1

Table 3.3.2

Table 3.3.3

Table 3.4.1

Table 3.4.2

Table 3.4.3

Table 3.4.4

Table 3.4 .5

Table 3.4 .6

Table 3.4.7

Table 3.4.8

Table 3.4.9

Table 3.4.10

Table 3.4.11

Table 4.2.1

Table 4.2.2

Table 4.3.1

Table 4.3.2

Table 4.3.3

Table 4.3.4

Table 4.3.5

Table 4.3.6

Table 4.3.7

Table 4.3.8

Table 4.3.9

Table 4.3.10

Table 4.3.11

Table 4.3.12

Table 4.3.13

Table 4.3.14

Table 4.3.15
Two Country Mundell Fleming Model

Effect of a Domestic Shock on Foreign Variables

Two Country Dombusch Model $\quad 40$

Long Run Effect of Monetary and Fiscal Policy Shocks 75

Chronological History of the Snake $\quad 75$

Relative Openness of the Countries $\quad 76$

$\begin{array}{lr}\text { Realignments } & 80\end{array}$

Consumer Price Index $\quad 81$

CPI Average EMS Countries $\quad 81$

Current Account as \% of GDP $\quad 83$

Public Debt $\quad 83$

Fiscal Deficit $\quad 84$

The 1992 Crisis $\quad 85$

Money Market Rates $\quad 94$

Monetary Aggregates $\quad 94$

Public Debt as \% of GDP 95

Nominal Exchange Rates $\quad 122$

Real Exchange Rates $\quad 122$

Correlation Coefficients 123

Unit Roots Tests 1973.03-1994.04 ADF Test 123

Unit Roots Tests 1973.01-1979.03 ADF Test 124

Unit Roots Tests 1987.03-1992.09 ADF Test 124

LR Cointegration Tests 125

Granger Causality Test between Nominal Exchange Rate and Real Exchange Rate

126

Variance Decomposition. Snake 1973.01-1979.03 127

Variance Decomposition Hard EMS 1987.03-1992.09 128

Variance Decomposition Wide Bands $\quad 129$

Latin American Current Regional Integration Schemes $\quad 150$

MERCOSUR Reduction Tariff Program $\quad 159$

Basic Indicators 163

Structure and Evolution of the Regional Economies 163

Manufactured Added Value 164

Real Gross Domestic Product (GDP) 164

GDP Structure $\quad 166$

Distribution of the Population 166

Gross Domestic Investment/ GDP 167

Gross Domestic Savings/GDP 167

Real Exchange Rate $\quad 171$

Openness of the Economy 172

Exports of Goods and NFT / GDP 172

Intra-MERCOSUR Countries Exports $\quad 173$

Argentina: Impact of MERCOSUR Countries
on Imports 19751994

Brazil: Impact of MERCOSUR Countries

on Imports 1975-1994

173

Paraguay: Impact of MERCOSUR

Countries on Imports 1975-1994 
Uruguay: Impact of MERCOSUR

Countries on Imports 1975-1994

Table 4.3.17

Foreign Debt Position 


\section{List of Figures}

Figure 2.2.1.1

Figure 2.2.1.2

Figure 2.2.2.1

Figure 2.2.2.2

Figure 2.3.1.1

Figure 2.3.1.2

Figure 2.3.1.3

Figure 2.3.1.4

Figure 2.2.1.5

Figure 2.2.1.6

Figure 2.2.1.7

Figure 2.4.1

Figure 2.4.2

Figure 2.4.3

Figure 3.3.1

Figure 3.3.2

Figure 3.3.3

Figure 3.3.4

Figure 3.3.5

Figure 3.3.6

Figure 3.3.7

Figure 3.3.8

Figure 3.3.9

Figure 3.3. 10

Figure 3.3. 11

Figure 3.3.12

Figure 3.3.13

Figure 3.4.1

Figure 4.3.1

Figure 4.3.2

Figure 4.3.3

Figure 4.3.4

Figure 4.3.5

Figure 4.3.6

Figure 4.3.7

Figure 4.3.8

Figure 4.3.9

Figure 4.3.10

Flexible Exchange Rate. Fiscal Policy

Flexible Exchange Rage. Monetary Policy 24

Fixed Exchange Rate. Fiscal Policy 25

Fixed Exchange Rate. Monetary Policy $\quad 25$

Money Market Equilibrium Condition $\quad 41$

Goods Market Equilibrium Condition $\quad 41$

Saddle Path $\quad 42$

Monetary Policy $\quad 42$

Time Path of the Variables. Monetary Policy 43

Fiscal Policy 44

Time Path of the Variables. Fiscal Policy 45

Money Market Equilibrium in a Two Country Model $\quad 50$

$\begin{array}{ll}\text { Symmetric Solution } & 50\end{array}$

Asymmetric Solution $\quad 51$

Inflation Rates $\quad 90$

CPI Group $1 \quad 91$

CPI Group 2

Interest Rates 1973-1979 and 1979-1992 93

Deficit as Proportion of GDP $\quad 95$

Phillips Curve Germany $\quad 96$

$\begin{array}{ll}\text { Phillips Curve UK } & 97\end{array}$

Phillips Curve Belgium $\quad 97$

Phillips Curve Denmark $\quad 98$

Phillips Curve France $\quad 98$

Phillips Curve Italy $\quad 99$

Phillips Curve Canada $\quad 99$

Phillips Curve USA $\quad 100$

Nominal and Real Exchange Rates 1960.4-1994.04 105

Real GDP Growth 191

Productive Structure $\quad 191$

Public Sector Overall Balance $\quad 192$

Monetary Sector. Domestic Credit 192

Consumer Price Index 193

Monetization Ratios. Money Supply (M 1)

as Percent of GDP 193

Interest Rate $\quad 194$

Balance of Payments. Capital Account 194

Total Intra-MERCOSUR trade 195

$\begin{array}{ll}\text { Relation Between Argentinian Brazilian Trade } & \\ \text { Balance and Currency Parities } & 195\end{array}$ 


\section{List of Charts}

$\begin{array}{lll}\text { Chart 3.4.1 Impulse Response Function. Snake 1973.03-1979.03 } & 130\end{array}$

Chart 3.4.2 Impulse Response Function. Hard EMS 1987.03-1992.09 132

$\begin{array}{lll}\text { Chart 3.4.3 Impulse Response Function. EMS wide bands } & 135\end{array}$ 


\section{Chapter 1}

\section{Overview}

In January 1995, four Latin American countries, Argentina, Brazil, Uruguay and Paraguay joined their destinies within a common and ambitious enterprise called MERCOSUR ${ }^{1}$. MERCOSUR ${ }^{2}$, the Common Market of the South, represents an important economic integration area that generates a GDP of \$US 600 billion, providing a market of 200 million people ${ }^{3}$ spread over an area of 12 million square $\mathrm{km}$. It comprises 70 percent of the total land mass of South America, stretches from the tropical jungles of northern Brazil to the sub-Antarctic zone of Argentina, and includes some of the world's most important agricultural and mineral resources. It constitutes the Latin American response to the overall trend towards regional economic integration which includes NAFTA, EU and ASEAN.

Although economic integration is not a new issue in Latin America, this new integrationalist trend is significantly different from previous Latin American experiences of economic integration, such as LAFTA (Latin American Free Trade Association), LAIA (Latin American Integration Association), because of the economic philosophy which underlies it. Whilst past attempts at integration were based on an import-substitution strategy of development, with an infant industry approach playing a decisive role, a new development model has gained popularity within the region, labeled by Williamson (1991) as the "Washington consensus", with the new economic policies being primarily based on a neo-liberal model with the emphasis on market forces Consequently, Latin American states are facing important structural economic reforms. Markets are being opened to international competition; the goods, labor and capital markets are being deregulated; and central governments are undergoing restructuring. Thus, governments have recognized the importance of achieving macroeconomic stability as a precondition for faster growth. MERCOSUR constitutes an important factor within this process. It increases the efficiency and competitiveness of member countries by enlarging the size of the market, taking advantage of economies of scale and increasing returns. This facilitates the acceleration of economic development across the region through a more efficient use of available resources.

Initially, MERCOSUR performance has been more than successful, as intra-MERCOSUR trade has increased significantly, and, since the widened market has attracted foreign direct investment, the member countries have been able to enjoy investment at a higher level than their national saving rates would make possible. However, some difficulties within the process have been introduced by the high variability of the intraMERCOSUR exchange rate, and in particular by the real exchange rate between the Argentine peso and the Brazilian real. If a process of trade integration is to be successful, it seems inevitable that member countries must agree to maintain a

\footnotetext{
${ }^{1}$ MERCOSUR in Spanish, Mercado Común del Sur, also MERCOSUL in Portuguese.

${ }^{2}$ MERCOSUR was created in March 1991 by the Treaty of Asunción, which called for the signatories to establish a full common market arrangement among its members by January 1995.

${ }^{3}$ Almost one third of total South America's population.
} 
relatively stable intra-currency relationship Although the Treaty of Asuncion ${ }^{4}$ mentions as one of the main four objectives of MERCOSUR the necessity to coordinate macroeeconomic policies, no explicit consideration has been paid to this issue. Hence, the MERCOSUR countries have adopted unilateral exchange rate agreements with respect to the US dollar, but they have not developed any explicit link among their own currencies. While Argentina has operated a currency board system since 1991, which is an extreme version of a fixed exchange rate system, Brazil applies a fixed exchange rate system with a permissible band of fluctuation around a central value, Uruguay a crawling peg, and Paraguay allows the domestic currency to float. Exchange rate corrections take place in a fully unilateral and discretionary way without taking into account the other MERCOSUR currencies The elimination of intra-MERCOSUR tariffs will not be efficient if at the same time the sharp variability of nominal exchange rates artificially affects the relative prices of different products. Thus, high exchange rate volatility introduces a negative effect on trade within the region, discouraging the integration process. The question as to the choice of the optimal exchange rate system to be adopted among MERCOSUR countries becomes critical if MERCOSUR states attempt to go further along the path of increasing their trade flows of goods and services. Although there exists a "general consensus" in the academic as well as in the political world concerning the necessity of some kind of exchange rate coordination, no valid response to the problem has as vet been made. In the Treaty of Asuncion ${ }^{5}$, monetary and exchange rate agreements have been neglected, and until now there has not been any research undertaken in this specific field. Hence, the purpose of this study is to contribute to filling this gap by providing some alternative answers to this issue. The analysis is based on three pillars: a theoretical review of exchange rate systems; a review of the European experience; and an analysis of the Latin American experience. The study is organized as follows. In Chapter 2, first, I will analyze the interdependence effect among countries when they are linked under two extreme exchange rate regimes, fixed and floating. I will develop a twocountry Mundell-Fleming-Dornbusch model and I will compare the effects of fiscal and monetary policy on the individual country implementing them and on the neighbor country. I will discuss the coordination problem that arises in the presence of fixed exchange rates, which is known in the literature as the $\mathrm{N}-1$ problem. I will then review the time-inconsistency approach. I will introduce a theoretical model that allows comparison of the inflation outcome that results from a binding rule and that which arises from a discretionary monetary policy, and I will discuss some solutions for overcoming the time-inconsistency problem.

In chapter 3, a review of the European experience is presented. The European integration process was followed by the introduction of different exchange rates agreements. Thus, in the opinion of the European Commission, some fixity across exchange rates had to be introduced if the full benefits of integration were to be reaped. Although the argument also applies to the MERCOSUR case, no exchange rate agreement has as yet been introduced in that context. The experience of the European Union constitutes an excellent example of a successful economic integration process. It has been working for more than three decades, and it thus becomes important to draw

\footnotetext{
${ }^{4}$ See footnote 2 .

${ }^{5}$ See footnote 2 .
} 
some lessons from this experience. Although at first sight there are important differences between the EU and MERCOSUR in the degree of industrialization, average GDP per capita and size of the market, some similarities also exist, especially between the Southern European members of the EU and the MERCOSUR countries. But the main resemblance is probably to be found in the overall integration process, in the historical and political basis that gave impulse to the economic integration. In both cases, member states decided to follow a new path after having faced a political and economic disaster, in Europe the Second World War, in Latin America the debt crisis of the 1980s and several authoritarian regimes. The European Economic Community began as a joint cooperation between two countries, Germany and France, who had historically been traditional enemies during the last two world wars, and afterwards was opened to other European countries. MERCOSUR began with cooperation between two countries, Brazil and Argentina, whose permanent political and military rivalry had in the past imposed restrictions upon economic cooperation and had created obstacles to trade between them. At a later date, it was opened up to their two closest neighboring countries, Uruguay and Paraguay, and recently to Chile and Bolivia as associate members. Other similarities are present with respect to rigidities in labor markets, as well as to the existence of different attitudes towards inflation rates among the member countries, due mainly to past experiences with hyperinflationary processes. In this chapter, an analysis of the historical experience makes it clear that the search for stability among the domestic currencies of European members was a constant theme since the break down of the Bretton Woods system destroyed the underlying net. The search for appropriate exchange agreements has persisted over more than three decades. During this period, different agreements have been introduced, the Snake being followed by the European Monetary System, with discussion now being centered upon the achievement of a single currency. It has been a "trial and error" process, and it has not yet been completed. In this chapter, I will also analyze in some detail the results delivered by the European Monetary System as regards price and exchange rate stability. Especially, I will investigate the dynamic response of nominal and real exchange rates to monetary and real shocks by inquiring whether the EMS has introduced some significant changes in those responses.

In Chapter 4, I will analyze the Latin American experience. First I will review previous attempts at integration, as well as the economic circumstances under which they were undertaken, and the reasons for their failure. Second, I will present some stylized facts of the macroeconomics profile of the MERCOSUR countries that permits the underlying asymmetries and the problems that they raise to be seen. Third, I will examine the relevant MERCOSUR experience with fixed exchange rate agreements. To do so, I will analyze the circumstances under which they emerged: they have primarily formed part of stabilization plans, and therefore I will review the factors that have been common to them. Finally, I will present the two most recent experiences with exchange rate agreements between Argentina and Brazil. They constitute two original and ingenious mechanisms to cope with currency substitution and inertial inflation and have attracted the attention of other Latin American countries and nonLatin American countries as well. Additionally, taking into account the fact that Argentina and Brazil constitute the two largest partners in MERCOSUR, from the political point of view a common exchange rate agreement will not be feasible without the support of these two members. Even more, in the past they have experienced the 
most serious macroeconomic imbalances and therefore the role of stabilization plans and exchange rates is crucial for them.

The last chapter introduces three alternative proposals regarding the exchange rate policies for the MERCOSUR countries: a currency board system, target zones with a peg to the US dollar, and a peg to a basket of currencies, the last of which in my view follows from the overall analysis of this study. 


\section{Chapter 2: A Theoretical Approach}

\subsection{Introduction}

Although the economic controversy with respect to the choice of exchange rate regime has persisted for a very long time, it still remains at the center of economic discussion. Since the breakdown of the Bretton Wood system, under which countries had for the previous quarter century kept their exchange rates fixed, economists have shown concern about the advantages and disadvantages of alternative exchange rate systems, although there has been much disagreement between them. The debate concentrated on different topics of economic theory during that period. The views advanced by Friedman in his controversial 1953 article still suffused the way of thinking of most economists in the early $1970{ }^{\prime} \mathrm{s}^{6}$. Friedman's main aim was to attain unrestricted free trade and the freedom of each country to pursue internal stability following its own policies. He argued that the most efficient policy to achieve this goal was to adopt a flexible exchange rate. According to him, the alternatives would be either direct controls on trade and internal prices, or income adjustments, or changes in official reserves. He considered flexible exchange rates as particularly appropriate to respond to monetary disturbances, and supported the idea that a floating exchange rate could prevent the transmission of disturbances among countries whereas fixed rates would induce them. With exception of Europe, since the 1970s the major industrial countries have adopted flexible exchange rate arrangements and market pressures have been allowed to operate freely, generating large fluctuations in exchange rates. Johnson (1970) emphasized that floating rates allow governments to pursue their own internal goals without consequences for the balance of payments. Under fixed exchange rates, on the contrary, government's attempts to manage their internal and external balance would lead to restrictions on trade. He did not agree with the argument that fixed exchange rates might induce monetary and fiscal discipline. On the contrary, he argued that governments would always be able to pursue expansionary policies, even while adopting a fixed exchange rate system, because the option of changing the fixed parity was still available ${ }^{7}$.

Kindleberger (1970) argued in favor of fixed exchange rates by alleging that a permanent fixed parity would be optimal for international trade. He did not believe that floating would give national authorities any extra degree of freedom, since they would be likely to adopt exchange rate targets. Summarizing, the literature of early 1970's emphasized the desirability of allowing market forces to determine exchange rate levels. In this sense, fixed exchange rates would increase levels of protection since governments, in order to maintain external balance, would introduce tariffs and quantitative controls on trade. But, floating exchange rates would provide an additional degree of freedom for domestic policy. Thus, by adopting floating exchange rates, governments only acquire the possibility to determine a domestic rate of inflation that differed from that in the rest of the world.

\footnotetext{
${ }^{6}$ Representative studies of this point of view can be found in Johnson (1970) as well as in the contributions to the so-called Bürgerstock Papers edited by Halm (1970).

${ }^{7}$ Governments can always announce a devaluation.
} 
However, the introduction of floating exchange rates introduced high variability within financial markets and thus the economic discussion was reopened. Renewed interest in the economics of exchange rates reflects the fact that exchange rate arrangements are important. Changes in exchange rates have important effects, with consequences not only for prices, wages and interest rates but also for production levels and employment opportunities. Therefore, large and unpredictable changes in exchange rates present a major concern for macroeconomics stabilization policy. Traditionally, it has been argued that an increase in price uncertainty resulting from a more volatile exchange rate would lead to a reduction in the volume of trade and other international transactions. The empirical evidence concerning developed countries is, however, contradictory $^{8}$, though conclusive evidence has been presented that exchange rate uncertainty has damaged trade in developing countries. ${ }^{9}$

The discussion as to ability of different degrees of exchange rate flexibility to stabilize domestic economies has attracted the attention of many economists ${ }^{10}$ The first formal treatment of the basic insight had already been developed by Poole (1970), although his analysis did not concentrate on the advantages of fixed versus floating exchange rates but on a related problem for the closed economy. He assumed that governments have the implicit objective of stabilizing the level of output. However, they can only use one instrument for the purpose: either they have an interest rate target or a money stock target, but not both. Thus, he demonstrated that, in general, if shocks affecting domestic economies are mainly real in nature, adopting an interest rate target constitutes a better choice. On the contrary, if shocks are predominately monetary in nature, then following a money stock target will be optimal. Boyer (1978) extended Poole's analysis to the open economy. He considered that, if the objective of monetary policy is to stabilize output, fixed exchange rates are optimal when the IS curve is stable and monetary shocks are present. But if only real shocks occur, a fixed money supply and a floating exchange rate would be a better option.

After the innovative article of Kydland and Prescott (1977), the credibility argument attracted great interest among economists. Barro and Gordon (1983) and Cukierman and Meltzer (1991) followed this approach that generated a new wave of literature. According to this view, economies that show a lack of credibility and high inflation rates could benefit from adopting a fixed exchange rate regime. Credibility can be improved by committing to a fixed exchange rate of a country with a traditionally low inflationary history. In this sense, by pegging its domestic currency to a traditionally low inflationary currency, a country will import the credibility from the foreign country ${ }^{11}$.

New approaches introduce political economic considerations and apply new techniques such as game theory. Hamada (1985) suggested that, when analyzing the optimal exchange rate agreement, economists should not only focus on cost-benefit analysis but also take into account the negotiating process that will emerge between the participants that reveal the benefit-cost structure that each regime confers on the

\footnotetext{
${ }^{8}$ See De Grauwe and Bellefroid (1987), Kenen and Rodrik (1986) Bailey and Tavlas (1988), Gotur (1985), Gagnon (1990), Gosling (1986).

${ }^{9}$ See Diaz Alejandro (1976).

${ }^{10}$ See Frenkel and Aizenman (1984).

${ }^{11}$ See Persson and Tabellini (1990).
} 
participating countries. Fischer (1988) analyzed the case in which two countries will each be better off if they coordinate their policies. Thus both countries could adopt expansionary policies, but in the absence of cooperation and/or coordination mutually beneficial expansion would be prevented ${ }^{12}$ Genberg (1989) discussed the traditional point of view that, under floating exchange rates, it is no longer necessary to harmonize the economic policies. Floating exchange rates make it possible for the country to set its policy instruments independently from the rest of the world. But this does not of itself imply that it will be an optimal policy. Since floating exchange rates do not insulate the economy from foreign shocks, it may be in the interest of the domestic authorities to react to policies initiated abroad. A satisfactory functioning of a floating rate system may thus require policy harmonization. The question is whether harmonization under floating exchange rate regime is more or less expensive than harmonization under fixed exchange rates.

Marston (1985) and Canzoneri, Henderson and Rogoff (1981) derived the conditions under which a flexible exchange rate was preferable to a fixed one. Fixed exchange rates are superior (inferior) to floating if the variance of the aggregate composite shock is sufficient large (small) relative to the variance of the consolidated shock. In particular, if the domestic money demand is very unstable or if domestic monetary control is very imprecise, then fixed exchange rate will stabilize output. Alternately, if the demand function for domestic goods is highly unstable, a floating rate is preferable. Flood (1982) derived the following conclusions: some degree of exchange rate management will be better than either free floating or complete fixity. If the authorities only have a choice between a fixed rate regime and pure floating, then the latter will be better in presence of some wage indexation. Henderson (1984) researched the conditions under which two large countries show a common interest in either floating exchange rate or a fixed exchange rates, as well as those that lead to conflicts of interest. He found that there is no policy conflict when there are shifts in demand between home and foreign goods (both would be in favor of floating) and when there are shifts in asset preferences between home and foreign assets (both would be in favor of fixed rates). Nevertheless, if there are shifts in labor productivity in either country, conflicts will arise. A shift in asset preferences from one country to another will lead to exchange rate and interest rate variation and therefore will induce fluctuations in output, unless accommodating fluctuations in assets surplus are forthcoming. A fixed exchange rate would allow such changes in assets supplies to come about automatically and thereby insulate the real economy from asset market disturbances. A switch in demand between home and foreign goods requires relative price and real wage adjustments in both countries. If wages are rigid, adjustment will be accomplished with minimum output loss when the exchange rate is allowed to adjust. A shift in labor in the home country requires a real wage adjustment there, whereas none is necessary abroad. The home country would prefer some degree of exchange rate flexibility to help in the adjustment process but the foreign country will be better off with a fixed exchange rate. Helpman (1981) compared the welfare levels that are attained under different exchange rate systems, floating, fixed and one side peg. He

\footnotetext{
${ }^{12}$ This problem is known in the literature as prisoner dilemma. Two partners could be better-off if they would co-operate. The absence of coordination though induces to a worse situation. For details Rapoport and Chammah (1965) and Schotter (1981).
} 
analyzed the implications of those regimes with respect to global efficiency and the distribution of welfare as well as the determination of financial variables such as prices, exchange rates and interest rates. He showed that the equilibrium allocation of consumption is efficient in every exchange rate system and that, in a floating exchange rate system as well as in a one-sided peg regime, it corresponds to the equilibrium allocation of consumption in a barter economy. Independently of the exchange rate, all perfect foresight equilibria are Pareto optimal, which is an extremely strong result because it implies, in Helpman's framework, that exchange rates are irrelevant from the efficiency point of view. It may happen that different exchange rate regimes have different distributional implications in the sense that, under some of them, one particular country is better off than the others. The equivalence result depends on the ability of governments to pursue non-distorting absorption policies whenever they are needed in order to accompany an exchange rate regime. Every exchange rate system is associated with its specific financial market clearing conditions. It is plausible that a particular exchange rate system performs better than others under certain types of imperfections (wage contracts, market imperfections, etc.) whose existence may have a bearing on the relative desirability of alternative exchange rate regimes. In general, in the literature, economists compare different exchange rate regimes under different initial assumptions, with the conclusions, of course, depending on them. Helpman (1981), Razin (1986) and Mc Kibbin and Sachs (1986) sought empirical evidence as to the global performance of alternative exchange rate arrangements. They developed a simulation model of the world economy and showed that the performance of each regime depends crucially on the performance and the nature of the shocks affecting the economies. With country specific shocks, fixed exchange rates performed poorly; with global shocks, such as oil price rises, fixed exchange rates performed tolerably well. For other types of shocks, mainly monetary shocks, the system proposed by Mc Kinnon offers a better solution ${ }^{13}$.

In this study, I shall concentrate my analysis on the optimal exchange rate arrangement for the MERCOSUR case. As a methodological approach, the analysis can be reduced, firstly, to the comparison from the theoretical point of view of two extreme alternative systems: flexible versus fixed exchange rates. Although in the real world "ideal cases," do not exist but only a relative approximation to one of the two extreme cases in the form of differing degrees of flexibility, in order to simplify the problem it is reasonable to start with pure theoretical cases to be able to draw some conclusions.

I begin, therefore, by analyzing the transmission mechanisms of both exchange rate regimes by means of the well-known Mundell-Fleming model, which offers an excellent framework in which the effect of different policies can be compared as well as the introduction of different assumptions. Second, I introduce the Dornbusch model

\footnotetext{
${ }^{13} \mathrm{Mc}$ Kinnon (1984) suggested that the problem under flexible exchange rate system was mainly due to the fact that the rules governing the creation of the stock of international money were not well defined. He assumed that large shocks in the currency preferences of economic agents led to large movements of the world money stock. In his opinion, these movements could have been avoided by designing better rules concerning the monetary policy of the major countries. The suggestion of Mc Kinnon, known in the literature as Mc Kinnon rule, consists of a fixed exchange rate regime with a coordinated determination of the world money stock. For details see De Grauwe (1994).
} 
by incorporating dynamic behavior into the traditional Mundell-Fleming model and adding the Phillips curve and exchange rate expectations. Third, I discuss the coordination problem that arises under a fixed exchange rate regime which is known as the N-1 problem. Finally, I concentrate on credibility issues by introducing the time inconsistency approach, and I analyze the consequences that follow from different policy options (commitment versus discretionary policy) and its relation to the institutional design of exchange rate regimes. The high complexity of the issue under analysis allows for the adoption of diverse theoretical frameworks by focusing on different aspects of the same problem. Thus, in this study I have omitted the optimal currency area theory (OCA), the problem of the choice of the exchange rate regime under inflationary financing of budget deficits (seignorage approach ${ }^{14}$ ), as well as balance of payments crises. With respect to the first issue, the initial studies on optimal currency areas were done by Mundell (1960) and McKinnon (1966). This theory analyzes the benefits and costs of adopting a single currency across several regions or countries. The benefits are larger than the costs and thus the monetary area is an optimum if the economic structure of the countries is relatively similar and if the labor and goods markets are highly flexible. A profuse empirical literature related to this topic has recently been published applying modern econometric techniques. The focus has concentrated on the analysis of the symmetry of shocks applied mainly to the cases of Europe, USA and Canada ${ }^{15}$. The underlying rationale is as follows: if shocks are symmetrical across regions, the area is likely to be an OCA. However, the results provided by these empirical analyses are not very conclusive and are unable to give concrete answers and policy recommendations. Firstly, no one area seems to be an optimum, not even the USA which already is working under a single currency. Secondly, the empirical analysis is done "a priori", before a single currency has been adopted and hence it cannot consider the changes that would arise were a single currency to be "de facto" introduced.

Concerning the inflationary financing of budget deficits issue and balance of payment crises, Agell, Calmfors and Jonsson (1996) discuss the problem of defining the exchange rate regime in the presence of a desirable seignorage revenue. They argue that, if governments use the inflation tax ${ }^{16}$ to finance their expenditure, different exchange rate regimes will have different repercussions for fiscal policy because they will affect seignorage revenue. De Kock and Grilli (1993) analyze similar issues and conclude that it is not possible to rank different exchange rate regimes from the Pareto point of view, since governments that care about their tax revenue must account for the fact that different exchange rate systems have implications for the flexibility of future seignorage revenue. Jensen (1994) develops a model in which a small open economy is operating with a high rate of unemployment because of the existence of distortionary

\footnotetext{
${ }^{14}$ Seignorage is the revenue collected by the government as a result of its monopoly power to print money. Because the central bank can print money without cost, the seignorage can be measured as the purchasing power of the money put into circulation in a given period. See Sachs and Larrain (1993).

${ }^{15}$ See Weber (1990), Bayoumi and Eichengreen (1993), Jordan (1994), Poloz (1990), Funke (1995).

${ }^{16}$ Inflation tax is the capital losses suffered by money holders as a result of inflation. See Sachs and Larrain (1993).
} 
taxes in the labor market. As the government accumulates seignorage over time, it can use the proceeds to gradually phase out those distortionary labor market taxes. In this framework, a binding policy rule that makes it more difficult to raise seignorage revenue, such as a credible fixed exchange rate, will only serve to slow down the adjustment towards the steady state. Under a fixed exchange rate, the problem of the inflationary financing of budget deficits is closely related to the balance of payment crises. While under a flexible exchange rate the government can collect an inflationary tax, under a fixed exchange rate a monetary financing of a budget deficit will induce a loss of reserves. Consequently, if a country has a persistent budget deficit, reserves will be continuously falling and eventually the central bank will run out of reserves and will no longer be able to intervene in the foreign exchange market. Thus, it will have no other option than to allow the exchange rate to depreciate, either as a devaluation of the local currency or by adopting a floating exchange rate regime.

However, the collapse of a pegged exchange rate regime when a central bank runs out of reserves is a traumatic process and is known in the literature as a balance of payments crisis or an exchange rate crisis. Krugman $(1979)^{17}$ presented a formal model describing the exchange rate collapse. Initially, the loss of reserves is gradual and equivalent to the budget deficit. As reserves fall to a low level, however, the public becomes aware of this fact and suspects an imminent collapse of the exchange rate system. Therefore, households suddenly move massively to convert their domestic holdings into foreign currency because they anticipate a sharp rise in inflation. Although all the aspects mentioned above are very important, the starting point of the seignorage approach is to assume that there might be some gains for the domestic economy of having an inflation rate higher than the rest of the world. In the case under analysis, MERCOSUR, the countries do not have the option of choosing a higher inflation in order to collect inflationary tax. Because in the past they have abused the seignorage, the member countries are unable to raise inflation without rapidly entering onto the path of the hyperinflation. Additionally, the inflationary policies have damaged the economies because of the distortions that they have introduced. Therefore, the seignorage approach does not constitute an optimal approach for the countries under consideration.

\subsection{The Mundell-Fleming Model}

The Mundell-Fleming model constitutes an extension of the IS-LM framework to the open economy. Its foundations are found in the writings of Mundell (1960, 1961, 1963, 1964 and collected in 1968) and Fleming (1962). It has become a reference model of the open economy to which other models can be confronted. According to Krugman (1993), the Mundell-Fleming model supplemented with price reaction functions and price expectations constitutes the only theoretical model that permits concrete answers to be given to economic policy problems. The model is thus extremely comprehensive and can be manipulated to analyze the international

\footnotetext{
${ }^{17}$ Additional references on currency crisis are found in Flood and Garber (1984). Wyplosz (1986) discusses the importance of capital controls in order to overcome a currency crises. For recent analyses see Tavlas (1996), Bordo and Schwarz (1996), Kenen (1996).
} 
transmission mechanism of monetary and fiscal policies and the effects of a variety of disturbances originating at home or abroad on the variables: output, exchange rate and interest rates for different exchange rate regimes, for differing degrees of capital mobility and also for different assumptions about expectation formation of economic agents .

The Mundell-Fleming model was initially developed as a short-run approach for the small, open economy. Consistently with the Keynesian assumptions, prices and wages are fixed, aggregate demand is perfectly elastic and actual output is then determined. Over the decades, the model has been extended in several directions: developments of the model for alternative exchange rate regimes and different degrees of capital mobility can be found in Swoboda and Dornbusch (1973) and Mussa (1982). Recent surveys of several open economy macroeconomic issues discussed in the context of this model are contained in Frenkel and Mussa (1985), and Kenen (1985). Marston (1985) presented a survey of application of stabilization policies. Obstfeld and Stockman (1985) provide a survey on exchange rate dynamics relating to this and other competitive models. Frenkel and Razin (1987) developed a version that integrates the different aspects of the Mundell-Fleming model into a unified analytical framework by distinguishing between the short- and long-run effect and discuss an application related to the government budget and the role of the exchange rate regime ${ }^{18}$. In this study, I shall present, first, a traditional two-country version ${ }^{19}$ which permits the interdependence between economies linked by goods and bonds markets to be analyzed. It is also feasible to extend the analysis to a larger number of countries, although the economic interpretations become quite abstruse ${ }^{20}$

Firstly, the traditional Keynesian assumptions are considered: prices and wages are fixed, hence output is demand determined because the economy has not reached the full employment level. There is perfect capital mobility, thus the domestic interest rate is equal to the international interest rate. Price and exchange rate expectations are assumed to be static and therefore the nominal and real interest rates are identical. I will analyze the comparative statics of the short run impact of monetary and fiscal shocks on foreign and domestic output under flexible and fixed exchange rates. Secondly, I will present a two-country version of the extension of the model derived from the original analysis of Dornbusch (1976), which allows for the dynamic analysis of the variables and introduces the Phillips curve and rational expectations. Finally, I will apply the Dornbush framework to the fixed exchange rate regime.

\footnotetext{
${ }^{18}$ For an introduction to the Mundell-Fleming model see Jarchow and Rührmann (1994). Branson (1989), Denburg (1989), Dornbusch and Fischer (1989). Dornbusch (1980), Koray (1987), MacDonald (1988), Neumann (1988) and Gandolfo (1986) present a good summary of the literature on the Mundell-Fleming model.

${ }^{19}$ Dornbusch (1973), Frenkel and Mussa (1985) and Frenkel and Razin (1987), among others, present a two-country version of the Mundell-Fleming model.

${ }^{20} \mathrm{Gandolfo}(1986)$ presents a N-country version model.
} 


\subsubsection{Flexible Exchange Rate}

\section{The Model}

\section{The Goods Market}

Under a flexible exchange rate system, the good market equilibrium condition can be expressed as equations (2.2.1.1) and (2.2.1.2) for the home and foreign countries respectively. In these equations, $y_{j}{ }_{j}^{d}$ represents the domestic aggregate demand; $y_{j}$ is the output level, e the nominal exchange rate and $\mathrm{p}_{\mathrm{j}}$ the price level, $\mathrm{g}_{\mathrm{j}}$, the government expenditure ${ }^{21}$; and $r_{j}$ the real interest rate. The subindex 1 represents home and 2 the foreign country. All variables, except the interest rate, are expressed in logarithmic terms. ${ }^{22}$

Aggregate demand depends positively on the real exchange rate ${ }^{23}$, foreign output and on the government demand and negatively on the real interest rate ${ }^{24}$.

The structural parameters are assumed to be identical in both countries ${ }^{25}$ and adopt values between 0 and $1 . \delta$ represents the exchange rate elasticity and denotes the proportion by which aggregate demand would rise in presence of an increase of $1 \%$ of the real exchange rate, $\sigma$ is the interest rate semi-elasticity; and finally, $\mathrm{f}$ represents the import-income elasticity and explains the impact of the foreign propensity to import on domestic aggregate demand.

In this section, I shall assume that the exchange rate is fully flexible and therefore its value is determined in the exchange rate market. There is no central bank interventions,

$$
\begin{aligned}
& y_{1}{ }^{d}=\delta\left(e-p_{1}+p_{2}\right)+g_{1}-\sigma r_{1}+f y_{2} \\
& y_{2}{ }^{d}=-\delta\left(e-p_{1}+p_{2}\right)+g_{2}-\sigma r_{2}+f y_{1}
\end{aligned}
$$

Domestic and foreign output, nominal exchange rate and interest rates are endogenous variables, while the government expenditure is exogenous. Because output is demand determined as in the keynesian tradition and then ${ }^{26}$

$$
y_{j}^{d}=y_{j} .
$$

\footnotetext{
${ }^{21}$ The parameter $\mathrm{g}$ can be interpreted as all exogenous variables that represent the domestic absorption, as autonomous consumption, autonomous investment, government expenditure. For simplicity, I will refer only to the government expenditure but the analysis can be extended to consumption and investment in analogous way.

${ }^{22}$ For details respect to the derivation of the logarithmic form see Argy (1994) and Maennig (1992).

${ }^{23}$ The model assumes that the Marshall-Lerner condition holds: $\eta_{m}+\eta_{x}>1$, where $\eta_{x}$ and $\eta_{m}$ are exchange rate elasticity of demand for exports and exchange rate elasticity of demand for imports respectively.

${ }^{24}$ In this case because expectations are static there is no difference between nominal and real interest rates.

${ }^{25}$ The two countries are symmetric.

${ }^{26} \log X=\mathbf{X}$
} 


\section{The Money Market}

In each country the money market is in equilibrium whenever the demand for money equals the supply of money. As usual, the demand for money depends positively on domestic income and negatively on the nominal interest rate.

$$
M_{j}^{d}=P_{j} L_{j}\left(Y_{j}^{d}, i_{j}\right) .
$$

The supply of money $M_{j}$ is made up of the domestic component $D_{j}$ and the foreign component $R_{\mathrm{j}}$,

$$
M_{j}^{s}=D_{j}+R_{j} .
$$

I shall consider a more general version of the model by deflating the money real balances by the consumption price index $(\mathrm{CPI})^{27} \mathrm{P}_{\mathrm{cj}}$ which is defined as the weighted average of the domestic price and the foreign price of goods expressed in domestic currency,

$$
p_{c 1}=\beta p_{1}+(1-\beta) p_{2}+(1-\beta) e \text { and } p_{c 2}=\beta p_{2}+(1-\beta) p_{1}+(1-\beta) e \text {. }
$$

However, in this part of the analysis I shall assume $\beta=1^{28}$

In equilibrium,

$$
\text { (2.2.1.7) } \quad\left(D_{j}+R_{j}\right) / P_{j}=L\left(Y_{j}, i_{j}\right) \text {. }
$$

The demand for money adopts the following functional form:

$$
M_{j}^{d}=Y_{j}^{\phi}(\exp )-\lambda i \text {. }
$$

$\lambda$ represents the interest rate semi-elasticity of money demand and $\phi$ the income elasticity, which is the percentage increase in money demand in response to a 1 per cent increase in domestic income.

Therefore expressed logarithmically,

$$
\ln \mathrm{M}_{\mathrm{j}}=\phi \ln \mathrm{Y}_{\mathrm{j}}-\lambda \mathrm{i} \text {. }
$$

By equalization of money demand and money supply, then:

$$
\ln \left(D_{j}+R_{j}\right)-\ln P_{j}=\phi \ln Y_{j}-\lambda i
$$

(2.2.1.11) $\quad \ln \mathrm{M}_{\mathrm{j}}-\ln \mathrm{P}_{\mathrm{j}}=\phi \operatorname{Ln} \mathrm{Y}_{\mathrm{j}}-\lambda \mathrm{i}$.

Then the money market equilibrium condition expressed in logs can be defined as:

\footnotetext{
${ }^{27}$ See De Grauwe (1989a) and Scarth (1988).

${ }^{28}$ In this part, this assumption does not play a relevant role; and it reduces the complexity of the algebra significantly. I will relax this assumption later on.
} 


$$
\mathrm{m}_{\mathrm{j}}-\mathrm{p}_{\mathrm{j}}=\phi \mathrm{y}_{\mathrm{j}}-\lambda \mathrm{i} .
$$

Money market equilibrium conditions in both countries are represented by the equation (2.2.1.13) and (2.2.1.14). The money supply in both countries is controlled by the respective central bank. Domestic economic agents only hold domestic money and viceversa. ${ }^{29}$

$$
\begin{aligned}
& \mathrm{m}_{1}-\mathrm{p}_{1}=-\lambda \mathrm{i}_{1}+\phi \mathrm{y}_{1} \\
& \mathrm{~m}_{2}-\mathrm{p}_{2}=-\lambda \mathrm{i}_{2}+\phi \mathrm{y}_{2}
\end{aligned}
$$

\section{Interest Parity Condition}

As in the traditional version of the Mundell-Fleming model price and exchange rate expectations are assumed to be static, and the nominal interest rate is equal to the real interest rate. The Fisher condition for the closed economy can be expressed as follows:

$$
\mathrm{i}=\mathrm{r}+\pi^{\mathrm{e}} \text {. }
$$

where $i$ is the nominal interest rate, $r$ the real interest rate and $\pi^{e}$ the expected inflation. In this case $\pi^{\mathrm{e}}=0$.

Because of the assumption of perfect capital mobility, in absence of a risk premium and exchange rate expectations, the domestic interest rate is equal the foreign interest rate. The Fisher condition for the open condition is as follows:

(2.2.1.16) $\quad \mathrm{i}_{1}=\mathrm{i}_{2}+\mathrm{E}_{\mathrm{t}}\left(\mathrm{e}_{\mathrm{t}+1}-\mathrm{e}_{\mathrm{t}}\right)+\rho$,

$E_{t}\left(e_{t+1}-e_{t}\right)=0$ represents the static exchange rate expectation, and $\rho=0$ the risk premium.

$$
\mathrm{i}_{1}=\mathrm{i}_{2} \text {. }
$$

\section{Comparative Statics}

In order to solve the model, I will consider the goods market and the money market equilibrium in both countries, that means equations (2.2.1.1), (2.2.1.2), (2.2.1.3), (2.2.1.13), (2.2.1.14) and the interest parity equilibrium condition (2.2.1.17). By replacing (2.2.1.17) in (2.2.1.1), (2.2.1.2), (2.2.1.13) and (2.2.1.14) the following system of 4 equations is obtained,

(2.2.1.18) $\quad \mathrm{y}_{1}=\delta\left(e-\mathrm{p}_{1}+\mathrm{p}_{2}\right)+\mathrm{g}_{1}-\sigma \mathrm{i}+\mathrm{fy}_{2}$

(2.2.1.19) $\quad y_{2}=-\delta\left(e-p_{1}+p_{2}\right)+g_{2}-\sigma i+f y_{1}$

${ }^{29}$ Currency substitution has not been considered. For details see Girton and Roper (1981), Calvo and Rodríguez (1977), Kuori (1976), Gärtner (1990). 


$$
\begin{aligned}
& (2.2 .1 .20) \quad \mathrm{m}_{1}-\mathrm{p}_{1}=-\lambda \mathrm{i}+\phi \mathrm{y}_{1} \\
& (2.2 .1 .21) \quad \mathrm{m}_{2}-\mathrm{p}_{2}=-\lambda \mathrm{i}+\phi \mathrm{y}_{2} \text {, }
\end{aligned}
$$

which contains 4 endogenous variables, both output levels $y_{1}, y_{2}$, nominal interest rate $i$, and nominal exchange rate e. The exogenous variables are $m_{1}, m_{2}, g_{1}, g_{2}$ and price levels, $p_{1}$ and $p_{2}$, which are fixed in this part of the analysis.

By differentiating the system of equations (2.2.1.18), (2.2.1.19), (2.2.1.20) and (2.2.1.21), it is possible to analyze the comparative statics of the effects of changes in the exogenous variables on the endogenous variables.

In this case, I consider only the impact of a positive domestic fiscal shock $\left(\mathrm{dg}_{1}\right)$ and a positive domestic monetary shock $\left(\mathrm{dm}_{1}\right)$ on domestic and foreign output, exchange rate and interest rates.

\section{Fiscal Shock}

A domestic expansionary fiscal shock will induce a disequilibrium in the goods market. Given that the aggregate demand determines output $\left(y_{j}{ }^{d}=y_{j}\right)$, domestic output will increase. The final effect on domestic output will be positive, as the multiplier explains.

$$
\left.\mathrm{dy}_{\mathrm{l}} / \mathrm{dg}_{1}=\lambda / 2[\lambda(1-\mathrm{f})+\phi \sigma)\right]>0
$$

because by assumption $0<\mathrm{f}<1$.

A higher domestic output will disequilibrate the money market, money demand will increase because money supply remains constant, the domestic interest rates will increase in order to reestablish the equilibrium, and so the multiplier is positive. This increase in the interest rate, however, will moderate the positive impact of the fiscal policy on domestic output through the crowding out effect on domestic investment:

$$
\left.\mathrm{di} / \mathrm{dg}_{1}=\phi / 2[\lambda(1-\mathrm{f})+\phi \sigma)\right]>0 .
$$

Under perfect capital mobility, a transitory higher domestic interest rate will induce large capital inflows. Nevertheless, because of the interest parity condition, interest rates in both countries will return to equality but at a higher level than the original. The capital inflows induced by a temporarily higher domestic interest rate will appreciate the domestic currency as the multiplier shows:

$$
\text { (2.2.1.24) } \quad \mathrm{de} / \mathrm{dg}_{1}=1 /(-2 \delta)<0 \text {. }
$$

The spill-over effect on foreign output will be positive. This effect is the consequence of the increase in domestic output together with the appreciation of the domestic currency. Although the fiscal shock increases the domestic and foreign interest rate, which has a negative impact on foreign output, this effect is more than compensated for the output and exchange rate effects and the final impact is as follows:

$$
\mathrm{dy}_{2} / \mathrm{dg}_{1}=\lambda / 2[(\lambda(1-\mathrm{f})+\phi \sigma)]>0
$$


Figure 2.2.1.1 (on page 24) represents the effects of an expansionary fiscal policy in country 1 in the traditional IS-LM diagram. An expansionary fiscal policy shifts IS $_{1}$ curve to the right and income $y_{1}$ and interest rate rise. The higher income in country 1 induces an increase in the demand for foreign products, and $\mathrm{IS}_{2}$ shifts to the right. However, the shift of $I S_{2}$ curve in country 2 is smaller than the shift originated in country 1 and thus there is in the short run an interest rate differential that induces capital movements between countries.(From country 2 to country 1). The domestic currency will appreciate in country 1 and therefore the IS $S_{1}$ curve will move back to the left. There is some reduction in income in country 1 , but is still higher than its initial level. In country 2 , the exchange rate will depreciate and hence the $\mathrm{IS}_{2}$ will shift again to the right reinforcing the output increase. In the final equilibrium position, both output levels are higher and the interest rate is also higher. The spill-over effect of the fiscal policy has induced a positive impact on output in the foreign country. ${ }^{30}$

\section{Monetary Shock}

By applying the same procedure as before, it is possible to analyze the effect of a domestic expansionary monetary shock on the endogenous variables (y,e,i) An expansion of the money supply will disequilibrate the money market. Money supply will be larger than money demand and domestic interest rates will decrease in order to re-establish the equilibrium, so that the effect on interest rates will be negative:

$$
\mathrm{di} / \mathrm{dm}_{1}=(\mathrm{f}-1) /[2(\lambda(1-\mathrm{f})+\phi \sigma)]<0 .
$$

Lower interest rates will generate a positive impact on the aggregate demand through investment and therefore domestic output will increase.

(2.2.1.27) $\mathrm{dy}_{1} / \mathrm{dm}_{1}=[\lambda(1-\mathrm{f})+2 \phi \sigma] / 2 \phi[\lambda(1-\mathrm{f})+\phi \sigma]>0$.

In the capital market, lower interest rates will induce capital outflows, thus leading to a depreciation of the domestic currency.

$$
\mathrm{de} / \mathrm{dm}_{1}=\lambda\left(1-\mathrm{f}^{2}\right)+\phi \sigma(1+\mathrm{f}) / 2 \phi \lambda[\lambda(1-\mathrm{f})+\phi \sigma]>0 .
$$

The impact on the foreign output will be negative, although the monetary expansion increases domestic output and hence the exports of the foreign country, and reduces the domestic interest rate. The depreciation of the domestic currency will more than compensate the first two effects, and the final result will be a negative impact on foreign output. The monetary policy works as a "beggar my neighbor policy". ${ }^{31}$

$$
\mathrm{dy}_{2} / \mathrm{dm}_{1}=\lambda(\mathrm{f}-1) /(2 \phi(\lambda(1-\mathrm{f})+\sigma \phi)<0
$$

Figure (2.2.1.2) on page 24 presents the effect of an expansionary monetary policy in a IS-LM diagram. The monetary expansion originated in country 1 shifts the $L_{1}$ curve

${ }^{30}$ Compare with the multipliers presented above.

${ }^{31}$ McDonald (1988), Gärtner (1994). 
to the right. The interest rate declines and therefore income in country 1 rises. The increase in income in country 1 increases the demand for foreign goods. The $\mathrm{IS}_{2}$ curve of the foreign country, therefore, shifts to the right. In country 1 , two effects take place, on the one hand, the increased demand for foreign goods additionally worsens the current account; on the other hand, the decline in the domestic interest rate induces net capital outflows and the domestic currency will depreciate, which in turn has an effect on the domestic goods market, and IS $_{1}$ shifts to the right.

Country 2 experiences an appreciation of its currency and a reduction in its exports, so $\mathrm{IS}_{2}$ shifts to the left. Finally, the income of country 1 will increase, while that of country 2 will decline. There is a negative spill-over effect on output in country 2.

Summarizing, under a floating exchange rate regime, on the one hand a positive domestic fiscal shock increases domestic output and induces a positive spill-over effect on output in the foreign country, interest rates are higher than initially and the domestic currency (in terms of country 1) will appreciate.

On the other hand, a positive domestic monetary shock impacts positively on domestic output, and it also induces a spill over effect on the foreign country, but this time is negative. Interest rates will be lower and the domestic currency will depreciate.

\subsubsection{Fixed Exchange Rate}

\section{The Goods Market}

Under a fixed exchange rate system, in the absence of devaluations, the exchange rate will be held constant and thus it can drop out of the goods market equilibrium condition of both countries. Because prices are held constant, it is feasible to write the good market equilibrium condition as equations (2.2.2.1) and (2.2.2.2). Aggregate demand depends positively on government expenditure $\left(g_{j}\right)$ and on foreign output and negatively on real interest rates. ${ }^{32}$

$$
\begin{aligned}
& y_{1}{ }^{d}=g_{1}+f y_{2}-\sigma r_{1} \\
& y_{2}{ }^{d}=g_{2}+f_{1}-\sigma r_{2} \\
& y_{j}{ }^{d}=y_{j} .
\end{aligned}
$$

Output is as before demand determined.

\section{The Money Market}

Under a fixed exchange rate regime, both money markets are linked through the fixed parity of the exchange rate. Therefore, the aggregated money market equilibrium condition can be expressed as follows:

$$
\mathrm{M}_{1}+\mathrm{M}_{2}=\mathrm{P}_{1} \mathrm{~L}_{1}\left(\mathrm{Y}_{1}, \mathrm{i}_{1}\right)+\mathrm{P}_{2} \mathrm{~L}_{2}\left(\mathrm{Y}_{1}, \mathrm{i}_{1}\right)
$$

\footnotetext{
${ }^{32}$ Compare with goods market equilibrium condition in the case of flexible exchange rates.
} 
The individual money demands show the same functional form as in the previous case, depending positively on output and negatively on interest rates. The individual money supply of both countries is composed, as usual, of foreign currency and each domestic component.

$$
\begin{aligned}
& M_{1}=R-R_{2}+D_{1} \\
& M_{2}=R-R_{1}+D_{2}{ }^{33} .
\end{aligned}
$$

The total amount of foreign reserves is assumed to be constant and fixed:

$$
\mathrm{R}=\mathrm{R}_{1}+\mathrm{R}_{2}=\text { constant. }
$$

Therefore, the aggregate money supply can be defined as follows:

$$
\mathrm{M}_{\mathrm{u}}=\mathrm{M}_{1}+\mathrm{M}_{2}=\mathrm{R}+\mathrm{D}_{1}+\mathrm{D}_{2} .
$$

In equilibrium, money demand is equal to money supply

$$
R+D_{1}+D_{2}=P_{1} L_{1}\left(Y_{1} i_{1}\right)+P_{2} L_{2}\left(Y_{2}, i_{2}\right),
$$

and

$$
R+D_{1}+D_{2}=M_{u}\left(R, D_{1}, D_{2}\right)
$$

The aggregate money supply is a function of both domestic components and of the reserves. By replacing,

$$
\mathrm{M}_{\mathrm{u}}\left(\mathrm{R}, \mathrm{D}_{1}, \mathrm{D}_{2}\right)=\mathrm{P}_{1} \mathrm{~L}_{1}\left(\mathrm{Y}_{1}, \mathrm{i}_{1}\right)+\mathrm{P}_{2} \mathrm{~L}_{2}\left(\mathrm{Y}_{2}, \mathrm{i}_{2}\right) .
$$

Because of the perfect capital mobility assumption, the interest parity equilibrium condition holds:

(2.2.2.12) $i_{1}=i_{2}$, thus the subindex can be eliminated.

Expressing the aggregated money market logaritmically:

$$
\mathrm{m}_{\mathrm{u}}-\mathrm{p}_{1}-\mathrm{p}_{2}=\phi \mathrm{y}_{1}+\phi \mathrm{y}_{2}-2 \lambda \mathrm{i}
$$

As in the flexible exchange rate case, price expectations are static and thus nominal interest rates are equal to real interest rates

\footnotetext{
${ }^{33}$ In this case it is assumed that the reserve currency $\mathrm{R}$ is either gold or a currency of a third country for example the US dollar. If for example country 1 were the currency country then the money supply equation of both countries would be $M_{1}=D_{1}$ and $M_{2}=D_{2}+R_{2}$. For details see Neumann (1988).
} 
$(2.2 .2 .14) \quad \mathrm{i}_{\mathrm{j}}=\mathrm{r}_{\mathrm{j}}$.

Replacing (2.2.2.12), (2.2.2.14) and (2.2.2.3) in (2.2.2.1) and (2.2.2.2), and considering (2.2.2.13), I obtain both goods and money market equilibrium conditions for the home and for the foreign country

(2.2.2.15) $\quad \mathrm{y}_{1}=\mathrm{g}_{1}+\mathrm{fy}_{2}-\sigma \mathrm{i}$

(2.2.2.16) $\quad \mathrm{y}_{2}=\mathrm{g}_{2}+\mathrm{fy}_{1}-\sigma \mathrm{i}$

(2.2.2.17) $\quad \mathrm{m}_{\mathrm{u}}-\mathrm{p}_{1}-\mathrm{p}_{2}=\phi \mathrm{y}_{1}+\phi \mathrm{y}_{2}-2 \lambda \mathrm{i}$.

The goods and money market equilibrium conditions consist of a 3-equation system with 3 endogenous variables $y_{1}, y_{2}$ and $i$, hence the system is determined and can be solved.

By differentiating the system, as before, I analyze the impact effect of an expansionary domestic monetary and a fiscal shock on the endogenous variables.

\section{Fiscal Shock}

A domestic positive fiscal shock will have an expansionary impact on the home income. The aggregate demand will increase and therefore will affect domestic output positively. (2.2.2.18) $\quad \mathrm{dy}_{1} / \mathrm{dg}_{1}=(2 \lambda+\sigma \phi) /(1+\mathrm{f})[2 \lambda(1-\mathrm{f})+2 \sigma \phi]>0$.

$\Delta=(1+\mathrm{f})[2 \lambda(1-\mathrm{f})+2 \sigma \phi]$ is always positive for $0<\mathrm{f}<1$.

The increase in aggregate demand will induce tensions in the domestic money market and the interest rate will rise in order to reestablish the equilibrium.

$$
\mathrm{di} / \mathrm{dg}_{1}=\phi(1+\mathrm{f}) /(1+\mathrm{f})[2 \lambda(1-\mathrm{f})+2 \sigma \phi] \quad>0 .
$$

The effect on foreign income is ambiguous: it will be positive or negative depending on the relative values of the income-, export- and interest rate elasticities. Thus $2 \mathrm{f} \lambda$ $\sigma \phi><0$.

The expansionary effect on the home income will have a positive impact on the foreign output through the increase in the demand for imports and a negative impact through the higher interest rates. The higher the interest elasticity $(\sigma)$ of the demand for investment and the income elasticity of money demand $(\phi)$ the more contractive will be the effect on the foreign output. On the other hand, the higher is the country 1's propensity to import $(f)$ and the higher the interest elasticity of money demand $(\lambda)$ the larger will be the positive impact on foreign output.

$(2.2 .2 .10) \mathrm{dy}_{2} / \mathrm{dg}_{1}=(2 \mathrm{f} \lambda-\sigma \phi) /(1+\mathrm{f})[2 \lambda(1-\mathrm{f})+2 \sigma \phi]><0$, and

$\mathrm{dy}_{2} / \mathrm{dg}_{1}>0$

when $2 \mathrm{f} \lambda-\sigma \phi)>0$

if $2 \mathrm{f} \lambda>\sigma \phi$

and $\mathrm{dy}_{2} / \mathrm{dg}_{1}<0$ 
when $2 \mathrm{f} \lambda-\sigma \phi<0$

if $2 \mathrm{f} \lambda<\sigma \phi$.

Figure 2.2.2.1 shows the impact of an expansive fiscal policy originated in country 1 . Initially, output in country 1 increases and therefore induces higher demand for imports of goods which are produced in country 2 . Both IS curves shift to the right. The interest rate has increased while the money supply remains constant. Thus, in the very short run there is a tendency for the interest rate to be higher in country 1 than in country 2 . This is due to the income effect on money demand, which is higher in country 1 than in country 2 because the direct effect on the goods market in country 1 is, of course, higher than the indirect effect through exports in country 2 . There is a capital flow from country 2 to country 1 and therefore an increase of the monetary base in country 1 and a decrease in country 2 . While this capital flows effect reinforces the output increase in country 1 , it moves in a negative way in country 2 , leaving undetermined the final effect on output. Therefore, the final effect on $y_{2}$ depends on the export elasticity (shift of IS 2 curve to the right) and on the shift of the $\mathrm{LM}_{2}$ curve to the left. Finally, the spill-over effect on country 2 can be positive or negative depending on the export elasticity, the income elasticity of the money demand, and on interest rate elasticity. ${ }^{34}$

\section{Monetary Shock}

As it was shown before, under fixed exchange rates, money markets in both countries are closely linked, and monetary policy is not longer independent. ${ }^{35}$ Thus if, for example, country 1 initiates an expansive monetary policy, the central bank of country 2 will only operate in order to guarantee the fixed parity of the exchange rate. After all adjustments have taken place, the redistribution of reserves between the two countries will differ from its initial level.

\section{Distribution of Money Supply Across Countries}

Before analyzing the impact of an expansionary monetary policy on outputs and interest rates, I will consider the effect of the monetary policy with respect to the redistribution across countries. ${ }^{36}$ I will consider an expansionary monetary policy initiated by country 1 which translates into an increase of its monetary domestic component $\left(D_{1}\right){ }^{37}$ At the same time, the reserves in country $1\left(R_{1}\right)$ decrease and those of to country 2 increase $\left(R_{2}\right)$. The total increase in the money supply is identical to the increase in the domestic component of the first country.

\footnotetext{
${ }^{34}$ Compare above $2 \mathrm{f} \lambda-\sigma \phi><0$.

${ }^{35}$ In section 2.4, the $\mathrm{N}-1$ problem is detailed explained. Additionally, different solutions to this problem are presented.

${ }^{36}$ See De Grauwe (1992), Papadopoulou (1992), Neumann (1988), Dornbusch and Swoboda (1973).

${ }^{37}$ The domestic component of country $2 \mathrm{D}_{2}$ remains unchanged.
} 
The redistribution across countries is as follows:

$$
\begin{aligned}
& \mathrm{dM}_{1}=\mathrm{dD}_{1}+\mathrm{dR}_{1}=(1 / 2) \mathrm{dD}_{1} \\
& \mathrm{dM}_{2}=\mathrm{dD}_{2}+\mathrm{dR}_{2}=(1 / 2) \mathrm{dD}_{1}
\end{aligned}
$$

The money supply in each country increases by half the increase in the domestic component of country 1 . This means that the reserves of country 1 will decrease by an amount $(1 / 2) \mathrm{dD}_{1}$ and the reserves of country 2 will increase by $(1 / 2) d D_{1}$. The offset coefficient in this case is $0.5^{38}$

\section{Effect of the Monetary Policy on Output and Interest Rates}

The mechanism of transmission works as follows: the central bank of country 1 undertakes an open market operation by increasing its domestic component $D_{1}$, and there is a tendency for the domestic interest rate to decline and to differ from the foreign interest rate. Because of the assumption of perfect capital mobility, this situation induces a large net capital outflow. Pressures appear in the exchange rate market, where there is a tendency for the exchange rate to depreciate. Because the exchange rate is fixed, both central banks will intervene in the market by defending the agreed exchange rate parity. The central bank of country 1 will sell foreign reserves and the central bank of country 2 will buy foreign reserves. Through this operation, the interest rate will remain equal across countries. However, as it was shown above, the monetary expansion distributes itself between the money markets of both countries in equal proportions. Therefore, the domestic and foreign interest rates will equalize at a level which is lower than the original one.

(2.2.2.14) $\mathrm{di} / \mathrm{dm}_{\mathrm{u}}=\left(\mathrm{f}^{2}-1\right) /(1+\mathrm{f})[2 \lambda(1-\mathrm{f})+2 \sigma \phi]<0$, and $0<\mathrm{f}<1$.

A lower interest rate induces an increase in domestic investment and in this way influences the aggregate demand and finally impacts positively on domestic output.

$$
\mathrm{dy}_{1} / \mathrm{dm}_{\mathrm{u}}=\sigma(1+\mathrm{f}) /(1+\mathrm{f})[2 \lambda(1-\mathrm{f})+2 \sigma \phi]>0 .
$$

The increase in domestic output and lower interest rates impact positively on the foreign output, this spill-over effect will be larger, the larger is the income elasticity (f) and interest rate elasticities of investment $(\sigma)$.

$$
\mathrm{dy}_{2} / \mathrm{dm}_{\mathrm{u}}=\sigma(1+\mathrm{f}) /(1+\mathrm{f})[2 \lambda(1-\mathrm{f})+2 \sigma \phi]>0 .
$$

\footnotetext{
${ }^{38}$ For details on the offset coefficient see Giavazzi and Giovannini (1988).
} 
Table 2.2

Two Country Mundell-Fleming Model

Effect of a Domestic Shock on Domestic and Foreign Variables

\begin{tabular}{|lllll|}
\hline & \multicolumn{2}{l}{ Flexible exchange rate } & \multicolumn{2}{l|}{ Fixed exchange rate } \\
\hline & Monetary & Fiscal & Monetary & Fiscal \\
\hline & Shock & Shock & Shock & Shock \\
\hline $\mathrm{p}_{1}-\mathrm{p}_{2}$ & + & + & 0 & + \\
\hline $\mathrm{e}$ & + & - & 0 & 0 \\
\hline$\theta$ & 0 & - & 0 & - \\
\hline $\mathrm{y}_{1}$ & 0 & 0 & 0 & 0 \\
\hline $\mathrm{y}_{2}$ & 0 & 0 & 0 & 0 \\
\hline
\end{tabular}

Figure 2.2.2.2 shows the impact of an expansive monetary policy originated in country 1. Initially the interest rate decreases, once $\mathrm{LM}_{1}$ in country 1 shifts to the right. The monetary expansion increases domestic output and will push both the current account and capital account into a deficit. In country 2 , the increase in the exports will push $\mathrm{IS}_{2}$ curve to the right, and output in country 2 will increase.

The increase in the foreign output $\left(\mathrm{y}_{2}\right)$ will shift $I S_{1}$ to the right. Because the interest rate in country 2 is, in the short run, higher than in country 1 , there will be a capital flow from country 1 to country 2 and the $\mathrm{LM}_{2}$ curve shifts to the right. Capital movements will take place until both interest rates have equalized at a lower level than originally and both output levels will be higher.

Table 2.2 summarizes the impact of both shocks on domestic and foreign variables in both exchange rate regimes.

\subsubsection{Concluding Remarks}

The main message of the two-country Mundell-Fleming model can be summarized as follows: spill-over effects of domestic policies on foreign countries and vice versa are unavoidable in both exchange rate regimes. Under a floating exchange rate regime, an expansionary fiscal policy will have a positive impact on foreign output while an expansionary monetary policy will have contractive effect on the output of the foreign country. On the contrary, under a fixed exchange rate system an expansive monetary policy has a positive impact on the output of the foreign country, while the impact of an expansionary fiscal policy will be positive or negative depending on the degree of income and interest rate elasticities.

Therefore, the conclusion of this first section is that not even the flexible exchange rate system insulates completely from foreign shocks: the high mobility of capital ensures that foreign monetary or fiscal policies are transmitted to the domestic economy 
through the impact on interest rates. However, while countries working under a floating exchange rate regime are able to follow independent monetary policies, under fixed exchange rates they lose this autonomy, with monetary policy becoming completely endogenous. 
Figure 2.2.1.1.

Flexible Exchange Rate Fiscal Policy

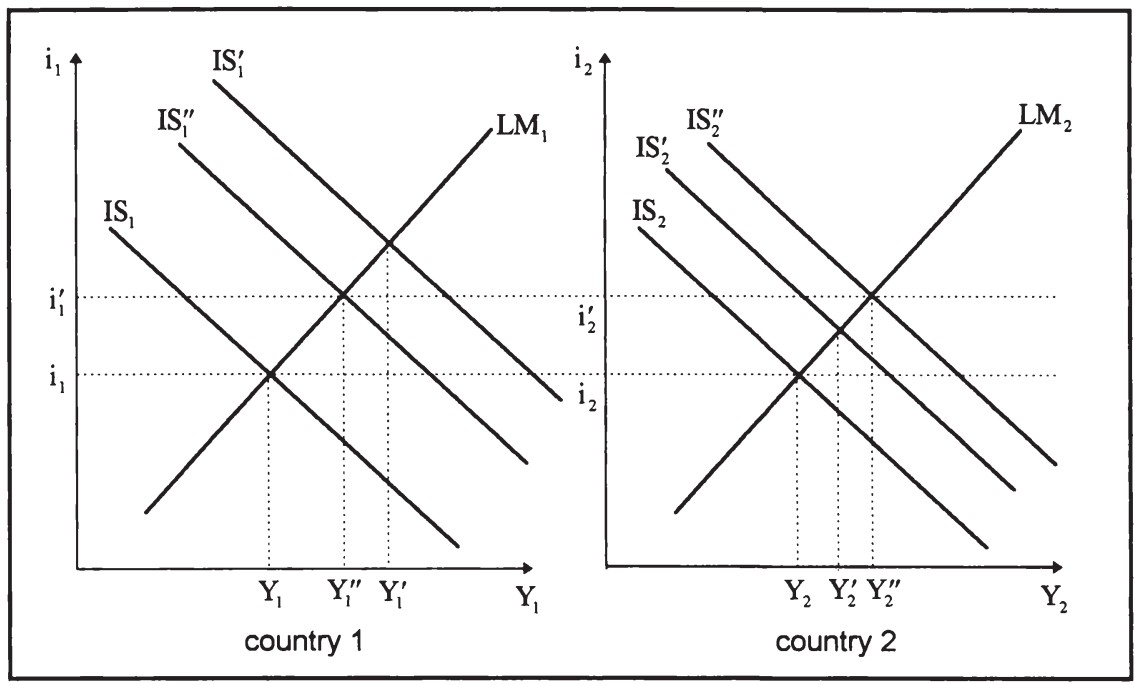

Figure 2.2.1.2.

Flexible Exchange Rate Monetary Policy

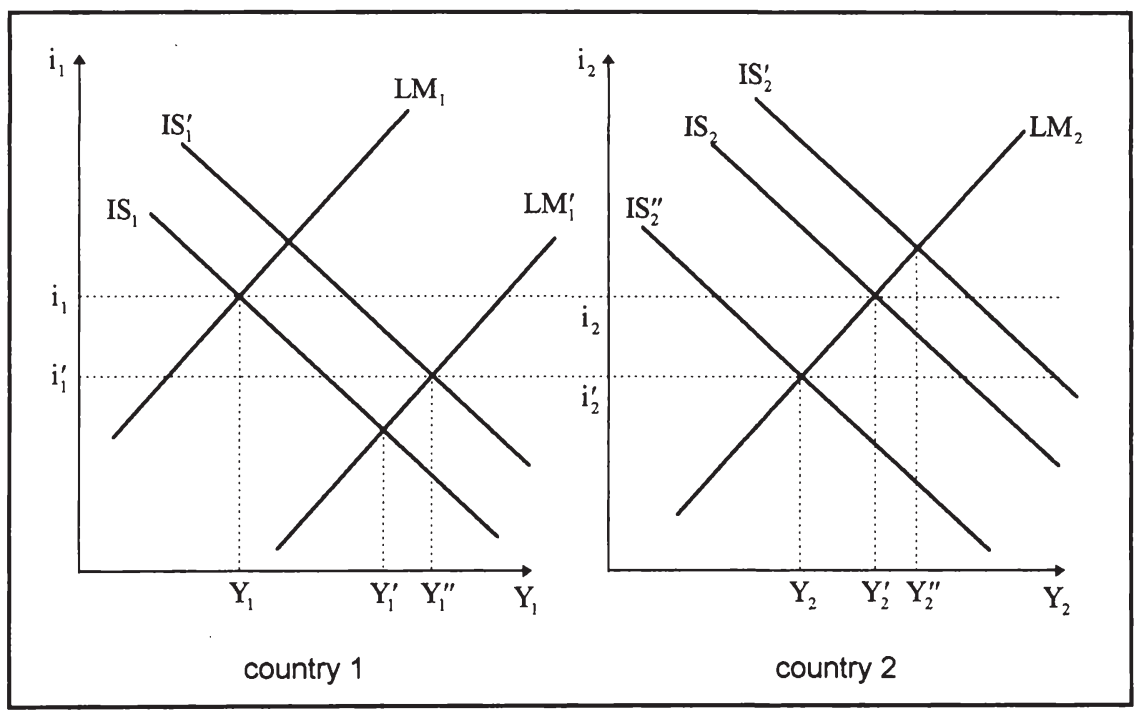


Figure 2.2.2.1.

Fixed Exchange Rate Fiscal Policy

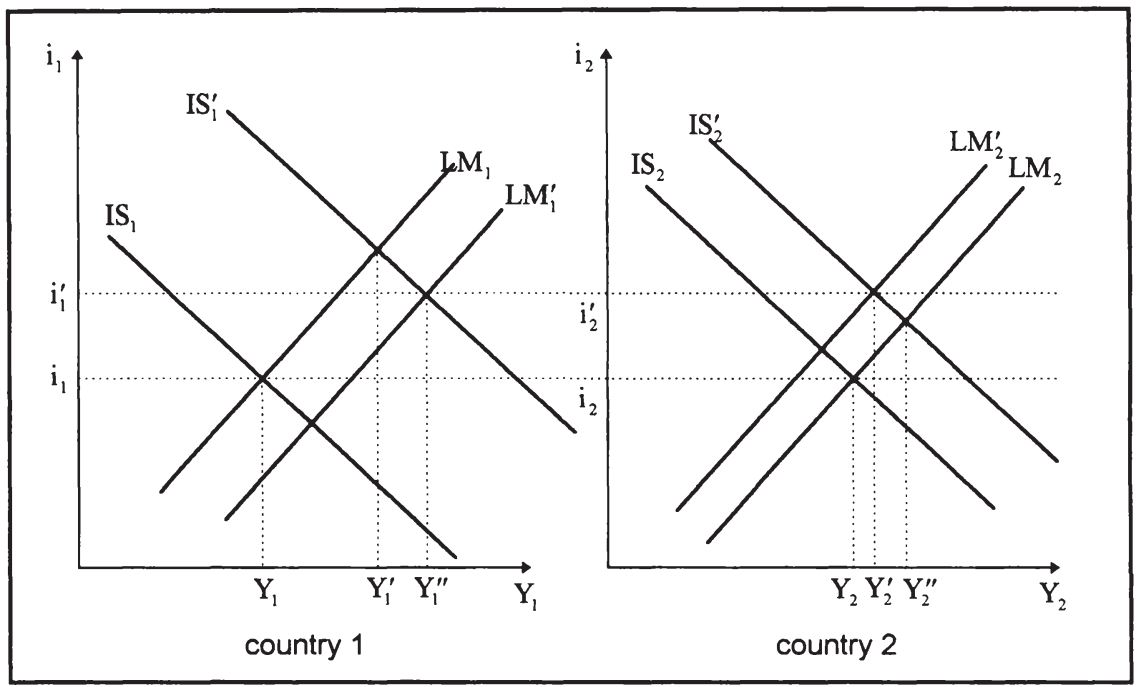

Figure 2.2.2.2.

Fixed Exchange Rate Monetary Policy

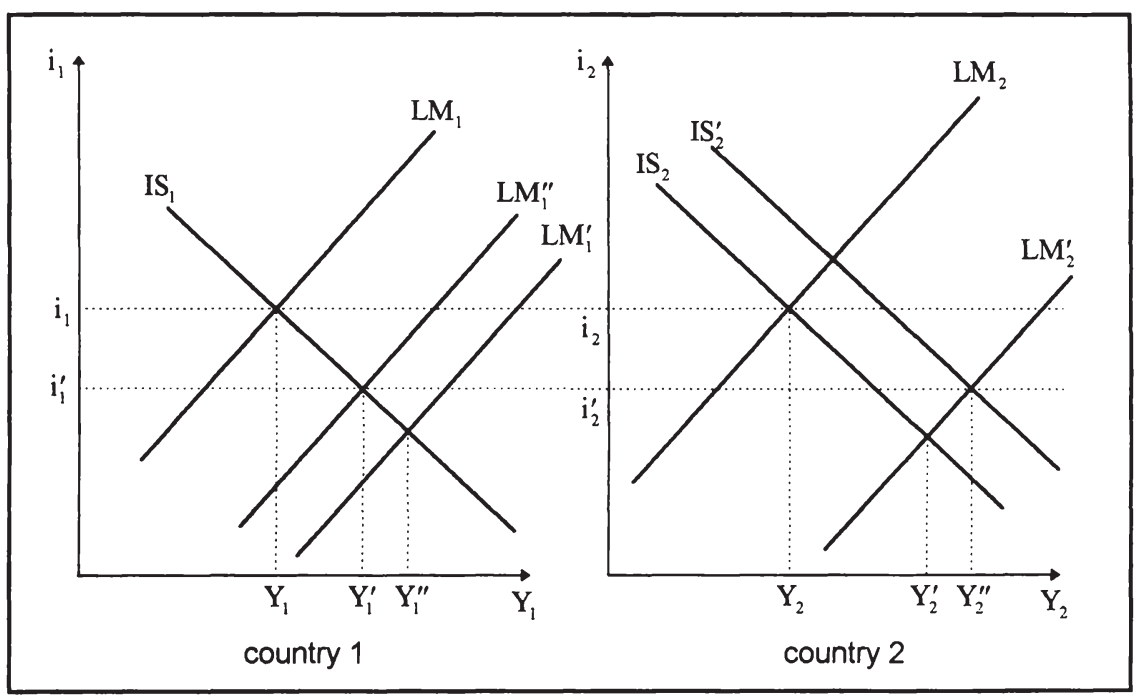




\subsection{Dynamic Effects: the Dornbusch Model}

The Dornbusch "overshooting" model constitutes an extension of the Mundell-Fleming model and was set out in the original and innovative article published by Dornbusch in 1976. Dornbusch extended the perfect capital mobility version of the Mundell-Fleming flexible exchange rate model by incorporating exchange rate expectations and analyzed the dynamic of price and exchange rates adjustment in the basic framework of open economies. The Dornbusch model focuses on the exchange rate implications of economic policies and in particular on the propensity of the exchange rate to overor undershoot its equilibrium value. The crucial assumption of the model is the asymmetric adjustment speeds of goods and financial markets. Thus, asset markets react quickly as compared with goods markets. While price adjustment is assumed to be gradual, "sticky" in the terminology applied by Dornbusch (1976), exchange rates and interest rates can jump in anticipation of future developments ${ }^{39}$ Actually, because prices cannot react immediately, the exchange rate overreacts by overshooting or undershooting its equilibrium level. In this section, I shall introduce a two-country version of the Dornbusch model that I will then use to compare the effect of monetary and fiscal shocks in the long-run and the short-run dynamics. As in the MundellFleming model presented previously, I consider two countries home and foreign. The subindex 1 corresponds to the respective variables of the first country, and 2 to those of the second. Each country produces domestically one good. Output is at the full employment level. All the variables are expressed in logs, with the exception of the interest rate, and the structural parameters are assumed to be the same in both countries.

\subsubsection{Flexible Exchange Rates}

\section{The Model}

\section{The Goods Market}

The assumed adjustment pattern of prices is described by the equation (2.3.1.1) and (2.3.1.2) for the home and foreign country respectively.

$\mathrm{y}_{j}{ }^{\mathrm{d}}$ represents aggregate demand, $\mathrm{q}_{\mathrm{j}}$ the full employment output level, $\dot{\mathrm{p}}_{\mathrm{j}}$ the change in price level. Prices will increase (decrease) whenever there is an excess of demand (supply). For both countries, the price reaction functions are expressed by (2.3.1.1) and (2.3.1.2) and represent the Phillips curve unadjusted for expectations. ${ }^{40}$

\footnotetext{
${ }^{39}$ See Branson (1988) and Gärtner (1994).

${ }^{40}$ The addition of price expectation would reproduce the augmented Phillips curve, which constitutes an extension of the Dornbusch model. For details see Buiter and Miller (1981), Bhandari and Turnovsky (1982), Mussa (1982). The augmented Phillips curve can be expressed as follows: $\dot{p}=E_{t} \dot{p}+\varphi(y-q)$. Expectation of future inflation can follow different
} 


$$
\dot{\mathrm{p}}_{1}=\varphi\left(\mathrm{y}_{1}-\mathrm{q}_{1}\right)
$$

$\varphi$ is the velocity of price adjustment. Thus price behavior encompasses two extreme cases: $\varphi=0$ represents fixed prices as in the traditional Mundell-Fleming presented in the previous section; and on the other extreme $\varphi=\infty$ represents the neo-classical case with perfect price flexibility, where $y_{j}{ }^{d}=q_{j}$ i.e. output cannot deviate from the equilibrium level. In the traditional Dornbusch model, $0<\varphi<\infty$ because prices are assumed to be sticky and therefore adjust slowly to excess of demand or supply. In the original version of the Dornbusch model, it is assumed that the money growth rate is zero, and the steady state inflation is also zero. Therefore, no steady state inflation term is included in the Phillips curve. ${ }^{41}$

Equations (2.3.1.4) and (2.3.1.5) represent the aggregate demand for home and foreign country

$$
\begin{aligned}
& y^{d}{ }_{1}=g_{1}-\sigma r_{1}+f y_{2}+\delta\left(e-p_{1}+p_{2}\right) \\
& y^{d}{ }_{2}=g_{2}-\sigma r_{2}+f y_{1}-\delta\left(e-p_{1}+p_{2}\right) .
\end{aligned}
$$

In both countries the aggregate demand depends positively on the real exchange rate, on the fiscal policy and on the foreign output and negatively on real interest rates ${ }^{42}$. Ouput is demand-determined then:

$$
\text { (2.3.1.6) } \mathrm{y}_{\mathrm{j}}^{\mathrm{d}}=\mathrm{y}_{\mathrm{j}} \text {. }
$$

By replacing (2.3.1.4), (2.3.1.5) and (2.3.1.6) in (2.3.1.1) and (2.3.1.2) I obtain both goods market equilibrium conditions.

$$
\dot{\mathrm{p}}_{1}=\varphi\left[\mathrm{g}_{1}-\sigma\left(\mathrm{i}_{1}-\dot{\mathrm{p}}_{\mathrm{l}}\right)+\mathrm{fy}_{2}+\delta\left(\mathrm{e}-\mathrm{p}_{1}+\mathrm{p}_{2}\right)-\mathrm{q}_{1}\right]
$$

$$
\dot{\mathrm{p}}_{2}=\varphi\left[\mathrm{g}_{2}-\sigma\left(\mathrm{i}_{2}-\dot{\mathrm{p}}_{2}\right)+\mathrm{fy}_{1}-\delta\left(e-\mathrm{p}_{1}+\mathrm{p}_{2}\right)-\mathrm{q}_{2}\right]^{43}
$$

forms either adaptive or backward looking or rational. The former was proposed by Friedman

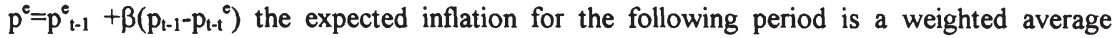
between the inflation expected for the past period plus a percentage of the error incurred in the inflation forecast of the previous period. The introduction of rational expectation will transform the Phillips curve into its Lucas curve version, where output is always on its full employment level and will deviate of it only in the presence of unexpected stochastic shocks. $E_{t-1}\left(p_{t}\right)=p_{t}+v_{t}$ where $v_{t}$ is the error term which follows a random walk behavior with $E_{t}\left(v_{t}\right)=0$ and $E\left(v_{j}, v_{i}\right)=0$. In average the error term is always zero and is not autocorrelated with the past error terms. The Phillips curve "a la Lucas" would be as follows: $y_{t}=a\left(p_{t}-E_{t-1}-p_{t}\right)+v_{t}$

${ }^{41} \mathrm{By}$ assuming money growth rate different of 0 , the expression adopts the following form $\dot{\mathrm{p}}=\pi^{\mathrm{e}}+\mathrm{a}(\mathrm{y}-\mathrm{q})$ and $\dot{\mathrm{m}}=\pi^{\mathrm{e}}$. Buiter and Miller (1981) analyze the effect of including a money growth term in the Phillips curve equation.

${ }^{42}$ In the original version presented by Dornbusch (1976) both money and goods markets depend on nominal interest rate. Buiter and Miller (1981) show, however, that this limitation does not influence the prediction of the model since in the long run $\dot{p}=0$. 
By rearranging terms,

$$
\begin{aligned}
& \dot{\mathrm{p}}_{1}=\varphi /(1-\varphi \sigma)\left[\mathrm{g}_{1}-\sigma \mathrm{i}_{1}+\mathrm{fy}_{2}+\delta\left(\mathrm{e}-\mathrm{p}_{1}+\mathrm{p}_{2}\right)-\mathrm{q}_{1}\right] \\
& \dot{\mathrm{p}}_{2}=\varphi /(1-\varphi \sigma)\left[\mathrm{g}_{2}-\sigma \mathrm{i}_{2}+\mathrm{fy}_{1}-\delta\left(\mathrm{e}-\mathrm{p}_{1}+\mathrm{p}_{2}\right)-\mathrm{q}_{2}\right],
\end{aligned}
$$

and $(1-\varphi \sigma)>0$ when $\varphi<1 / \sigma$, the price adjustment velocity must be smaller than the inverse of the investment interest rate elasticity.

\section{The Money Market}

In equilibrium, the demand for money equals the supply for money. Money demand depends positively on output and negatively on the nominal interest rate. Real balances are explicitly deflated by the $\mathrm{CPI}^{44}$ (consumer price index) of each country. ${ }^{45} \mathrm{As}$ before, CPI is calculated as a weighted average of domestic prices and import prices and therefore the exchange rate appears on both money functions. ${ }^{46} \beta$ weights the home prices and $(1-\beta)$ the foreign. This time, however, the assumption $\beta=1$ is relaxed and thus $0<\beta<1$.

All the variables are expressed in logs, $\phi$ is the income money demand elasticity, $\lambda$ the interest rate semielasticity of money demand for real balances.

$$
\begin{aligned}
& \mathrm{m}_{1}-\mathrm{p}_{\mathrm{cl}}=\phi \mathrm{y}_{1}-\lambda \mathrm{i}_{1} \\
& \mathrm{~m}_{2}-\mathrm{p}_{\mathrm{c} 2}=\phi \mathrm{y}_{2}-\lambda \mathrm{i}_{2} \\
& \mathrm{p}_{\mathrm{cl}}=\beta \mathrm{p}_{1}+(1-\beta) \mathrm{p}_{2}+(1-\beta) \mathrm{e} \\
& \mathrm{p}_{\mathrm{c} 2}=\beta \mathrm{p}_{2}+(1-\beta) \mathrm{p}_{1}+(1-\beta) \mathrm{e} .
\end{aligned}
$$

\footnotetext{
${ }^{43}$ In order to reduce the complexity of the algebra the real interest rate is deflated by domestic prices instead by the consumption price index. As the domestic investment is mainly influenced by national component, in this case the omission of the consumer price index does not have a relevant impact on the final result.

${ }^{44}$ In the model presented originally by Dornbusch (1976) $\beta=1$ and thus money demand was only deflated by domestic prices. However, Dornbusch only analyzed the effect of a monetary shock. By deflating the real balances by the CPI is possible to obtain an effect of the fiscal policy different of zero. Alternatively, it is possibly to introduce the output equilibrium level as depending on the real exchange rate and therefore the fiscal policy has also a positive effect See Reither (1992).

${ }^{45}$ See Buiter and Miller (1981), Eastwood and Venables (1982), Buiter and Purvis (1983).

${ }^{46}$ See Argy and Salop (1979) and Branson and Buiter (1983).
} 
and by replacing (2.3.1.13) and (2.2.1.14) in (2.3.1.11) and (2.3.1.12) respectively, I get: ${ }^{47}$

$$
\begin{aligned}
& \mathrm{m}_{1}-\beta \mathrm{p}_{1}-(1-\beta) \mathrm{p}_{2}-(1-\beta) e=\phi \mathrm{y}_{1}-\lambda \mathrm{i}_{1} \\
& \mathrm{~m}_{2}-\beta \mathrm{p}_{2}-(1-\beta) \mathrm{p}_{1}-(1-\beta) e=\phi \mathrm{y}_{2}-\lambda \mathrm{i}_{2}
\end{aligned}
$$

\section{Uncovered Interest Parity Condition}

$$
i_{1}=i_{2}+E_{t}\left(e_{t+1}-e_{t}\right)+\rho .
$$

Assuming perfect capital mobility, domestic interest rate is equal to the foreign interest rate corrected by the devaluation expectation plus the risk premium ${ }^{48}$. I assume $\rho=0 .{ }^{49}$ The model is robust to this assumption. ${ }^{50}$

$$
E_{t}\left(e_{t+1}-e_{t}\right)=\dot{e} .
$$

From (2.3.1.17) and (2.3.1.18)

$$
\text { (2.3.1.19) } \dot{\mathrm{e}}=\mathrm{i}_{1}-\mathrm{i}_{2} \text {, }
$$

Economic agents form their exchange rate expectations rationally. Since the model does not involve uncertainty ${ }^{51}$ in any form, then rational expectations are equivalent to perfect foresight. In this sense, the anticipated capital gain term is set equal to the actual appreciation of the foreign currency.

\section{Monetary and Fiscal Shocks}

\section{The Long Run Comparative Statics}

Equations (2.3.1.9), (2.3.1.10), (2.3.1.15) and (2.3.1.16) form a system that can be reduced to a 2 equations system by subtracting the variables of country 2 from those of country $1^{52}$. Then all variables can be interpreted as relative values of country 1 respect to country 2 .

\footnotetext{
${ }^{47}$ Notice that in this case money demand is depending on aggregate demand $y_{j}$. In the original version of Dornbusch (1976) money demand was depending on potential output and therefore, the LM curve was an horizontal line. In this case the LM curve has the typical positive slope.

${ }^{48}$ See Branson (1988).

${ }^{49}$ In this case domestic and foreign bonds are perfect substitute.

${ }^{50}$ In the original version of the Dornbusch model risk premium was not considered. Branson (1988) analyzes the effect of changes in the risk premium in a Dornbusch framework.

${ }^{51}$ The model does not include an error term.

${ }^{52}$ See Jordi and Clarida (1992), Aoki (1981).
} 
The goods market equilibrium condition (2.3.1.20) is obtained by subtracting equation (2.3.1.10) from (2.3.1.9).

$(2.3 .1 .20) \dot{\mathrm{p}}_{1}-\dot{\mathrm{p}}_{2}=\varphi /(1-\varphi \sigma)\left[\left(\mathrm{g}_{1}-\mathrm{g}_{2}-\sigma\left(\mathrm{i}_{1}-\mathrm{i}_{2}\right)+\mathrm{f}\left(\mathrm{y}_{2}-\mathrm{y}_{1}\right)+2 \delta \mathrm{e}-2 \delta\left(\mathrm{p}_{1}-\mathrm{p}_{2}\right)-\left(\mathrm{q}_{1}-\mathrm{q}_{2}\right)\right]\right.$.

The money market equilibrium condition is obtained by subtracting (2.3.1.16) from (2.3.1.15) and replacing by (2.3.1.19)

$(2.3 .1 .21) m_{1}-m_{2}=-(1-2 \beta)\left(p_{1}-p_{2}\right)+2(1-\beta) e+\phi\left(y_{1}-y_{2}\right)-\lambda(\dot{e})$.

Equation (2.3.1.20) and (2.3.1.21) form a system that permits the comparative statics and the dynamic of the exchange rate $\dot{e}$ and the relative prices $\dot{\mathrm{p}}_{1}-\dot{\mathrm{p}}_{2}$ to be analyzed. However, in the long run equilibrium: $\dot{\mathrm{p}}_{1}-\dot{\mathrm{p}}_{2}=0$ and $\dot{\mathrm{e}}=0$. By differentiating the whole system it is possible to obtain the following expression for the long run:

$\left[\begin{array}{cc}2 \delta & -2 \delta \\ -(1-2 \beta) & 2(1-\beta)\end{array}\right]\left[\begin{array}{c}\mathrm{de} \\ \mathrm{d} \overline{\mathrm{p}}_{1}-\overline{\mathrm{p}}_{2}\end{array}\right]=\left[\begin{array}{cc}-1 & 0 \\ 0 & 1\end{array}\right]\left[\begin{array}{c}\mathrm{d}\left(\mathrm{g}_{1}-\mathrm{g}_{2}\right) \\ \mathrm{d}\left(\mathrm{m}_{1}-\mathrm{m}_{2}\right)\end{array}\right]$.

The determinant of the matrix is $2 \delta>0$.

\section{Monetary Shock}

An increase in the relative money supply raises the relative price $p_{1}-p_{2}$ and the exchange rate, e proportionally to the increase in the money supply. Hence money is neutral and therefore the corresponding multipliers are equal 1 as the expressions (2.3.1.22) and (2.3.1.23) show.

$$
\begin{aligned}
& d\left(m_{1}-m_{2}\right) / d\left(p_{1}-p_{2}\right)=1^{53} \\
& d\left(m_{1}-m_{2}\right) / d e=1 .
\end{aligned}
$$

\footnotetext{
${ }^{53}$ The increase in the relative money supply is due to a domestic monetary expansion and/or foreign monetary contraction or a combination of both as long as they are not totally compensated with each other.
} 


\section{Fiscal Shock}

An increase in the relative fiscal policy ${ }^{54}$ increases the relative price and appreciates the exchange rate.

$$
\begin{aligned}
& \mathrm{d}\left(\mathrm{g}_{1}-\mathrm{g}_{2}\right) / \mathrm{d}\left(\mathrm{p}_{1}-\mathrm{p}_{2}\right)=2(1-\beta)>0 \\
& \mathrm{~d}\left(\mathrm{~g}_{1}-\mathrm{g}_{2}\right) / \mathrm{de}=1-2 \beta<0 .
\end{aligned}
$$

\section{Dynamic Analysis}

In order to analyze the dynamic behavior, equation (2.3.1.21) is solved with respect to the nominal exchange rate. Equation (2.3.1.20) and (2.3.1.26) form a dynamic twoequation system. Both equations represent the nominal and the real exchange rate.

$$
\begin{aligned}
& (2.3 .1 .20) \dot{\mathrm{p}}_{1}-\dot{\mathrm{p}}_{2}=\varphi /(1-\varphi \sigma)\left[\left(\mathrm{g}_{1}-\mathrm{g}_{2}\right) \quad+\sigma(\dot{\mathrm{e}})+\mathrm{f}\left(\mathrm{y}_{2}-\mathrm{y}_{1}\right)+2 \delta \mathrm{e}-2 \delta\left(\mathrm{p}_{1}-\mathrm{p}_{2}\right)-\left(\mathrm{q}_{1}-\mathrm{q}_{2}\right)\right] \\
& (2.3 .1 .26) \dot{\mathrm{e}}=1 / \lambda\left[-1(1-2 \beta)\left(\mathrm{p}_{1}-\mathrm{p}_{2}\right)+2(1-\beta) \mathrm{e}+\phi\left(\mathrm{y}_{1}-\mathrm{y}_{2}\right)-\left(\mathrm{m}_{1}-\mathrm{m}_{2}\right)\right]
\end{aligned}
$$

Setting e and $\dot{\mathrm{p}}_{1}-\dot{\mathrm{p}}_{2}=0$ the following system is obtained for the long run:

$$
\begin{aligned}
& \left(p_{1}-p_{2}\right)=1 / 2 \delta\left[\left(2 \delta e+\left(g_{1}-g_{2}\right)+f\left(y_{2}-y_{1}\right)-\left(\bar{q}_{1}-\bar{q}_{2}\right]\right.\right. \\
& e=\lambda / 2(1-\beta)\left[(1-2 \beta)\left(p_{1}-p_{2}\right)-\phi\left(y_{1}-y_{2}\right)+\left(m_{1}-m_{2}\right)\right] .
\end{aligned}
$$

Figure (2.3.1.1) depicts the money equilibrium condition in the space $\mathrm{p}_{1}-\mathrm{p}_{2}$, e. Setting $\dot{\mathrm{e}}=0$ on $(2.3 .1 .26)$ yields a negative sloped curve that represents the locus of points along which the money market is in equilibrium with zero expected change in the exchange rate. An increase in the exchange rate requires a reduction in the domestic price relative to the foreign so that neither consumer prices change nor any disturbance is introduced into the monetary market.

A higher home price level will imply a lower level of real balances and a higher interest rate $i_{1}<i_{2}$. If $i_{1}<i_{2}$, then from the uncovered interest parity condition $\dot{e}$ must be positive. Under rational expectations a point above (below) the curve implies that the nominal exchange rate is rising (decreasing) as the arrows show.

Figure 2.3.1.2, depicts the good market equilibrium condition, which is an upwardly sloping curve. A point below the curve represents a situation in which the relative price of the home goods is too low to be consistent with the equilibrium. There is then an excess of demand for the home goods and excess supply of foreign goods, and then $\mathrm{p}_{1}-\mathrm{p}_{2}$ should rise in order to re-establish the equilibrium.

In figure 2.3.1.3, the dynamics of both markets is depicted showing a divergent path and a downwardly sloped convergent path. The latter is called the "saddle path", so termed because it always leads to the equilibrium and expectations are realized. All

\footnotetext{
${ }^{54}$ The expansionary relative fiscal policy implies an expansion of the domestic fiscal policy or a contraction of the foreign fiscal policy or a combination of both.
} 
other paths are unstable and constitute speculative bubbles. Along them, the expectations can be realized from one period to the next but they do not lead to the equilibrium. ${ }^{55}$ If for any reason the economy is pushed away from the equilibrium, it is assumed that rational actors will always find the stable saddle path that converges to the new equilibrium. This is the common assumption under rational expectations ${ }^{56}$.

\section{Monetary Shock}

An unanticipated monetary expansion abroad and or a monetary contraction at home is depicted in figure 2.3.1.4. The economy is at the starting point on A. A reduction of $\left(\mathrm{m}_{1}-\mathrm{m}^{2}\right)$ will shift both the $\dot{e}$ curve and the saddle path towards the origin. The new saddle path leads to a new equilibrium at $C$. Following the monetary impact, the exchange rate jumps from the old saddle path to the new one at $\mathrm{B}$, because prices have not yet reacted. In anticipation of the future fall in the relative price level, the currency immediately appreciates. The relative price level $\left(\mathrm{p}_{1}-\mathrm{p}_{2}\right)$ and the exchange rate will gradually move along the new path $\mathrm{SS}^{\prime}$ in the direction of $\mathrm{C}$; prices will change until the new equilibrium level is reached at $\mathrm{C}$. Initially, the interest rate rises at home relative to abroad, consistent with the expectation that the exchange rate will raise. The interest rate at home will once again equal the foreign interest rate once price level at home has increased relative to the foreign. Immediately after the monetary shock, the exchange rate overshoots its new equilibrium level. The initial jump downwards of the exchange rate is consistent with the expectation that it will rise again. The interest rate at home rises less relative to that abroad, consistent with the expectation that the exchange rate will appreciate after the overshooting impact. Figure 2.3.1.5 depicts the time paths of the relative variables, prices, nominal interest rate, exchange rate and money supply.

\section{Fiscal shock}

The figure 2.3.1.6 shows the result of an expansionary policy abroad. Initially, the economy is at the point $\mathrm{A}$. The shock shifts the goods market equilibrium condition to the right. The exchange rate will jump to the new saddle path SS at B and it will move along SS until reaching the equilibrium at C. Initially, the exchange rate will depreciate but by less than required at the final equilibrium. Once the relative price level begins to adjust, the exchange rate will continue depreciating until it has reached the equilibrium point $C$. In this case, the exchange rate undershoots the equilibrium level in response to a real disturbance. Fig 2.3.1.7 depicts the time paths of the relative variables prices, nominal interest rates, exchange rate and fiscal policy.

Summarizing, in the two-country Dornbusch model under flexible exchange rates, a foreign monetary and/or fiscal shock has an impact on the domestic variables through changes in the exchange rate. The exchange rate jumps after the impact effects but continues adjusting until reaching the new equilibrium level. However, while an unanticipated expansionary monetary policy abroad induces an overshooting effect, an

\footnotetext{
55 See Chiang (1984), Scarth (1988).

${ }^{56}$ See Begg (1987).
} 
expansionary fiscal policy abroad creates an undershooting effect. The most important conclusion to be drawn from the two-country Dornbusch model is that, under a flexible exchange rate system, the nominal exchange rate will react with high volatility in response to both monetary and real shocks.

\subsubsection{Fixed Exchange Rates}

Although the Dornbusch model was originally constructed to explain the variability of flexible exchange rates, the framework of the model can be applied to the case in which both countries are linked by a fixed exchange rate.

\section{The Model}

\section{The Goods market}

The price adjustment mechanism remains the same as in the case of flexible exchange rates and is described by equations (2.3.2.1) and (2.3.2.2) for the home and foreign country respectively.
(2.3.2.1) $\quad \dot{\mathrm{p}}_{1}=\varphi\left(\mathrm{y}_{1}-\mathrm{q}_{1}\right)$
(2.3.2.2) $\quad \dot{\mathrm{p}}_{2}=\varphi\left(\mathrm{y}_{2}-\mathrm{q}_{2}\right)$.

The aggregate demands for the home and foreign countries depend positively on the fiscal parameter g, negatively on real interest rates an positively on the real exchange rate. However, the exchange rate is now fixed $\overline{\mathrm{e}}$.

$$
\begin{aligned}
& y_{1}{ }^{d}=g_{1}-\sigma r_{1}+f_{2}+\delta\left(\bar{e}-p_{1}+p_{2}\right) \\
& y_{2}{ }^{d}=g_{2}-\sigma r_{2}+f y_{1}-\delta\left(\bar{e}-p_{1}+p_{2}\right) .
\end{aligned}
$$

\section{The Money Market}

In equilibrium, money demand is equal money supply in both countries. Real balances are considered as deflated by the consumer price indexes, $P_{c 1}$ and $P_{c 2}$ which are the average of domestic and foreign prices. Money demand depends negatively on the nominal interest rate and positively on the level of aggregate demand

$$
\begin{array}{ll}
(2.3 .2 .5) & \mathrm{M}_{1}=\mathrm{P}_{\mathrm{cl}} \mathrm{L}\left(\mathrm{i}_{1}, \mathrm{Y}_{1}\right) \\
\text { (2.3.2.6) } & \mathrm{M}_{2}=\mathrm{P}_{\mathrm{c} 2} \mathrm{~L}\left(\mathrm{i}_{2}, \mathrm{Y}_{2}\right) .
\end{array}
$$

Consumer price indexes are as follows:

(2.3.2.7) $\quad \mathrm{p}_{\mathrm{cl}}=\beta \mathrm{p}_{1}+(1-\beta) \mathrm{p}_{2}+(1-\beta) \overline{\mathrm{e}}$

$(2.3 .2 .8) \quad p_{c 2}=\beta p_{2}+(1-\beta) p_{1}+(1-\beta) \overline{\mathrm{e}}$. 
Under the assumption that the exchange rate is fixed both money markets are linked and money supply is endogenous. ${ }^{57}$

$$
\begin{aligned}
& M_{1}=D_{1}+R_{1}=P_{c 1} L_{1}\left(Y_{1}, i_{1}\right) \\
& M_{2}=D_{2}+R_{1}=P_{c 2} L_{2}\left(Y_{2}, i_{2}\right) .
\end{aligned}
$$

The money supply of the home country is made up of the domestic component $\left(D_{1}\right)$ and the foreign reserves $\left(R_{1}\right)$. In the same way, the money supply of the foreign country is made up of the domestic component $\left(\mathrm{D}_{2}\right)$ and the foreign reserves $\left(R_{2}\right)$. The foreign reserves of both countries are assumed to be held constant, therefore:

$$
\mathrm{R}=\mathrm{R}_{1}+\mathrm{R}_{2}=\text { constant. }
$$

The common equilibrium in the money market is:

$$
\mathrm{M}_{\mathrm{u}}=\mathrm{M}_{1}+\mathrm{M}_{2}=\mathrm{D}_{1}+\mathrm{D}_{2}+\mathrm{R}=\mathrm{P}_{\mathrm{cl}} \mathrm{L}_{1}\left(\mathrm{Y}_{1}, \mathrm{i}_{2}\right)+\mathrm{P}_{\mathrm{c} 2} \mathrm{~L}\left(\mathrm{Y}_{2}, \mathrm{i}_{2}\right)
$$

and

$$
D_{1}+D_{2}+R=M_{u}\left(D_{1}, D_{2}, R\right) .
$$

$M_{u}$ represents the common monetary supply and depends on both domestic components $D_{1}$ and $D_{2}$ and on the foreign reserves.

By rearranging terms,

$$
\mathrm{M}_{\mathrm{u}}\left(\mathrm{D}_{1}, \mathrm{D}_{2}, \mathrm{R}\right)=\mathrm{P}_{\mathrm{cl}} \mathrm{L}_{1}\left(\mathrm{Y}_{1}, \mathrm{i}_{1}\right)+\mathrm{P}_{\mathrm{c} 2} \mathrm{~L}\left(\mathrm{Y}_{2}, \mathrm{i}_{2}\right) .
$$

Under a fixed exchange rate, as was shown in the Mundell-Fleming model, money supply is completely endogenous. ${ }^{58}$

It is assumed that an expansionary monetary policy will take place whenever the home country (country 1) increases its domestic component of its monetary base $\left(D_{1}\right)$ through an open market operation. The foreign country will never induce, independently, a change in its domestic component $\left(D_{2}\right)$, but changes in its monetary base will occur whenever the foreign country has to defend the fixed parity.

By expressing the common money market in logs, the following expression is obtained, representing the common monetary equilibrium equation. ${ }^{5960}$

$$
\mathrm{m}_{\mathrm{u}}-\mathrm{p}_{\mathrm{cl}}-\mathrm{p}_{\mathrm{c} 2}=\mathrm{y}_{1}+\mathrm{y}_{2}-2 \lambda \mathrm{i}
$$

${ }^{57}$ See Papadopulou (1992) and De Grauwe (1990).

${ }^{58}$ Compare with section 2.2

${ }^{59}$ Buiter (1985).

${ }^{60}$ The aggregation with logarithmized values present some problems because the underlying relationship is additive in nature. Since both countries are symmetric the above specification can be used as a reasonable good approximation. See Buiter (1986) for details on aggregation of logarithmized money supplies. 
and by replacing $\mathrm{p}_{\mathrm{cl}}$ and $\mathrm{p}_{\mathrm{c} 2}$ by the respective expressions $(2.3 .2 .7)$ and $(2.3 .2 .8)$ then, $\mathrm{I}$ get:

$$
m_{u}-p_{1}-p_{2}-2 \bar{e}(1-\beta)=y_{1}+y_{2}-2 \lambda i
$$

\section{Fisher Condition}

$$
\begin{aligned}
& (2.3 .2 .17) \quad \mathrm{i}_{1}=\mathrm{r}_{1}+\dot{\mathrm{p}}_{1} \\
& (2.3 .2 .18) \quad \mathrm{i}_{2}=\mathrm{r}_{2}+\dot{\mathrm{p}}_{2}{ }^{61} .
\end{aligned}
$$

For each country, the nominal interest rate is equal to the real interest rate plus the expected rate of inflation. Expectation as to inflation are formed rationally. (2.3.2.19) $\quad \dot{\mathrm{p}}_{\mathrm{j}}=\dot{\mathrm{p}}_{\mathrm{j}}^{\mathrm{e}}$.

\section{Uncovered Interest Parity}

(2.3.2.20) $\quad \mathrm{i}_{1}=\mathrm{i}_{2}+\dot{\mathrm{e}}$.

As before, there is perfect capital mobility and thus the domestic interest rate is equal to the foreign interest rate plus the expected change in the exchange rate. But because of the fixed exchange rate assumption $\dot{\mathrm{e}}=0$, thus interest rates must equalize between both countries ${ }^{62}$.

(2.3.2.21) $\quad \mathrm{i}_{1}=\mathrm{i}_{2}$.

The change in the real exchange rate, however, can be expressed as the difference of both real interest rates:

(2.3.2.22) $\quad \dot{\theta}=r_{1}-r_{2}$.

Replacing by (2.3.2.17) and (2.3.2.18)

$$
\dot{\theta}=i_{1}-\dot{\mathrm{p}}_{1}-\left(\mathrm{i}_{2}-\dot{\mathrm{p}}_{2}\right)
$$

But because $i_{1}=i_{2}$ then, (2.3.2.24) $\quad \dot{\theta}=\dot{\mathrm{p}}_{2}-\dot{\mathrm{p}}_{1}$.

\footnotetext{
${ }^{61}$ See footnote 42 of this chapter.

${ }^{62}$ In this analysis I assume that the exchange rate is fixed at a credible value. The introduction of other assumption leads to the analysis of currency crisis and peso problem. See DeGrauwe (1992).
} 
The real exchange rate can only depreciate/appreciate if the change in prices is not exactly the same in both countries. Because of the symmetry assumption, the velocity of price adjustment is identical in both countries.

\section{Solving the Model}

By replacing both aggregate demands on the price reaction functions, the following expressions are obtained:

$$
\begin{aligned}
& \dot{\mathrm{p}}_{1}=\varphi\left[\mathrm{g}_{1}-\sigma\left(\mathrm{i}-\dot{\mathrm{p}}_{1}\right)+\mathrm{fy}_{2}+\delta\left(\overline{\mathrm{e}}-\mathrm{p}_{1}+\mathrm{p}_{2}\right)-\mathrm{q}_{1}\right] \\
& \dot{\mathrm{p}}_{2}=\varphi\left[\mathrm{g}_{2}-\sigma\left(\mathrm{i}-\dot{\mathrm{p}}_{2}\right)+\mathrm{fy}_{1}-\delta\left(\overline{\mathrm{e}}-\mathrm{p}_{1}+\mathrm{p}_{2}\right)-\mathrm{q}_{2}\right] .
\end{aligned}
$$

Therefore,

$$
\dot{\mathrm{p}}_{1}=\varphi /(1-\sigma \varphi)\left[\mathrm{g}_{1}-\sigma \mathrm{i}+\mathrm{fy}_{2}+\delta\left(\overline{\mathrm{e}}-\mathrm{p}_{1}+\mathrm{p}_{2}\right)-\mathrm{q}_{1}\right]
$$

$$
\dot{\mathrm{p}}_{2}=\varphi /(1-\sigma \varphi)\left[\mathrm{g}_{2}-\sigma \mathrm{i}+\mathrm{fy}_{1}-\delta\left(\overline{\mathrm{e}}-\mathrm{p}_{1}+\mathrm{p}_{2}\right)-\mathrm{q}_{2}\right],
$$
and as before $(1-\sigma \varphi)>0{ }^{63}$.

\section{Comparative Statics}

\section{The Long Run Effect}

In this section, the effect of monetary and fiscal shocks will be analyzed once all the variables have reached their equilibrium level.

In the long run, prices $\dot{\mathrm{p}}_{1}=0$ and $\dot{\mathrm{p}}_{2}=0$ because all the necessary adjustments have already taken place and outputs of both countries have reached their potential level, $\mathrm{y}_{1}=\mathrm{q}_{1}$ and $\mathrm{y}_{2}=\mathrm{q}_{2}{ }^{64}$.

\section{Monetary Shock}

I analyze the case in which country 1 initiates an expansive monetary policy. The effects on both prices and interest rates are as follows: an increase in the monetary base of country 1 induces an increase in both domestic and foreign in the same magnitude $1 / 2$ (see 2.3.2.29 and 2.3.2.30). A symmetric effect is obtained because both countries have the same parameters and have the same size. The final effect on the interest rate is zero.

\footnotetext{
${ }^{63}$ See flexible exchange rate case of Dornbusch model.

${ }^{64}$ See Jarchow (1994).
} 
(2.3.2.30) $\quad \mathrm{dp}_{2} / \mathrm{dm}_{\mathrm{u}}=1 / 2$

(2.3.2.31) $\quad \mathrm{di} / \mathrm{dm}_{\mathrm{u}}=0$.

There is no effect on the real exchange rate, because price levels in both countries increase by exactly the same amount. A real appreciation can only take place if prices in country 1 rise more than prices in country $2^{65}$. However, the symmetry assumption eliminates the possibility of real appreciation in the short run as well as in the long run because, by assumption, prices will increase not only exactly by the same amount but also with the same speed of adjustment. ${ }^{66}$

Actually, if the countries had a different economic structure, in the sense that the flexibility of labor markets differed between them, it would be possible to obtain temporarily an appreciation of the real exchange rate in response to the monetary shock.

As the expression (2.3.2.33) shows, there is no effect on the real exchange in the long run.

$$
\dot{\theta}=\dot{\mathrm{p}}_{1}-\dot{\mathrm{p}}_{2}=1 / 2-1 / 2=0
$$

If price flexibility were higher in country 2 than in country 1 , in the short run country 1 would enjoy a real depreciation of its domestic currency. On the contrary, if the stickiness of prices in country 2 were higher than in country 1 , then country 1 would observe a real appreciation of its domestic currency. In contrast with the case of flexible exchange rate, in this case neither overshooting nor undershooting of the real exchange rate is observed. The fixed exchange rate has simply reduced exchange rate variability, however inflation is transmitted from one country to another.

\section{Distribution of Money Supply across the Countries}

An expansionary monetary policy of country 1 leads to a new distribution of the monetary base and reserves across the two countries. The reserves of country 1 fall and the reserves of the country 2 rise. ${ }^{67}$

$$
\begin{aligned}
& \mathrm{dM}_{1}=\mathrm{dD}_{1}+\mathrm{dR}_{1}=(1 / 2) \mathrm{dD}_{1}, \\
& \mathrm{dM}_{2}=\mathrm{dD}_{2}+\mathrm{dR}_{2}=(1 / 2) \mathrm{dD}_{1} .
\end{aligned}
$$

\footnotetext{
${ }^{65}$ See Eichengreen and Wyplosz (1993).

${ }^{66}$ Notice that the speed of price adjustment depend on the flexibility of labor markets. Prices are sticky because wages are not perfectly flexible. See Taylor (1979).

${ }^{67}$ The effect is identical to the one obtained in the Mundell Fleming model under fixed exchange rate. See section 2.2 .
} 
The money supply in both countries increases by the same amount as the domestic component of the first country.

$$
\text { (2.3.2.36) } \quad \mathrm{dM}_{\mathrm{u}}=\mathrm{dD}_{1} \text {. }
$$

Both individual money supplies increase by one-half of the increase in the domestic component of country 1 . This means that the reserves of country 1 will decrease by an amount $(1 / 2) \mathrm{dD}_{1}$ and the reserves of the second country will increase by $(1 / 2) \mathrm{dD}_{1}$.

\section{Short Run Adjustment}

The mechanism of transmission works as follows: the central bank of country 1 introduces an open market operation by increasing the domestic component of its monetary base. First, there is a tendency for the domestic interest rate to fall, which therefore induces capital outflows and an exchange rate depreciation. Because the exchange rate is fixed, both central banks will intervene in the market to defend the fixed parity. The central bank of country 1 will sell foreign reserves and the central bank of country 2 will buy foreign reserves. Through this operation, the interest rate is maintained equal in both countries and the monetary expansion is distributed across them. Second, the smaller interest rate leads to a rise in investment, thus pushing output in both countries $\left(y_{1}\right.$ and $\left.y_{2}\right)$ above their respective natural levels $q_{1}$ and $q_{2}{ }^{68}$. This situation is facilitated because prices are sticky and do not react instantaneously, otherwise there would be no effect on output. The expansion in domestic output increases the imports of both countries, but, because the two countries are symmetric, exports increase by the same amount as imports. Third, the excess demand will cause prices to rise in both countries. That will reduce real balances and the interest rate will return to its initial level. Output in both countries will decline and finally will come back to the initial equilibrium level $y_{1}=q_{1}$ and $y_{2}=q_{2}$.

Once all adjustments have taken place, prices in both countries will be higher and the interest rate will return to its initial level.

Summarizing: a monetary shock will induce a price rise in both countries. However, so long as the two countries are symmetric and therefore have the same speed of price adjustment, there is no effect on either the real exchange rate nor on real and nominal interest rates. In the case of a monetary shock, neither overshooting nor undershooting of the real exchange rate is observed. In this sense, under a fixed exchange rate, although the inflationary impact is transmitted from country 1 to country 2 , the fixed exchange rate system eliminates the variability not only of the nominal exchange rate but also of the real exchange rate. ${ }^{69}$

\footnotetext{
${ }^{68}$ The short run effect is similar to the one obtained under a Mundell-Fleming model.

${ }^{69}$ This conclusion is quite strong because implies that fixed exchange rate would reduce not only nominal variability but also real. Rose (1996) tests empirically the hypothesis whether fixed exchange rate reduce nominal variability by increasing variability in real markets. He concludes that fixed exchange rate reduces variability and they do not shift variability over time.
} 


\section{Fiscal Policy}

An expansionary fiscal policy originated in country $1 \mathrm{dg}_{1}$ has the following effects on prices and interest rates. In the appendix 3, detailed explanation with respect to the algebra is provided.

$\begin{array}{llll}(2.3 .2 .37) & \mathrm{dp}_{1} / \mathrm{dg}_{1} & = & (2 \lambda+\sigma) / 4 \sigma>0 \\ (2.3 .2 .38) & \mathrm{dp}_{2} / \mathrm{dg}_{1} & = & -(2 \lambda+\sigma) / 4 \sigma<0 \\ (2.3 .2 .39) & \mathrm{di} / \mathrm{dg}_{1} & = & 1 / 2 \sigma>0 .\end{array}$

Price change in each country. However, while they rise in country 1 , they fall in country 2, as expression (2.3.2.37) and (2.3.2.38) show, but the change, although in opposite direction, is exactly the same.

$$
\mathrm{dp}_{1} / \mathrm{dg}_{1}=\quad-\mathrm{dp}_{2} / \mathrm{dg}_{2}
$$

The effect on real exchange rate is positive: prices rise in the first country and fall in the second, and thus there is a real appreciation of the exchange rate for country 1 . See expression (2.3.3.41).

$$
\mathrm{d} \theta=\mathrm{dp}_{2}-\mathrm{dp} \mathrm{p}_{1}=-(2 \lambda+\sigma) / 4 \sigma-(2 \lambda+\sigma) / 4 \sigma=(2 \lambda+\sigma) / 2 \sigma<0 .
$$

\section{Short Run Adjustment}

An expansionary fiscal policy $\mathrm{dg}_{1}$ implies an expansion in the aggregate demand of country $1 y_{1}{ }^{d}$. On the one hand, initially prices do not react and there is an increase in output $y_{1}$. In country 1 the demand for money increases and there is a rise in the interest rate. Because there is a tendency to an exchange rate appreciation, the central bank of country 1 buys reserves and therefore there is an expansion in the monetary base of country 1 . In the short run, aggregate demand $y_{1}{ }_{1}$ will be higher than $q_{1}$, and prices will react after a while. The increase in prices reduces the real balances, and the interest rate increases again, reducing the aggregate demand. Finally, output returns to its equilibrium level, prices have increased and interest rate is higher.

On the other hand, the effect in country 2 is as follows: there is a tendency to an exchange rate depreciation, thus central bank of country 2 intervenes in the exchange rate markets by selling foreign reserves, therefore the monetary basis of country 2 declines, and the interest rate of country 2 is equal to that in country 1. Aggregate demand in country $2, y^{d}{ }_{2}$ is lower than the output equilibrium level and therefore, prices will fall and aggregate demand will eventually become equal to the output equilibrium level. At the final equilibrium level, prices will be higher in country 1 and lower in country 2 than initially and the interest rate will be higher.

Summarizing, a fiscal shock originated in the first country induces a price increase in the first country and a price reduction in the second. In contrast to the case of a monetary shock, the final effect on the real exchange rate is a domestic appreciation. Because the behavior of the real exchange rate depends exclusively on both price adjustments and they are sticky by assumption, the adjustment of the real exchange 
rate is smooth and thus neither overshooting nor undershooting is observed and the dynamic of the exchange rate is absent. Table 2.3 summarizes the long-run effect of a monetary and a fiscal policy under a flexible and a fixed exchange rate system in a Dornbusch two-country model.

\section{Table 2.3}

\section{Two Country Dornbusch Model Long Run Effect of a Monetary and Fiscal Policy}

\begin{tabular}{|llllll|}
\hline & \multicolumn{2}{l}{ Flexible exchange rate } & \multicolumn{2}{l|}{ Fixed exchange rate } \\
\hline Monetary & Fiscal & & Monetary & & Fiscal \\
\hline Shock & Shock & & Shock & & Shock \\
\hline $\mathrm{p}_{1}-\mathrm{p}_{2}$ & + & + & & 0 & \\
\hline $\mathrm{e}$ & + & - & & 0 & + \\
\hline$\theta$ & 0 & - & & 0 & 0 \\
\hline $\mathrm{y}_{1}$ & 0 & 0 & & 0 & - \\
\hline $\mathrm{y}_{2}$ & 0 & 0 & & 0 & 0 \\
\hline
\end{tabular}

\subsubsection{Concluding Remarks}

The following conclusions are drawn from the Dornbusch two-country model previously presented. First, in the short run, while prices have not reacted, $\mathrm{dp}_{1}=\mathrm{dp}_{2}=0$, the model delivers the same results as the Mundell-Fleming model presented in the previous section. This is reasonable, given that in the short run, the Dornbusch model has the same structure as a Mundell-Fleming model because of the price stickiness. Therefore, the effects of monetary and fiscal policy on outputs $y_{1}$ and $y_{2}$ and the interest rate are exactly the same as those obtained in the first section. However, in the long run, no effect is observed on the output level. Second, in the case of a flexible exchange rate system, the effect of a nominal shock induces an overshooting effect in the nominal and real exchange rates. On the contrary the real shock induces an undershooting effect on nominal and real exchange rates. However, in the case of a fixed exchange rate system, a nominal shock has no effect on the real exchange rate. However, price increases are transmitted from one country to another. A fiscal shock induces an appreciation of the real exchange rate. This is the result of a price increase in the country that induced the expansionary fiscal policy and a price decrease in the other one. However, in contrast to the results obtained in the case of a flexible exchange rate, the real exchange rate adjusts smoothly and neither overshooting nor undershooting is observed. Third, the fixed exchange rate has reduced variability not only in the nominal exchange rate, which is by assumption fixed, but also in the real exchange rate. 
Figure 2.3.1.1 Money Market Equilibrium Condition

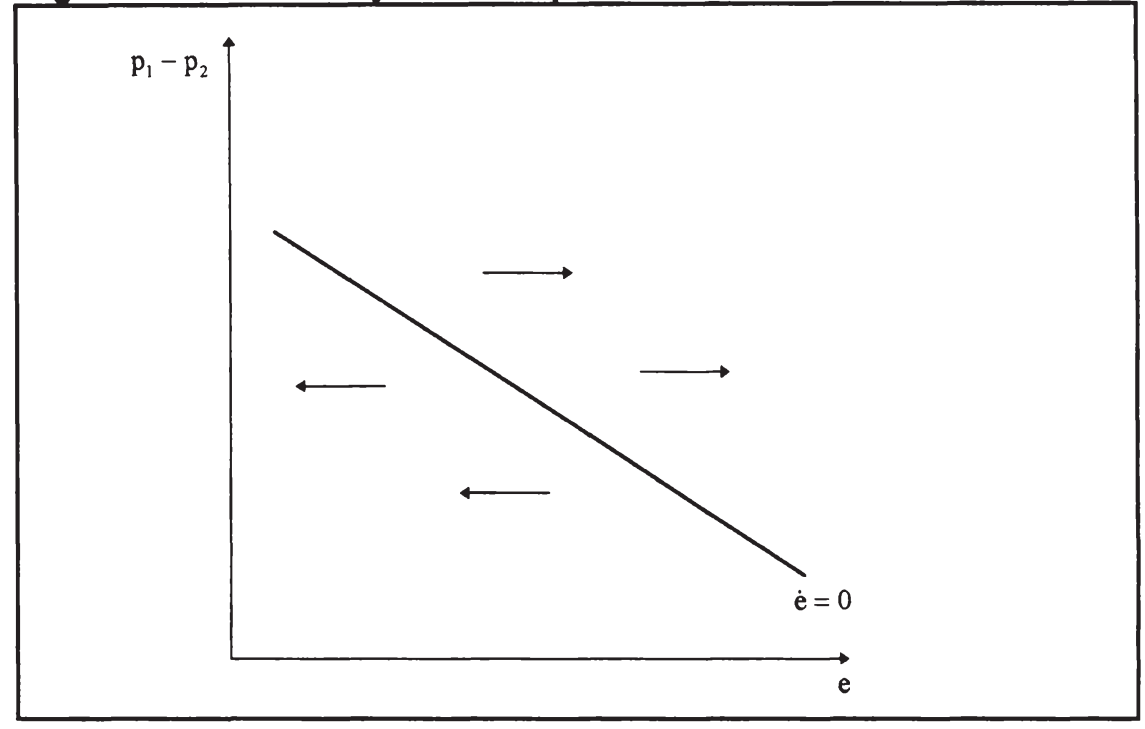

Figure 2.3.1.2 Goods Market Equilibrium Condition

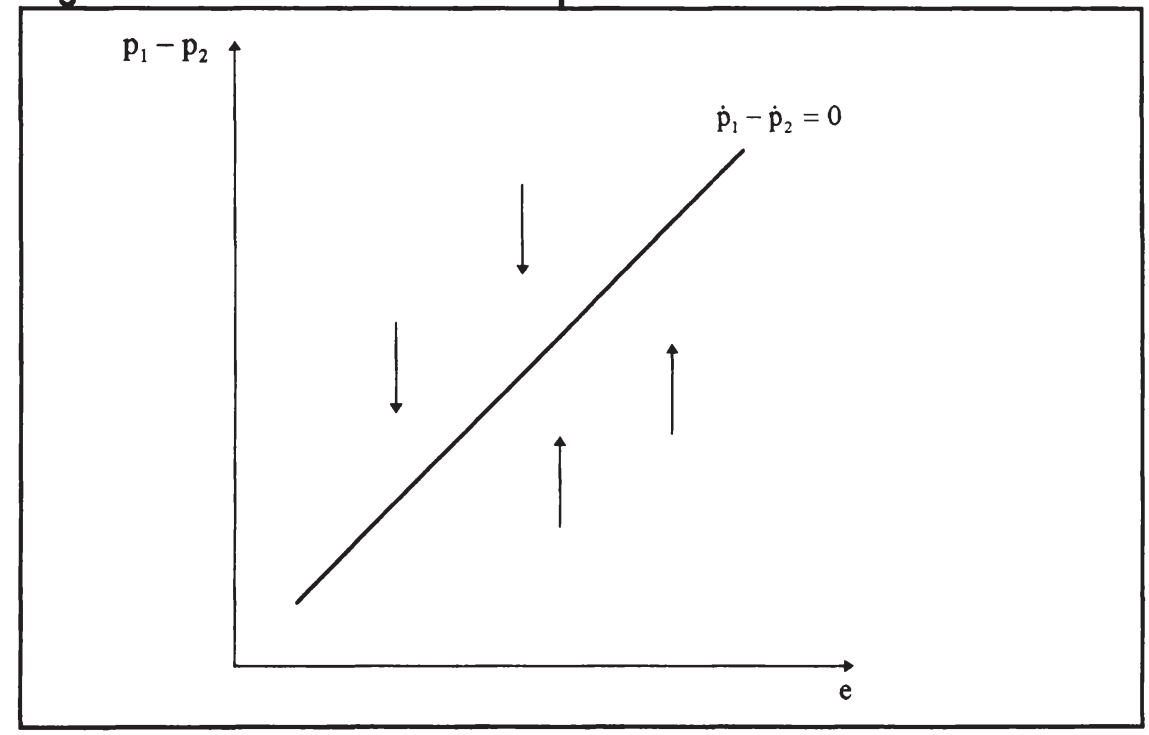


Figure 2.3.1.3 Saddle Path

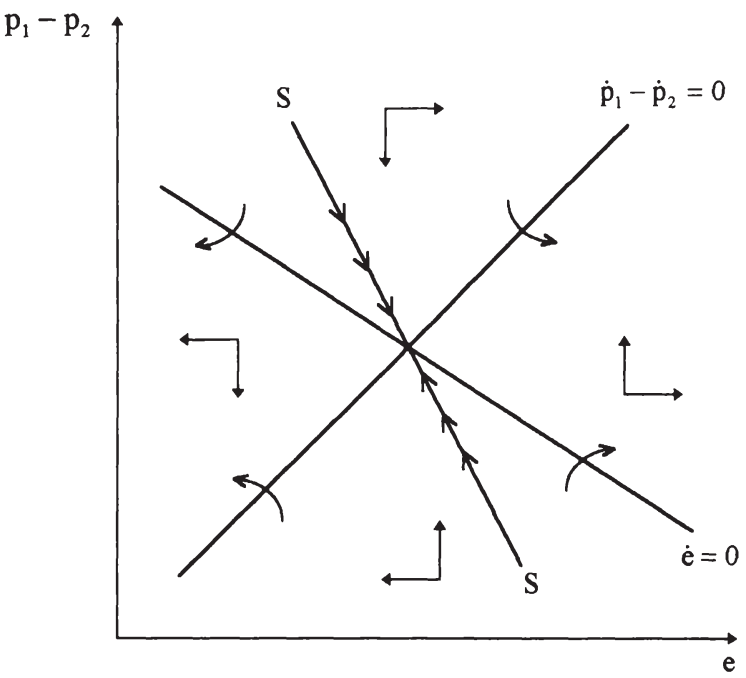

Figure 2.3.1.4 Monetary Policy

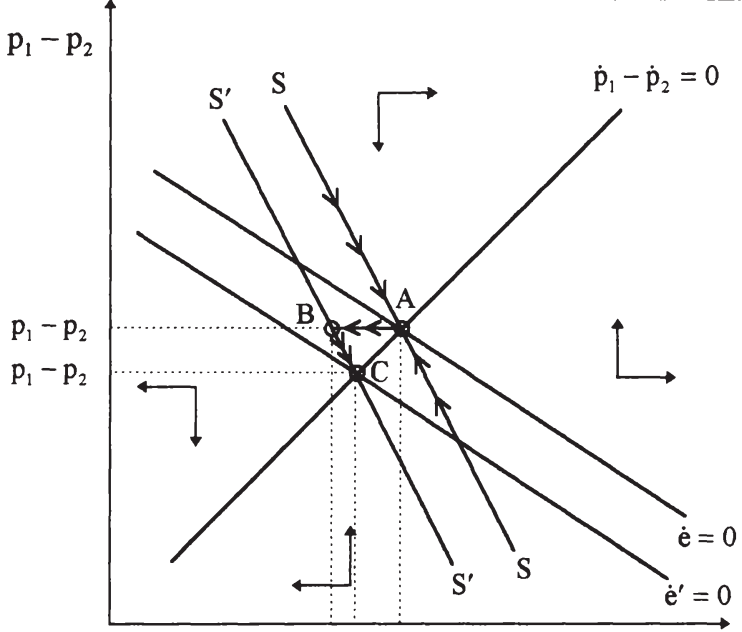

$\mathrm{e}_{2} \mathrm{e}_{3} \mathrm{e}_{1}$

e 
Figure 2.3.1.5 Time Path of the Variables

Monetary Policy

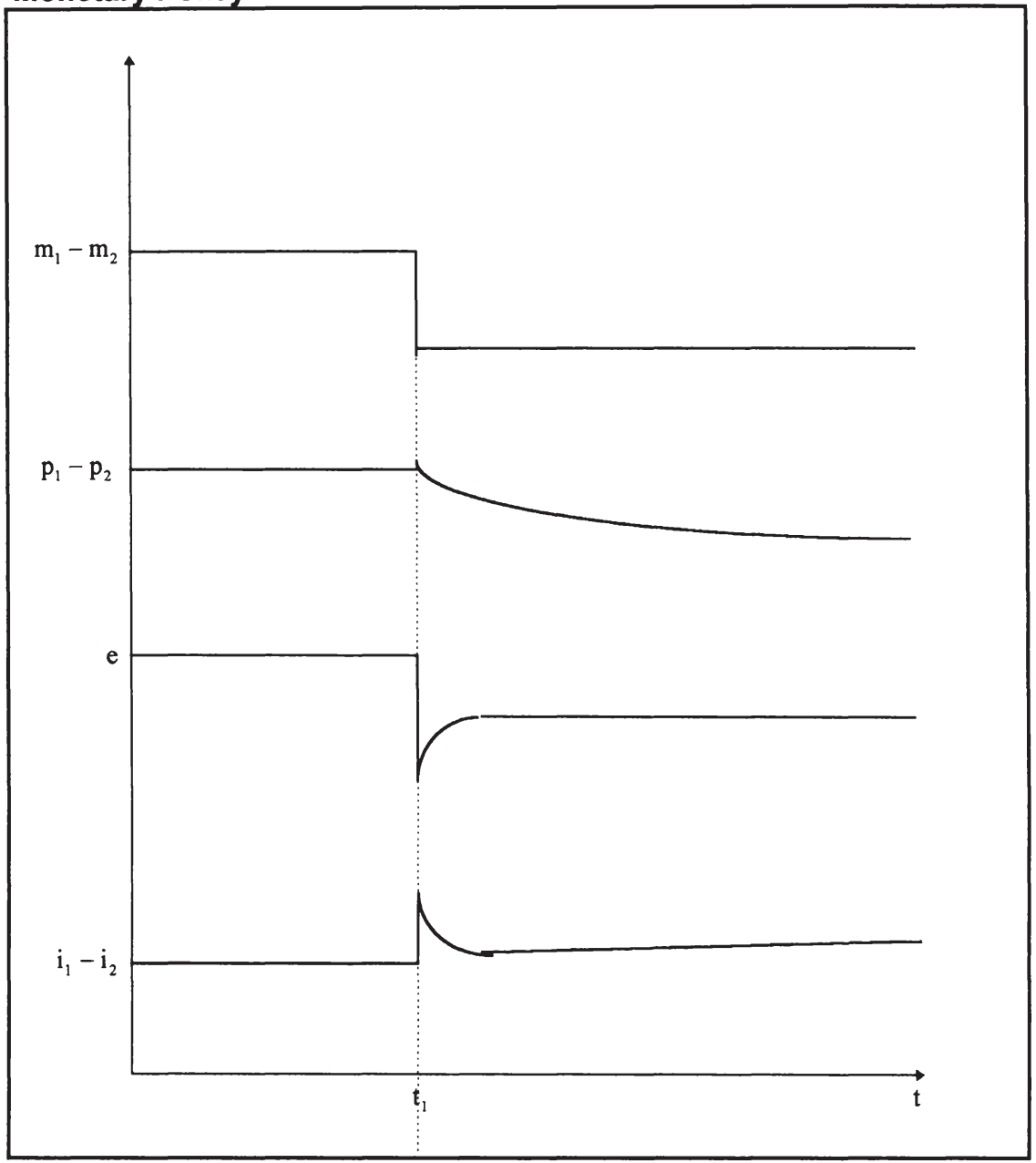


Figure 2.3.1.6

Fiscal Policy

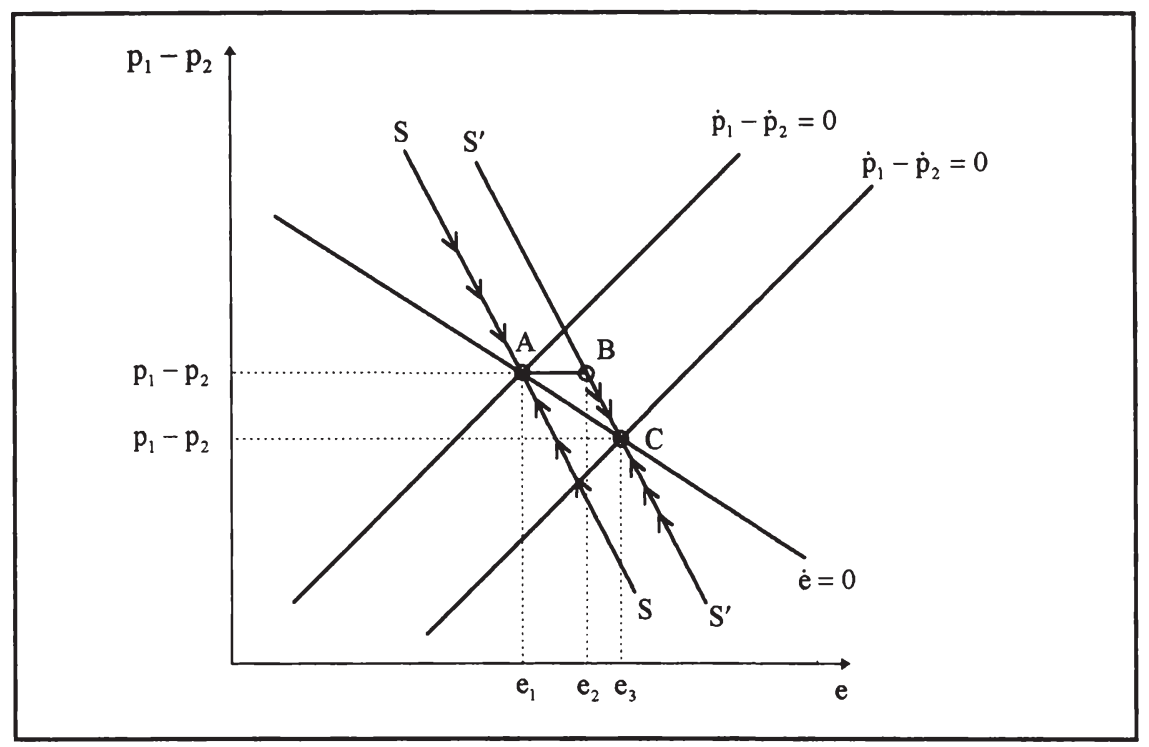


Figure 2.3.1.7 Time Path of the Variables Fiscal Policy

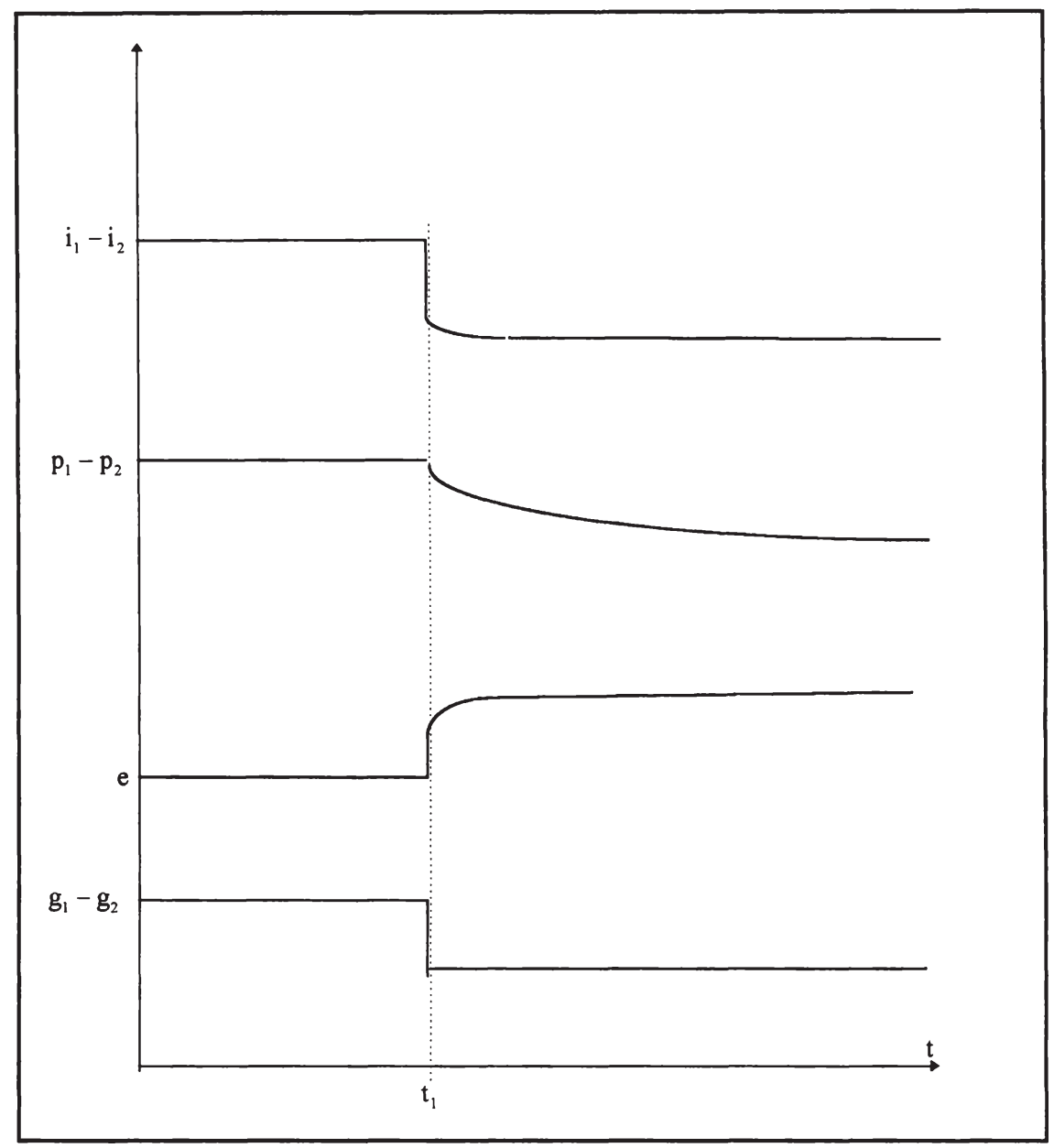




\subsection{The N-1 Problem in a Fixed Exchange Rate System}

In the models presented in section 2.2 (Mundell-Fleming) and 2.3 (Dornbusch model), in the case of fixed exchange rates, countries have a coordination problem to solve. Actually, every fixed exchange rate system faces the difficulty of how to set the system-wide level of the money stock or the interest rate. This issue is described in the literature as the $\mathrm{N}-1$ problem ${ }^{70}$. In a system of $\mathrm{N}$ countries, there are only $\mathrm{N}-1$ exchange rates and therefore only $\mathrm{N}-1$ monetary authorities that are free to set their monetary policy independently. Thus, the system has one degree of freedom. The problem that arises is how to assign this degree of freedom, or in other words, which central bank will have the assignment of using this degree of freedom. From the theoretical point of view, there are two alternatives: an hegemonic solution, where only one central bank determines monetary policy for the system as a whole, or a cooperative solution.

In this section, these two possible solutions are analyzed by means of a very simplified two-country money market model. The money markets in both countries are as follows:

Money demand

$$
\begin{aligned}
& \mathrm{M}_{1}{ }^{\mathrm{d}} / \mathrm{P}_{\mathrm{cl}}=\mathrm{L}_{1}\left(\mathrm{Y}_{1}, \mathrm{i}_{1}\right)^{71} \\
& \mathrm{M}_{2}{ }^{\mathrm{d}} / \mathrm{P}_{\mathrm{c} 2}=\mathrm{L}_{2}\left(\mathrm{Y}_{2}, \mathrm{i}_{2}\right) . \\
& \text { Money supply } \\
& \mathrm{M}_{1}{ }^{\mathrm{s}}=\mathrm{R}_{1}+\mathrm{D}_{1} \\
& \mathrm{M}_{2}{ }^{\mathrm{s}}=\mathrm{R}_{2}+\mathrm{D}_{2} .
\end{aligned}
$$

The money demand is defined in the usual way as depending upon domestic output and interest rates. A rise in interest rates reduces the demand for money and an increase in output increases it.

The money supply consists of two components: the domestic components $D_{1}, D_{2}$ (credit to the government sector) and $R_{1}, R_{2}$ the foreign reserve component. ${ }^{72}$

The total amount of reserves is fixed.

Perfect capital mobility is assumed and therefore the uncovered interest parity condition holds. ${ }^{74}$

$$
\mathrm{i}_{1}=\mathrm{i}_{2}+\dot{\mathrm{e}} \text {. }
$$

\footnotetext{
${ }^{70}$ Collins (1990) analyzes this N-1 problem with game theory instruments. See De Grauwe (1990) and Giavazzi and Giovannini (1992).

${ }^{71}$ Money supplies are deflated by the CPI, however in this case it does not play a relevant role.

${ }^{72}$ See Issing (1984), Claassen (1990).

${ }^{73}$ See previous sections.

${ }^{74}$ The interest rate of country 1 will exceed the interest rate of country 2 in order to compensate holders of assets of country 1 for the expected loss.
} 
and is the expected rate of depreciation because the exchange rate is assumed to be fixed. Then $=0$, and therefore interest rates in the two countries are brought into equality.

$$
\mathrm{i}_{1}=\mathrm{i}_{2} \text {. }
$$

Figure 2.4.1 depicts the system graphically. Money supply and demand are represented with the money demand curve downward sloping and the money supply as a vertical line. The money market is in equilibrium when the both curves intersect in both countries, and the interest parity condition is satisfied (when interest rates are equal between countries).

At points such as A and B, money demand equals money supply in both countries and the interest rates are equalized. However, there are infinitely many combinations of points for which this condition is satisfied. For each of these infinite combinations there is only one level of money stock and one level of interest rate. Therefore, a fixed exchange rate is compatible with any possible level of the interest rate and the corresponding money stock. The system is not determined, and this is exactly the N-1 problem, which produces one degree of freedom in the system.

There are two possible solutions to this problem: a symmetric (cooperative) or an asymmetric (hegemonic) one. ${ }^{75}$

\subsubsection{The Asymmetric or Hegemonic Solution}

The hegemonic solution consists in allowing one country (the reserve currency country) to take the leadership role ${ }^{76}$. If, for example, country 1 is the hegemonic country and fixes its monetary stock independently at the level $\mathrm{M}_{1}$, then the interest rate will be $i_{1}$. Country 2 has no choice but to take the interest rate as a parameter. $i_{2}$ will be identical to $i_{1}$ and therefore the money supply of country $2, M_{2}$, is uniquely determined. Country 2 has to accept the monetary supply imposed by country 1 and in this sense has no autonomy to determine its own monetary policy. Country 1 is the leader and country 2 is the follower.

This is the case of an hegemonic arrangement ${ }^{77}$ and country 1 has the role of anchoring the money stock in the system. Hence the degree of freedom that the system allows is used by country 1 to set its monetary policy totally independently of country 2 .

\footnotetext{
${ }^{75}$ Another way of solving the $\mathrm{N}-1$ problem is through an external reserve such as gold. In the gold standard system, the amount of total reserves was given externally and none of the participating members was able to increase this amount. See Neumann (1988) for further details

${ }^{76}$ In the real world the market decided which is the stronger currency.

${ }^{77}$ The Bretton Woods was an hegemonic system in which the US dollar was the reserve currency.
} 


\subsubsection{Symmetric or Cooperative Solution}

\section{Intervention Rules}

The second possibility of solving this N-1 problem consists in both countries taking a joint decision as to the levels of their money stocks and interest rates. This decision is no longer independent as it was in the hegemonic case, but relies on the cooperation of both countries. ${ }^{78} 79$ In this sense, both countries could decide jointly the level of $\mathrm{M}_{1}$ and $M_{2}$ or the level of the common interest rate. In Figure 2.4.2 the cooperative solution is proposed with intervention rules. Assume that a change in preferences has taken place in country 2 and that then the interest rate in country 1 is higher than in country $2^{80}$. This differential between the two interest rates is the expected rate of devaluation/appreciation. Thus, if the domestic interest rate in country 2 is higher than in country 1 , people expect the currency in country 2 to devalue. In the foreign exchange rate market, the expectation of a future devaluation of currency 2 leads speculators to sell currency 2 and buy currency 1 . In order to prevent the market rate of currency 2 from dropping below the agreed fixed exchange rate, the central bank of country 2 must buy its own currency and sell currency 1 . This situation is only possible through the short term financing that forces country 1 to provide the necessary amounts of its currency to country $2 .{ }^{81}$ This intervention has symmetric effects on the money stocks in the two countries. The money stock of country 2 will decline and that of country 1 will increase. The latter arises from the fact that the sale of currency 1 by country 2 increases the amount of currency 1 in circulation. In Figure 2.4.2, the money stock of country 2 should moves leftwards and that of country 1 should move rightwards. As a result, the interest rate in country 2 would increase and would decline in country 1 . However, suppose that country 1 sterilizes, offsetting the effect of the intervention and not allowing the interest rate to decline, by maintaining constant the money stock. When the central bank of country 2 sells currency of country 1 , and the central bank of country 1 buys back this currency by an open market operation, the final effect of the sterilization policy is that the weak currency is forced to undertake

\footnotetext{
${ }^{78}$ See Corden (1987), Buiter and Eaton (1985), Guerrero and Padoan (1987), Horn and Masson, (1987).

${ }^{79}$ The original EMS proposal was aimed at promoting the cooperative solution, with the ECU acting as the indicator of divergence that would operate as an instrument to promote symmetry in the system. When a market exchange rate of a currency strongly deviated from its central rate, it would show in the indicator of divergence. The country involved would then be singled out to take necessary action. This implied that a country with a strong currency would be required to expand its monetary policy and the country with the weak currency would contract its monetary supply. The second way to allow the symmetric solution was provided by the system of interventions in the foreign exchange rate market. The rule is as follows: when two currencies hit their upper limits, the intervention would be in each others' currency so that the monetary effect in the two countries would be symmetrical. For details see Giavazzi and Giovannini (1992) and Gros and Thygesen (1992).

${ }^{80}$ For reasons of simplicity, I have not drawn the movements in the money demand curve.

${ }^{81}$ It is clear that country 2 has a limited amount of currency 1 ; and ,therefore, the intervention is limited if is not being supported by country 1 .
} 
all the adjustment. The money stock of country 2 is forced to contract and the interest rate is allowed to increase to a much higher level. The money stock of country 1 remains unchanged and the adjustment follows an asymmetric pattern. See Fig. 2.4.3.

\subsubsection{Concluding Remarks}

This section 2.4 has had the objective of illustrating the possibilities and problems that a fixed exchange rate system introduces with respect to the coordination of monetary policy.

In a fixed exchange rate system money, the money supply is completely endogenous and both money markets are closely linked. Because of perfect capital mobility, interest rates must equalize across countries and there is an infinite number of combinations of money stocks that are compatible with an identical interest rate.

This is precisely the so-called N-1 problem. Because of the peculiarity of the system itself, a fixed exchange rate system has a degree of freedom. The problem that arises is how to assign this degree of freedom, in other words, which country will enjoy this degree of freedom by independently determining monetary policy. From the theoretical point of view, there are two possible ways of solving this problem, the hegemonic or asymmetric and the cooperative or symmetric solution. In the first, one country, the hegemon, assigns the monetary policy and the other has to follow. In the second, the symmetric solution consists in both countries coordinating their monetary policies and agreeing on the total stock of money. The symmetric solution can only work in the presence of intervention rules: thus the central bank of the strong currency must support the other central bank.

The hegemonic solution has historically been dominant in all exchange rate systems (Bretton Woods, the gold standard). The EMS was initially designed as a symmetric system, but has ultimately operated as an asymmetric or hegemonic system with the $\mathrm{DM}$ as the hegemonic currency. 
Figure 2.4.1

Money Market Equilibrium in a Two Country Model

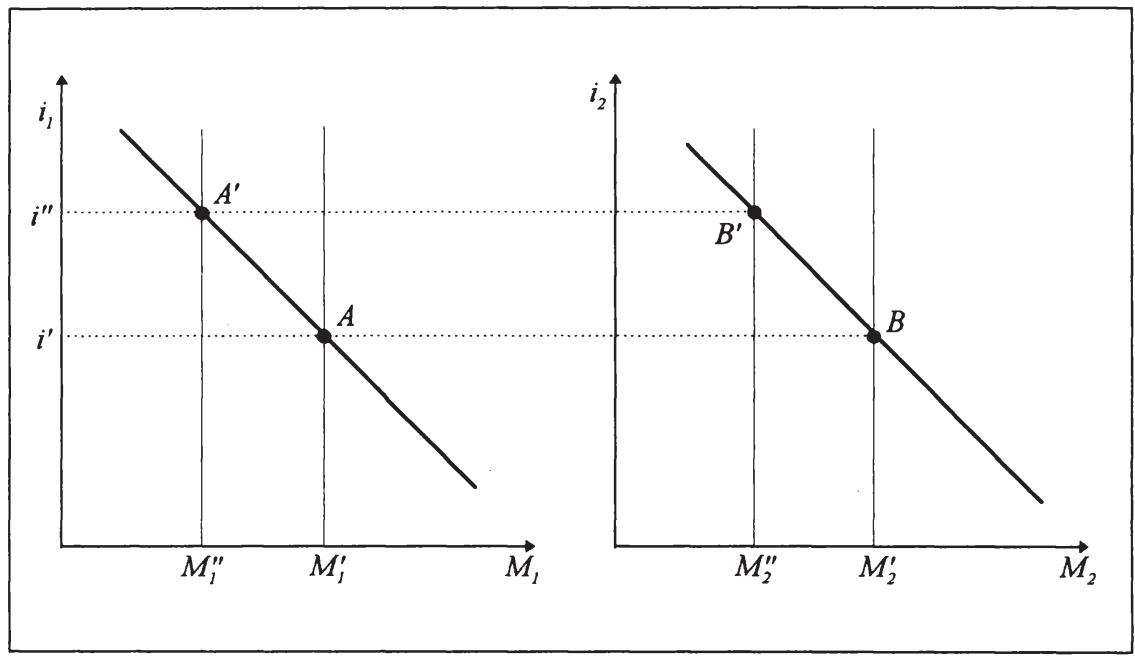

Figure 2.4.2

Symmetric Solution

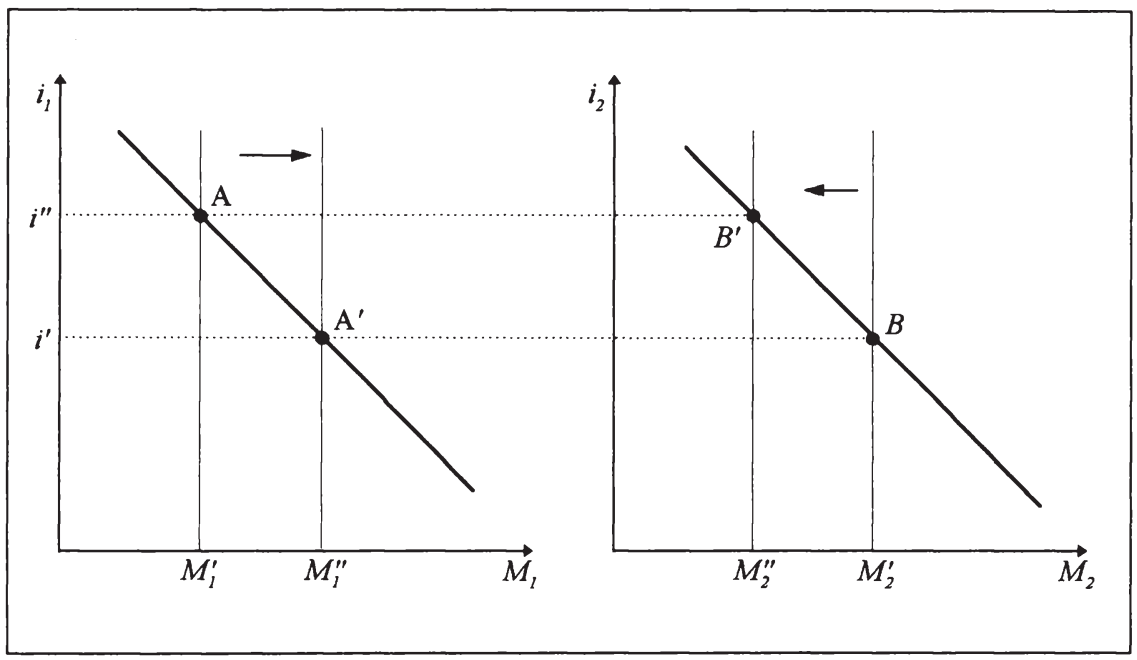


Figure 2.4.3

Aymmetric Solution

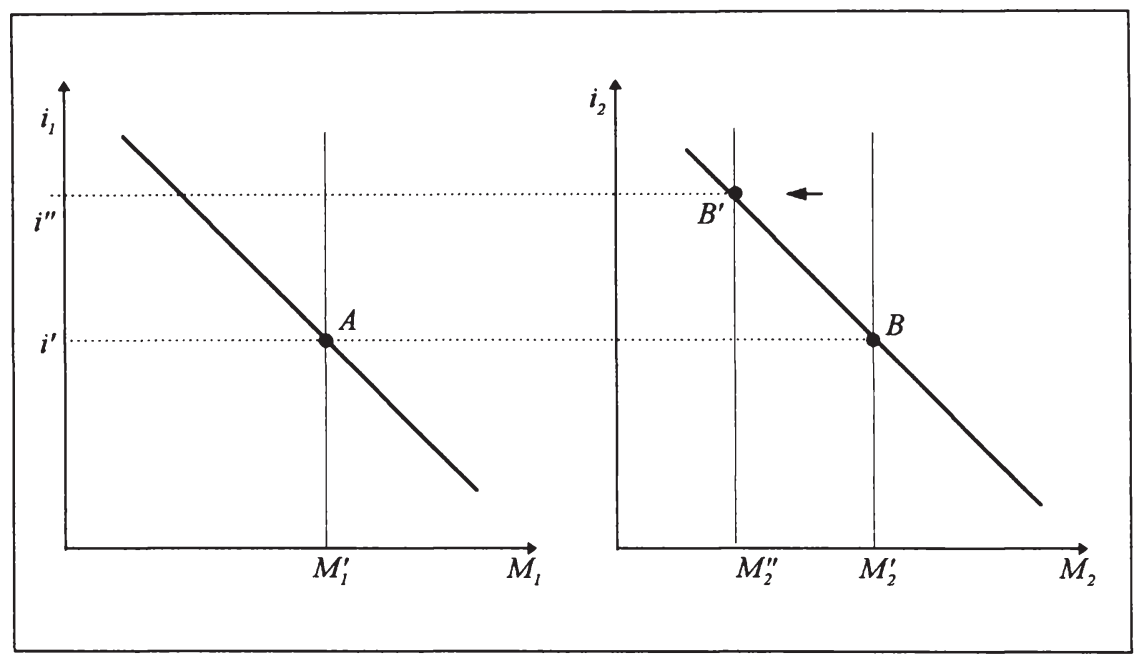




\subsection{Time Inconsistency and the Credibility Problem}

\subsubsection{Introduction}

In previous sections, it was shown that although there are spill-over effects in both fixed and flexible exchange rates, under flexible exchange rates the governments have full discretion on their own monetary policies. On the contrary, when exchange rates are fixed and there is perfect capital mobility ${ }^{82}$, national governments lose all control over monetary policy, which becomes fully endogenous so that discretion is completely eliminated. Additionally in the previous analysis concerning the Dornbusch model, it was demonstrated that a flexible exchange rate induces higher variability not only in the nominal exchange rate but also in the real exchange rate. This is because, during their dynamic adjustment, exchange rates overshoot or undershoot their new equilibrium level. Therefore, although the fixed exchange rate system introduces some constraints on government policies, there are some advantages related to its adoption. There are also other factors that favor the adoption of a fixed exchange rate system, in addition to the credibility that it introduces. The theoretical framework that formally explains the advantages of adopting rules in pursuing monetary policy, and interpreting the fixed exchange rate as a rule, are based on the literature known as time inconsistency, which analyzes the problem that arises from introducing discretion into government policies. ${ }^{83}$

The traditional theory of macroeconomic policy dealt with the economic consequences of given policy rules. However, the consequences and the policy objectives were supposed to be known in advance and therefore once the optimal rule was identified, the policymaker only needed to implement it and the private sector adapted to it.

In contrast to the traditional literature, this new approach, which constitutes a branch of the so-called New Classic Macroeconomics ${ }^{84}$, deals with the problems that arise from including politically strategic behavior in macroeconomic models ${ }^{85}$. It assumes that policymakers are typically rational and maximizing agents who respond to incentives and constraints in the same way as the rest of the economy. The policy formation process is now at the center of the analysis. The starting point of this new approach consists in the analysis of a principal-agent problem, where the citizens are the principals, who delegate the formulation of economic policy to an agent. The agent selects the policy that maximizes his objectives, subject to the relevant constraints. The

${ }^{82}$ Wyplosz (1986) among others shows that, under a fixed exchange rate, the government can conduct an independent monetary policy if there are capital controls.

${ }^{83} \mathrm{~A}$ policy plan is time inconsistent if, given the fact that it is expected by the private sector, the optimal plan made for the period $t+j$ at time $t$ is different from the optimal plan made for that period at time $\mathrm{t}+\mathrm{j}$. Thus, if a policy is time inconsistent, the government would wish to deviate from it during its implementation. In this sense, time inconsistency and credibility are two sides of the same coin.

${ }^{84}$ The new classical macroeconomic framework assigns a key role to expectations which are assumed to be rationally formed. The leading representatives of this school of thought are Sargent, Lucas, Wallace and Barro.

${ }^{85}$ See Argy (1994), Persson and Tabellini (1990), Wagner (1992). 
responses by the principals constitute, in this theory, an additional constraint. The normative problem is given by the fact that it is necessary to design incentives with the objective that the agent implements a policy that maximizes the collective interests of the citizens (principals).

The time inconsistency approach thus analyzes the credibility problems that arise when governments have full discretion in the design of monetary policy ${ }^{86}$ and the private sector, by forming its expectations fully rationally, can anticipate potential government strategic behavior. Time inconsistency arises because the effectiveness of government policy depends not only on the current policy, but also on the expectations of future policy. Ex ante, before some choices have been made by the private sector (principals), an optimal policy induces a defined response. However, ex post, once choices have been made, the response to policies may be different from the ex ante response, which makes the government's ex post constraints different from the ex ante constraints. The presence of a distortion or a lack of policy instruments makes the ex ante optimal policy a second best rather than a first best. Therefore, there is an ex post incentive to deviate from the ex ante optimal policy. If the government is able to commit itself to the ex ante optimal policy, the incentive to deviate is absent. ${ }^{87}$

In this section, I will introduce the concept of time inconsistency and review the literature on this issue. Then I will present a very simplified model in the tradition of Kydland and Prescott (1977), which allows comparison of the social losses of following a rule and discretionary policy under certainty and in the presence of shocks. Finally, I will review the theoretical solutions proposed to solve the time inconsistency problem and draw some conclusions from the analysis.

\subsubsection{Social Losses under Discretionary Policy vs Commitment}

The initial theoretical developments on time inconsistency problems were due to the seminal articles of Kydland and Prescott (1977) and Barro and Gordon (1983). Later extension and further developments can be found in the studies by Persson and Tabellini (1993), Lohmann (1992), Rogoff (1985), Fischer (1995), Walsh (1995) and Mc Callum (1995).

The starting point of this analysis consists of a simple repetitive game between two sectors: the labor union and the monetary authority. Monetary authorities might have an incentive to increase the money growth in order to get an increase in output above its natural rate. However, once the workers become aware of this fact, they will adjust their inflationary expectations and at the end of the process there will be no gain in either output or employment, and inflation will be higher than at the initial point. Kydland and Prescott's basic observation is that if expected inflation is low, so that the

\footnotetext{
${ }^{86}$ The time inconsistency approach was initially analyzed in relation to monetary policies by Kydland and Prescott (1977) and Barro (1983). However, new developments of the literature apply the time inconsistency framework in the context of fiscal policy. See Persson and Tabellini (1990), Edwards and Tabellini (1991) and Alesina and Tabellini, (1989) and also in a context of trade policies. See Fernandez and Rodrik (1990), Gärtner (1994).

${ }^{87}$ Because of government sovereignty it becomes hard to find real binding commitments that are enforced upon policymakers. In the final analysis, policy commitments can always be altered.
} 
marginal cost of additional inflation is low, policymakers will pursue expansionary policies to push output temporarily above its natural level. Nevertheless, because the public knows that policymakers have this incentive, they will not expect low inflation and therefore no output increase will take place and the inflationary policy pursued by the policymakers will only lead to higher inflation.

\subsubsection{The Model}

In this section, in order to clarify the concepts presented above, I will formalize the ideas described in the previous section. The analyzes draws mainly upon research due to Kydland and Prescott (1977) and Barro and Gordon (1983). However, the version presented here is much more simplified although it contains the main message.

It is assumed that aggregate demand disturbances and inflation expectations can affect aggregate supply. Aggregate supply is given by following expression: ${ }^{88}$

$$
y_{t}=q_{t}+b\left(\pi-\pi^{e}\right)
$$

$y_{t}$ is the aggregate supply, $q_{t}$ is the natural output level, i.e. the level at which the economy is in full employment, $\pi$ represents the actual inflation and $\pi^{e}$ is the expected inflation.

Equation (2.3.5.1) is derived as follows. Given a Cobb-Douglas production function:

$$
\mathrm{Y}_{\mathrm{t}}=\mathrm{AK}_{\mathrm{t}}^{\alpha} \mathrm{L}_{\mathrm{t}}^{\beta} \text {, }
$$

where $Y_{t}$ is output , $K_{t}$ is capital and $L_{t}$ is labor applied to produce output. ${ }^{89} \alpha$ and $\beta$ are the factor shares of capital and labor respectively.

By expressing the function (2.3.5.2) in logs, I get:

$$
\mathrm{y}_{\mathrm{t}}=\alpha \mathrm{k}_{\mathrm{t}}+\beta \mathrm{l}_{\mathrm{t}} ; \text { and } \alpha+\beta=1 \text {. }
$$

Under perfect competition, labor is being employed to the point at which the real wage rate is equal to the marginal product; and capital stock being fixed in the short run, then:

$$
\mathrm{y}_{\mathrm{t}}=\mathrm{b}\left(\mathrm{p}_{\mathrm{t}}-\mathrm{w}_{\mathrm{t}}\right)
$$

where $b$ is the share of wages to profits $b=\beta / \alpha, p_{t}$ is the price of goods and $w_{t}$ is the nominal wage rate.

By assuming absence of indexation and that workers set wages during negotiations to assure full employment at the natural rate, then the wage contract will be:

$$
w_{t}=(-1 / b) q+E_{t-1} p_{t}
$$

\footnotetext{
${ }^{88}$ See Romer (1996).

${ }^{89}$ For details on Cobb Douglas production function see Henderson and Quandt (1985).
} 
where $E_{t-t}$ is the price expected for the period $t$ in the previous period $t-1$ when the negotiation were taking place.

Then, by replacing (2.5.3.5) in (2.5.3.4), I obtain:

$$
\mathrm{y}_{\mathrm{t}}=\mathrm{q}_{\mathrm{t}}+\mathrm{b}\left(\mathrm{p}_{\mathrm{t}}-\mathrm{E}_{\mathrm{t}-1} \mathrm{p}_{\mathrm{t}}\right)^{90}
$$

and defining $\pi=\mathrm{p}_{\mathrm{t}}-\mathrm{p}_{\mathrm{t}-1}$ and $\pi^{\mathrm{e}}=\mathrm{E}_{\mathrm{t}-1} \mathrm{p}_{\mathrm{t}}-\mathrm{p}_{\mathrm{t}-1}$ it is possible to arrive to the expression (2.5.3.1), where $y$ is the $\log$ of output, $q$ is the natural level of output. Following Kydland and Prescott (1977) I assume that $q$ is lower than the social optimal natural level $\left(\mathrm{y}^{*}\right)$ :

$\mathrm{q}<\mathrm{y}^{*}$.

In the literature, several theoretical explanations are attributed to this situation, for example, the existence of tax rates that do not allow individuals to capture the full effect of additional labor supply. ${ }^{91}$ Taxes on labor and unemployment contributions reduce disposable income, therefore the social cost of unemployment exceeds its private cost. Taxes reduce disposable wages, which in turn are lower than the labor marginal productivity of an employed person. When an employed person loses his job, he simultaneously loses the disposable income that he was perceiving at the time when he was employed. However, society as a whole loses the (private) disposable income plus the additional taxes contributions. Another explanation can be found in the existence of imperfect competition: private firms do not capture the full benefit of additional output. Another explanation (Hibbs, 1987) is given by the fact that governments depend on voters and therefore the common interest might not necessarily coincide with the interest of a particular group of society that supports the government party.

Inflation is assumed to be costly if it is higher than a certain level ${ }^{92}$. The cost of inflation increases as inflation rises. In order to capture these two effects I will define, as is usual in the literature, a loss function which the government will minimize. The loss function $(\mathrm{L})$ is quadratic on the one hand, on the difference between actual output $y$ and the socially optimal output $\mathrm{y}^{*}$ and on the other hand, on the actual inflation rate $\pi$ and the socially optimal inflation rate $\pi^{*} .{ }^{93}$

$$
\mathrm{L}=\left(\mathrm{y}-\mathrm{y}^{*}\right)^{2}+\mathrm{a}\left(\pi-\pi^{*}\right)^{2}
$$

a $>0$.

There is a relation between the socially optimal output and the natural output:

\footnotetext{
${ }^{90}$ Notice this is the usual form of the Lucas supply curve. Assuming $q_{t}=0$ then $y_{t}=b\left(p_{t}-E_{t-1} p_{t}\right)$

${ }^{91}$ See Wagner (1992) and Romer (1996).

${ }^{92}$ From the seignorage point of view there is a certain optimal level of inflation. However, optimal inflation needs not necessarily be zero.

${ }^{93}$ The loss function is thought for the closed economy and thus the exchange rate does not appear in the function. However, the analysis can be extended for the open economy by assuming that to fix the exchange rate in a credible way implies on the one hand $\dot{e}=0$, and on the other hand, to adopt an optimal inflation rate. This inflation rate will be the inflation rate of the foreign country to which the domestric country has been pegged its currency, and which is by assumption much lower than the domestic one.
} 


$$
\mathrm{y}^{*}=\mathrm{kq} \text { and } \mathrm{k}>0 .
$$

The function $\mathrm{L}$ can be interpreted as follows: social costs increase if either output and/or inflation deviate from its socially optimal level.

The parameter a represents the relative importance given to the effect of inflation in social welfare. ${ }^{94}$

In order to simplify the algebra, I will assume that $\pi^{*}=0$ and therefore the loss function has the following form: ${ }^{95}$

$$
L=\left(y-y^{*}\right)^{2}+a \pi^{2} .
$$

The policymaker also controls money growth, which determines the behavior of aggregate demand $y_{t}$. Because of the absence of uncertainty the policymaker can choose directly the rate of inflation, subject to the constraint that inflation and output are linked according to the aggregate supply curve $y_{t}=q_{t}+b\left(\pi_{t}-\pi_{t}^{e}\right)$. The policymaker faces two possibilities of conducting its monetary policy, either he can announce and follow a binding commitment, then he chooses the inflation rate that minimizes the loss function $L$ with the result that inflation rate will be $\pi=\pi^{e}$, and the output level will be $y_{t}=q_{t}$ but $q_{t}<y^{*}$. The policymaker can choose inflation, taking expectation of inflation as given. ${ }^{96}$

By substituting (2.5.3.1) in (2.5.3.9), I get:

$$
L=\left[\left(q+b\left(\pi-\pi^{e}\right)-k q\right)^{2}+a(\pi)^{2}\right] .
$$

The government will minimize (2.5.3.10) with respect to $\pi$ and therefore following expression is obtained:

(2.5.3.11) $\quad \min \mathrm{L}, \partial \mathrm{L} / \partial \pi=0$.

$$
2\left[\left(q(1-k)+b\left(\pi-\pi^{e}\right)\right) b+2 a(\pi)\right]=0^{97} .
$$

and by solving the expression (2.5.3.12) for $\pi$ the optimal inflation under discretion $\pi^{\mathrm{d}}$ is obtained:

$$
\left.\pi^{d}=\left[b^{2} \pi^{e}+b q(k-1)\right)\right] / a+b^{2} .
$$

However, in the steady state, the actual rate of inflation will equal the expected rate, because people form expectation rationally, hence:

$\pi=\pi^{\mathrm{e}}$

\footnotetext{
${ }^{94}$ Note that the parameter a is a preference parameter that can vary across countries even across political parties.

${ }^{95}$ The results are totally independent of the functional form of the loss function.

${ }^{96}$ This situation can occur if expected inflation is determined before money growth. Because people forms expectation rationally, however, it can do only if the government announces a lower rate of money growth and unexpectedly increases it.

${ }^{97}$ The second order condition for a minimum will be: $L^{2}=0,2 \pi b+a \pi>0$.
} 
Then by replacing in (2.3.5.13)

$$
\pi^{\mathrm{d}}=\mathrm{b} / \mathrm{a}(\mathrm{k}-1) \mathrm{q} .
$$

By replacing (2.3.5.14) into the loss function, I obtain:

(2.5.3.15) $\left.\quad L^{d}=\{q(1-k)]^{2}+a[b / a(k-1) q]\right\}^{2}$.

Because $(1-\mathrm{k})^{2}=(\mathrm{k}-1)^{2}$ then,

$$
L^{d}=(k-1)^{2}+b^{2} / a(k-1)^{2} q^{2} .
$$

Simplifying the expression (2.3.5.16) delivers the loss function under discretion

$$
L^{d}=(k-1)^{2} q^{2}\left(1+b^{2} / a\right) .
$$

The expression (2.3.5.17) represents the loss that the government will incur if implements a discretionary monetary policy, as the expression shows that it is positive. In order to compare this policy with the situation that would arise if the government followed a rule, I will next calculate the social loss under a policy when the government follows a rule.

If the government does so, inflation and expected inflation will be equal to 0 . Because the public knows that the government will not pursue an inflationary policy, it will expect zero inflation $\pi=\pi^{e}=0$.

Replacing then into the loss function (2.5.3.9), the following expression is obtained, which represents the value of the loss function if the government follows a rule

$$
\mathrm{L}^{\mathrm{r}}=(\mathrm{k}-1)^{2} \mathrm{q}^{2}
$$

The expression (2.3.5.18) is also positive. However, on comparing both loss functions (2.3.5.17) and (2.3.5.18), we observe that the loss under discretion is much bigger than under the rule.

Then, by subtracting (2.3.5.18) from (2.3.5.17), I get:

$$
L^{d}-L^{r}=(k-1)^{2} q^{2}\left(1+b^{2} / a\right)-(k-1)^{2} q^{2}
$$

$$
L^{d}-L^{r}=b^{2} / a>0 .
$$

Because $b^{2} / a>0$, the loss under discretion is larger than under a rule. Expected inflation rises to the point at which the policymaker taking $\pi^{e}$ as given chooses the actual rate of inflation, which equals $\pi^{\mathrm{e}}$. Ultimately, the policymaker only raises inflation without any gain in output. ${ }^{98}$ The reason why the ability to choose inflation after expected inflation is determined makes the policymaker worse off is due to the fact that the

98 This results do not depend on this specific functional forms. See Romer (1996). See for example Wagner (1992), or Barro (1983), Persson and Tabellini (1990), Backus and Driffill (1985) who adopts another functional form of the loss function and arrive to the same outcome. 
policy of announcing an inflation rate $\pi$ and afterwards producing an inflation rate after expected inflation is determined is not consistent. ${ }^{99}$ If the policymakers announces that inflation will be equal to zero and the public forms expectation rationally, the policymaker will deviate from the policy once expectation have been formed. The public's knowledge that the policymaker would do this causes it to expect inflation greater than zero, this expected inflation worsens the menu of choices that the policymaker faces.

Actually, the source of the problem is not the fact that the policymaker has discretion itself but the knowledge by the public that he does have it.

If in fact the policymaker has discretion but the public believes he has not, then the policymaker will announce that inflation will be zero and thereby cause expected inflation to equal zero. The policymaker can however set inflation according to (2.3.5.13). Because (2.3.5.13) is the solution to the minimizing problem of the loss function of the policymaker given expected inflation, to deviate from the rule will increase social welfare. Dynamic inconsistency arises because the optimal policy is not consistent in the long run. ${ }^{100}$

However, if the policymaker could cheat the public and lead them to believe that inflation will be $\pi=0$, and people really believe it, but then introduces $\pi^{d}$ the actual inflation will be:

$$
\pi^{d}=b 2 \pi \mathrm{e}+\mathrm{bq}(\mathrm{k}-1) / \mathrm{a}+\mathrm{b}^{2} .
$$

By replacing $\pi^{e}=0$, the actual inflation that cheats the public will be:

$$
\pi^{\mathrm{ch}}=\mathrm{bq}(\mathrm{k}-1) / \mathrm{a}+\mathrm{b} 2 .
$$

By introducing the actual inflation of cheating into the loss function, I get:

$$
L^{c h}=\left[q(1-k)+b\left(b q(k-1) / a+b^{2}\right)\right]^{2}+a\left\{b q(k-1) / a+b^{2}\right]^{2} .
$$

Simplifying the expression yields:

$$
L^{c h}=q^{2}(1-k)^{2}\left[a /\left(a+b^{2}\right)\right] .
$$

Then (2.5.3.24) represents the loss that the government would incur if it can really cheat the public.

Now, by comparing the government loss function when the policymaker follows the rule (2.5.3.18) and (2.5.3.24) when the policymaker can really cheat the people and lead them to believe that inflation will be zero but pursue an inflationary policy, we see that the loss function is smaller because $a+b^{2}$ is bigger than 0 .

\footnotetext{
${ }^{99}$ See Persson and Tabellini (1990).

${ }^{100}$ By introducing fully indexed wages, the problem of time inconsistency can be eliminated. Argy (1994) argues that the inconsistency disappears if wages are ex-post automatically indexed to the price level of period $t$, because the real wage cannot fall, output cannot increase and the monetary expansion is absorbed in higher prices. This situation follows even if the monetary expansion is fully anticipated, because the problem of discretion completely disappears. The paradoxical result is that wage indexation reduces the equilibrium rate of inflation to its optimal level of zero because the incentive to cheat vanishes.
} 
There are therefore some gains of cheating the public if the government really can do it. The problem is that if the game could only be played once, as in our one-period model, then people still do not know government incentives and therefore they can be cheated. However, in the next period people will have learned policymaker's behavior and therefore will not allow the government to cheat them. Even if the government would like to obtain a result as $L^{\mathrm{ch}}$, it will obtain $\mathrm{L}^{\mathrm{d}}$ and therefore will be in a worse situation than if it had followed a rule.

Dynamic inconsistency is applied in the literature not only to monetary policy but in other contexts as well. Recent surveys of this kind of literature can be found in Blackburn and Christensen (1989), Rogoff (1987), Persson (1988), Chari, Kehoe and Prescott (1989). Application of the time inconsistency problem to fiscal issues can be interpreted as follows: if policymakers wish to encourage capital accumulation by adopting a low tax rate, once capital has been accumulated, taxing it is nondistortionary, thus it is then optimal for policymakers to tax it at a higher rate ${ }^{101}$. Calvo (1978) analyzes the case when setting $\pi=\pi^{* 102}$ is inconsistent not only because of an output unemployment tradeoff but also because of government debt which is denominated in nominal terms. An unanticipated inflation shocks acts as a lump sum tax on debt holders. The corollary is that even, if monetary shocks do not have real effects on output, a low inflationary policy can be dynamically inconsistent. Indexed bonds according to the inflation would eliminate the time inconsistency problem. Other examples with time inconsistency are related with the indebtedness problem (Krugman, 1995). Thus debtor countries can surprise their creditors by defaulting on foreign debt. Therefore, because creditors mistrust future possible defaults the outcome is that foreign borrowing is much lower than the optimal ${ }^{103}$ Canzoneri and Henderson (1987) and Crawford (1983) present surveys on international policy coordination and external debt. Governments can fail to honor patents after invention have been made (Barro and Grilli, 1994). As a result, because people understand the government's incentives, the equilibrium level of invention will be too low.

In general governments could profit from promising that they will resist the temptation to surprise people, yet the main problem remains: how can these commitments be made credible?

\subsubsection{Rules versus Discretion and the Presence of Stochastic Shocks}

In the previous analysis it was demonstrated that, under discretionary monetary policy, inflation rises above the optimal rate and no gain in output is obtained. Kydland and Prescott (1977) argue that in order to avoid this situation monetary policy should be determined by rules rather than discretion. However, there are basically two main problems in designing rules. First, it is not easy to design rules that are really binding.

${ }^{101}$ See Wagner (1992), Argy (1994).

${ }^{102} \pi *$ is the optimal inflation it must not be necessary 0 .

${ }^{103}$ During the foreign debt crisis of 1982 creditors interrupted lending to all developing countries and even those countries which have not intention of deflating suffered from this phenomenon. 
Policymakers can announce that they will determine monetary policy according to a defined procedure, for example pegging the exchange rate or making the money stock grow at a constant rate. However, if the public believes the commitment and expects low inflation, the government could raise social welfare by departing from the announced policy and choosing a higher rate of money growth. Thus, the public has no reason to believe this announcement. Only if the monetary authority relinquishes the ability to determine the money supply does a rule solve the problem.

Secondly, rules cannot account for completely unexpected circumstances ${ }^{104}$ and if an unexpected shock appears the policymaker has no instrument with which to respond.

Rogoff $(1985)^{105}$ formally analyzes the problem when the economy is affected by shocks. Under plausible assumptions, a policymaker whose preferences between output and inflation differ from those of society does not respond optimally to shocks. Thus choosing to whom to delegate monetary policy produces better results in terms of average inflation but a worse outcome in terms of response to disturbances. Therefore, Rogoff concludes that there is an optimal level of anti-inflationary policy for central bankers.

I present a very simplified version of the model developed by Rogoff (1985). I follow the same model presented in the previous section. I now consider that aggregate supply is a stochastic function. ${ }^{106} 107$

$$
y_{t}=q_{t}+b\left(p_{t}-E_{t-1} p\right)+u_{t}
$$

where $u_{t}$ is a disturbance term with mean equal zero, not serially correlated and with a constant variance.

$$
\begin{aligned}
& E_{t}\left(u_{t}\right)=0 \text { and } E_{t}\left(u_{t}^{2}\right)=s^{2} \\
& E_{t}\left(u_{t}, u_{t-1}\right)=0 .
\end{aligned}
$$

Replacing the aggregate supply in the loss function (2.5.3.9) yields:

$$
\begin{aligned}
& \mathrm{L}=\left(\mathrm{y}-\mathrm{y}^{*}\right)^{2}+\mathrm{a}(\mathrm{p})^{2}, \text { then } \\
& \mathrm{L}=\left[\left(\mathrm{q}+\mathrm{b}\left(\mathrm{p}-\mathrm{E}_{\mathrm{t}-1} \mathrm{p}\right)+\mathrm{u}_{\mathrm{t}}-\mathrm{kq}\right)^{2}+\mathrm{a}(\mathrm{p})^{2}\right] .
\end{aligned}
$$

\footnotetext{
${ }^{104}$ During the $1980 \mathrm{~s}$, the USA experienced a severe liquidity crisis which originated in the stock market crash. By adhering to its monetary target, the government could not react to help the banking system, severely affecting economic activity. By adopting a currency board system in 1991, Argentina committed itself to backing the monetary base $100 \%$ with foreign reserves. The financial crisis induced by an external such as the Mexican devaluation in December 1994 led to a significant fall in output. No rule that could have anticipated all these kinds of external shocks.

${ }^{105}$ Rogoff (1985) analyzes the trade-off between flexibility and rules. The elimination of the time inconsistency problem by the introduction of rules can in some cases be very costly.

${ }^{106}$ Because this time, I will apply expectation to the whole function. Expected inflation at time $\mathrm{t}-1$ is expressed as Et-1 $\mathrm{p}$ instead of $\mathrm{p}^{\mathrm{e}}$, but this does not alter the meaning.

${ }^{107}$ Note that the only difference between equation $(2.5 .4 .1)$ and $(2.5 .3 .1)$ is the stochastic shock.
} 
Ordering the expression:

(2.5.4.4) $\quad \mathrm{L}=\left[\left(\mathrm{q}(1-\mathrm{k})+\mathrm{b}\left(\mathrm{p}-\mathrm{E}_{\mathrm{t}-1} \mathrm{p}\right)+\mathrm{u}_{\mathrm{t}}\right)^{2}+\mathrm{a}(\mathrm{p})^{2}\right]$.

By minimizing the loss function as before:

$\left.(2.5 .4 .5) 2 a p+2\left[(k-1) q+b p+b E_{t-1} p\right)-u_{t}\right] b=0$,

$$
p=1 /\left(a+b^{2}\right)\left[b(k-1) q+b^{2} E_{t-1} p-u_{t} b\right]
$$

Taking expectation to the whole expression, then

$$
E_{t-1}=1 /\left(a+b^{2}\right)\left[b(k-1) E_{t-1} q+b^{2} E_{t-1} E_{t-1} p-b E_{t-1} u_{t}\right.
$$

But, $E_{t-1} p=p$ because inflation expectations are formed in the previous period rationally and $E_{t-1}\left(E_{t-1} p\right)=E_{t-1} p \cdot q_{t}$ the natural output is not a stochastic variable and, therefore, $E_{t-1} q_{t}=q_{t}$ and the mean of the error $u_{t}$ is equal to zero by assumption $E_{t}\left(u_{t}\right)=0$.

$$
E_{t-1} p=\left(1 / a+b^{2}\right)\left[b(k-1) q+b^{2} E_{t-1} p\right]
$$

and simplifying the expression:

$$
E_{t-1} p=[b / a(k-1) q] .
$$

This is the inflation rate that minimizes the loss function. By introducing (2.5.4.9) in (2.5.4.6) and simplifying, then,'

$$
p=(b / a)(k-1) q-u_{t} b /\left(a+b^{2}\right)
$$

From (2.5.4.9) and (2.5.4.10)

$(2.5 .4 .11) p-E_{t-1} p=-u_{t}\left(b / a+b^{2}\right)$.

And introducing (2.5.4.11) into the loss function and taking expectations of the squared function and simplifying:

$$
E_{t-1} L^{d}=q^{2}(1-k)^{2}\left(1+b^{2} / a\right)+s^{2}\left(1 / a+b^{2}\right)
$$

The expression (2.5.4.12) represents the expected loss function under uncertainty that arises when the policymaker acts under discretion.

On the contrary, if the policymaker now follows a rule and sets inflation equal to zero, the inflation rate as well as the expected inflation rate will equal zero. Therefore, 
replacing $\mathrm{p}$ and $\mathrm{E}_{\mathrm{t}-1} \mathrm{p}$ by zero in $(2.5 .4 .4)$, the loss function under uncertainty is as follows:.

$$
E_{t-1} L^{r}=(1-k)^{2} q^{2}+s^{2}
$$

By comparing (2.5.4.13) and (2.5.4.14) $\mathrm{L}^{\mathrm{d}}$ and $\mathrm{L}^{\mathrm{r}}$, we observe that the first term is larger under discretion while the second is smaller. This can be interpreted as follows: in the absence of shocks, the second term is equal to zero and therefore the rule is preferred to the discretionary policy. This was the situation analyzed in the previous section. On the contrary, if shocks are present, the discretionary policy is preferred to the rule, because the losses will be smaller this time.

The intuitive interpretation is very simple: in the absence of shocks, the rule always will be preferred to the discretionary policy. A binding rule will avoid the possibility of the policymaker cheating the public, and the public will be sure that the policymaker will not do so. However, there is no rule that can foresee unexpected shocks and therefore some flexibility in the monetary policy can allow the policymaker to react to unexpected shocks and to moderate their impact. The argument presented above means that, under plausible assumptions, a policymaker whose preferences between output and inflation differ from those of society does not respond optimally to shocks. Thus, there is a trade-off in choosing somebody to whom to delegate monetary policy who strongly dislikes inflation. In terms of average inflation, it will lead to a lower inflation rate but to a worse result in terms of response to disturbances. As a result, there is some optimal level of conservatism in the design of monetary policy. Thus an extremely conservative monetary policy is not necessarily the first best.

\subsubsection{Multiple Period Horizon}

The social loss function presented in the previous section represents a one period function. It is possible to assume that the government maximizes a multi-period loss function and therefore the policymaker will minimize the discounted present value of a multi-period loss function (Wagner, 1992):

$$
\mathrm{L}=\mathrm{a} \mathrm{L}_{\mathrm{t}+\mathrm{i}} /(1+\mathrm{d})^{\mathrm{i}} \text {, }
$$

where $d$ represents the discount factor applying to the whole of the given infinite horizon. The function $\mathrm{L}$ is similar to the loss function in the previous case The value of the discount factor plays a crucial role. The higher is $d$, the stronger are the preferences of the policymaker for the present and the lower the valuation he places upon future losses. If $\mathrm{d}$ tends to infinity, the policymaker evaluates only a one period loss function. If governments have a longer horizon, they need to offset all future losses discounted to the present against the one-period short-run gain. Hence it is no longer evident that the government will pursue shortsighted policies. If the discount 
rate is not too high, the authorities might well opt for a longer-term strategy. Taking the reputational aspect into account, inflation can be set close to the optimal rate. However, this situation also offers some problems because of the limited permanence of a political party in government. A political party could pursue an expansive monetary policy while still in power because it believes that it will not win the next democratic polls and therefore the next government, which is composed by another party, will have to carry the costs.

\subsubsection{Dealing with the Time Inconsistency Problem}

In the analysis presented above, it was shown that discretionary policies give rise to inefficiently high inflation without obtaining any gain in output. The question is thus what can be done to avoid this situation. The first approach consists in designing monetary policy according to strict rules ${ }^{108}$. Nevertheless, as we have also seen, it is not easy to design really binding rules which governments cannot abandon. Second, if strictly binding commitments could be implemented, they present other problems; thus they might be very inflexible in the presence of shocks. Rules can be extremely costly if unexpected shocks arise. ${ }^{109}$

There is an additional empirical problem: some of the countries that enjoy a low inflation rate do not necessarily conduct their monetary policy according to strictly fixed rules. ${ }^{110}$

In the literature, some suggestions have been made to overcome the time inconsistency problem. Theoretical models in this context were originally introduced by Rogoff (1985, 1987), Barro and Gordon (1983) Persson and Svensson (1984), Tabellini (1987) and Kotlikoff, Persson and Svensson (1988). Two mechanisms that permit the time inconsistency problem to be solved without incurring the high cost of fixed rules and which seems to be of practical relevance are delegation and reputation.

Reputation can be applied whenever policymakers are in office for more than one period and if the public ignore their preferences. The public may not the know policymakers's preferences between output and inflation or whether their announcements on future policies are really binding. In this situation, policymakers behavior through time will provide some information about the characteristics of a particular policymaker and thus affect the public's expectations in future periods. ${ }^{11}$ The lower the inflation observed today, the lower the expectations of inflation in future periods. This gives policymakers an incentive to keep inflation low. Because of the simplicity of the central idea, the basic result is that uncertainty about policymaker preferences itself reduces inflation. However, this does not seem to be either theoretically robust ${ }^{112}$ or realistic. Central banks appear to be very concerned with establishing reputations as being hard-nosed against inflation and first of all as being credible. If the public were certain of policymakers' preferences and beliefs, there would be no reason for such

\footnotetext{
${ }^{108}$ This was actually the suggestion made by Kydland and Prescott (1987).

${ }^{109}$ This case was analyzed in section 2.5.4.

${ }^{110}$ For example, the USA and Germany.

${ }^{111}$ See Backus and Driffill (1985).

${ }^{112}$ See Vickers (1986), Cukierman and Meltzer (1986) and Rogoff (1987).
} 
behavior. Only if the public is uncertain and if expectations matter will these concerns be quite important.

The second way to overcome the dynamic inconsistency of low inflation monetary policy is to delegate policy to individuals who do not share the common view about the relative importance of output and inflation. The central idea is due to Rogoff (1985). Inflation is lower when monetary policy is controlled by someone who is known to be especially adverse to inflation. When the monetary policy is controlled by such a person, the public realizes that the policymaker has no desire to pursue expansionary policy and as a consequence expected inflation will be low. Several authors, among them Bade and Parkin (1982), Grilli, Masciandaro and Tabellini (1991), Barro and Grilli (1994), Alesina and Summers (1991), Schiemann (1992), investigated how this mechanism could be implemented in practice. They analyzed the way in which the public can be convinced that monetary policy is under the control of an inflation- adverse monetary authority. All the authors arrived at the conclusion that the anti-inflationary reputation of a central bank is closely related to its degree of independence from the government. ${ }^{113}$ Alesina (1988) argues that central bank independence provides a measure of the delegation of policymaking to conservative policymakers. The greater the independence of the central bank, the less is the possibility of the government inducing inflationary policies.Empirical investigation of the relation between these measures of independence and inflation produce a consistent result: independence and inflation are strongly negatively related. ${ }^{114}$ Posen (1993) and Romer (1996) suggest that this analysis has some limitations. The outcome that there exists a correlation between central bank independence and low inflation is "per se" a fact and does not indicate which is the direction of the causality ${ }^{115}$. Pollard (1993) suggests that the index applied to measure central bank independence is biased in favor of finding a relationship between independence and low inflation. The measures often introduce some weight on whether the board of the central bank gives low inflation as its principal goal. It is not clear that theories of dynamic inconsistency and delegation predict that the greater the independence of the central bank the lower will be inflation. The argument that they do predict this implicitly assumes that both central bank and government policymakers' preferences do not vary systematically with central bank independence. Nevertheless, the delegation hypothesis implies that they will. For example, if monetary policy depends on the central bank's and the government's preferences, with the weight attached to the bank's preferences increasing with its degree of independence. Then, when the bank is less independent, government officials should compensate by appointing more inflation-averse individuals to the

\footnotetext{
${ }^{113}$ Rogoff (1985) and Persson and Tabellini (1990) discuss the characteristics of an optimal central bank.

${ }^{114}$ Alesina (1988), Grilli, Masciandaro and Tabellini (1991), and Cukierman, Webb and Neyapti (1992).

${ }^{115}$ Posen (1993) observes that those countries whose citizens are particularly averse to inflation are likely to try to insulate their central banks from political pressures. He presents the example of Germany whose citizens dislike inflation and the institutions governing the German central bank (Bundesbank) appear to have been created mostly because of this desire to avoid inflation. Therefore Germany's low inflation is due more to the general inflationary aversion than to the independence of the central bank.
} 
bank. Similarly, when the government is less able to delegate policy to the bank, voters should elect more inflation-averse governments. These effects will mitigate and might even offset the effects of reduced central bank independence ${ }^{116}$. There are two additional theoretical solutions proposed to eliminate the time inconsistency problem. They are actually special cases of those explained above. The first consists in introducing punishment and the second incentive contracts in the design of the rules of monetary authority behavior. The underlying idea is that the time inconsistency problem arises because society has no means to punish the government if it deviates from the announcement. Therefore, society could profit if punishment measures could be introduced. Punishment ${ }^{17}$ is usually described as a sub-model of reputation in an infinite horizon model. These models present the problem that they are usually multiple equilibrium models and therefore difficult to compute. Low inflation is in turn sustained by beliefs that if the policymaker were to choose high inflation, the public would punish him by expecting high inflation in the following periods. Incentive contracts are arrangements in which the central banker is penalized (either financially or through loss of prestige) for inflation, therefore the appropriate choice of penalties produces the optimal policy. ${ }^{118}$ However, although the introduction of incentive contracts seem to be intellectually attractive, in the real world it is not so clear what is the practical relevance of such kind of contracts.

\subsubsection{Concluding Remarks}

In this section, I have analyzed the theoretical background that supports the idea that governments would choose a fixed exchange rate regime as a committing rule. The explanations are found in the time inconsistency literature. I have presented a very simplified model based on Barro and Gordon (1983) that allows comparison of the effects of the introduction of a discretionary policy against those of a rule. Under conditions of certainty, it was demonstrated that the rule leads to a better solution.

Second, I have compared the solution that the government would obtain if it he could lead the public to believe that he would follow the rule but in fact were to follow a discretionary policy. It was shown that this solution leads to lower losses than following the rule. This is exactly the reason why the time inconsistency problem arises: public knows that the government could profit if it announces a rule which it could then avoid.

Third, I transformed the model previously presented into a stochastic one, and again compared the social costs of following the rule as against a discretionary policy. In this case, it was shown that, in the presence of unexpected shocks, the discretionary policy leads to a better solution. The rule cannot account for unexpected shock and therefore

\footnotetext{
${ }^{116}$ See Romer (1996).

${ }^{117}$ Barro and Gordon (1983), Rogoff (1987).

${ }^{118}$ Persson and Tabellini (1993), Walsh (1995), and Persson and Svensson (1984) suggest that the time inconsistency problem could be eliminated if some incentive can be introduced to make attractive to the next period government to follow the time consistent policy initiated in the previous period. Tabellini (1987) shows that a low inflationary rule can be time consistent if there is an infinite-life decision body, which decides under the simple majority rule which party will be reelected.
} 
leaves the monetary authority without instruments to react to shocks hitting the economy.

Finally, I discussed several proposals advanced to cope with the time inconsistency problem: Delegation, reputation, incentive contracts and punishment. By delegating monetary policy to an authority which is by nature against inflation, the time inconsistency problem would be eliminated. If the government is more than one period in office, it can benefit from following an anti-nflationary policy because it will generate a reputation of being hard nosed against inflation. Punishment is a variant of reputation. The governments deviate from rules because there is no cost to them of doing so. Therefore, the society as a whole would benefit if governments that deviate from the rules could be punished. Incentive contracts are a second variant of the same instrument. Institutional arrangements should be constructed in such a way that those in charge of or designing the monetary policy could profit by reducing inflation and would suffer the consequences of introducing inflation.

The adoption of a fixed exchange rate regime implies that the central bank commits itself to follow a rule in pursuing monetary policy by relinquishing its the discretionary power. The conduct of monetary policy according to binding rules becomes specially important in countries with a long history of high inflationary policies as in the case of most of MERCOSUR economies. Although a fixed exchange rate is not the only alternative to the introduction of binding rules in the design of monetary policy ${ }^{119}$, it is a very attractive one because of the credibility effects that it introduces into the system. First, a fixed exchange rate system is easy to understand for the public and therefore much easier to follow and monitor than either a monetary or an inflationary target. Second, it contains itself some punishment effects if the government deviates from the rules in the form of pressures in the exchange rate markets and the consequent exchange rate crisis. ${ }^{120}$ Therefore, under a fixed exchange rate regime, in the presence of capital mobility it becomes very costly for the authorities to introduce expansionary monetary policies. ${ }^{121}$ Third, a fixed exchange rate allows reputation to be imported from a traditionally conservative central bank (Giavazzi and Giovannini, 1988). In countries with a long inflationary history, it might take decades to build up a new reputation of being a conservative central bank.

\footnotetext{
${ }^{119}$ There are other kind of committing rules, e.g. monetary targets and inflation targets. For details see Reither (1996).

${ }^{120}$ For additional literature on collapsing exchange rates see Flood and Garber (1984), Obstfeld (1986), and Krugman (1979). New research on the topic is to be found in Tavlas (1996), Tobin (1996), Bordo, Finn, Kydland (1996), Buiter, Corsetti, Pesenti (1996), Kenen (1996), and Flood and Kramer (1996).

${ }^{121}$ This is the so called impossibility theorem. See Isard (1995).
} 


\subsection{Summary and Conclusions}

The objective of this chapter 2 has been to present a theoretical framework that allows the analysis of optimal exchange rate policy for MERCOSUR countries. First, in order to compare the advantages and disadvantages of flexible and fixed exchange rates, I introduced a two country Mundell-Fleming model. The model is framed for the very short run when prices are fixed and expectations are static and, therefore, some effects on output levels are observed. The main conclusion that can be drawn from this model is that monetary as well as fiscal shocks induce spill- over effects on foreign output. However, the impact depends on the nature of the exchange rate regime, and also on the kind of shock, monetary or fiscal. In the case of a flexible exchange rate system, an expansionary monetary policy induces an increase in domestic and in foreign output as well. On the contrary, an expansionary fiscal policy induces an expansion in domestic output, but a contraction in foreign output. Nevertheless, if a fixed exchange rate regime has been adopted, an expansionary monetary policy induces a positive effect on domestic and foreign output. In this case, the effect of an expansionary fiscal policy on domestic output is positive. The effect on foreign output is not unequivocal and depends on income and exchange rate elasticities.

Second, the Mundell-Fleming model was extended by introducing the modification suggested by Dornbusch (1976). Thus, exchange rate expectations and a Phillips curve were introduced, and dynamic behavior was also incorporated. Again within a two country framework, the model allowed the analysis of the effect of a fiscal and a monetary policy, on the one hand in the long run, once all adjustments have taken place and there are no longer any effects on output levels, though some effects on price levels persist. Additionally, the dynamic adjustment of nominal and real exchange rates in response to nominal and fiscal shocks was analyzed in detail. Under a flexible exchange rate system, a nominal shock as well as a fiscal shock introduces large variability in both nominal and real exchange rates, which translates into the overshooting and undershooting effect of nominal and real exchange rates. Because prices are sticky and show a delay in reaction, the impact of a monetary shock forces an overreaction in the nominal and real exchange rate, which is the well-known overshooting effect of the exchange rate.

A fiscal shock, on the contrary, induces an undershooting effect. In this sense, the exchange rate does not reach the new equilibrium level immediately, though a lower one, and continues moving until it has reached the new steady state. However, a fixed exchange rate regime in a two-countries Dornbusch structure model, in contrast, delivers totally different results. On the one hand, a monetary shock has no effect at all on the real exchange rate. Both price levels increase by the same amount and at the same speed, eliminating the possibility of an appreciation/depreciation. An expansionary fiscal shock initiated in country 1 and/or a contractive shock initiated in country 2 induces a real appreciation of the country 1's currency. Nevertheless, high volatility is no longer observed; on the contrary, there is a soft adjustment until the new steady state is reached.

I drew the following conclusion from this section: a fixed exchange rate system with perfect capital mobility forces the countries to give up autonomy in their monetary policy. Moreover, this kind of institutional arrangements provides a clear advantage: the high volatility of the exchange rate is eliminated. The model demonstrates that the 
volatility is not transferred to other parts of the system, but is simply reduced because one of the unknown variables has dropped out of the system. In a Mundell-FlemingDornbusch model, fixed exchange rates reduce not only nominal but also real variability.

Third, I analyzed in detail the problem that arises in all fixed exchange rate system and which is known in the literature as the $\mathrm{N}-1$ problem. In a fixed exchange rate system in which $\mathrm{N}$ countries participate, there are $\mathrm{N}-1$ exchange rate parities. The system has, by construction, one degree of freedom because money supply for each country is endogenous and under perfect capital mobility interest rates must equalize across countries. The practical problem is given by the fact that either one country independently or all countries in a cooperative way have to decide how the money stock will be assigned. Although from the theoretical point of view, there are two possible solutions: the asymmetric or hegemonic and the symmetric or cooperative. From Bretton Woods to the EMS, all fixed exchange rate systems have worked "de facto" in an asymmetric way. Therefore, the adoption of a fixed exchange rate implies for the non-hard currency countries a complete surrender of autonomy in their monetary policy. On the contrary the anchor country can afford to follow a completely independently monetary policy.

Fourth, I introduced in the last section an alternative approach to exchange rate policy that concentrated on other aspects that have not been considered in the previous sections. This part analyzed credibility issues and the problem that arises from time inconsistent policies. Time inconsistency arises because governments can obtain benefits if they announce a rule yet can ultimately avoid it without that the public fully realizing that they have done so. The time inconsistency appears exactly because the public knows that the government could obtain some gains by behaving strategically and therefore will also try to avoid being cheated. In the final analysis, no party will obtain any benefit and as a whole they will have suffered welfare losses. In order to clarify these concepts, a theoretical model was presented to compare the inflation outcome from a binding rule to a discretionary monetary policy. I concluded that the outcome is better under rules than under a discretionary policy. The model was subsequently solved in order to compare the outcome that arises if the government follows rules with that which would ensue if the government were to announce a rule: the public would believe that the government would fulfill its promises and at the end the policymaker could deviate from the rule.

The conclusion is that if the government could afford to "cheat" the public, the results would be much better than under a rule. The model was extended into a stochastic version and thus it was demonstrated that if unexpected shocks arise the outcome provided by discretionary policies will be preferred. A strict binding rule cannot account for unforeseen situations and leave the policymaker without instruments with which to react.

Finally, I discussed some solutions proposed in the literature to overcome the time inconsistency problem, such as the delegation of the monetary policy to an authority which is by nature adverse to inflation, the introduction of punishment, reputation and incentives contracts. The idea behind such proposals is that policymakers deviate from the announced rules because there do not exist effective instruments to punish them. Society as a whole could benefit by forcing the policymaker to respond for their faults. The conclusion that I drew from this section is as follows: important gains can be 
achieved by designing policy rules. The fixed exchange rate system acts as a binding rule that eliminates strategic behavior by policymakers. It contains in and of itself a punishment mechanism, whenever the policymaker deviates from the announced monetary policy rule there will be some pressures in exchange rate markets, which can end up as exchange rate collapses.

Additionally, in the case of such high inflationary economies as MERCOSUR countries, these concepts are particularly important. A reputation of being hard-nosed against inflation cannot be acquired as fast as desired. It might take decades until a government can generate the reputation of being against inflation. Credibility can be destroyed extremely quickly, but it takes a very long time to rebuild it again. The fixed exchange rate offers the possibility to borrow credibility from another country that is already well known as being in favor of low inflation.

Summarizing, in this second chapter I discussed in the light of different theories the effect of two extreme cases of exchange rate system: fixed and flexible, which assisted me to draw up some policy recommendations for the MERCOSUR case. Although fixed exchange rates imposed a severe constraint, given by the fact that the follower country must give up completely its monetary policy, losing in this sense an instrument of economic policy, there are some reasons to believe that it nevertheless constitutes a better option. First, because of the reduction on the volatility that it introduces, and second because it increases credibility in the system and helps to coordinate expectations. 


\section{Appendix}

\section{Stability Condition and Solution of the System}

\section{Dornbusch Model}

\section{Flexible Exchange Rate}

By recalling each difference of two variables as a new variable

$\mathrm{x}^{*}=\mathrm{x}_{1}-\mathrm{x}_{2}$.

Then, the system is reduced to a simple two equation dynamic system

$\dot{\mathrm{p}}^{*}=\varphi /(1-\varphi \sigma)\left[\mathrm{g}^{*}-\sigma \mathrm{i}^{*}+\mathrm{f} \mathrm{y}^{*+}+2 \delta \mathrm{e}-2 \delta \mathrm{p}^{*}-\overline{\mathrm{q}}^{*}\right]$

$\dot{\mathrm{e}}=1 / \lambda\left[-1(1-2 \beta) \mathrm{p}^{*}+2(1-\beta) \mathrm{e}+\phi \mathrm{y}^{*}-\mathrm{m}^{*}\right]$.

In order to analyze the stability conditions the system is linearized ${ }^{123}$ and can be expressed as follows:

$\left[\begin{array}{cc}\partial \dot{p}^{*} / \partial e & \partial^{*} / \partial p^{*} \\ \partial \dot{e} / \partial e & \partial e / \partial p^{*}\end{array}\right]\left[\begin{array}{c}\mathrm{p}^{*}-\overline{\mathrm{p}}^{*} \\ \mathrm{e}-\overline{\mathrm{e}}\end{array}\right]=\left[\begin{array}{c}\dot{\mathrm{p}} \\ \dot{\mathrm{e}}\end{array}\right]$

$\left[\begin{array}{cc}\varphi /(1-\sigma \varphi) 2 \delta & -\varphi(1-\varphi \sigma) 2 \delta \\ 1 / 2 \lambda(1-\beta) & 1 / \lambda(1-2 \beta)\end{array}\right]\left[\begin{array}{c}\mathrm{p}^{*}-\overline{\mathrm{p}}^{*} \\ \mathrm{e}-\overline{\mathrm{e}}\end{array}\right]=\left[\begin{array}{c}\dot{\mathrm{p}} \\ \dot{\mathrm{e}}\end{array}\right]$

By recalling the expression in order to simplify the algebra then,

$$
\begin{array}{ll}
a_{1}=\varphi /(1-\varphi \sigma) 2 \delta & a_{2}=-\varphi /(1-\varphi \sigma) 2 \delta \\
a_{3}=1 / \lambda 2(1-\beta) & a_{4}=1 / \lambda(1-2 \beta) .
\end{array}
$$

$\left[\begin{array}{ll}a_{1} & a_{2} \\ a_{3} & a_{4}\end{array}\right] \cdot\left[\begin{array}{c}\mathrm{p}^{*}-\overline{\mathrm{p}}^{*} \\ \mathrm{e}-\overline{\mathrm{e}}\end{array}\right]=\left[\begin{array}{c}\dot{\mathrm{p}} \\ \dot{\mathrm{e}}\end{array}\right]$ and

${ }^{123}$ From a non-linear differential equation system is possible to draw a linear approximation derived from the Taylor expansion of the given system around its equilibrium. For details see Chiang (1984) Turnovsky (1995). 
$\left[\begin{array}{ll}a_{1} & a_{2} \\ a_{3} & a_{4}\end{array}\right]=\mathrm{B}$

According to the characteristic equation then,

$[B-\eta I]=\left[\begin{array}{c}\mathrm{p}^{*}-\overline{\mathrm{p}}^{*} \\ \mathrm{e}-\overline{\mathrm{e}}\end{array}\right]$

The trace of the jacobian $B$ is then, $\operatorname{Tr} B=a_{1}+a_{4}$

The determinant of the jacobian Det $B=a_{1} a_{4}-a_{2} a_{3}$

In order the equilibrium to be a saddle path solution the determinant must be negative.

Det $B==\varphi /(1-\varphi \sigma) 2 \delta 1 / \lambda(1-2 \beta)-1 / \lambda 2(1-\beta)[-\varphi /(1-\varphi \sigma) 2 \delta]<0$

The characteristic roots will be:

$\eta_{1} / 2=\left[\operatorname{TrB} \pm \sqrt{(\operatorname{Tr} B)^{2}-4|B|}\right] / 2$

and the general solution of the system is:

$e(t)=\bar{e}+A_{1} e^{\eta 1 t}+A_{2} e^{\eta 2 t}$

$p(t)=\bar{p}+k_{1} A_{1} e^{\eta 1 t}+k_{2} A_{2} e^{\eta 2 t}$

where $A_{1}$ and $A_{2}$ are the arbitrary constants. Let $\eta_{1}<0<\eta_{2}$ and the saddle path solution is found. $k_{1}$ and $k_{2}$ are the Eigenvectors 


\section{Chapter 3}

\section{Lessons from the European Experience: The EMS as an Instrument to Achieve Price and Exchange Rate Stability}

\subsection{Introduction}

The analysis of the monetary agreements concluded by the European Union during the last three decades constitutes the natural starting point of any study on monetary integration in other geographical regions. Thus, the European experience establishes an example of a successful economic integration process. It has already been functioning for more than 30 years, trade has significantly increased among member states, and the European countries were able to rapidly rebuild their economies after the Second World War. Although the history of monetary agreements in Europe does not begin with the aftermath of the Second World War, this date constitutes probably the best starting point for the analysis of the long-term developments in European monetary integration. ${ }^{123}$ This period is particularly important because it constitutes the beginning of the overall integration process that led to the creation of the European Economic Community (ECC), the European Monetary System (EMS), and finally the present plans for the economic and monetary union (EMU). The European Monetary System (EMS), launched on March 13, 1979, was conceived as another step in the unification of economic policies of the European countries. The EMS constitutes only one element of an important set of agreements (Giavazzi and Giovannini, 1988) among European countries in areas of trade, industrial and agricultural and these agreements rest on exchange rate stability. The EMS was widely perceived, at least until 1992, as a success, and probably the most interesting aspect of it to study is whether it has achieved the goal of providing sufficient stability in European prices and exchange rates.

The argument of the European Commission that reaping the full benefits of economic integration requires exchange rates to be firmly fixed, and ultimately a single currency for Europe applies with equal force to the MERCOSUR case.

Although at first view there exist important differences between European and MERCOSUR countries regarding the degree of development, GDP per capita, and the degree of industrialization, there are also relevant similarities between the two groups of countries. Both started the process of integration after a period of destruction, in Europe the world war, in MERCOSUR, a deep debt crisis, an hyperinflationary process and several non-democratic administrations. Both processes were initially based on political elements and attempted to eliminate historic rivalries, Germany-France in Europe, Argentina-Brazil in MERCOSUR. Both established as a basic condition for joining the club the preservation of democracy in the individual countries. Additionally, labor market behavior is identical as between the two groups, in both cases lacking flexibility, which has some consequences for monetary policies as well as for exchange rate policies. In general, the economic structures of the MERCOSUR countries are similar to those of the Southern European countries. Therefore, some lessons can

${ }^{123}$ Gros and Thygesen (1992), Molle (1990), El-Agraa (1994), Ohr (1996). 
be drawn from the European experience for other regions such as MERCOSUR that attempt to link economically their economies in order to increase competitiveness and foster trade and growth.

Chapter 3 is organized as follow: first, I will briefly review the monetary agreements that the European Union has introduced over time. I will concentrate especially on the European Monetary System, which has been in operation for $\mathbf{1 8}$ years and is probably the most serious attempt to introduce some fixity among European currencies. Second, I will evaluate the performance of the EMS by discussing the contribution of the EMS to the achievement of price stability across Europe and the costs in terms of unemployment that it has incurred. Third, I will perform an econometric analysis in order to study the effect of the EMS on exchange rate stability, particularly; particularly, I will concentrate on the dynamic response of nominal and real exchange rates to monetary and real shocks.

\subsection{Review of the European Exchange Rate Agreements:}

\section{The Origins}

In 1957 the Treaty of Rome was signed, giving birth to the European Common Market ${ }^{124}$.Initially, however, monetary unification was not one of the main objectives, although the Treaty of Rome contains two short chapters on economic policy coordination $^{125}$. The international system established by Bretton-Woods provided a stable framework for the activities of the European Community. ${ }^{126}$

In the late 1960s, the European Community had completed the customs union and established the Common Agricultural Policy. The member countries showed their desire to move towards further integration. At the same time, on the international scene the Bretton Wood system showed the first symptoms of weakness, and so the EC countries

\footnotetext{
${ }^{124}$ I am reviewing only the monetary aspects of the European integration. For surveys concerning the history of the EC, the implementation of the customs unions and other non-monetary aspects of the European integration see Molle (1990), Swann (1990), El Agraa (1994), Ohr (1996).

${ }^{125}$ Paragraph 103 to 107 explicitly refer to the exchange rate policy by saying that each member country considers its short-term policy and its exchange rate policy as a matter of common concern. See Gros and Thygesen (1992).

${ }^{126}$ The Bretton Woods system consisted of a fixed exchange linked to the US dollar and the US dollar to gold. Changes in the parities were allowed only in case of fundamental disequilibria; temporary disequililbria were financed through IMF short-term credits. The IMF rules allowed for a 1 per cent fluctuation band around the central parities against the US dollar. Therefore, two European countries could move by as much as $4 \%$ against each other. The countries agreed to limit their European fluctuation vis-à-vis the dollar to 0.75 per cent, therefore reducing the potential margin for intra-European exchange rate fluctuation to 3 per cent. For details see Isard (1994) and Bayoumi and Eichengreen (1994).
} 
agreed upon the need to develop their own monetary individuality. ${ }^{127}$ Willy Brandt, at that time German chancellor, ${ }^{128}$ proposed that, as a first step, EC member states should jointly formulate medium-term objectives for the participants, and aim to harmonize short-term policies. In a second phase, a monetary union of permanently fixed exchange rate could then be achieved. ${ }^{129}$

In October 1970, Pierre Werner presented a report suggesting the setting-up of a single European currency, which should be implemented in steps by 1980 (Werner, 1970). The Werner Report was extremely explicit regarding the objective of reaching a monetary union as a final step (Willgerodt, Dormsch, Hasse and Marx, 1972). The monetary union should be achieved by permanently fixing all European currencies reaching, thus achieving the elimination of the intra-community exchange rate fluctuations, and the complete liberalization of capital movements. (Werner Report, chapter III, p 10). The Werner report considered two alternative ways of implementing the monetary union, either by establishing a single community currency or by maintaining the national monetary symbols and permanently fixing their parities. A Community central bank in analogy with the US Federal Reserve would be established to conduct the monetary policy and the exchange rate policies with respect to third currencies. These two elements were the only institutional framework that the Werner report suggested for the monetary union. However, it did not describe in detail how this European monetary authority could be constituted. ${ }^{130}$ The Werner report emphasized the importance of free movement of goods, services, people and capital, but stressed that factor mobility could be replaced by public financial transfers to eliminate regional and structural disequilibria. However, it did not mention as an important objective to achievement of convergence to low inflation among European countries. Price divergence was not a matter of concern at that time. ${ }^{131}$

In 1971, the EEC Council of Ministers decided to implement a more modest goal than a monetary union by introducing a mechanism that permits the reduction of exchange rate variability. This was the origin of the so-called Snake in the tunnel. ${ }^{132}$ The original participants in the agreement were Germany, France, Italy Benelux, UK, Ireland, Norway and Denmark, and in 1973 the European Monetary Cooperation Fund was created. (Table 3.2.1 summarizes the chronology of the Snake). However, the Werner Report could never be implemented. It failed to see the relevance of a common monetary institution. The Bretton Wood system had somehow allowed the Community to attain almost completely fixed exchange rates during the 1960s without constructing any European monetary institution. The Werner Report relied on the Bretton Woods sys-

${ }^{127}$ In 1969 in the Hague the wish to move towards an Economic and Monetary Union was reaffirmed, and at the same time it was decided to open the community to new members. See Gros and Thygesen (1992).

${ }^{128}$ See Kloten (1980).

${ }^{129}$ See Gros and Thygesen (1992)

${ }^{130}$ See Gros and Thygesen (1992).

${ }^{131}$ See Baer and Padoa Schioppa (1989).

${ }^{132}$ The tunnel referred to the relation of the EC currencies with respect to the US dollar. 
tem, but this system was collapsing exactly when the first stage of EMU (European Monetary Union) had to be implemented.

\section{TABLE 3.2.1}

\section{Chronological History of the Snake}

1972

24 April

1 May

23 May

23 June

27 June

10 October

1973

13 February

19 March

19 March

3 April

29 June

17 September

16 November

1974

19 January

1975

10 July

1976

15 March

17 October

1977

1 April

28 August

1978

13 February

17 October

12 December

1979

13 March
Basle Agreement enters into force.

Participants: Belgium, France, Germany, Italy, Luxembourg, the Netherlands.

The United Kingdom and Denmark join.

Norway becomes associated.

The United Kingdom withdraws.

Denmark withdraws.

Denmark returns.

Italy withdraws.

Transition to the joint float: Interventions to maintain fixed margins against the dollar ('tunnel') are discontinued. Sweden becomes associated. The DM is revalued by 3 per cent.

Establishment of a European Monetary Cooperation Fund is approved.

The DM is revalued by 5.5 per cent.

The Dutch guilder is revalued by 5 per cent.

The Norwegian krone is revalued by 5 per cent.

France withdraws.

France returns.

France withdraws again.

Agreement on exchange-rate adjustment ('Frankfurt realignment'): The Danish krone is devalued by 6 per cent, the Dutch guilder and Belgian franc by 2 per cent, and the Norwegian and Swedish krone by 3 per cent.

The Swedish krone is devalued by 6 per cent, and the Danish and Norwegian Korea are devalued by 3 per cent.

Sweden withdraws; the Danish and Norwegian krone are devalued by 5 per cent. The Norwegian krone is devalued by 8 per cent. The DM is upvalued by 4 per cent, the Dutch guilder and Belgian franc by 2 per cent. Norway announces decision to withdraw.

The European Monetary System becomes operational.

Source: Gros and Thygesen (1992) 


\section{The EMS: the Quest for Stability}

The snake should have been the first step towards monetary unification, but the international economic and financial volatility in the mid-1970s led to the following steps not being taken. The next attempt to attain exchange rate stability brought about the creation of the EMS in $1979 .{ }^{133}$

The EMS ${ }^{134}$ was conceived as an intermediate step on the road to a full economic and monetary union ${ }^{135}$. The main objective was to avoid violent movements in nominal exchange rates among European currencies. The decision (Coffey, 1993, Giavazzi and Giovannini, 1988) was based on the logical consequence of moving further towards more openness and integration of the member states' economies. Additionally, the management of the Common Agricultural Policy (CAP) required stable exchange rates. The desire to develop an European monetary individuality of one's own as a symbol of one the most important world trading blocs played also an important role toward a closer monetary coordination.

\section{Table 3.2.2}

Relative openness of countries ${ }^{136}$
Imports as share of GDP (percentage)

\begin{tabular}{|l|l|l|l|}
\hline Country & 1960 & 1987 & 1994 \\
\hline Belgium & 39.3 & 75.6 & 66.02 \\
\hline Ireland & 37.2 & 60 & 72 \\
\hline Netherlands & 45.9 & 59.3 & 51.3 \\
\hline Denmark & 33.4 & 36.7 & 48.7 \\
\hline Germany & 16.2 & 22.5 & 19.9 \\
\hline United Kingdom & 22.4 & 28.2 & 25.4 \\
\hline France & 12.9 & 25 & 26.03 \\
\hline Italy & 12.5 & 23.4 & 25.04 \\
\hline USA & 4.4 & 10.1 & 10.06 \\
\hline Japan & 11 & 11.4 & 9.3 \\
\hline
\end{tabular}

Source: Main Economic Indicators, OECD

${ }^{133}$ Most of the economists were very pessimist about the probability of success of EMS.

${ }^{134}$ There is a vast literature on this topic and therefore, the modest propose of this part is to introduce a brief review of the European Monetary System. For details see: Artis (1987), Gros and Thygesen (1988 and 1992), Guitian (1988), Russo and Tullio (1988), Schinasi (1989), Eichengreen (1990), Giovannini (1990), Goodhart (1990), Ungerer (1990), Bovenberg (1991), Emerson and Huhne (1991), Frenkel and Goldstein (1986), Hildebrandt (1991), Masson and Taylor (1992).

${ }^{135}$ See Deutsche Bundesbank (1992), Jarchow and Rühmann (1993), Kenen (1995), Ypersele and Koeune (1984).

${ }^{136}$ The best indicator for openness of an economy is (Exports+Imports)/GDP. However, the share of imports on GDP is a good proxy. Giavazzi and Giovannini (1988), among others, use this concept to measure openness. 


\section{The Institutional Arrangements}

The EMS constitutes an agreement among European central banks to manage intraCommunity exchange rates and to finance exchange market interventions ${ }^{137}$. The Exchange rate mechanism (ERM) of the EMS is only one aspect of the system. ${ }^{138}$ While only a subset of the EC countries participates in the ERM, all of them belong to the EMS. The European Currency Unit (ECU), which was created with the EMS, is a monetary unit based on a basket of all EC currencies. The EMS constitutes in this sense a fixed exchange rate with a band of fluctuation. The following currencies participate in the arrangement: Belgian franc, Danish crone, French franc, Greek drachma, German mark, Irish pound, Italian lira, Luxembourg franc, the Dutch guilder, the Portuguese escudo, the Spanish peseta, the Finnish marc, the Austrian schilling. The main instruments of the EMS are the intervention rules and the financing facilities ${ }^{139}$. The first works as follows: each community currency has an ECU central rate, expressed as the price of one ECU in terms of that currency. ECU central rates are fixed and are revised only when there is a realignment. Although the members have the obligation to intervene in the foreign market to ensure that the bilateral exchange rates are maintained within the boundaries, changes in the central rates may be introduced previous mutual agreement ${ }^{140}$. The ratio of any two ECU central rates is the bilateral central rate of any pair of currencies which together from the parity grid of the system ${ }^{141}$. By joining the ERM mechanism of the EMS a central bank agrees to keep its market exchange rate vis-à-vis any other currency participating in the mechanism within prearranged margins from the bilateral central parity (Giavazzi and Giovannini, 1988). The parity grid is in this sense the heart of the exchange rate mechanism of the EMS, and in this mechanism the ECU is only a numeraire. Initially, the bilateral margin was set at $2.25^{142}$ per cent on either side of the central parity, so that the width of the band for any bilateral rate was 4.5 per cent. The currencies were allowed to fluctuate within the band, but when they reached the margin interventions were compulsory. However, there are two kinds of interventions, the so called "marginal intervention" and "intramarginal intervention". The first is compulsory and takes place when two currencies reach their bilateral margin, meaning when the bilateral exchange rate diverges by 2.25 per cent from the central parity. This marginal intervention must be carried out by both central banks involved in the currency at the opposite bilateral limit. Moreover, financing for bilateral intervention is unlimited: the central bank of the strong currency undertakes to grant its weaker partner an unlimited credit line (Giavazzi and

\footnotetext{
${ }^{137}$ A good description of the rules of the EMS is presented in European Policy 12 (July 1982), ECC, Monetary Committee (1986), Giavazzi and Giovannini (1988), Ungerer $(1983,1986)$, Cohen (1981).

${ }^{138}$ For details see Gros and Thygesen, (1992), Giavazzi and Giovannini (1992).

139 For details see Giavazzi and Giovannini (1988), Gros and Thygesen (1992), Ungerer (1986).

${ }^{140}$ See Argy (1994), Gros and Thygesen (1992), Giavazzi and Giovannini (1992), Ohr (1996).

141 The EMS introduced the divergence indicator, which is a formula that allows to determine which currency is approaching its outwards limit. See Argy (1994), Gros and Thygesen (1992).

${ }^{142}$ Italy was allowed to remain in a +-6 percentage band.
} 
Giovannini, 1988) ${ }^{143}$. The other kind of intervention, the intramarginal, allows the central bank to intervene before the currency has reached the limit of the bilateral band. However, this kind of intervention is subject to the approval of the central bank whose currency is being bought or sold. Nevertheless, there are no borrowing credit lines for these kinds of intervention.

The second interesting element of the EMS are the financing facilities, which constitute concession of mutual credits so that central banks are able to defend the agreed parity. Moreover, there are three kinds of financing facilities: the very short-term financing facility, the short-term monetary support and the medium-term financial assistance. While the first two are administrated by central banks, the third is administrated by the European Council of Ministers.

The very short-term financing facilities, which have been mentioned before, are designed to provide credibility to bilateral EMS parities by securing unlimited financing for marginal intervention. They consists of mutual credit lines between central banks of the system. The short-term monetary support is implemented to provide short-term financing for balance of payments problems and the medium-term financial assistance is designed to provide longer-term financing.

At the time of joining the EMS, the countries were obliged to deposit 20 per cent of their gross reserves in US dollar in exchange for ECUs. Interest was paid (earned) when their holdings fell below (above) the amounts received against their deposits. Although the ECU plays an important role within the EMS, it serves only as a unit of account, it never became, as it was initially expected, a popular reserve asset or a means of debt settlements. ${ }^{144}$ Initially, some member countries were allowed to maintain capital controls; in fact France, Italy, Ireland, Portugal and Spain made use of this right. They were phased out over time.

From the implementation of the EMS until the crisis of 1992, twelve realignments of central rates involving two or more currencies took place. Given the fact that the rules of the game in the EMS were changing over time, in order to analyze its performance, it is convenient to divide the whole period of analysis in three well-defined subperiods: from 1979 to 1987, EMS with frequent realignments; from 1987 to 1992, the EMS without realignments; and after the 1992 crisis, the EMS with wide bands. ${ }^{14}$

${ }^{143}$ The reason of the existence of these credit lines is that while the stronger currency has no limits to purchase the weak currency, the central bank of the weak currency faces the problem of having to sell the strong currency.

${ }^{144}$ The European Commission uses the ECU as a means of account and at government level some credit lines are settled in ECU. However, in the private sector the ECU is not widely used.

${ }^{145}$ This is the division mostly adopted among authors Gros and Thygesen (1992), Goodhart (1990), Ungerer (1990). 
As mentioned above the main objective of the EMS was to avoid violent movements in nominal exchange rates among the European countries ${ }^{146}$. Therefore, the simplest criterion to use in evaluating the past performance of the EMS consists of observing the frequency of realignments. In this sense, the beginning of the EMS was not very successful: central rates were modified at the rate of an average once every eight months. ${ }^{147}$ The experience raised the question of whether the EMS had any effect on the nominal exchange rate fluctuation, or whether it was simply a veil over the system of the facto floating rates. The strong political support for the EMS was based on the belief that, by stabilizing nominal exchange rates, it would be possible to stabilize relative prices across Europe. Between 1979 and 1987, 11 realignments took place (see table 3.2.3). The early phase of the EMS can be interpreted as a discretionary collective management. As the period ended, officials were disillusioned with the EMS performance, with very little convergence having been achieved. Nevertheless, this first period is not homogenous and it can be divided in two subperiods. In the first subperiod, realignments were frequent and convergence very limited. The EMS participants could succeed only in maintaining the mechanism they had constructed. No reforms were introduced, and policy divergence was ultimately corrected in France, Belgium and Denmark in 1982-1983, but Germany remained skeptical about the survival prospects for the EMS. ${ }^{148}$ The second subperiod from 1983 to 1987 revealed a better performance in terms of discipline and disinflation. ${ }^{149}$ Realignment became less necessary as national inflation rates began to converge, and they were implemented even less frequently than price divergence itself justified. The capital liberalization process started and was confirmed as one of the main objectives in the Single European Act of 1986.

${ }^{146}$ See Gros and Thygesen (1992), Kösters (1990), Kleinheyer (1987).

${ }^{147}$ See Deutsche Bundesbank (1979, 1983, 1989).

${ }^{148}$ For details see Godeaux (1989), Kloten (1983), Ungerer, Evans, Nyborg (1983).

${ }^{149}$ See Ungerer, Jouko, López-Claros, Mayer (1986) for details. 


\section{Table 3.2.3}

\section{Realignments}

\begin{tabular}{|c|c|}
\hline September 1979 & DM was revalued $2 \%$. Danish crone was devalued $3 \%$. \\
\hline November 1979 & Danish crone was devalued $5 \%$ \\
\hline March 1981 & Italian lira was devalued $6 \%$. \\
\hline September 1981 & DM was revalued $3 \%$. French franc was devalued $5.5 \%$. \\
\hline February 1982 & $\begin{array}{l}\text { Belgian franc was devaluated } 8.5 \% \text {. Danish crone was devaluated } \\
3 \% \text {. }\end{array}$ \\
\hline June 1982 & $\begin{array}{l}\text { DM was revalued } 4.5 \% \text {. Guilder was revalued } 4.5 \% \text {. Franc was } \\
\text { devalued } 5.75 \% \text {. }\end{array}$ \\
\hline March 1983 & $\begin{array}{l}\text { DM was devalued } 5.5 \% \text {. } \\
\text { French franc was revalued } 2.5 \%\end{array}$ \\
\hline June 1985 & Italian lira was devalued 85 . \\
\hline April 1986 & French franc was devalued $6 \%$. \\
\hline August 1986 & Irish pound was devalued $8 \%$ \\
\hline January 1987 & $\begin{array}{l}\text { DM was revalued } 3 \% \text { guilder was revalued } 3 \% \text {. Belgium franc was } \\
\text { revalued } 2 \% \text {. }\end{array}$ \\
\hline June 1989 & Spanish peseta enters the EMS under the wide band of $+-6 \%$. \\
\hline January 1990 & Italian lira moves to the narrow band of $+-2.25 \%$ \\
\hline October 1990 & British pound enters the EMS under the wide band of $+-6 \%$. \\
\hline
\end{tabular}

Source: Deutsche Bundesbank, several issues.

The speculative attacks in 1986/1987 and a general realignment induced the commissioners to emphasize the need of reaching exchange rate stability and new solutions were discussed in order to achieve it.

\section{The EMS without Realignments 1987- 1992}

After the last realignment on January 1987 there was a general agreement that the monetary authorities within the EMS countries should not be again in such a situation that they were unable to cope with speculative pressures. ${ }^{150}$ During this period, although countries reached a considerable convergence in national inflation rates at a low level (see table 3.2.4 and 3.2.5), national budgetary policies persisted on divergent paths (see table 3.2.7, 3.2.8).

${ }^{150}$ For details see Giavazzi and Giovannini (1988), Gros and Thygesen (1992). 
Table 3.2.4

\section{Consumer Price Index}

\begin{tabular}{|l|l|l|l|l|l|l|l|}
\hline & $\mathbf{1 9 7 1 - 8 0}$ & $\mathbf{1 9 8 0 - 8 9}$ & $\mathbf{1 9 9 0}$ & $\mathbf{1 9 9 1}$ & $\mathbf{1 9 9 2}$ & $\mathbf{1 9 9 3}$ & $\mathbf{1 9 9 4}$ \\
\hline Germany & 5.1 & 2.6 & 2.7 & 3.5 & 4.1 & 4.08 & 2.73 \\
\hline France & 10.1 & 6.6 & 3.4 & 3.2 & 2.5 & 2.08 & 1.7 \\
\hline U.K. & 14.2 & 6.2 & 9.5 & 5.9 & 3.7 & 1.54 & 2.25 \\
\hline Italy & 15.1 & 10.1 & 6.1 & 6.5 & 5.3 & 4.2 & 3.9 \\
\hline Belgium & 7.7 & 4.6 & 3.4 & 3.2 & 2.5 & $2-7$ & $2-3$ \\
\hline Denmark & 10.3 & 6.3 & 2.7 & 2.4 & 2.1 & 1.3 & 1.9 \\
\hline Nether- & 7.3 & 2.4 & 2.5 & 3.9 & 3.7 & 2.6 & 2.7 \\
\hline Spain & 16.1 & 9.6 & 6.7 & 5.9 & 5.9 & 6.5 & $4-7$ \\
\hline Canada & 8.08 & 6.5 & 4.8 & 5.6 & 1.5 & 1.8 & 0.01 \\
\hline USA & 7.85 & 5.56 & 5.4 & 4.2 & 3.7 & 2.9 & 2.53 \\
\hline
\end{tabular}

Source: Main Economics Indicators, OECD

Table 3.2.5

\section{CPI average EMS countries}

\begin{tabular}{|l|l|l|l|l|}
\hline Year & Average & & \multicolumn{3}{|l|}{ Standard deviation } \\
\hline & EMS & $\begin{array}{l}\text { Narrow }^{\mathbf{1}} \\
\text { band }^{\mathbf{1}}\end{array}$ & EMS & Narrow band \\
\hline 1979 & 8.6 & 6,3 & 4.38 & 2,61 \\
\hline 1980 & 11.6 & 8,4 & 5.72 & 2,94 \\
\hline 1981 & 11.7 & 8,6 & 5.47 & 2,66 \\
\hline 1982 & 10.7 & 8,3 & 4.30 & 2,42 \\
\hline 1983 & 7.9 & 6,0 & 4 & 2,72 \\
\hline 1984 & 6.6 & 5,3 & 2.52 & 1,89 \\
\hline 1985 & 4.8 & 4 & 2.05 & 1,49 \\
\hline 1986 & 2.4 & 1,5 & 2.03 & 1,44 \\
\hline 1987 & 2.2 & 1,6 & 1.81 & 1,67 \\
\hline 1988 & 2.5 & 2,1 & 1.59 & 1,42 \\
\hline 1989 & 4.5 & 3,7 & 1.76 & 1,19 \\
\hline 1990 & 3.9 & 3,5 & 2.30 & 1,25 \\
\hline 1991 & 4 & 3,7 & 1.40 & 1,19 \\
\hline 1992 & 4.1 & 3,8 & 1.29 & 1,15 \\
\hline 1993 & 4.38 & 2.31 & 3.52 & 1.01 \\
\hline 1994 & 3.74 & 1.99 & 2.50 & 1.02 \\
\hline
\end{tabular}

Source: Main Economic Indicators OECD

${ }^{151}$ Although since August 1993 the band has been widened for practical purposes, here in the narrow band are considered those countries which initially allowed their currencies to fluctuate. +-2.25 . 
In 1987 the European countries signed the Basle-Nyborg agreement, which introduced a new version of the EMS. Under this new EMS , the elimination of realignments was achieved. The credibility of exchange rate commitments improved and interest rate differentials declined. From 1987 until the crisis of 1992, no further realignment occurred. ${ }^{152}$ The critical factors that explain why it was possible to avoid additional realignments, at least until 1992, were on the one hand, the achievement of a reasonable degree of convergence, monetary coordination was strengthened and exchange rates were defended with a wider range of instruments than during the earlier period. On the other hand, some reforms were introduced into the EMS such as the removal of capital controls, and the discussion about the timetable for reaching EMU by stages made participants keen to demonstrate that they were indeed ready to move towards further integration. Although the average EMS inflation picked up from the artificially low level reached in 1986, $1.5 \%$, to nearly $3.5 \%$ in 1990, the dispersion around it as measured by standard deviation was stable or declined slightly further, at least among the initial members of the narrow band (see table 3.2.5). This fact reveals, however, clearly improved convergence in the group of seven countries that had from the start of the EMS observed narrow margins, and some divergence between this group and Italy plus the two new members Spain and the United Kingdom. For the group of seven the range of national inflation rates had narrowed to $1 \%$. Convergence in nominal interest rates was slower, but also unmistakable: by 1990 the differential in short-term rates was down to less than $2 \%$ in this group except for Ireland. With both inflation and interest rates converging, long-term real interest rates had become much more uniform across the first group. With respect to the external balances, at least the 7 original participants were moving closer to a sustainable external position. With the exception of the German surplus up to 1989, external imbalances proved to be transitory. The deficits of Denmark and Ireland were sharply reduced relative to earlier phases in the 1980 s, switching even into surplus at the end of the decade. Belgian and Dutch surpluses diminished while French accounts did not move far from balance. Italy moved into a modest deficit from 1989.(See table 3.2.6).

${ }^{152}$ See Fratianni and von Hagen (1992), Schiemann (1992). 
Table 3.2.6

\section{Current Account Balance as \% of GDP}

\begin{tabular}{|r|r|r|r|r|r|r|r|r|r|r|}
\hline Year & G & F & \multicolumn{1}{l|}{ I } & B & L & DK & \multicolumn{1}{l|}{ IRL } & S & GB & P \\
\hline 1979 & $-5,6$ & 5,1 & 5,5 & 0,2 & $-3,1$ & $-3,0$ & $-2,1$ & 1,1 & $-1,2$ & $-0,1$ \\
1980 & $-14,0$ & $-4,2$ & $-10,0$ & $-1,0$ & $-4,9$ & $-2,5$ & $-2,1$ & $-5,2$ & 7,0 & $-1,1$ \\
1981 & $-3,4$ & $-4,8$ & $-9,5$ & 3,7 & $-4,2$ & $-1,9$ & $-2,6$ & $-5,0$ & 13,2 & $-2,6$ \\
1982 & 5,0 & $-12,1$ & $-6,4$ & 4,5 & $-2,6$ & $-2,3$ & $-1,9$ & $-4,2$ & 8,0 & $-3,3$ \\
1983 & 5,4 & $-5,2$ & 1,4 & 5,0 & $-0,5$ & $-1,2$ & $-1,2$ & $-2,7$ & 5,8 & $-1,0$ \\
1984 & 9,8 & $-0,9$ & $-2,5$ & 6,6 & 0,0 & $-1,6$ & $-1,0$ & 2,0 & 2,6 & $-0,5$ \\
1985 & 17,0 & 0,0 & $-3,4$ & 4,2 & 0,7 & $-2,8$ & $-0,7$ & 2,9 & 4,1 & 0,4 \\
1986 & 39,9 & 2,4 & 3,1 & 4,0 & 3,1 & $-4,5$ & $-0,7$ & 4,0 & 0,2 & 1,2 \\
1987 & 46,0 & $-4,4$ & $-1,3$ & 3,9 & 2,8 & $-3,0$ & 0,4 & $-0,2$ & $-7,0$ & 0,4 \\
1988 & 50,3 & $-4,8$ & $-6,2$ & 6,9 & 3,6 & $-1,3$ & 0,6 & $-3,8$ & $-27,6$ & $-1,1$ \\
1989 & 56,9 & $-5,6$ & $-10,8$ & 9,8 & 3,2 & $-1,1$ & 0,4 & $-10,9$ & $-33,4$ & 0,2 \\
1990 & 46,4 & $-13,7$ & $-12,7$ & 9,2 & 4,5 & 1,4 & 0,9 & $-16,8$ & $-27,7$ & $-0,1$ \\
1991 & $-20,7$ & $-6,1$ & $-24,6$ & 9,2 & 4,7 & 2,2 & 0,9 & $-16,0$ & $-9,4$ & $-0,7$ \\
1992 & $-21,7$ & 3,9 & $-29,5$ & 7,3 & 6,7 & 4,3 & 1,7 & $-21,3$ & $-17,2$ & $-0,2$ \\
1993 & $-16,0$ & 9,0 & 9,4 & 12,2 & 11,2 & 4,7 & 2,4 & $-5,8$ & $-16,6$ & 0,7 \\
1994 & $-21,8$ & 8,1 & 14,9 & 13,6 & 13,0 & 2,1 & 2,7 & $-6,8$ & $-2,4$ & $-1,0$ \\
\hline
\end{tabular}

Source: International Financial Statistics, IMF

As far as regards fiscal policy, it becomes less clear that the EMS has introduced some contribution to improve the fiscal deficits and debt ratios. Probably, the main danger signal for the functioning of the EMS as a whole has remained the persistence of the public sector deficit of over $10 \%$ of GDP in Italy, and very high levels of debt in Belgium and Ireland (see tables 3.2.7, 3.2.8).

Table 3.2.7

Public Debt

$\%$ of GDP

\begin{tabular}{|l|l|l|}
\hline Year & average & standard deviation \\
\hline 1984 & 63,7 & 28379 \\
\hline 1985 & 66,7 & 30,45 \\
\hline 1986 & 68,7 & 32,66 \\
\hline 1987 & 69,3 & 35 \\
\hline 1988 & 69,04 & 36 \\
\hline 1989 & 67,10 & 34 \\
\hline 1990 & 66,05 & 34,16 \\
\hline 1991 & 66,62 & 34.51 \\
\hline 1992 & 66,95 & 34,41 \\
\hline 1993 & 72,11 & 36,78 \\
\hline 1994 & 72,31 & 36,25 \\
\hline 1995 & 79,65 & 28,23 \\
\hline
\end{tabular}

Source: Main Economic Indicators, OECD 
Table 3.2.8

Fiscal Deficit

$\%$ GDP

\begin{tabular}{|l|l|l|l|l|l|l|l|l|l|l|l|}
\hline year & G & F & I & NL & B & L & DK & IRL & S & UK & P \\
\hline 1984 & -1.9 & -2.8 & -11.6 & -6.3 & -9 & 3.4 & $-4,1$ & 9.8 & -5.4 & -4 & -12 \\
\hline 1985 & -0.9 & -2.9 & -12.5 & -4.8 & -8.5 & 5.3 & -2 & -11.2 & -6.9 & -2.8 & -10.1 \\
\hline 1986 & -1.3 & -2.7 & -11.7 & -6 & -9.1 & 3,5 & 3.4 & -11.2 & -6 & -2.4 & -7.2 \\
\hline 1987 & -1.8 & -1.9 & -11 & -6.6 & -7.1 & 1,6 & 2.4 & -9.1 & -3.2 & -1.3 & -6.8 \\
\hline 1988 & -2.1 & -1.8 & -10 & -5.2 & -6.9 & 2,4 & 0.5 & -5.2 & -3.3 & 1.1 & -5.4 \\
\hline 1989 & 0.2 & -1.2 & -10.9 & -5.2 & -6.7 & 4,3 & -0.5 & -3.5 & -2.7 & 1.3 & -3.4 \\
\hline 1990 & -1.9 & -1.6 & -10.1 & -5.3 & -5.6 & 4,7 & -1.5 & -3.6 & -4 & -0.7 & -5.8 \\
\hline 1991 & -3.6 & -1.5 & -10.6 & -4.4 & -6.3 & 1,9 & -1.7 & -4.5 & -3.9 & -1.9 & -5.4 \\
\hline 1992 & -3.4 & -1.7 & -9.9 & -4.1 & -6.2 & 2 & -1.5 & -4.1 & -3.6 & -3.6 & -4.6 \\
\hline 1993 & -3.5 & -5.8 & -9.6 & -3.2 & -6.7 & - & -3.9 & -2.4 & -7.5 & 7.8 & -7.1 \\
\hline 1994 & -2.5 & -5.8 & -9.0 & -3.2 & -5.3 & - & -3.5 & -2.3 & -6.9 & 6.8 & -5.6 \\
\hline
\end{tabular}

Source: Main Economic Indicators, OECD

\section{The Crisis}

The achievement of the EMS without realignments from January 1987 to August 1992 induced the belief that moving towards a monetary union would not necessarily involve substantially high costs, and instead would allow further benefits to be gained, as for example, the reduction of transaction costs. Capital controls in every form ${ }^{153}$ were eliminated, as a corollary of the 1992 program to complete the internal market ${ }^{154}$, and in fact most of EMS countries had removed their capital controls by the beginning of 1990, while Spain and Portugal had significantly reduced them before the crisis started.

For a period, the EMS without realignments was working even in the face of persistent inflation differentials. Therefore, there were some doubts about how to correct real exchange rates without affecting nominal exchanges rates in a world of structural rigidities in labor markets. The lack of feasible answers induced markets to threaten the new EMS system. The first currency to show some weakness was the Italian lira. The Bank of Italy intervened extensively over the summer, but it could not avoid the suspension of the Italian lira from the ERM. The British pound showed also disturbing symptoms, and despite extensive intervention from the Bank of England, the British Pound was forced to abandon the system. The facts are summarized in table 3.2.9. The

${ }^{153}$ Capital controls could be achieved either introducing taxes on foreign currency asset holdings, or by introducing restrictions on the ability of banks to lending abroad. See Gros and Tyghesen (1992)

${ }^{154}$ In the Single European Act (1986) was agreed the elimination of capital controls by July 1990 in all countries except Spain and Ireland who would be exempted until December 1992 and Portugal and Greece would be exempted until December 1995. 
persistent instability in financial markets and the crisis during the summer of 1993 led the European countries to agree in August 1993 to the implementation of a wide band +-15 . ${ }^{155}$ Since then, financial markets have been calmer and most currencies moved "de facto" inside a much smaller band.

\section{Table 3.2 .9}

\section{The 1992 crisis}

\begin{tabular}{|c|c|}
\hline $\begin{array}{l}\text { April } 1992 \\
\text { September } 1992\end{array}$ & $\begin{array}{l}\text { Portuguese escudo enters the EMS under the wide band }+-6 \% \\
\text { Italian lira devalued } 7 \% \\
\text { Italian lira membership is suspended. } \\
\text { British pound membership is suspended. } \\
\text { Spanish peseta devalued } 5 \%\end{array}$ \\
\hline January 1993 & Irish pound devalued $10 \%$. \\
\hline August 1993 & Wide band in the ERM +-15 \\
\hline
\end{tabular}

Source: Deutsche Bundesbank (several issues)

\section{Some Explanations of the Crisis of 1992}

Different economists attributed the responsibility of the crisis to diverse factors such as: competitiveness losses, inconsistent monetary policies combined with perfect capital mobility, and the external shock implied by the German unification. Probably all of them contributed partially to foster the crisis of 1992. The Commission of the European Community (1993) based the explanation on the competitiveness problems originated from significant distortions between prices of tradable and non-tradable goods from some countries that showed internal divergent policies ${ }^{156}$.

Viñals (1994) and Ungerer (1993) also argue also along these lines. Thus in their opinion, the causes of the crisis of 1992 can be found in the combination of two main elements: first, the inability to sufficiently coordinate monetary and especially fiscal policies among member countries led to competitiveness problems. Additionally, the fact that real exchange rate appreciation could not be corrected by itself plus the lack of mechanisms to defend the exchange rate parities agreed upon increased the probability of speculative attacks. ${ }^{157}$

However, Eichengreen and Wyplosz (1993) found by analyzing all the countries which were affected by the September crisis that not all of them showed important competitiveness problems. They classify the countries, whose currencies were under specula-

\footnotetext{
${ }^{155}$ For details Avesani, Gallo, Salomon (1995), Bladen and Hovel (1994), Kenen (1995), Melitz (1995), Willms (1995).

${ }^{156}$ For a detailed analysis of the EMS crisis of 1992 see Eichengreen and Wyplosz (1993) and Ungerer (1993)

157 Actually the instruments provided by the EMS to avoid currency crisis were the financing facilities. They did not optimally work because the individual countries were sterilizing the monetary effects..
} 
tive pressures during the crisis of 1992 into three categories: the first case: Italy, where there were clear competitive problems due to price distortion, the second group: United Kingdom, Spain and two non EMS countries (Sweden and Finland), the competitiveness problem was quite ambiguous. The third group, constituted by France, Belgium and Ireland, did not show significant competitiveness problems.

While internal imbalances resulting from losses in competitiveness have in some cases played an important role in prompting market pressures, there have been other factors behind the crisis. One of the most stylized explanations was based on the concepts already made popular by Padoa-Schioppa (1987), and extensively developed by Wyplosz (1989) and known as the "impossibility theorem". It is in fact the logical consequence of the N-1 problem that each fixed exchange rate faces, and which has been extensively developed in Section 2.4 of Chapter 2 . This proposition suggests that there are three conditions- free trade, free capital movements and exchange rate stabilitythat can only coexist together if they are followed by an excellent coordination of national economic policies (monetary and fiscal), otherwise there would be serious risk of exchange rate instability. ${ }^{158}$ The 1992 crisis would fit into this reasoning in the sense that the countries were enjoying free trade and free capital mobility without having achieved a perfect coordination of their internal policies. The attempt to pursue independent monetary policies under a quasi-fixed exchange rate system like the EMS induced the crisis as the natural consequence.

The external factor, as the shock implied by the German unification, was also responsible for the collapse, by inducing a coexistence of excess demand pressures in Germany linked to unification, and a weak demand pressures in other European countries. This situation made extremely costly for the authorities of the latter countries to maintain the exchange rate stability. As market participants became aware of these costs, foreign exchange pressures tended to intensify. Moreover, all these factors, competitiveness problems, and capital inflows had been undermining the system for a long time and speculative attacks did not arise until September 1992.

The question to be asked is why the crisis began in September 1992 and not before. Interest differentials between weak and strong currencies were persistent without any threat of the market. Probably, the stability of currencies until the crisis was based not so much in the contemporaneous policies being pursued, but rather on the expectations that future policies would be changed to achieve the convergence conditions required in the Maastricht treaty. The doubts as to whether the European countries would really implement the monetary union, as agreed in the Maastricht Treaty, ${ }^{159}$ induced the mistrust in the financial markets and capital flowed out of the weak currency countries, making it very difficult for the governments to defend the agreed parity.

\footnotetext{
${ }^{158}$ This condition is also known as the "impossibility triangle". Only a combination of two conditions can work.

${ }^{159}$ The rejection of the monetary union in the Danish Referendum and the $51 \%$ vote against EMU in France. See Eichengreen and Wyplosz (1993).
} 


\subsection{Effect of the EMS on Price Stability}

The previous analysis has, concerning the functioning of the EMS, clearly shown two things: during the time period from 1983 until 1992, and particularly after 1987 (BasleNyborg agreement), the behavior of the exchange was relatively stable. Additionally, the Bundesbank played, at least to some degree, a special role (as an anchor currency) in determining monetary policies for the community. As for the well-known antiinflationary policy of the German Bundesbank, this constellation suggests that the EMS served as a means towards price stability for the other member countries.

This section concentrates on two aspects: on the one hand, I will analyze the contribution of the EMS to the achievement of price stability; and on the other hand, I will discuss the costs in terms of unemployment rates that it has involved.

\section{Credibility and Inertia Inflation}

In this section, firstly, I will review the relevant empirical literature concerning the effect of the EMS on price stabilization among member countries and, secondly, provide further empirical evidence regarding this argument using some descriptive statistics.

\section{Review of the Empirical Literature}

The theoretical analysis that supports the idea that there are some benefits of pegging the exchange rates to a harder currency is based on the Barro and Gordon (1983) argumentation. ${ }^{160}$ The reasoning is as follows: central banks are not able to commit themselves to reduce inflation because there is no punishment suffered by them if they deviate from the rules. As long as wages are rigid and markets understand policy maker's incentives the economy will have a bias towards inflation, then the equilibrium inflation rate will be positive and there will be no gains at all in output and employment at all. Therefore, the society will benefit from an enforceable precommitment. The EMS fits in this way of thinking: thus, high inflation countries (France, Belgium, Italy) would have benefited from the EMS by delegating their monetary policy to the Bundesbank, who enjoys high credibility against inflation. There is a wide agreement that inflation differentials within the EMS have narrowed during the 1980s. Inflation in the member countries has converged to German standards. However, there is no consensus as to whether the mere presence of EMS itself has played the main role in the disinflationary process and whether it has reduced the costs of disinflation. Although some analysts point out that the benefits of EMS membership came from the enforcement of deflationary policies through exchange rate

\footnotetext{
${ }^{160}$ This theoretical approach as well as the relevant references were presented in the previous chapter in section 2.5 .
} 
constraints, which would allow inflation to be reduced at lower cost in terms of output and unemployment, others support the thesis that the disinflation process has been not only an European phenomenon but a generalized one and that the cost of disinflation in Europe has been even higher than in other part of the world. The view of the EMS as a disciplinary instrument was initially stressed by Giavazzi and Pagano (1988), Giavazzi and Giovannini (1989), Metz (1985) who empirically demonstrated that, by "tying" the exchange rate to a hard currency such as the DM, member countries have increased the credibility of their announced anti-inflation policies, thereby lowering inflation expectations and thus the cost of disinflation.

Kremers (1989) and Dornbusch (1989) analyzed the disinflation process in Ireland during the 1980s. They argued that the EMS increased the credibility of the Irish monetary policy and helped to reduce inflation expectations by moderating wage demands and contributed, in this way, to a disinflationary process in Ireland. In this sense the fixed exchange rate would have helped to discipline labor markets, even when they were not perfectly flexible, by allowing the coordination of expectations with respect to the future inflation rate.

Christensen (1987) reached a similar conclusion by analyzing the disinflation process in Denmark during the 1980s. He argued that the EMS contributed to the disinflation process by reducing inflationary expectations, making disinflationary policy in Denmark more credible.

Barrell (1990), analyzes the impact of the EMS on disinflation by examining its impact on wage policies in the European countries. He tested for structural breaks caused by the EMS in a Phillips-curve wage equation, concluding that the EMS contributed positively to disinflation in some European countries.

Giavazzi and Giovannini (1989) Robertson and Symon (1992) found evidence that membership in the EMS has lowered the cost of disinflation for high inflation countries, but has increased it for low inflation members.

Weber (1992) estimated credibility and reputation for the whole EMS. He found that borrowing credibility from the Bundesbank has worked for some countries (Denmark, Ireland, Netherlands, Belgium) but not for others (France, Italy). Giavazzi and Giovannini (1989) take a more skeptical view of the effect of the EMS on inflation. Using a VAR approach they found for the non-German countries an improvement in price stability in the 80 's. However, due to the long lag in the effect, it remains doubtful, whether this has been caused by the entry into the EMS or by other exogenous factors. Artis and Nachane (1990) examined the price-stabilizing effect of the EMS based on causality and cointegration tests of wage and inflation differentials in France, Belgium, Italy and the Netherlands. Although they found evidence that wages and prices were reduced after 1979, they argued that this had not necessarily been caused by the membership in the EMS, because similar evidence was obtained for the United Kingdom as well, which was not a member country during the observation period.

Considering a measure of reputation using a Kalman-Filter approach, Weber (1992) analyzed the price-stabilizing effect of the EMS. He found that, in small member countries, the reputation of the monetary authorities has improved. However, for Italy and France he could not confirm a similar effect. Although an overview of the inflation performance of the member countries of the EMS tends to support the discipline argument, Fratianni and von Hagen (1992) showed that inflation rate has been reduced 
during the EMS experience, but it does not seem to be only a phenomenon of having membership in the EMS because countries outside the EMS have also reduced inflation. Moreover, even the disinflation processes have brought important losses in output and employment in the EMS countries, which were higher than in non-EMS countries.

Some economists support the idea that EMS has introduced an artificial stabilization by linking nominal exchange rates and has imposed high costs in terms of output losses and unemployment upon the domestic economies, especially those which used to have high inflation. De Grauwe (1989c, 1994) analyzed the trade-off between inflation and unemployment in the $80 \mathrm{~s}$, reaching the conclusion that, compared to those countries relying on domestic policies, the effect of the EMS on disinflationary processes has been relatively less important. He argued that in those countries that have used domestic policies (budget policies, "own house in order"), inflation was reduced more forcefully because of the use of "shock-therapy-type of polices avoiding overvaluation of the home currency and thereby signaling a greater willingness for price stability. Schäfer (1990), Schiemann (1992) also argue in this direction. Summarizing, the empirical evidence regarding the credibility effects of EMS membership is quite mixed and the analyses provide a rather ambiguous picture of the price stabilization effect of the EMS, depending on the method applied and the countries observed.

\section{Stylized Facts}

The simplest criterion to analyze the EMS performance with respect to price stability consists in observing the row data. Concerning the monetary stability achieved by the EMS member countries, as despicted in Fig 3.3.1, the performance seems to be quite satisfactory. At first sight, inflation rates have tended to fall in all cases and in some cases to converge. Countries with high inflationary traditions like Belgium, France and Italy have undertaken strong measures to control inflation using their membership of the EMS. ${ }^{161}$ Whenever rates of inflation have diverged too sharply and too widely, pressures have built up on the weak currencies in the exchange rate markets. However, parity adjustments have taken place within rather than outside the system ${ }^{162}$. Arrangement within the EMS, at least until 1992, was smooth and in all cases appropriate, since speculative attacks stopped. ${ }^{163}$

\footnotetext{
${ }^{161}$ The countries have to some extent coordinated their monetary policies. See table 3.3.2, both the average of growth rate of monetary aggregate and its standard deviation declined.

${ }^{162}$ At least until the crisis of 1992 currencies could adjust their parity without leaving the EMS

${ }^{163}$ See Marquart (1994), Ungerer (1983,1986,1990), Collins (1988), Artis (1987), Schiemann (1992)
} 


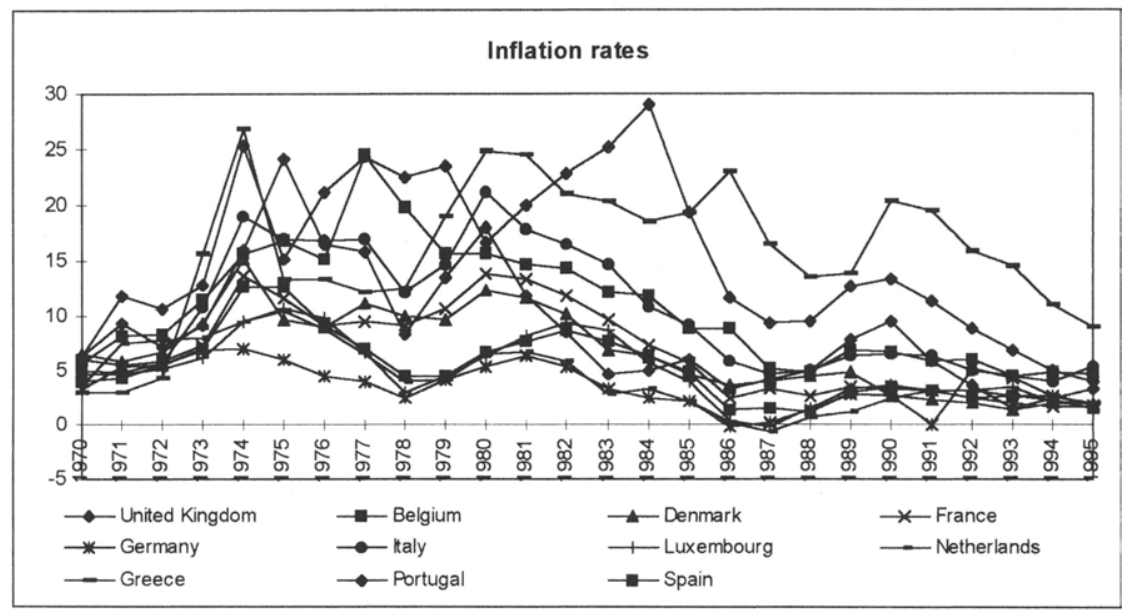

Source: International Financial Statistics, IMF

However, there are two very different group of countries, which I will call group 1 (Belgium, Denmark, Germany, Luxembourg and Netherlands) and the group 2 by France, Italy, Portugal, United Kingdom, Spain). Concerning group 1, one observes that inflation rates developed remarkably similarly (see Figure 3.3.2.). Only Denmark in the mid $70 \mathrm{~s}$ and early $80 \mathrm{~s}$ maintained a higher rate of inflation than the other countries. In all of those countries, the impact of the oil-shocks in 1973 and 1979 is clearly observable. In the early 80 s the inflation rate dropped significantly so that in the mid $1980 \mathrm{~s}$ a de facto state of price stability could be observed, which was supported by the fall in energy prices then. At the beginning of the 1990s a remarkable convergence of inflation rates is to be noted, lying between $2 \%$ and $4 \%$ at a relatively low level. Until 1986, Germany maintained a position of being the country with the lowest inflation rate, this situation was achieved, thereafter by the Netherlands and France. 
Figure 3.3.2

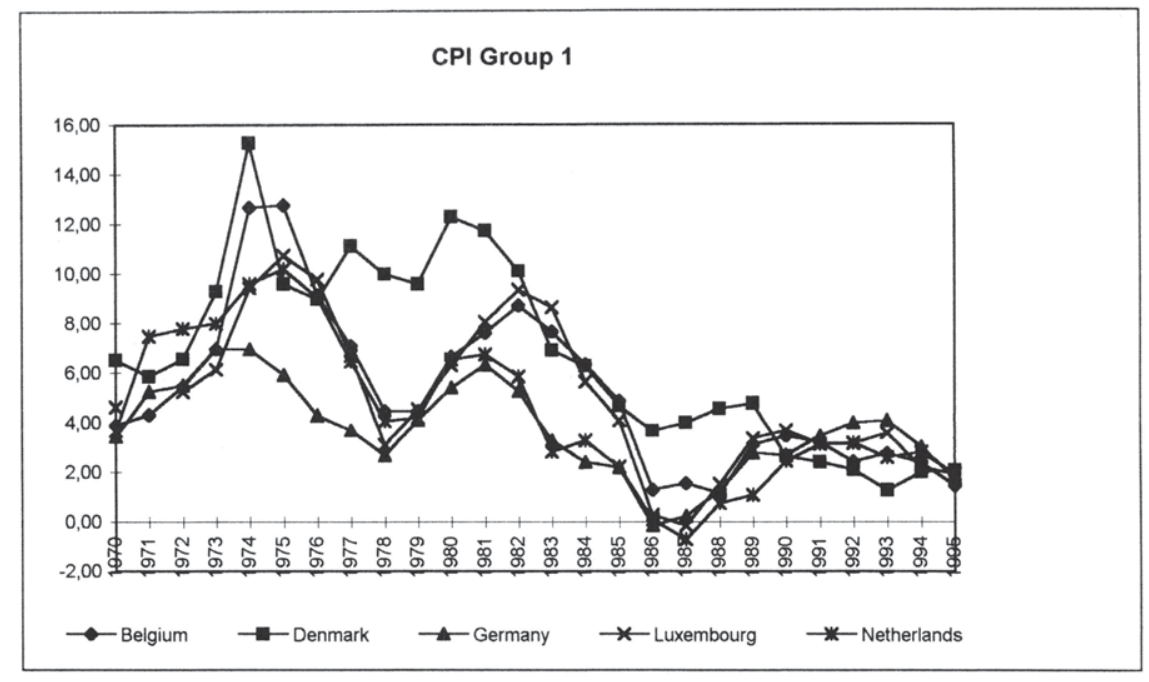

Source: International Financial Statistics, IMF

Figure 3.3.3

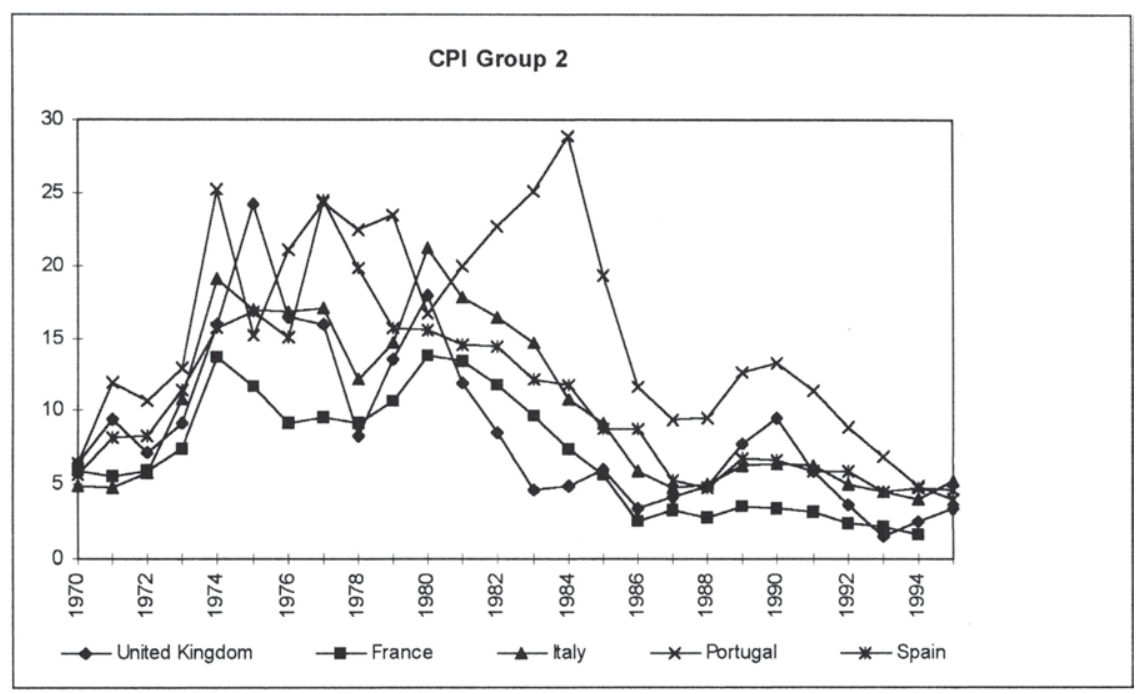

Source: International Financial Statistics, IMF 
Concerning the second group of countries, the behavior of inflation rates is remarkably similar to the one described above, particularly after the introduction of the EMS until 1986-1987. (see Fig. 3.3.3). The behavior parallels that of the countries of group 1, however to a higher level of inflation. After 1987, the behavior of domestic prices shows a significant convergence to the German inflation rate.

By comparing the pre-EMS period (1971-1978) and post-EMS (1979-1992) behavior, the Netherlands, which is probably the country following German's monetary policy most closely, apparently achieved the largest success in price stabilization. However, looking only at the EMS-period in comparison to the subperiod 1979-1982, those countries in the EMS not having been participating in the Snake seem to have achieved the greatest progress in their disinflation processes.

Regarding the interest rates and money growth, the EMS has introduced some convergence (See Fig. 3.3.4). The growth rate of the monetary aggregates has declined from 12.8 in 1979 to 7.4 in 1987 and the standard deviation from 8.16 to 1.96 in 1987 (See table 3.3.1) ${ }^{164}$. In this sense, the fact of fixing the exchange rates has contributed to the achievement of some convergence among the nominal indicators.

${ }^{164}$ See Schiemann (1992), Gros and Thygesen (1992) for details. 
Figure 3.3.4

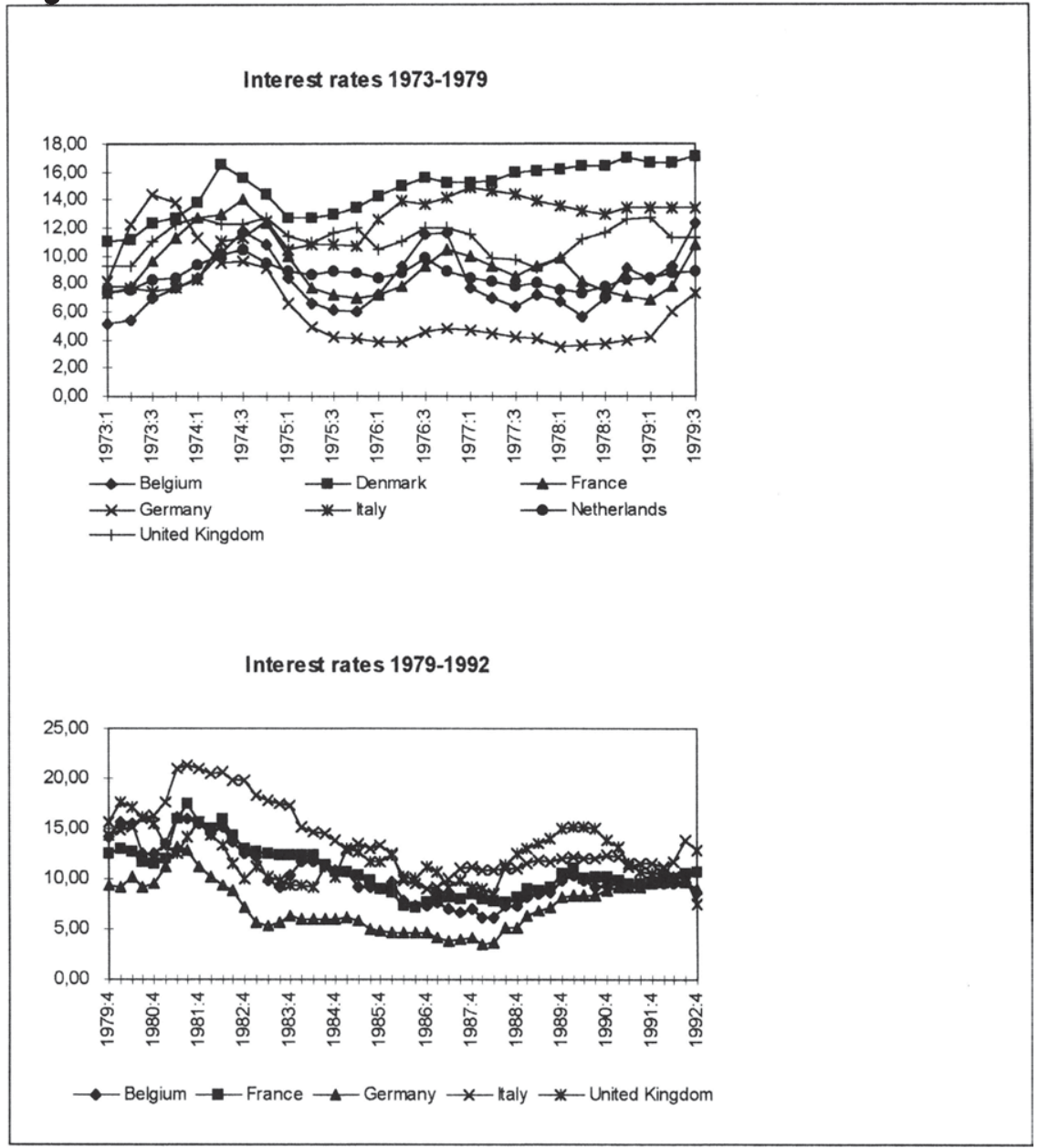

Source: International Financial Statistics, IMF 


\section{Table 3.3.1}

Money Market rates

\begin{tabular}{|l|l|l|}
\hline Year & $\begin{array}{l}\text { EMS } \\
\text { Average }\end{array}$ & $\begin{array}{l}\text { Standard } \\
\text { Deviation }\end{array}$ \\
\hline 1979 & 10.2 & 3.26 \\
\hline 1980 & 13.8 & 2.98 \\
\hline 1981 & 14.4 & 2.74 \\
\hline 1982 & 14 & 4.01 \\
\hline 1983 & 11.6 & 4.87 \\
\hline 1984 & 10.5 & 3.58 \\
\hline 1985 & 9.9 & 2.87 \\
\hline 1986 & 9.1 & 2.90 \\
\hline 1987 & 8.9 & 3.59 \\
\hline 1988 & 7.8 & 2.57 \\
\hline 1989 & 10 & 2.67 \\
\hline 1990 & 10.9 & 2.47 \\
\hline 1991 & 10.5 & 1.47 \\
\hline 1992 & 10.5 & 1.14 \\
\hline 1993 & 8.14 & 1.75 \\
\hline 1994 & 6.14 & 1.44 \\
\hline 1995 & 6.19 & 2.09 \\
\hline S
\end{tabular}

Source: International Financial Statistics, IMF

\section{Table 3.3.2}

\section{Monetary aggregates}

\begin{tabular}{|l|l|l|}
\hline Year & Av. Rate of Growth & Standard deviation \\
\hline 1979 & 12.8 & 8,16 \\
\hline 1980 & 5.8 & 4,72 \\
\hline 1981 & 8 & 4,97 \\
\hline 1982 & 7.6 & 3,55 \\
\hline 1983 & 11.9 & 5,01 \\
\hline 1984 & 9.8 & 5,77 \\
\hline 1985 & 8.9 & 5,61 \\
\hline 1986 & 9.5 & 5,19 \\
\hline 1987 & 7.4 & 1,96 \\
\hline 1988 & 7.7 & 3,40 \\
\hline 1989 & 7.9 & 4,09 \\
\hline 1990 & 8.6 & 4,78 \\
\hline 1991 & 9 & 5,99 \\
\hline
\end{tabular}

Source: International Financial Statistics, IMF

On the contrary, the behavior of fiscal indicators such as public debt and fiscal deficit show a quite divergent pattern. While some countries like Luxembourg show a very low indebtedness coefficient ${ }^{165} 6.4$ in 1992 , others show extremely large debt ratios such as Belgium, 129,6; Ireland 100.4; and Italy 103.9 for the same year (See table 3.3.3). Additionally, the performance has tended to worsen over time rather than improve. Observing the behavior of public deficits as share of GDP, they show

\footnotetext{
${ }^{165}$ Measured as percentage of GDP.
} 
especially high values in the case of Italy (over 10 per cent) and no sign of reduction over time is observed (See Fig 3.3.5). Only Ireland shows a significant improvement in its fiscal account by reducing the percentage from 9.8 in 1984 to 3.5 in 1989.

\section{Figure 3.3.5}

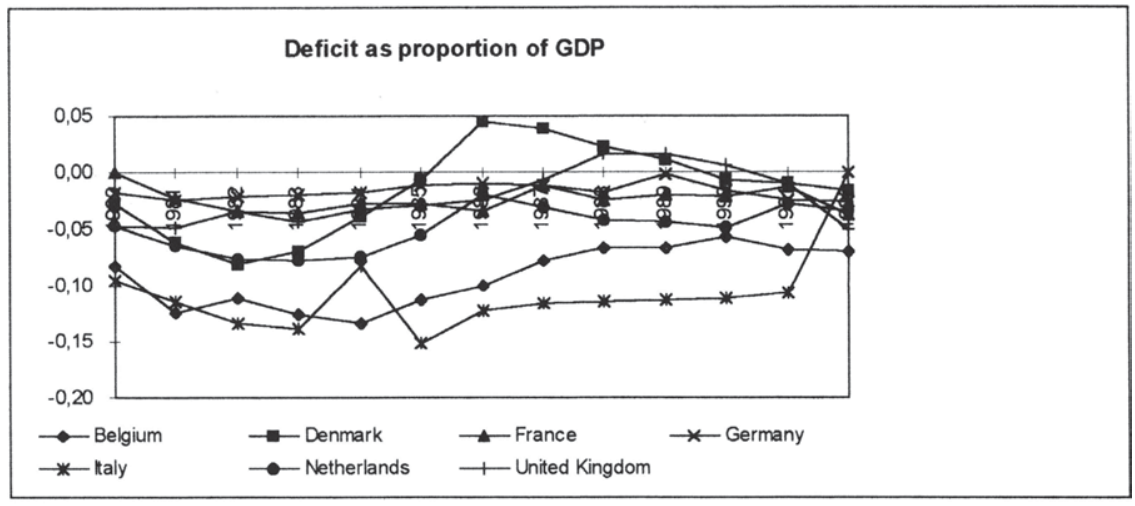

Source: International Financial Statistics, IMF

Table 3.3.3

Public Debt as percentage of GDP

\begin{tabular}{|l|l|l|l|l|l|l|l|l|l|l|l|}
\hline & G & F & Ir & Nl & B & L & DK & IRL & S & UK & P \\
\hline 1984 & 41,6 & 43,8 & 75,1 & 66,1 & 112,6 & 15 & 78,9 & 104,8 & 39,9 & 60,3 & 62,4 \\
\hline 1985 & 42,3 & 45,5 & 82 & 69,7 & 119,8 & 14 & 76,8 & 108,5 & 45,2 & 58,9 & 70,9 \\
\hline 1986 & 42,4 & 54,7 & 86,5 & 71,6 & 124 & 13,4 & 69 & 120,8 & 46,2 & 57,7 & 69,5 \\
\hline 1987 & 43,5 & 47,3 & 90,5 & 75,4 & 131 & 11,8 & 65,8 & 122 & 46,6 & 55,7 & 72,9 \\
\hline 1988 & 44,1 & 47,2 & 93,3 & 77,7 & 132,4 & 9,9 & 66,1 & 120,4 & 42,9 & 50,3 & 75,2 \\
\hline 1989 & 43 & 47,4 & 96 & 77,9 & 128,4 & 8,5 & 65,6 & 110,1 & 44,2 & 45,1 & 72 \\
\hline 1990 & 43,6 & 46,6 & 98,6 & 78,3 & 127,3 & 7,3 & 66,4 & 103 & 44,5 & 42,8 & 68,2 \\
\hline 1991 & 46,2 & 47,2 & 101,2 & 78,4 & 129,4 & 6,9 & 66,7 & 102,8 & 45,6 & 43,8 & 64,7 \\
\hline 1992 & 48,7 & 47,5 & 103,9 & 79,5 & 129,6 & 6,4 & 65,8 & 100,4 & 46,4 & 45,6 & 62,7 \\
\hline 1993 & 48,2 & 45,4 & 119,4 & 81,1 & 137,9 & 7,6 & 80,1 & 97,5 & 60,5 & 48,3 & 67,2 \\
\hline 1994 & 50,4 & 48,3 & 125,4 & 77,6 & 136 & 7,37 & 76 & 91,5 & 63,1 & 50,2 & 69,5 \\
\hline 1995 & 58,1 & 52,4 & 124,7 & 79,1 & 133,5 & - & 72 & 86,3 & 65,7 & 54 & 70,7 \\
\hline
\end{tabular}

Source: Main Economic Indicators, OECD

Summarizing, the descriptive statistics support the thesis that the EMS has helped to reduce inflation and a considerable improvement has been observed in the convergence of monetary variables. On the contrary, the behavior of the fiscal sector variables has not shown convergence but rather divergence. 


\section{The Unemployment-Inflation Trade - Off}

The data presented in the previous section showed that the EMS has been followed by a disinflationary process. Nevertheless, the movement towards lower inflation rates along the 1980 s seems to be a general process and not necessarily a particularly phenomenon of the European countries, and even more the costs of disinflation seem to have been significantly higher than in non- EMS countries. In general, disinflation policies lead to temporary increases in unemployment. However, the most puzzly feature is the fact that EMS and non- EMS countries have experienced both: during the 1980 's, a very sharp reduction of inflation rates, but a very different behavior of rates of unemployment. While the non- EMS countries were able to bring about a reduction in unemployment rates from 1986 onwards, the EMS countries were not.

Figure 3.3.6

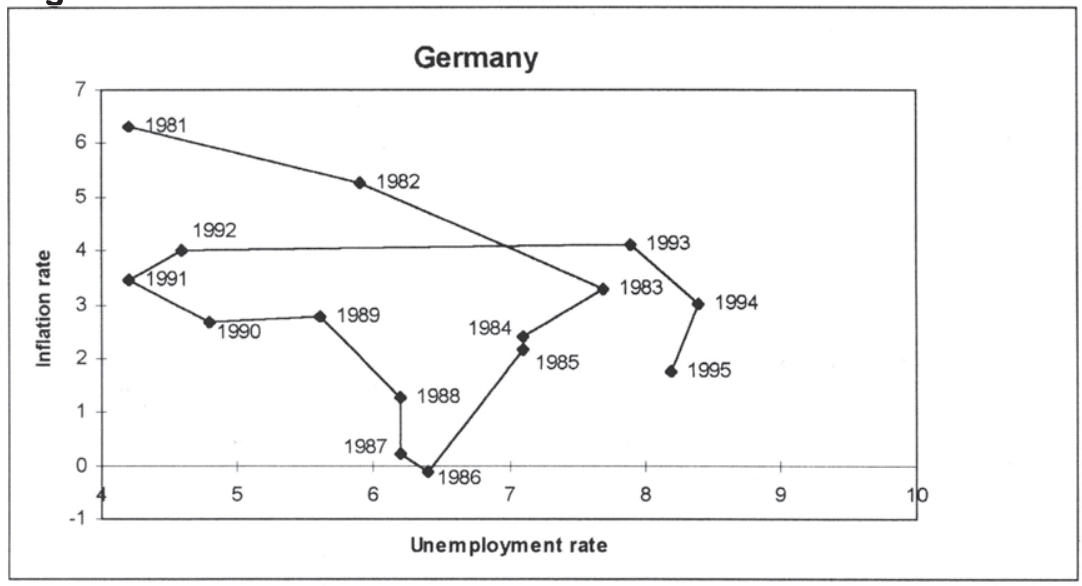

Source: Main Economics Indicators, OECD. ${ }^{165}$

Figure 3.3.6 depicts inflation and unemployment in Germany. Between 1980 and 1983 there was a trade-off between inflation and unemployment. From 1983 to 1987 less unemployment goes together with lower inflation, and finally from 1987 to 1993 the Phillips curve appears again. Denmark shows a similar. (See figure 3.3.9). The curve of France (Fig. 3.3.10) shows from 1980 to 1986 a clear Phillips curve, then from 1987 to 1990 lower inflation and lower unemployment, and finally from 1990 to 1993 the typical Phillips curve behavior again. The figure 3.3.7 (United Kingdom) shows a Phillips curve with two breaks along the whole period. ${ }^{166}$ Belgium (Fig- 3.3.8) shows a sharp decrease in inflation from 1980 to 1986 at relatively lower cost in terms of

\footnotetext{
${ }^{165}$ It considers only West Germany.

${ }^{166}$ The United Kingdom is probably the European country that presents the most deregulated labor market.
} 
unemployment, from 1987 to 1991 lower inflation is accompanied by high unemployment.

Figure 3.3.7

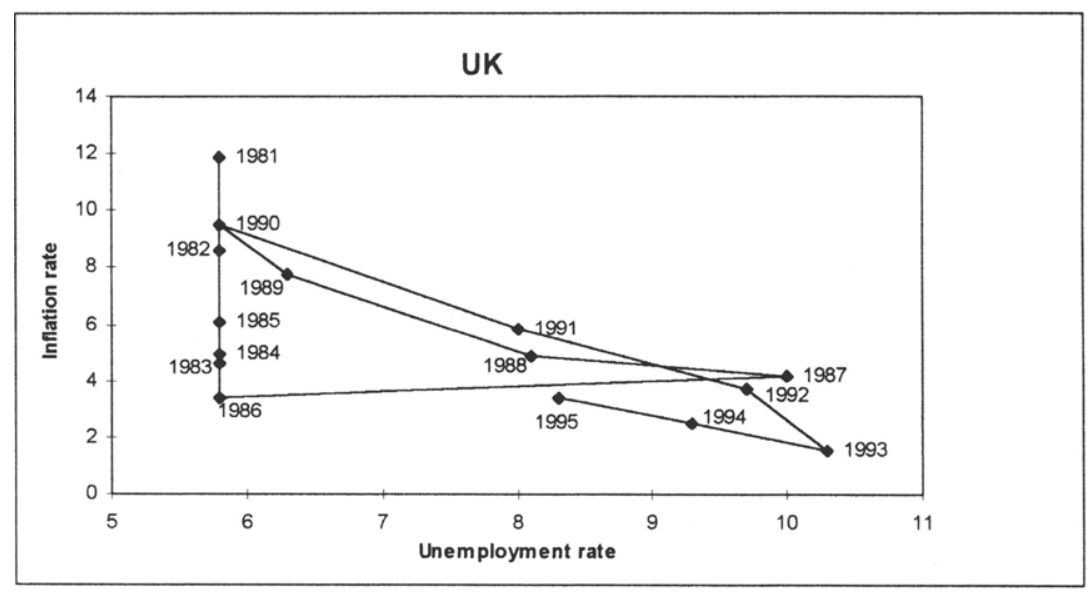

Source: Main Economics Indicators, OECD.

\section{Figure 3.3.8}

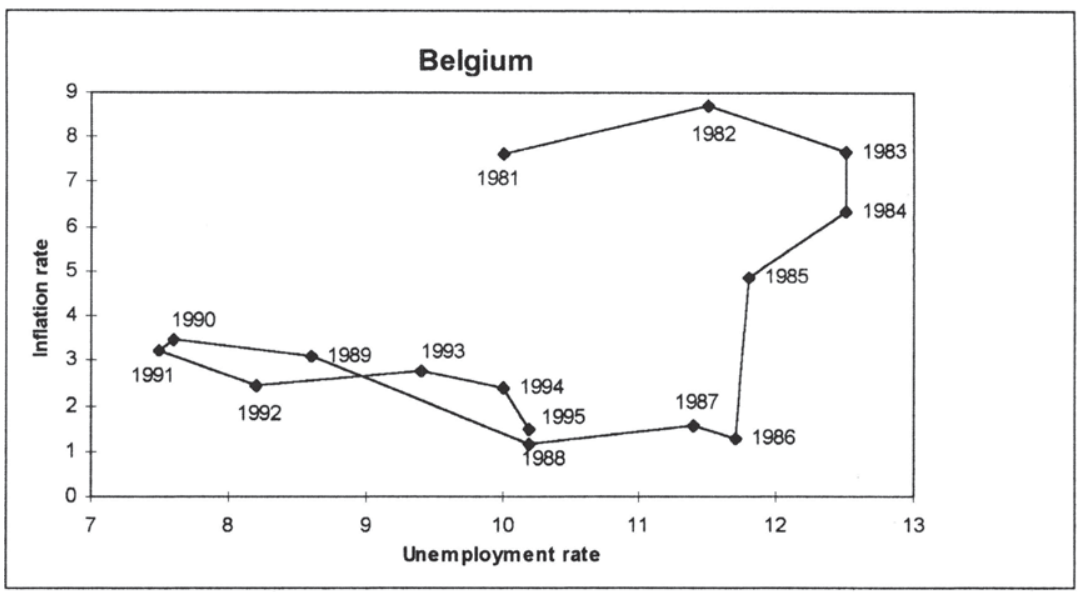

Source: Main Economics Indicators, OECD. 
Figure 3.3.9

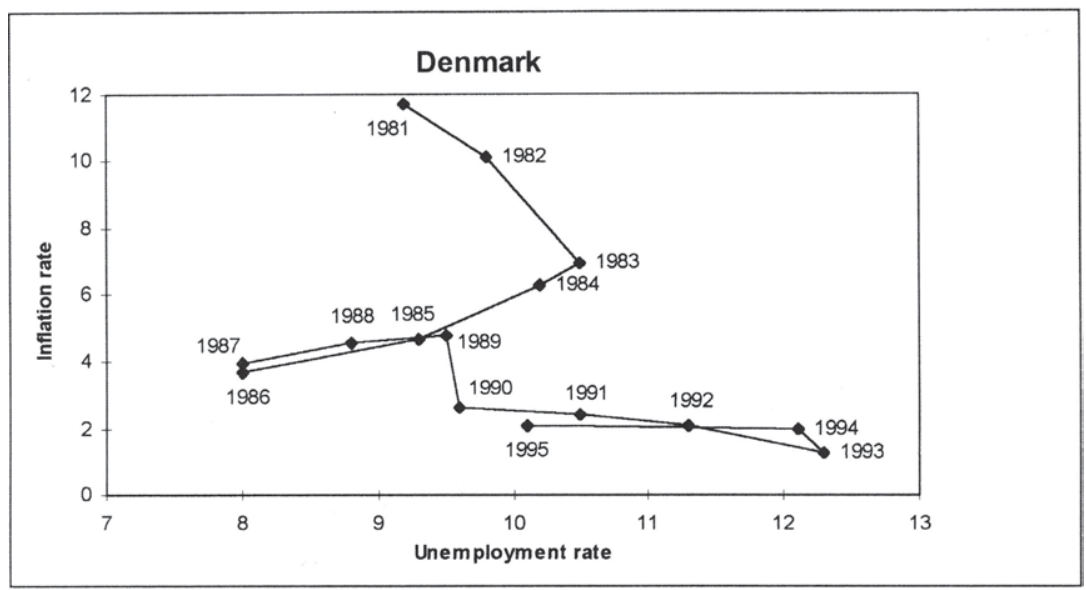

Source: Main Economics Indicators, OECD.

Figure 3.3.10

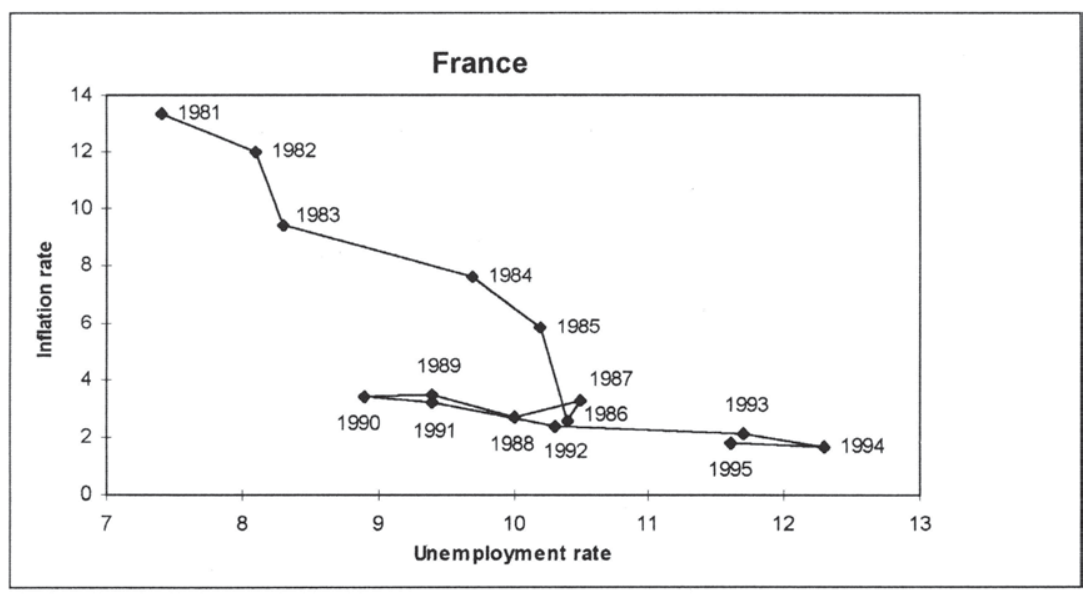

Source: Main Economics Indicators, OECD. 
Figure 3.3.11

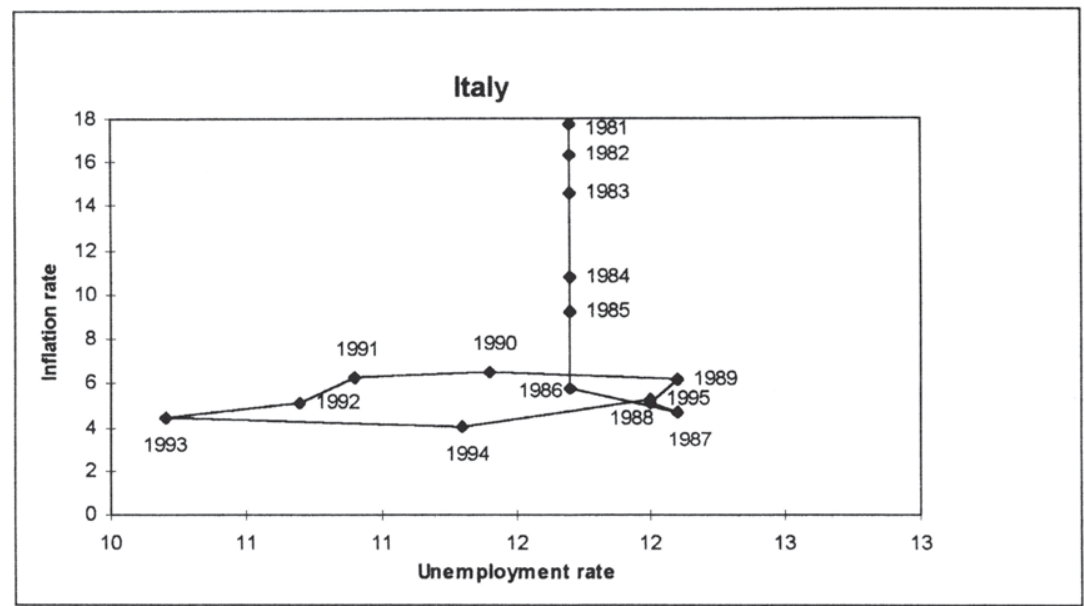

Source: Main Economics Indicators, OECD.

Figure 3.3.12

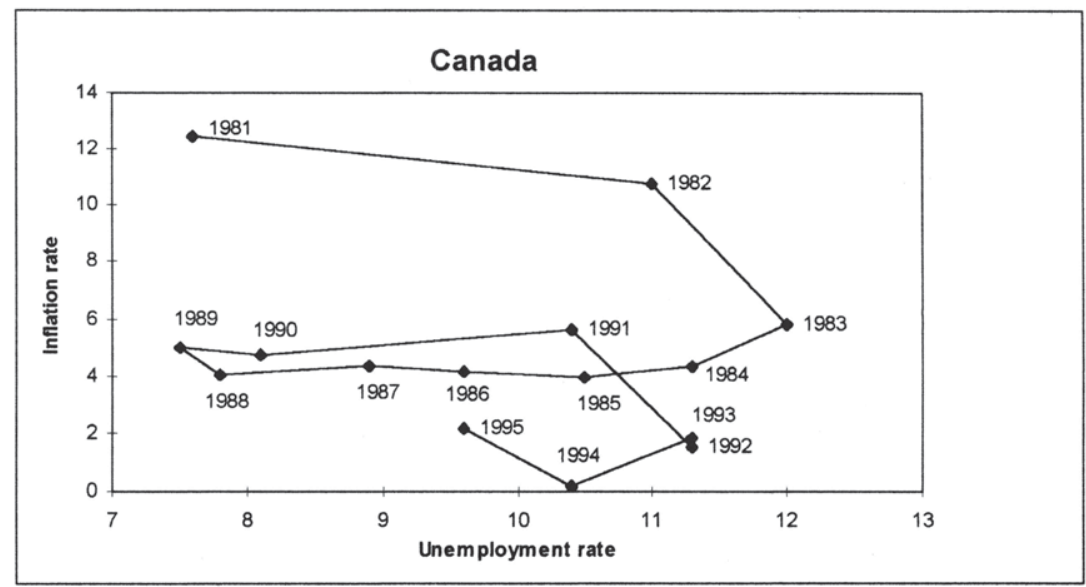

Source: Main Economics Indicators, OECD. 


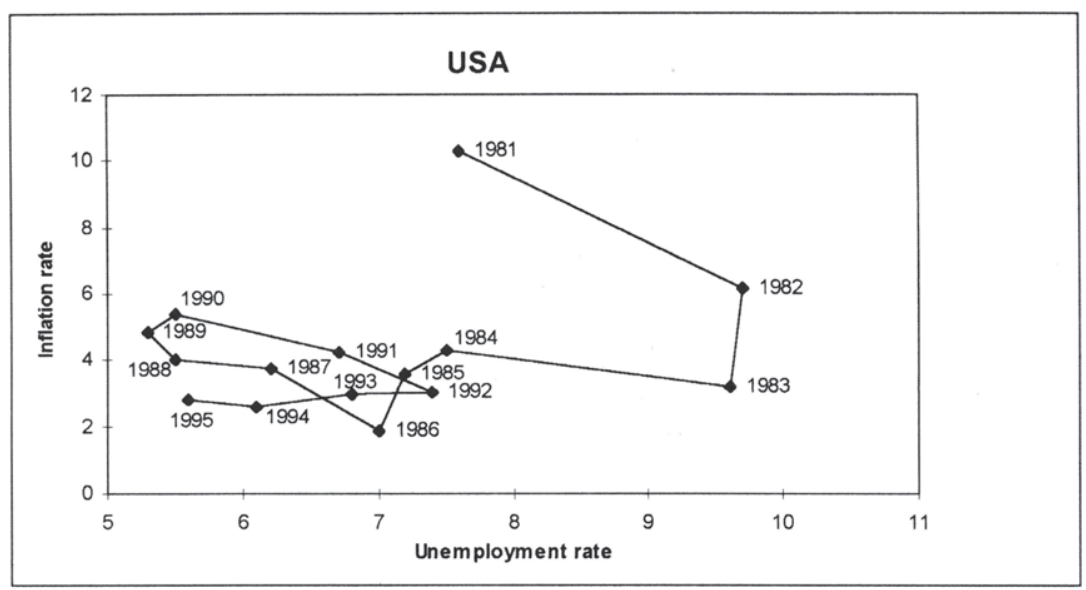

Source: Main Economics Indicators, OECD.

Italy (figure 3.3.11) shows a vertical Phillips curve from 1980 to 1995 . From 1987 the reduction in inflation was not followed by a reduction in unemployment. A quite different pattern is presented by the USA (figure 3.3.13); the reduction of inflation during the 1980s was associated with a sharp increase in unemployment. From 1983, however, there was a large reduction in unemployment without an increase in inflation. Canada (figure 3.3.12) shows a similar pattern than USA. Therefore, from the observation of the Phillips curve of the respective countries, it does not seem that the EMS helped to reduce the costs of disinflation, as most authors argued. De Grauwe $(1989$ a , 1989,b) provides some explanations for this puzzle. At the first stage, EMS would have provided little disciplining effect because there was a lack of credibility. Countries like France and Italy devalued very often during the first phase of the EMS, and so they could import very few inflationary discipline from Germany. In the second part of the 1980s France and (to a less degree Italy) made it clear that they were committed to maintaining more rigid exchange rates with the low inflation country in the system. At this time, unemployment remained very high. The change in behavior helped to improve the credibility in the fixity of the exchange rate within the system. The governments demonstrated that they were giving priority to the inflation target even when unemployment was high.

The second explanation is due to supply-side effects. Labor rigidities play a more important role among European countries than among non- European countries (USA, Canada $)^{167}$. Therefore, the supply shocks during the early 1980 s induced an increase in

${ }^{167}$ The European countries showed important rigidities in their labors markets due to a higher degree of labor unionization. In contrast, labor markets in USA and Canada are much more flexible. 
the natural level of unemployment and labor market rigidities did not permit the inflation-unemployment trade-off to move inwards.

Summarizing, the EMS showed a relatively good performance in achieving price stability during more than 15 years, at least until the crisis of 1992. Although the first years were relatively turbulent, the situation was progressively improving and during the 80 s the European countries reached a reasonable degree of inflation convergence that led the countries to attempt to go towards greater integration by eliminating capital controls and agreeing upon the way to achieve the single European currency. The fact that the EMS was working better than expected induced many to think that the transition to monetary union would be smoothly and costless. The elimination of capital controls without having achieved monetary, and especially fiscal co-ordination, plus the doubts about the degree of political support for the single currency, led to financial and monetary instability, accelerating the crisis in 1992 that induced the commissioners to adopt the decision to move towards an EMS with wider bands.

Nevertheless, it becomes less clear that the EMS had helped to improve the fiscal parameters. Even more, it seems that not only has not induced a convergent behavior on the fiscal side, but a divergent one worsening over time. In the same way, it is not clear that the EMS has contributed to lowering the costs of disinflation. Unemployment rates have increased across European countries since the 1980s while other non-European countries were able to reduce both inflation and unemployment rates. 


\subsection{The Effect of the EMS on the Dynamic Exchange Rate}

\section{Responses to Nominal and Real Shocks: An Econometric Analysis}

Although many economists have been interested in the real effect of alternative nominal exchange rate regimes, there exists no agreement among them about how the way in which exchange rate variations affect macroeconomic variables such as output and inflation. The controversy as to whether nominal disturbances have real effects has not been resolved, facing in the theoretical world of open-macroeconomics marketclearing approaches against models with inertia and nominal rigidities. ${ }^{168}$ Baxter and Stockman (1989) for example, investigated the behavior of real macroeconomic variables across alternative nominal exchange rate regimes. The evidence from the comparison of the Bretton Woods system with the flexible exchange rate regime suggested that a nominal exchange rate regime might be associated with significant real effects. Mussa (1986) analyzed the behavior of different price indexes in different time periods in several countries. He found relative prices to be more stable during periods of relatively fixed exchange rate regimes, and his evidence supported a sticky price model in the tradition of Dornbusch (1976).Stockman (1987) developed a general equilibrium model and pointed out that the collapse of Bretton Woods could reflect not the importance of sluggish price adjustment, but rather the influence of real shocks with large permanent components. The inability of economists to converge on a common model that allows the explanation of short run variability led to the development of atheoretic research, focusing directly on correlations in the data through time series methods. Examples of this style of work are provided by Baxter and Stockman (1989), Bordo (1992), and Eichengreen (1992). In the previous section, the EMS performance with respect to price stability and unemployment was analyzed; in contrast in this part 3.4, I will focus on other aspects that are relevant in any exchange rate regime. By means of econometric instruments, I will attempt to identify the sources of nominal and real exchange rate fluctuations among seven European countries (Belgium, Denmark, France, Germany, Italy, Netherlands and United Kingdom $)^{169}$ under different exchange rate arrangements. The main objective is to study whether the movement towards a more fixed exchange rate agreement, such as the EMS, has induced some changes in the dynamic response to nominal and real shocks. The methodology adopted is as follows, first, I estimate the two equation Mundell-Fleming-Dornbusch model under rational expectations, which was presented in chapter 2, on nominal and real exchange rates. I contrast the theoretical results predicted by the model with those provided by the data, and analyze whether the results are consistent with the model. I then inquire into the relative importance of nominal and real disturbances in periods of relatively fixed and relatively flexible exchange rate regimes. I examine not only the impact ef-

\footnotetext{
${ }^{168}$ See Bayoumi and Eichengreen (1992).

${ }^{169}$ The selection of these countries is based on the fact that they are representative of the different behaviors and that most of the time they have belonged to both exchange rate agreements (Snake and EMS).
} 
fect of disturbances, but also whether the economy's subsequent adjustment to shocks differs depending on the exchange rate regime. In the following analysis, I will focus on the Snake as a proxy of a flexible exchange rate regime and on the hard-EMS as a proxy of a fixed exchange rate regime. ${ }^{170}$ This part should thus be interpreted as a direct extension and application of the theoretical model presented in Chapter 2.

\section{Stylized Facts}

There is an extensive literature analyzing the effect of EMS on member countries on the basis of different criteria, among others Giavazzi and Giovannini (1989), Gros and Thygesen (1992), Giavazzi (1989), Fratianni and von Hagen $(1990)^{171}$. There seems to be considerable evidence that the EMS has reduced the variability of real and nominal exchange rates among member countries; at least nominal variables seem to have reached some convergence ${ }^{172}$. Basically, inflation rates have approached to the German level ${ }^{173}$. Although by simply observing the raw data it is already possible to derive some conclusions, that is not sufficient to enable us to analyze whether the introduction of the EMS has affected the response to different shocks impacting upon the domestic economies.

I will present first some descriptive statistics that allow the variability of nominal and real exchange rates of European economies along different exchange rate arrangements to be compared. The analysis covers the Bretton Wood period (1960-1972), the Snake (1971-1979) and the introduction of the EMS in 1979.

As it was shown in section 3.2, the EMS has not been an homogenous system over the years. In the early period the realignments occurred so often that it was not so very different from the Snake. The system evolved towards a more fixed regime along the years. Therefore, I will consider three periods according to the degree of flexibility: the flexible EMS (1979 -1987), the hard EMS or EMS without realignments (1987-1992) and EMS post-crisis or EMS with wide bands (1992-1994). The monthly data covers the period from 1960.05 to 1994.05 and was obtained from the CD Rom International Statistics Yearbook and corresponds to the variables nominal exchange rates and CPI (consumer price index) from OECD sources. The countries considered are: Belgium,

\footnotetext{
${ }^{170}$ As it has been described in the previous section, neither of the two systems has been either absolute fixed or absolutely flexible. The EMS also constitutes a floating system but the variability is much more limited. Because empirically there has never existed an absolute flexible nor an absolutely fixed exchange rate regime, the author believes that Snake and EMS can be interpreted as a good proxy of a floating and fixed exchange rate regime. Bayoumi (1989) adopts the same interpretation.

${ }^{171}$ For a survey see Haldane (1991).

${ }^{172}$ The evidence on effective exchange rate indices is more mixed. See Artis and Taylor (1988).

${ }^{173}$ Compare with section 3 .
} 
Denmark, France, Italy, Netherlands, and United Kingdom, whose exchange rates have been calculated with respect to the DM.

$E=$ domestic currency/DM and $\theta=E P^{*} / P$, being $E$ the nominal exchange rate, $\theta$ the real exchange rate, $\mathrm{P*}$ German $\mathrm{CPI}, \mathrm{P}$ domestic $\mathrm{CPI}$.

\section{Variability of Nominal and Real Exchange Rates}

The most straightforward way to measure the impact of the EMS on exchange rate variability is to compare the short-run intra-EMS exchange rates before and after the introduction of the EMS.

Fig. 3.4.1 depicts nominal and real exchange rates from 1960.05 to 1994.04 for the EMS countries. From the simple visual observation, it is possible to conclude that the variability of both nominal and real exchange rates was much greater during the Snake than under the EMS. 
Figure 3.4.1

Nominal and Real Exchange rates

1960.05-1994.04

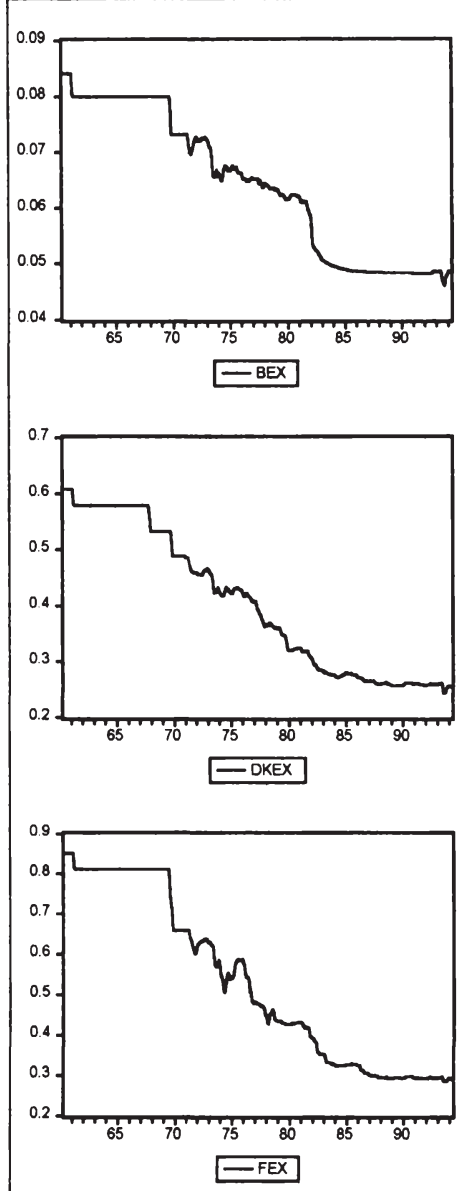

Bex: Nominal exchange rate Belgium Dkex: Nominal exchange rate Denmark Fex: Nominal exchange rate France
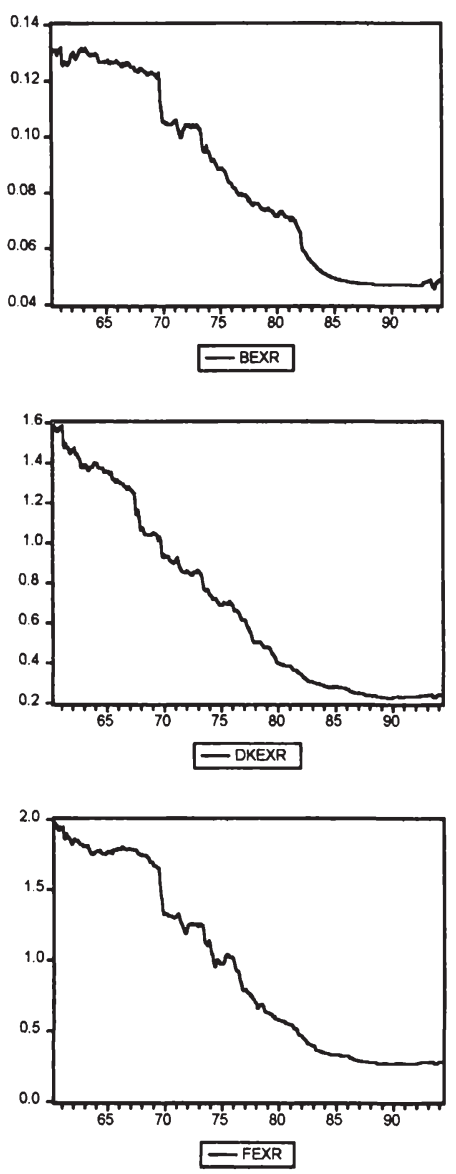

Bexr: Real exchange rate Belgium Dkexr: Real exchange rate Denmark Fexr: Real exchange rate France 


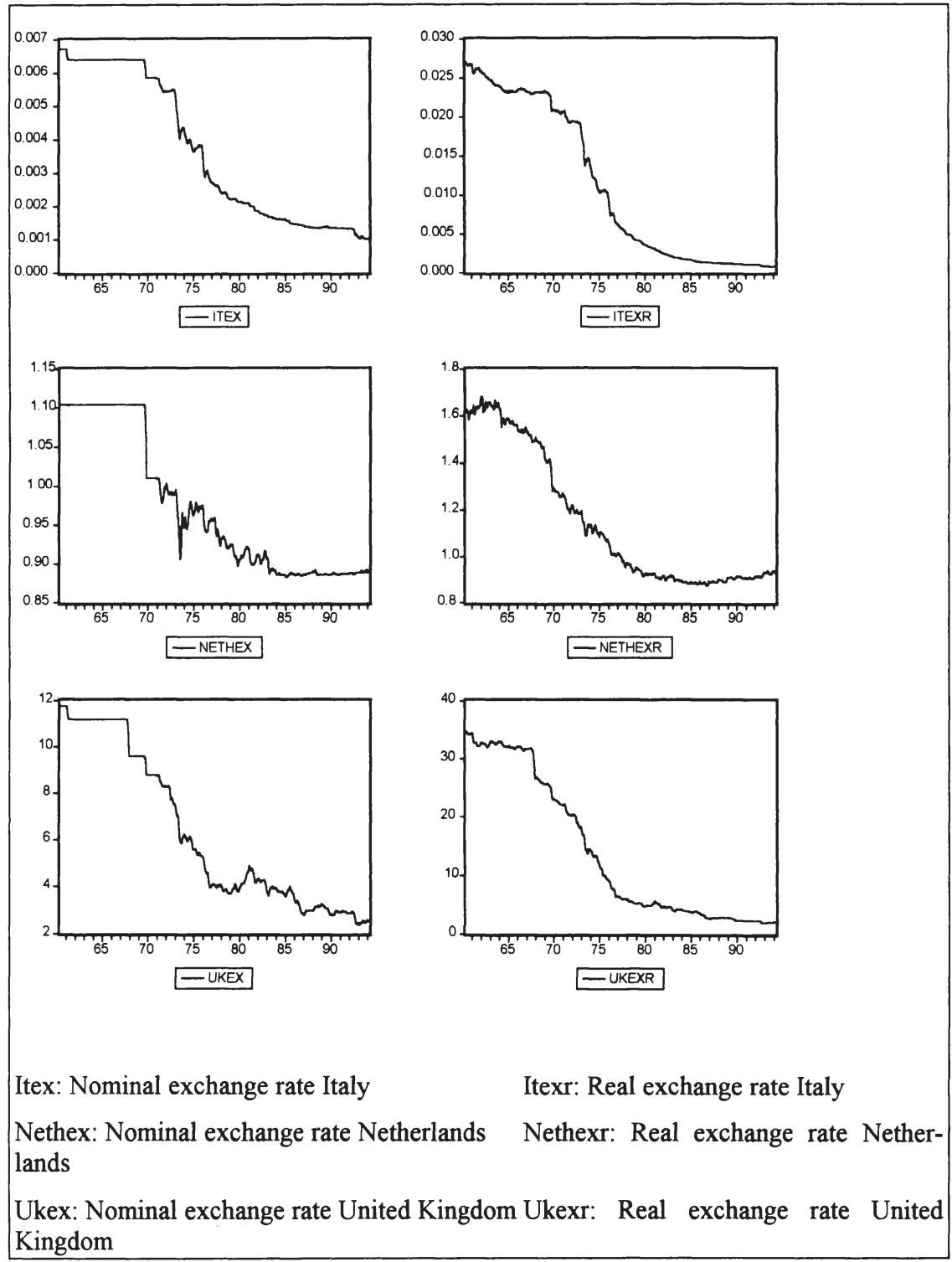

Note: All exchange rates have been calculated with respect to the DM.

Source: International Financial Statistics, IMF 
I applied the standard deviation of monthly percentages changes as a measure of the exchange rate variability. ${ }^{174}$ Table 3.4.1 depicts the variability of nominal exchange rates for the whole period and for the subperiods 1960-1972, 1972-1979, 1979-1992 and 1992-1994; table 3.4.2 shows the same issues in the case of real exchange rates. In most cases, the variability in the first stage of EMS was not significantly smaller than during the Snake. Italy and the UK showed the highest nominal (2.5 and $2.4 \%)$ and real (2.8 and $2.5 \%)$ exchange rate variability during the Snake. Nevertheless, there is a considerable reduction after the Basle-Nyborg agreement, in the period 1987.031992.09, until the September crisis, when the variability again increased and was even larger than during the Snake period for some countries (Belgium, Denmark, Italy and United Kingdom). Indeed, and in the last two cases was remarkably high (Italy 3.2 and United Kingdom 3.1) for nominal and real exchange rate respectively. In table 3.4.3 the correlation coefficients between the nominal and the real exchange rate are shown for the period 1973.03-1979.03 and 1979.03-1994.04. The coefficient is high in all cases and reaches a value larger than 0.85 , except for Netherlands, where it is 0.68 and 0.58 for the Snake and EMS respectively. A high correlation coefficient indicates a symmetrical behavior of nominal and real exchange rate as signal of absence of significant overvaluation/undervaluation. In most cases the coefficient is even higher during the EMS except for Italy, Denmark, and the United Kingdom. ${ }^{175}$

\footnotetext{
${ }^{174}$ The empirical literature considered several measures of exchange rate variability. Gros and Thygesen (1992) consider that the ideal measure would be the variability (standard deviation of variance) of unexpected exchange rate changes. But as Gros himself recognizes, the measure of unexpected changes requires exchange rate predictions, which are extremely difficult to form. Meese and Rogoff (1983) argue that most changes in exchange rates cannot be predicted; in this sense the standard deviation of monthly percentage changes represents a good proxy and for this reason is widely applied. See, among others, Ungerer (1986), Emerson (1991) and Weber (1990).

${ }^{175}$ In this sense, this empirical evidence supports the thesis that the EMS has not artificially reduced the exchange rate variability.
} 


\subsubsection{Model Specification Analysis}

\section{Univariate and Bivariate Analysis}

In order to investigate the behavior of the series under analysis, previous to the construction of the VAR (Vector Autoregression) model, I will perform the following statistical analyses, unit root test, test for cointegration, and Granger Causality test.

\section{Unit Root Tests}

The unit root tests, which were developed in the 1980s, have attracted most econometricians' attention, becoming very popular in the last decade ${ }^{176}$. The test attempts to identify the order of integration of each variable (assuming that each variable can be transformed into a stationary one). The unit root test was developed in response to the findings of Granger and Newbold (1976), who demonstrated, by carrying Monte Carlo simulation experiments, that two independent random walk series might show a very high $\mathrm{R}^{2}$ and highly significant $\mathrm{t}$ statistics, though there is no economic relation between them. In this way, they coined the concept of "spurious regressions" to explain this phenomenon.

Nelson and Plosser (1982) found that most of the economic series are trended and therefore contain an unit root. The unit root concept can be explained as follows:

Given the model:

$$
\mathrm{y}_{\mathrm{t}}=\alpha \mathrm{y}_{\mathrm{t}-1}+\varepsilon_{\mathrm{t}}
$$

with $\varepsilon_{\mathrm{t}}$ white noise, and $\alpha=1$, the estimation of (3.4.1.1) by Ordinary Least Square (OLS) is biased towards zero and the time series $y_{t}$, represents a random walk and can be expressed as follows:

$$
\Delta \mathrm{y}_{\mathrm{t}}=\varepsilon_{\mathrm{t}}
$$

However, if $|\alpha|<1$ the process generating $y_{t}$ is integrated of order zero and therefore, stationary, but the estimation is also biased if $\alpha$ not being one is close to one. ${ }^{177}$

This is the reason why equation (3.4.1.1) cannot be estimated by OLS and the hypothesis $\alpha=1$ cannot be tested by a Student t. Dickey and Fuller (1979) proposed the so-called DF (Dickey Fuller) test or unit root test, which tests whether $\alpha=1$. The test is based on following estimation:

$$
\mathrm{y}_{\mathrm{t}}=(1+\delta) \mathrm{y}_{\mathrm{t}-1}+\varepsilon_{\mathrm{t}}
$$

\footnotetext{
${ }^{176}$ See Diebold and Nerlove (1990) for a survey.

${ }^{177}$ See Maddala (1992) and Charemza (1992).
} 


$$
\Delta \mathrm{y}_{\mathrm{t}}=\alpha \mathrm{y}_{\mathrm{t}-1}+\varepsilon_{\mathrm{t}}
$$

and $\alpha=(1+\delta)$

If $\delta$ is negative then $\alpha<1$, the DF test consists of testing the negativity of $\delta$ within an OLS regression such as (3.4.1.4). The null hypothesis is $\delta=0$ and the alternative $\delta<0$. A rejection of the null hypothesis in favor of the alternative implies $\alpha<1$ and the time series $y_{t}$ is considered integrated of order zero and therefore stationary. Because equation (3.4.1.4) represents a regression of stationary time series $I(0)$ on a non-stationary time series $\mathrm{I}(1)$ the $\mathrm{t}$ Statistic has not a limiting normal distribution, therefore Fuller (1976) constructed a new table of limit values. There are also other tables like Guilkey and Schmidt (1989), and MacKinnon (1991), though all of them are simulated and not derived analytically. The Dickey-Fuller test can also be used for testing the order of integration for a variable generated as a stochastic process with a drift and/or a stochastic trend. ${ }^{178}$

The weakness of the original Dickey-Fuller test is that it does not take into account the possibility of autocorrelation in the error term $\varepsilon_{t}$. If the error term is not white noise, then the OLS applied to equation (3.4.1.4) are not efficient. Dickey and Fuller (1981) developed the so-called Augmented Dickey-Fuller test (ADF), which is widely regarded as being the most efficient test from among the simple tests for integration and is the one most frequently employed. ${ }^{179}$

The test consists in running a regression of the first difference of each series against the other series lagged $k$ times. The method analyzes if the coefficient $y_{t-1}$ in the regression is significantly different from zero. If this is the case, then the null hypothesis is rejected and the alternative hypothesis ( $y_{t}$ is stationary) is accepted. On the contrary, if the null hypothesis is accepted the series is considered to be a unit root. The critical values are the same as for the DF test.

$$
\Delta \mathrm{y}_{\mathrm{t}}=\delta \mathrm{y}_{\mathrm{t}-1}+\sum \delta_{\mathrm{i}} \Delta \mathrm{y}_{\mathrm{t}-\mathrm{i}}+\varepsilon_{\mathrm{t}}
$$

Tables 3.4.4, 3.4.5 and 3.4.6 report the values corresponding to the ADF test for all the countries for the periods 1973.03-1994.04, 1973.01-1979.03 and 1983.01-1992.09 for the nominal and real exchange rate respectively.

By considering the whole period 1973.03-1994.04, all nominal exchange rates are nonstationary at $1 \%$ significance except for Italy and United Kingdom. The real exchange rates are stationary for Denmark, France, Italy, Netherlands and United Kingdom (see table 3.4.4). For the snake period 1973.03-1979.03 all nominal and real exchange rates behave as unit root. (see table 3.4.5). For the hard-EMS all nominal exchange rates have an unit root except for Netherlands, and all the real exchange rates are stationary at $10 \%$ except for Belgium.

\footnotetext{
${ }^{178}$ In this case the equation would look like: $\Delta y_{t}=\mu+\delta y_{t-1}+\varepsilon_{t}$ and $\Delta y_{t}=\mu+\eta t+\delta y_{t-1}+\varepsilon_{t}$.

${ }^{179}$ Recently Phillips (1986) suggested two other test statistics the $Z_{\alpha}$ and $Z_{t}$ which are based in non-parametric modifications of the Dickey Fuller test.
} 


\section{Test for Cointegration}

Granger (1986) and Engle and Granger (1987) developed the concept of Cointegration, which addresses the possibility of integrating short-run dynamic with long-run dynamic. They found that two non-stationary series would be cointegrated if a stable relationship between them in the long-run exits. This concept became very important for the modeling of time series, because if two series are cointegrated, they can be represented as an error correction model (ECM) and viceversa. ${ }^{180}$ Two non-stationary series, integrated of order one $I(1) x_{t}$ and $y_{t}$ are cointegrated if there exists a $\beta$ such that $y_{t}-\beta x_{t}$ is $\mathrm{I}(0)$ (stationary) and then $x_{t}$ and $y_{t}$ are $C I(1,1)$ which means that the regression equation:

$$
y_{t}=\beta x_{t}+u_{t}
$$

makes economic sense because both variables do not drift too far apart from each other over time; and there is a long-run equilibrium relationship between them; and thus the regression is not spurious. Initially, in order to test for cointegration the ADF test was applied to the residuals of the cointegrated equation. This method, however, did not allow for the existence of more than two cointegrated variables to be tested. Johansen (1988) and Johansen and Juselius (1990) developed a method that allows the number of cointegrating equations, which is called the cointegrated rank, to be determined. The method applies the maximum-likelihood procedure to determine the presence of cointegrating vectors and allows for tests of hypotheses regarding elements of the cointegrating vector. The test is known as LR (Likelihood Ratio) test for cointegration. According to Dickey (1991) and Choudhry (1996) cointegrating vectors are obtained from the reduced form of a system in which all the variables are assumed to be jointly endogenous. Thus cointegration vectors cannot be interpreted as representing structural equations. However, cointegrating vectors may be due to constraints that an economic structure imposes on the long-run relationship among the jointly endogenous variables. Osterwald-Lenum (1992) provides the appropriate critical values required for these cointegration tests.

The results of the LR cointegration tests are reported in table 3.4.7. The test rejects the hypothesis of no cointegration vector in all cases, and for Denmark, France, and Netherlands, the test shows that there exist two cointegration vectors. However, by partitioning the sample into the Snake period 1973.03-1979.03, the EMS period 1982.031992.09, the hard EMS 1987.03-1992.09 and EMS wide-bands 1993.08-1994.04 both variables are not cointegrated. ${ }^{181}$ Note that this finding implies that there exists a long-

\footnotetext{
${ }^{180} \mathrm{ECM}$ models and therefore, the cointegration concept are very useful in economics because they allows for a good adjustment if a long-run stable relationship exists together with sluggish adjustments in the short-run. This concept is really appealing to economists given the fact that it seems to be a very commonly assumed behavior in economic theory (sticky prices assumption, etc).

${ }^{181}$ This is reasonable because the cointegration concept always applies in the long run. When partitioning the series into sub-periods, the series is then not long enough for the cointegration relation can apply.
} 
run relationship between nominal and real exchange rate over the whole period although different exchange rate agreements were in force. ${ }^{182}$

\section{Granger Causality Test}

Granger (1986) and Engle and Granger (1987) developed the concept known as "Granger causality" that takes into consideration the information provided by the cointegrated properties of variables. This test considers the possibility that the past level of a variable $\left(e_{t}\right)$ explains the current changes in the other variable or variables $\left(r_{t}\right)$ even though the past changes in $e_{t}$ do not.

Given a VAR representation of a stationary bivariate series $e_{t}$ and $r_{t}$ then;

$$
\pi(\mathrm{L}) \mathrm{z}_{\mathrm{t}}=\varepsilon_{\mathrm{t}} \text { and } \mathrm{z}_{\mathrm{t}}=\left(\mathrm{e}_{\mathrm{t}}, \mathrm{r}_{\mathrm{t}}\right)
$$

where $\pi_{\mathrm{ii}}$ is a matrix $\mathrm{nxn}, \mathrm{z}_{\mathrm{t}}$ is a vector $1 \times \mathrm{xn}_{\mathrm{t}}$ is a vector $1 \mathrm{xn}$ and $\mathrm{L}$ represents the lag operator. ${ }^{18}$

then , $\pi(\mathrm{L})=\mathrm{I}+\pi \mathrm{L}+\pi \mathrm{L}^{2}+\ldots$ can be expressed as:

$$
\left[\begin{array}{ll}
\pi_{11}(\mathrm{~L}) & \pi_{12}(\mathrm{~L}) \\
\pi_{21}(\mathrm{~L}) & \pi_{22}(\mathrm{~L})
\end{array}\right]\left[\begin{array}{l}
\mathrm{e}_{1 \mathrm{t}} \\
\mathrm{r}_{1 \mathrm{t}}
\end{array}\right]=\left[\begin{array}{l}
\xi_{1 \mathrm{t}} \\
\xi_{2 \mathrm{t}}
\end{array}\right] \text {, and } \varepsilon_{\mathrm{t},}=\left[\begin{array}{l}
\xi_{1 \mathrm{t}} \\
\xi_{2 \mathrm{t}}
\end{array}\right]
$$

If $\pi_{11}(\mathrm{~L})=0 e_{t}$ cause $r_{t}$ and if $\pi_{21}(\mathrm{~L})=0 \mathrm{r}_{\mathrm{t}}$ cause $\mathrm{e}_{\mathrm{t}}$.

I performed the Granger causality test, which consists in regressing $e_{t}$ on two lags of itself and two lags of $r_{t}$, and by regressing $r_{t}$ on two lags of itself and two lags of $e_{t}$. An F statistic is performed to establish the validity of the hypothesis. As table 3.4.8. shows, it is not possible to conclude which variable Granger causes the other. There seems to be a feedback relationship between nominal and real exchange rate.

\footnotetext{
${ }^{182}$ Lastrapes (1992) analyzes the nominal and real exchange rates with respect to the dollar over the flexible post-Bretton Woods period. He found that in all cases nominal and real exchange rates were not cointegrated. It is possible to interpret this finding so as that somehow the underlying exchange rate agreement induce a coordination of nominal and real exchange rates, even when not perfect, at least in the long run.

${ }^{183} \mathrm{Lx}=\mathrm{x}_{\mathrm{t}-1}$ and $\mathrm{L}^{2} \mathrm{x}_{\mathrm{t}}=\mathrm{x}_{\mathrm{t}-2} \ldots \mathrm{L}^{\mathrm{n}}=\mathrm{x}_{\mathrm{t}-\mathrm{n}}$.
} 


\subsubsection{VAR Analysis}

\section{The Methodology}

In order to analyze the relative magnitude and sources of exchange rate fluctuations under different exchange rate arrangements, I will study the relative importance of nominal and real shocks, and the dynamic response of nominal and real exchange rates to the shocks impacting upon the economies by estimating a VAR model. ${ }^{184}$

I will follow to some extent the methodology applied by Lastrapes (1992), Clarida and Gali (1994), Mark (1990), and Jordan and Lenz (1995), which facilitates the empirical analysis of sources of fluctuations of time series. In contrast to the papers mentioned above, I will study the sources of fluctuation in real and nominal exchange rates by concentrating on the comparison between the Snake and the EMS period. As usually assumed in the literature, I will consider that the economies, and consequently the exchange rates, are affected by two kinds of shocks: real and nominal. Typical real shocks are changes in resource endowments, technological shocks or fiscal policies. An example of a nominal shock is a change in money growth.

Both variables, nominal and real exchange rates, present a joint stochastic behavior that can be represented by a two variables VAR process.

The VAR methodology was originally developed by Sims (1980) and has become a popular tool in empirical macroecomomics. A VAR system may be thought of as a specific reduced form of a set of dynamic simultaneous equations describing the economy $^{185}$. Initially, interest in VAR methodology arose because of the inability of economists to agree on the economy's true model. VAR users thought that important dynamic characteristics of the economy could be revealed by these models without imposing structural restrictions stemming from a particular economic theory. In its most unrestricted form, such a system expresses each variable of interest as a function of all variables, believed to be interacting, lagged $t$ times.

${ }^{184}$ Other authors have performed the analyses taking into account real variables. See Bayoumi and Eichengeen (1994): they considered consumer prices indexes and output. Blanchard and Quah (1989) considered unemployment rates and a consumer prices index.

${ }^{185}$ See Sims (1980), Genberg (1985), Keating (1992), Genberg, Salemi, Swoboda (1984), Sargent (1979), Maddala (1992), Charemza (1992).

${ }^{186}$ In practice the selected variables are those that the economist believes concentrate most information about other variables

${ }^{187}$ The Akaike information criterion (AIC) constitutes a guide to the selection of a number of terms in an equation. It places a penalty on extra coefficients. Therefore, the length of a lag distribution can be determined by choosing the specification with the lowest value of AIC. It can be applied to any model that can be estimated by the method of maximum-likelihood. It consists in minimizing the following expression: $-2 \log \mathrm{L} / \mathrm{n}+2 \mathrm{k} / \mathrm{n}$ where $\mathrm{k}$ is the number of parameters in L. The Schwarz criterion is an alternative to the AIC based on the same interpretation. See Maddala (1992), Griffiths, Hill and Judge (1993). 
No a priori restrictions have been imposed which would prevent a specific variable from influencing others directly. Therefore, the data are allowed maximum freedom to determine the dynamic relationships between the variables in the model.

A two-variables VAR system lagged twice can be expressed as follows:

$$
\begin{aligned}
& e_{t}=a_{11} e_{t-1}+a_{12} e_{t-2}+b_{11} r_{t-1}+b_{12} r_{t-2}+u_{e t} \\
& r_{t}=a_{21} e_{t-1}+a_{22} e_{t-2}+b_{21} r_{t-1}+b_{22} r_{t-2}+u_{r t}
\end{aligned}
$$

where $e_{t}$ is the nominal exchange rate and $r_{t}$ is the real exchange rate.

In the equational system presented above, each variable of interest depends on its own lagged value as well as on the lagged value of the other ones. An error term $u_{t}$ is also present and represents those influences that cannot be accounted otherwise than by the model. Thus, $u_{e t}$ is thought as the current innovation of $e_{t}$ and constitutes the part of $e_{t}$ that could not have been predicted from the history of all variables of the system. Equation (3.4.2.1) and (3.4.2.2) form the so-called autoregressive representation of the system of order $p, A R(p){ }^{188}$ and can be applied to test hypotheses about the dynamic relationships between the variables.

Equations (3.4.2.1) and (3.4.2.2) can also be represented in a compact way as a vector, where $z_{t}=\left(e_{t}, r_{t}\right)$ is a $n x 1$ vector, $A$ is the matrix of coefficients $n \times n, L$ represents the lag operator and $v_{t}=\left(u_{t t}, u_{r}\right) n \times 1$ represents the vector of innovations.

$$
\begin{aligned}
& \mathrm{z}_{\mathrm{t}}=\mathrm{A}(\mathrm{L}) \mathrm{z}_{\mathrm{t}}+\mathrm{v}_{\mathrm{t}} \\
& \mathrm{A}(\mathrm{L})=\mathrm{A}_{0}+\mathrm{A}_{1} \mathrm{~L}+\mathrm{A}_{2} \mathrm{~L}^{2} \ldots .+\mathrm{A}_{\mathrm{n}} \mathrm{L}^{\mathrm{p}}
\end{aligned}
$$

The equation (3.4.2.3) also constitutes an $\mathrm{AR}(\mathrm{p})$ and can be interpreted as determining the joint reaction of each of the endogenous variables of the matrix $z_{t}$ to the vector of shocks $v_{t}$ affecting the economy.

To study this reaction it is convenient to transform the system as a VMA(q) (vector moving average) representation, which implies expressing the matrix of variables $x_{t}$ as a function of the vector of residuals $\mathrm{v}_{\mathrm{t}}{ }^{189}$

A VMA(q) structure implies that the solution of each dependent variable will depend on the past values of all innovations. For example, the solution of $e_{t}$ will be:

$$
\begin{gathered}
e_{t}=h_{0} u_{e t}+h_{1} u_{e t-1}+h_{2} u_{e t-2}+\ldots h_{q} u_{e t-q \ldots . . .} u r t+\ldots \\
\ldots+c_{1} u_{r t-1}+c_{2} u_{r t-2} \ldots+c_{q} u_{r t-q} .
\end{gathered}
$$

By operating on (3.4.2.3)

$$
\begin{aligned}
& \text { (3.4.2.5) } \quad[\mathrm{I}-\mathrm{A}(\mathrm{L})] \mathrm{z}_{\mathrm{t}}=\mathrm{v}_{\mathrm{t}} \\
& \text { and }[\mathrm{I}-\mathrm{A}(\mathrm{L})]=\mathrm{B}(\mathrm{L})
\end{aligned}
$$

then,

$$
\mathrm{B}(\mathrm{L}) \mathrm{z}_{\mathrm{t}}=\mathrm{v}_{\mathrm{t}}
$$

\footnotetext{
${ }^{188}$ In this case $\mathrm{p}=2$.
}

${ }^{189}$ It is always possible to transform an $\operatorname{AR}(p)$ in a MA(q) whenever the system is invertible. See Harvey (1992). 
with $\operatorname{Cov}\left(\mathrm{u}_{\mathrm{et}}, \mathrm{u}_{\mathrm{rt}}\right)=0$.

By inverting the expression (3.4.2.6) the $\mathrm{MA}(\mathrm{q})$ (moving average of order $\mathrm{q}$ ) is obtained. with

$$
\mathrm{z}_{\mathrm{t}}=\mathrm{C}(\mathrm{L}) \mathrm{v}_{\mathrm{t}}
$$

$$
\mathrm{B}^{-1}=\mathrm{C}(\mathrm{L}) \text {. }
$$

Both variables $e_{t}$ and $r_{t}$ are assumed to be serially and mutually uncorrelated in lags and leads. As is usual in this kind of models, the variances are normalized to unity. The identification assumption consists on $\mathrm{C}_{12}(0)=0$ that restricts shocks to the nominal exchange rate equation $e_{t}$ not to have a contemporaneous effect on the real exchange rate equation. However, shocks to the real exchange rate equation by definition affect the real exchange rate contemporaneously. The restriction allows for a permanent effect of both types of shocks on the level of real exchange rate, as well as on the equilibrium of the nominal exchange rate. Because of the unit root assumption $r_{t}$ and $e_{t}$, at least one of both shocks must have a permanent effect on the level of each variable.

The empirical work presented in this section concentrates on two aspects, the computation of response patterns over time in a variable due to an innovation in itself or in the other variable, and the determination of the relative importance of each of the innovations in accounting for the variations in the dependent variables.

The first effect is known as impulse-response function: if there is an increase in $u_{\mathrm{et}}$ in period $t$ and no changes in the other innovations, the response of $e_{t}$ values will be as follows:

$$
\begin{aligned}
& \mathrm{e}_{\mathrm{t}}=\mathrm{d}_{0} \\
& \mathrm{e}_{\mathrm{t}+1}=\mathrm{d}_{1} \\
& \mathrm{e}_{\mathrm{t}+2}=\mathrm{d}_{2}
\end{aligned}
$$

The sequence of values $d_{0}, d_{1}, d_{2} \ldots$ is the so-called impulse-response function of the system, and it shows the response of a variable over time to a specific disturbance. In the following section, the impulse-response functions are estimated to describe the way in which the nominal and the real exchange rates respond to shocks in the nominal and in the real exchange rate equations.

In order to measure the relative importance of one variable in accounting for movements in another, the expression for the forecast of the variable is needed. Notice this implies the prediction of one period in advance of equation (3.4.2.4).

$$
\begin{aligned}
& e_{t+1}=b_{0} u_{e t+1}+b_{1} u_{e t}+b_{2} u_{e t-1} \ldots \\
& c_{0} u_{r t+1}+c_{1} u_{r t}+c_{2} u_{r t-1}+\ldots
\end{aligned}
$$

Using (3.4.2.10) it is possible on the basis of knowledge of all current (period t) and past shocks to the economy to forecast the most likely value of $e$ in period $t+1$. Since no information about disturbances during the next period $\left(\mathrm{u}_{\mathrm{e} t+1}\right)$ is available, their expected value is set to zero. Then, I obtain: 


$$
\begin{aligned}
& e_{t+1}^{e}=b_{1} u_{e t}+b_{2} u_{e t-1 \ldots} \\
& c_{1} u_{r t}+c_{2} u_{r t-1}+.
\end{aligned}
$$

Combining (3.4.2.4), (3.4.2.10) and (3.4.2.12) the forecast error is:

$$
e_{t+1}-e_{t+1}^{e}=b_{0} u_{e t+1}+c_{0} u_{r t+1}
$$

The size of the forecast error depends on the impulse-response coefficients (bs and cs) as well as on the sizes of the innovations to each of the variables. This property can be used to define a measure of the relative size of the forecast error variance that can be attributed to each of the innovations.

\section{Empirical Results}

In this section the empirical results provided by the two-equations $\operatorname{VAR}(2)$ model are presented. The lag was established in two because the Akaike and Schwarz criteria indicated that it was the optimal in most countries, and an uniform lag of two was chosen to preserve the uniformity of the model across countries.

\section{Impulse Response Analysis}

An impulse response analysis was performed in order to study the effect of the introduction of the EMS on the response to different shocks affecting the economies. I consider the following periods: the Snake 1973.03 -1979.03, the EMS without realignments 1987.03-1992.09, and the EMS wide bands 1993.08-1994.04.

\section{Snake 1973.03-1979.03}

In chart 3.4.1 the impulse-response functions for the levels of real and nominal exchange rate of six European countries are displayed.

Each panel plots the dynamic response of the nominal/real exchange rate to a standard deviation of either a shocks in the nominal exchange rate equation $\left(u_{\mathrm{et}}\right)$ or the shock in the real exchange rate equation $\left(u_{\mathrm{rt}}\right)$ over a forecast horizons from 1 to 35 months.

Because the real exchange rate is a relative price between domestic and foreign goods, it seems reasonable to interpret the shock to the nominal exchange rate equation as a nominal shock and a shock to the real exchange rate equation as a real shock ${ }^{190}$.

For most of the countries, the response of the nominal exchange rate to a shock to the nominal exchange rate equation shows a hump-shaped form which peaks within approximately two or three months and afterwards decreases smoothly. Nevertheless,

${ }^{190}$ Monetary shock was interpreted in the theoretical model as an expansionary/contractive monetary policy and a real shock can be interpreted as an expansionary/ contractive fiscal policy.(See Chapter 2). 
there is a small permanent effect in the long run. In the case of Belgium, as the panel shows, the nominal shock induces an immediate response in the nominal exchange rate of about $0.05 \%$ of its initial level; but this effect increases to $0.06 \%$ and afterwards decreases slowly over the next 10 months, reaching the steady state after approximately 24 periods. The panel shows an overshooting response to a nominal shock. Nominal shocks seem to be absorbed in the short-run by the nominal exchange rate instead by the prices. This result is consistent with a sticky-price behavior. ${ }^{191}$

The response of the nominal exchange rate to a shock in the nominal exchange rate equation for the others countries is depicted in the following panels. All of them show a similar behavior, though the degree of response differs from country to country. In Denmark the response reaches $0.5 \%$ at the peak, in France $1.2 \%$, Italy $0.01 \%$, Netherlands $0.85 \%$, in the UK the response is unusually large, $15 \%$, but after the impact effect the nominal exchange rate seems to move back to the initial level.

The response of the real exchange rate to a shock in the nominal exchange rate equation shows also a hump-shaped form which is very similar to the previous case, but the impact seems to have a transitory effect, which disappears over time. For Belgium, the immediate response to a nominal shock is about $0.07 \%$, increasing to $0.083 \%$ and reaching the peak after 3 months. It then declines relatively quickly over the next 10 months, and finally the rate of decrease appears to be slowly, disappearing over the next 3 years, with some statistical confidence, almost completely. For the other countries, the pattern of response turns out to be similar. In France the responses reaches a peak $2.5 \%$, Italy $0.03 \%$, Netherlands $1 \%$ and Denmark $0.9 \%$. The U.K. is again unusually high, $32 \%$.

The response of nominal exchange rate to a shock in the real exchange rate equation reacts with a negative correlation, showing in most of the cases a mirror image to the response of the nominal exchange rate to a nominal shock. The result seems to be consistent with the prediction of the theoretical model in response to a fiscal shock (appreciation of the domestic currency in response to a positive fiscal shock). For Belgium it peaks at $-0.015 \%$ after 3 months, afterwards increases slowly over the next 10 months and remains a persistent effect. For all the other countries, the panels show similar pattern. Only the degree of impact of shocks differs from country to country. For example, in the United Kingdom the impact is much larger. Finally, the effect of a real shock to a real exchange rate reaches a peak after 4 or 5 periods the effect. In most cases, remains at this level, which is the new steady state. The results seems to show the permanent effect predicted by the Mundell-Fleming-Dornbusch theoretical model presented in Chapter 2.

Summing up, though differing in magnitude, the response seems to show a relatively similar behavior in most of the countries. In general, the empirical results seem to be consistent with the predictions delivered by the Mundell-Fleming-Dornbusch theoretical model. Nominal shocks induce a permanent effect on nominal exchange rates; however, the impact overshoots the new equilibrium level. Nominal exchange rates absorb the nominal shock fully. Once prices react, the nominal exchange rates approach to the new equilibrium level. The impact of the nominal shock on the real exchange rate is transitory. Real shocks to both nominal and real exchange rate equations

${ }^{191}$ See Dornbusch (1976). 
show a permanent impact, and in general, they are inversely correlated to the shocks. ${ }^{192}$

\section{Hard EMS 1987.03-1992.09}

In this section by applying the same procedure as before for the period corresponding to the hard EMS, the response behavior of nominal and real exchange rates to shocks in the nominal and real exchange rate equation are presented. See chart 3.4.2. The second graph on the left side (continuous line) shows the response of the nominal exchange rate to a shock in the nominal exchange rate equation for Denmark. The response shows a hump-shaped form, and peaks after 3 periods. The effect disappears completely after 9 or 10 periods. Denmark, $0.12 \%$; France, $0.22 \%$; Italy, $0.0014 \%$; Netherlands, $0.2 \%$. The highest impact is observed in the case of Belgium, $12 \%$ and U.K., $8 \%$. The response of the nominal exchange rate to a shock in the real exchange rate equation is depicted in the same panel (discontinuous line). The impact peaks after approximately 3 months and tends to disappear over time. The impact reaches $3.8 \%$ in Belgium, $-0.02 \%$ in Denmark, $0.02 \%$ in France, $0.0002 \%$ Italy, $0.001 \%$ in the Netherlands, $2 \%$ in the U.K.

The response of the real exchange rate to a shock in the nominal exchange rate equation is depicted in the chart on the right side (continuous line). It also shows a humpshaped form peaking after 3 or 4 periods, $80 \%$ of the effect; declines over the next 6 periods and become even negative; afterwards it declines slowly, but persists for some time. This real exchange rate volatility can be attributed to the sluggish prices behavior: once prices react to the shock, there is some real exchange rate appreciation. In Belgium the peak is reached at $12 \%$; in Denmark, $0.1 \%$; in France, $0.8 \%$; Italy, $0.00012 \%$; Netherlands, $1 \%$; UK, $8 \%$. Finally, the response of the real exchange rate to a shock in the real exchange rate equation peaks after 4 or 5 periods and the effect, in most cases, shows a persistence in the long run. However, in the Netherlands the effect disappears completely. Nominal exchange rates seem to show a much lower and a more similar response to nominal shocks during the EMS than during the Snake. The result seems to be consistent with the limited flexibility imposed by the EMS. However, the larger impact of nominal shocks is observed on real exchange rates which after the first positive impact tend to react negatively. This behavior is consistent with a sluggish response of prices. An expansionary monetary will induce a small improvement in real exchange rate, and once prices react, the effect is more than compensated for and finally the real exchange rate appreciates. By comparing the magnitude of the response to nominal shocks between the EMS and the Snake, the first is much lower and more similar across countries. Nevertheless, the responses to fiscal shocks seem to be very different across countries. In general, by analyzing the responses of the EU countries, the EMS seems to have reduced exchange rate volatility. In addition, it has also lowered the speed at which member countries respond to shocks. The results imply that by introducing a greater degree of fixity in the exchange rate regime, the response to shocks seems to be more prolonged and much more correlated across coun-

${ }^{192}$ A positive fiscal shock will induce a nominal and real exchange rate appreciation 
tries, which is the direct consequence of the co-ordination to some extent of the monetary policies

\section{EMS Wide Bands 1993.07-1994.04}

Chart 3.4.3 shows the impulse response function for the post-crisis period. The response of the nominal and real exchange rate to a shock in the nominal exchange rate equation shows a greater volatility than under the previous arrangements. The form of the response function shows a zigzag form: the peak is reached in most of the cases after 3 or 4 periods, but this is followed by a negative response. The effects disappear completely converging to zero after 15 periods ${ }^{193}$. The only countries that show a relatively stable pattern after the shock in the nominal exchange rate equation are UK and Italy, which are exactly those countries that left the ERM after the crisis of September 1992.

The response of the nominal and real exchange rate to a shock in the real exchange rate equation shows a relative less volatile pattern and the effect disappear completely after approximately 10 periods.

\section{Forecast Error Variance Decomposition}

Tables 3.4.9, 3.4.10 and 3.4.11 depict the variance decomposition (VCD) for the Snake, hard EMS and the EMS-wide bands respectively. The variance decomposition shows the proportion of variance of $n$-quarter ahead forecast errors for the nominal and real exchange rate attributable to nominal shocks innovation and to the real shocks innovation according to the $\operatorname{VAR}(2)$ model. While the impulse-response function shows the dynamic effect of a one-time shock, the VDC is a convenient measure of the relative importance of such a shock to the system.

According to table 3.4 .9 , nominal shocks are the primary contributors to the variance forecast error. In the case of Belgium, when forecasting the level of nominal exchange rate, $92.5 \%$ of the forecast error variance is attributed to nominal shocks for horizons up to 16 months; in Denmark, $96.44 \%$; in France, $98.31 \%$; Italy, $86.29 \%$; in the Netherlands, $95.08 \%$; United Kingdom, $86.01 \%$. In the long run, over 35 months the contribution of output declines very little and remains over $70 \%$ for all the countries.

For the hard-EMS period, in most of the countries nominal shocks also explain over $90 \%$ of the forecast error; and for longer horizon over 35 months, nominal shocks still explain over $80 \%$ of the forecast errors, except for the case of Belgium.

During the EMS-wide bands the nominal shocks also explain over $90 \%$ of the forecast error; only in the case of Italy is the figure extremely low at $59.23 \%$. Real shocks seem to have a relative lower effect in explaining nominal exchange rate fluctuations in all the periods. During the Snake, when forecasting real exchange rates, nominal shocks seem to have a less uniform effect across countries: $52.78 \%$ in Belgium; 74.22 $\%$ in Denmark; $89.68 \%$ in France; $65.18 \%$ in Italy; $30.75 \%$; in the Netherlands, and $48.68 \%$ in the United Kingdom. In all cases, the effect decreases when forecasting for

${ }^{193}$ This period is not long enough, so that the result must be interpreted very carefully. 
longer horizons. During the hard-EMS, the effect is very irregular across countries: $32.23 \%$ in Denmark; $19.23 \%$; in France, $28.85 \%$; in Italy, $31.20 \%$; in Netherlands; and $52.19 \%$ in the United Kingdom. Finally, during the EMS-wide bands, nominal shocks seem to explain an even larger proportion of the real exchange rate fluctuations: $98.81 \%$ in Belgium; $96.74 \%$ Denmark; $93.63 \%$ France; $54.30 \%$ Italy; $68.75 \%$ Netherlands; $96.77 \%$ United Kingdom. The decrease of the effect over time is not very significant.

Summing up, the results obtained in these two sections are as follows: in all the countries there is an interdependent relationship between nominal and real exchange rates. The results are to some extent consistent with the predictions of a two-country Mundell-Fleming-Dornbusch model under rational expectations. Nominal shocks seem to be mainly responsible for exchange rate fluctuations in all periods. However, nominal shocks tended to have a transitory effect on real exchange rates during the Snake but a permanent one during the EMS. Real shocks tended to have a permanent effect in both nominal and real exchange rates; and in general the response was negatively correlated with the shocks. Nevertheless, while nominal shocks seem to show a more similar pattern during the EMS, real shocks seem to show a less uniform pattern. Finally, the forecast-error-variance-decomposition shows that nominal shocks seem to be the main contributors of exchange rate fluctuations in both periods Snake and EMS, while the exchange rate fluctuations attributed to real shocks seems to be less important.

\section{Concluding Remarks}

In this section 3.4, I estimated a VAR model in nominal and real exchange rates for six European countries. I investigated the dynamic behavior in response to nominal and real shocks during the Snake and the EMS periods. I found that the dynamic behavior seems to be consistent to some extent with the prediction of a two-country MundellFleming-Dornbusch model under rational expectations. During the more flexible exchange rate period, the Snake, nominal shocks seem to have had permanent effect on nominal exchange rate, but a transitory effect on real exchange rates. On the contrary, during the EMS the effect on real exchange rates is not significant. Real shocks showed a permanent effect in both nominal and real exchange rates in both periods. Second, the result of the variance-decomposition-analysis suggests that nominal shocks explain the larger proportion of exchange rate volatility. Real shocks appear to be less important in explaining exchange rate fluctuations. The evidence provided in this part is consistent with the finding reported by Dornbusch and Giovannini (1988) and Giavazzi and Giovannini (1989), and with the theoretical model presented in chapter 2. It indicates that members of the EMS have enjoyed, to some extent, a reduction in exchange rate volatility. This is a direct consequence of the fact that nominal shocks were mainly responsible for exchange rate fluctuations. Therefore, a movement towards a more fixed exchange rate agreement induces the coordination among monetary policies, reducing in this way the source of exchange rate volatility. Nevertheless, a fixed exchange rate regime has no power to coordinate either fiscal policies or other kind of real shocks, and therefore the variability due to real shocks cannot be moderated. 


\subsection{Summary and Conclusions}

In this third chapter, I analyzed the European experience with exchange rate agreements in order to be able to draw some lessons for the MERCOSUR case. In the European Union, the single market program has created growing momentum for deeper integration and thus the movement towards a single European currency was regarded as an additional component of this integration. The European Union constitutes an excellent example of a successful integration process, and therefore, it becomes interesting to analyze how the discussion on exchange rates agreements developed over time. In contrast with the European case, within MERCOSUR countries the debate about exchange rate agreements has been barely touched on altering current monetary arrangements, although the arguments as to the advantages of fixing exchange rates in order to obtain the full benefits of economic integration apply in the same way as in the European case.

I reviewed, first, the historical experience since the founding of the European Union towards monetary agreements. In the early period, when the European Community was founded, the stability of intra-European currencies did not constitute a problem by then, with the Bretton Woods system providing sufficient nominal and real stability among currencies. After the breakdown of Bretton Woods, the European states were concerned about developing their own monetary agreements to allow them to maintain stability among their currencies. Actually, some of the arrangements that the EC had introduced, such as the CAP, relied on relatively stable exchange rates. In this context, a number of exchange rate agreements developed through the years, first the Snake and later on the EMS. The EMS, which constitutes a quasi-fixed exchange rate system with escape clauses, has been widely perceived as a success, at least until the crisis of September 1992. Therefore, it becomes interesting to analyze the extent to which it has contributed to the reduction of exchange rate variability and inflation across European countries. The EMS has not been an homogenous system over eighteen years, since a learning- by-doing process has been present, and the system has been adjusted through the years. Thus, although initially designed as a symmetric system, it has worked "de facto" in an asymmetric way. Additionally, the frequency of realignments also has changed dramatically from its beginnings until the aftermath of the Basle-Nyborg agreement.

Second, I concentrated on the EMS performance towards the achievement of price and exchange rate stability. I found that convergence has been observed in monetary variables such as inflation rates, interest rates and monetary growth rates. Fiscal indicators, however, like the debt ratios and fiscal deficits did show divergence rather than convergence. In addition, I analyzed the costs in rates of unemployment the EMS has introduced. It does not seem that the EMS has significantly reduced the costs of disinflation. On the contrary, in comparison to non-European countries, the cost has been significantly higher: at least, unemployment rates have increased over 10 percent across Europe. This fact can be explained through the rigidities in European labor markets. Thus, the sluggish adjustment of nominal wages contributed to increase unemployment rates.

Third, I introduced an econometric analysis in order to discuss the performance of the EMS regarding nominal and real exchange rate variability. I estimated the two- equations Mundell-Fleming-Dornbusch model under rational expectations presented in 
chapter 2. I analyzed the dynamic behavior of nominal and real exchange rates in response to nominal and real shocks. I found the results to be consistent with the theoretical model previously presented. The Snake, which was considered as a proxy for a flexible exchange rate, seems to have induced more variability in both real and nominal exchange rates. Additionally, the variance-decomposition analysis suggests that monetary shocks explain a larger proportion of exchange rate variability. In this sense, by coordinating monetary policies some stability was introduced. Nevertheless, the EMS had no influence on fiscal policies. Summarizing, the adoption of a relative fixed exchange rate agreement among members of an economic area seems to be a desirable target, even when it is difficult to achieve. At least the European experience has shown that after the breakdown of Bretton Woods quite significant efforts have been invested in designing a feasible monetary arrangement that could reduce exchange rate variability and could help to achieve price stability. However, the collapse of the EMS in $1992-93$ and the movement toward wide bands (+-15\%) showed the fragility of the system.

A fixed exchange rate system helps to coordinate monetary policies among its members. However, it does not eliminate the necessary adjustment in domestic policies. A fixed exchange rate regime can only help to coordinate expectations, but cannot replace the introduction of austerity measures and has no power at all to coordinate fiscal policies. To fix artificially the exchange rates in order to pursue price stability only delays the adjustment, and in the end the market threatens the domestic currencies, accelerating exchange rate collapses. Because nominal shocks explain a larger proportion of exchange rate fluctuations, a movement towards a more fixed exchange rate arrangement represents a partial solution, even when it cannot solve all the problems. In order to avoid speculative attacks, additionally rules to coordinate macroeconomic policies among the countries should be introduced, especially some measures that allow the incorporation of fiscal 
Nominal Exchange Rates

\begin{tabular}{|l|l|l|l|l|l|}
\hline Country & $\begin{array}{l}1960.05- \\
1972.02\end{array}$ & $\begin{array}{l}1972.02- \\
1979.02\end{array}$ & $\begin{array}{l}1979.02- \\
1987.02\end{array}$ & $\begin{array}{l}1987.02- \\
1992.09\end{array}$ & $\begin{array}{l}1992.09- \\
1994.04\end{array}$ \\
\hline Belgium & 0.7 & 0.08 & 0.8 & 0.1 & 1.0 \\
\hline Denmark & 0.9 & 0.09 & 0.9 & 0.4 & 1.3 \\
\hline France & 1.1 & 1.17 & 1.7 & 0.4 & 0.8 \\
\hline Italy & 0.7 & 2.5 & 2.5 & 0.9 & 3.2 \\
\hline Neth. & 0.6 & 0.9 & 0.9 & 0.08 & 0.1 \\
\hline UK & 1.1 & 2.4 & 2.4 & 1.6 & 2.0 \\
\hline
\end{tabular}

Source: Main Economic Indicators. OECD Own calculation. Standard deviation*(100). All exchange rates has been calculated in relation to the DM.

\section{Table 3.4.2}

\section{Real Exchange Rates}

\begin{tabular}{|l|l|l|l|l|l|}
\hline Country & $\begin{array}{l}1960.051 \\
972.02\end{array}$ & $\begin{array}{l}1972.02- \\
1979.2\end{array}$ & $\begin{array}{l}1979.02- \\
1987.02\end{array}$ & $\begin{array}{l}1987.02- \\
1992.09\end{array}$ & $\begin{array}{l}1992.09- \\
1994.04\end{array}$ \\
\hline Belgium & 1.0 & 0.8 & 0.9 & 0.3 & 1.1 \\
\hline Den. & 1.4 & 1.3 & 0.8 & 0.6 & 1.5 \\
\hline France & 1.2 & 1.8 & 0.9 & 0.4 & 1.0 \\
\hline Italy & 0.9 & 2.8 & 1.1 & 0.9 & 3.1 \\
\hline Neth. & 0.11 & 1.0 & 0.6 & 0.4 & 0.5 \\
\hline UK & 1.3 & 2.5 & 2.3 & 1.6 & 3.1 \\
\hline
\end{tabular}

Source : OECD. Own calculation. Standard deviation*100 
Table 3.4.3

\section{Correlation Coefficients}

\begin{tabular}{|l|l|l|}
\hline Country & $\begin{array}{l}1973.03- \\
1979.03\end{array}$ & $\begin{array}{l}1979.03- \\
1994.04\end{array}$ \\
\hline Belgium & 0.85 & 0.99 \\
\hline Denmark & 0.97 & 0.99 \\
\hline France & 0.98 & 0.99 \\
\hline Italy & 0.99 & 0.97 \\
\hline Netherlands & 0.68 & 0.58 \\
\hline $\begin{array}{l}\text { United } \\
\text { Kingdom }\end{array}$ & 0.98 & 0.97 \\
\hline
\end{tabular}

Source: Main Economic Indicators. OECD.(own calculation)

Table 3.4.4

\section{Unit Root Tests1973.03 1994.04}

\section{ADF tests}

\begin{tabular}{|l|l|l|}
\hline Country & $\begin{array}{l}\text { Nominal } \\
\text { exchange rate }\end{array}$ & $\begin{array}{l}\text { Real } \\
\text { exchange rate }\end{array}$ \\
\hline Belgium & -2.133239 & -1.166671 \\
\hline Denmark & -3.113155 & -5.013087 \\
\hline France & -2.624535 & -4.048114 \\
\hline Italy & -5.108968 & -6.852874 \\
\hline Neth. & -2.544548 & -4.081215 \\
\hline $\begin{array}{l}\text { United } \\
\text { Kingdom }\end{array}$ & -3.4794 & -6.343717 \\
\hline
\end{tabular}

Mc Kinnon critical values for rejection of a unit root are:-3.4575 (1\%),

$-2.8729(5 \%), 2.5728(10 \%)$. 
Table 3.4.5

Unit Root tests 1973.01-1979.03 Snake

ADF test

\begin{tabular}{|l|l|l|}
\hline Country & $\begin{array}{l}\text { Nominal } \\
\text { exchange rate }\end{array}$ & $\begin{array}{l}\text { Real } \\
\text { exchange rate }\end{array}$ \\
\hline Belgium & -2.9015 & -0.832493 \\
\hline Denmark & -1.049073 & -1.19781 \\
\hline France & -1.149322 & -0.898137 \\
\hline Italy & -2.382603 & -2.946311 \\
\hline Neth. & -2.236265 & -1.308577 \\
\hline $\begin{array}{l}\text { United } \\
\text { Kingdom }\end{array}$ & -2.204210 & -2.6650 \\
\hline
\end{tabular}

Mc Kinnon critical values -3.5188 (1\%),-2.9001 (5\%), -2.5871 (10\%).

\section{Table 3.4.6}

\section{Unit Root Test}

\subsection{3-1992.09 Hard EMS}

\section{ADF test}

\begin{tabular}{|l|l|l|}
\hline Country & $\begin{array}{l}\text { Nominal } \\
\text { exchange rate }\end{array}$ & $\begin{array}{l}\text { Real } \\
\text { exchange rate }\end{array}$ \\
\hline Belgium & -1.964536 & -2.196983 \\
\hline Denmark & -1.733503 & -2.71697 \\
\hline France & -2.848109 & -4.179883 \\
\hline Italy & -1.484312 & $-3-727021$. \\
\hline Netherlands & -5.274979 & -3.4870 \\
\hline $\begin{array}{l}\text { United } \\
\text { Kingdom }\end{array}$ & -1.010681 & -3.4870 \\
\hline
\end{tabular}

Mc Kinnon critical values -3.4870 (1\%) -2.8861 (5\%) -2.5797 (-10\%). 
Table 3.4.7

\section{LR Cointegration Tests}

\begin{tabular}{|l|l|l|}
\hline Country & Hypothesis & $\begin{array}{l}\text { Likelihood ratio } \\
\lambda=\text { trace }\end{array}$ \\
\hline Belgium & $\mathrm{k}=0$ & 38.45797 \\
& $\mathrm{k}=1$ & 3.187193 \\
\hline Denmark & $\mathrm{k}=0$ & 38.84000 \\
& $\mathrm{k}=1$ & 5.684977 \\
\hline France & $\mathrm{k}=0$ & 49.25595 \\
& $\mathrm{k}=1$ & 4.099065 \\
\hline Italy & $\mathrm{k}=0$ & 44.04576 \\
& $\mathrm{k}=1$ & 0.846847 \\
\hline Netherlands & $\mathrm{k}=0$ & 57.58639 \\
& $\mathrm{k}=1$ & 4.207899 \\
\hline United & $\mathrm{k}=0$ & 59.57305 \\
Kingdom & $\mathrm{k}=1$ & 2.875713 \\
\hline
\end{tabular}

Note: Critical values according the tables developed by Osterwald-Lenum (1992) are for the hypothesis $\mathrm{k}=0,15.41(5 \%)$ and $20.04(1 \%)$ and for $\mathrm{k}=13.76(5 \%)$ and $6.65(1 \%)$ 


\section{Table 3.4.8}

\section{Granger Causality Test between the Nominal Exchange Rate and Real Exchange Rate}

$$
\begin{aligned}
& \Delta \mathrm{e}_{\mathrm{t}}=\alpha_{1}+\sum \beta_{\mathrm{i}} \Delta \mathrm{e}_{\mathrm{t}-\mathrm{i}}+\sum \gamma_{\mathrm{i}} \Delta \mathrm{r}_{\mathrm{t}-\mathrm{i}}+\varepsilon_{\mathrm{et}} \\
& \Delta \mathrm{r}_{\mathrm{t}}=\alpha_{1}+\sum \beta_{\mathrm{i}} \Delta \mathrm{r}_{\mathrm{t}-\mathrm{i}}+\sum \gamma_{\mathrm{i}} \Delta \mathrm{e}_{\mathrm{t}-\mathrm{i}}+\varepsilon_{\mathrm{rt}}
\end{aligned}
$$

\begin{tabular}{|l|l|l|}
\hline Country & $\begin{array}{l}\Delta \mathrm{e}_{\mathrm{t}} \text { does not } \\
\text { cause } \Delta \mathrm{r}_{\mathrm{t}}\end{array}$ & $\begin{array}{l}\Delta \mathrm{r}_{\mathrm{t}} \text { does not } \\
\text { cause } \Delta \mathrm{e}_{\mathrm{t}}\end{array}$ \\
\hline Belgium & 1.92519 & 0.67027 \\
\hline Denmark & 1.84574 & 1.86098 \\
\hline France & 3.10732 & 3.12918 \\
\hline Italy & 2.42463 & 1.25194 \\
\hline Netherlands & 0.54117 & 3.62856 \\
\hline $\begin{array}{l}\text { United } \\
\text { Kingdom }\end{array}$ & 4.51820 & 2.61400 \\
\hline
\end{tabular}

Note : Critical $\mathrm{F}$ value 4.61 
Table 3.4.9

Variance Decomposition

Snake 1973.03-1979.03

\begin{tabular}{|l|l|l|l|}
\hline Country & $\begin{array}{l}\text { Forecast horizons } \\
\text { (in quarters) }\end{array}$ & \multicolumn{3}{|l|}{$\begin{array}{l}\text { Proportion of variance explained } \\
\text { by nominal exchange rate }\end{array}$} \\
\hline & & $\begin{array}{l}\text { Nominal } \\
\text { exchange rate } \\
\text { et }\end{array}$ & $\begin{array}{l}\text { Real exchange } \\
\text { rate } \\
\text { rt }\end{array}$ \\
\hline Belgium & 1 & 100 & 79.36 \\
& 4 & 94.48 & 82.37 \\
& 16 & 92.50 & 52.78 \\
& 30 & 89.37 & 40.80 \\
\hline Denmark & 1 & 100 & 59.19 \\
& 4 & 99.54 & 73.34 \\
& 16 & 96.44 & 74.22 \\
& 30 & 92.77 & 73.21 \\
\hline France & 1 & 100 & 88.25 \\
& 4 & 99.77 & 96.35 \\
& 16 & 98.31 & 89.68 \\
& 30 & 94.49 & 80.99 \\
\hline Italy & 1 & 100 & 95.04 \\
& 4 & 99.87 & 89.77 \\
& 16 & 86.29 & 65.18 \\
& 30 & 77.22 & 53.75 \\
\hline Netherlands & 1 & 100 & 68.31 \\
& 4 & 99.84 & 64.99 \\
& 16 & 95.08 & 30.75 \\
& 30 & 92.51 & 23.24 \\
\hline United & 1 & 100 & 89.32 \\
& 4 & 99.49 & 89.87 \\
& 16 & 86.01 & 48.68 \\
& 30 & 69.97 & 32.74 \\
\hline
\end{tabular}

Note: Variance decomposition gives the proportion of variance of n-quarter ahead forecast error for the nominal and real exchange rate, attributable to nominal exchange rate innovations. According to the VAR(2) model with nominal exchange rate ordered in the first place. Proportion of the variance explained by real exchange rate innovation can be obtained as one minus entry on the table. 
Table 3.4.10

Variance Decomposition

Hard EMS 1987.03-1992.09

\begin{tabular}{|l|l|l|l|}
\hline Country & $\begin{array}{l}\text { Forecast horizons } \\
\text { (in quarters) }\end{array}$ & \multicolumn{2}{|l|}{$\begin{array}{l}\text { Proportion of variance explained } \\
\text { by nominal exchange rate }\end{array}$} \\
\hline & & $\begin{array}{l}\text { Nominal } \\
\text { exchange rate } \\
\text { e }\end{array}$ & $\begin{array}{l}\text { Real exchange } \\
\text { rate } \\
r_{t}\end{array}$ \\
\hline Belgium & 1 & 100 & 87.55 \\
& 4 & 91.84 & 79.39 \\
& 16 & 67.76 & 61.88 \\
& 30 & 62.58 & 58.20 \\
\hline Denmark & 1 & 100 & 33.50 \\
& 4 & 99.60 & 47.40 \\
& 16 & 97.41 & 32.23 \\
& 30 & 96.96 & 30.95 \\
\hline France & 1 & 100 & 74.91 \\
& 4 & 99.80 & 54.41 \\
& 16 & 91.03 & 29.17 \\
& 30 & 89.40 & 28.28 \\
\hline Italy & 1 & 100 & 93.44 \\
& 4 & 99.96 & 89.70 \\
& 16 & 98.83 & 71.03 \\
& 30 & 97.35 & 60.70 \\
\hline Netherlands & 1 & 100 & 51.40 \\
& 4 & 97.24 & 31.20 \\
& 16 & 95.76 & 31.24 \\
& 30 & 95.75 & 31.24 \\
\hline United & 1 & 100 & 88.22 \\
& 4 & 99.96 & 84.98 \\
& 16 & 92.96 & 52.19 \\
& 30 & 84.61 & 37.85 \\
\hline
\end{tabular}


Table 3.4.11

Variance Decomposition

EMS Wide Bands 1993.07-1994.04

\begin{tabular}{|l|l|l|l|}
\hline Country & $\begin{array}{l}\text { Forecast horizons } \\
\text { (in quarters) }\end{array}$ & \multicolumn{2}{|l|}{$\begin{array}{l}\text { Proportion of variance explained } \\
\text { by nominal exchange rate }\end{array}$} \\
\hline & & $\begin{array}{l}\text { Nominal } \\
\text { exchange rate } \\
\text { e }_{\text {t }}\end{array}$ & $\begin{array}{l}\text { Real exchange } \\
\text { rate } \\
\mathrm{r}_{\mathrm{t}}\end{array}$ \\
\hline Belgium & 1 & 100 & 94.17 \\
& 4 & 95.99 & 90.60 \\
& 16 & 93.82 & 89.81 \\
& 30 & 93.82 & 89.81 \\
\hline Denmark & 1 & 100 & 92.66 \\
& 4 & 95.48 & 96.84 \\
& 16 & 92.63 & 96.74 \\
& 30 & 92.8 & 96.74 \\
\hline France & 1 & 100 & 92.90 \\
& 4 & 98.94 & 93.44 \\
& 16 & 91.76 & 93.63 \\
& 30 & 90.79 & 93.62 \\
\hline Italy & 1 & 100 & 99.19 \\
& 4 & 88 & 84.83 \\
& 16 & 59.23 & 54.30 \\
& 30 & 59.19 & 54.26 \\
\hline Kingdom & 1 & 100 & 48.59 \\
& 4 & 99.85 & 68.79 \\
& 16 & 99.82 & 68.75 \\
& 16 & 99.82 & 68.75 \\
\hline & 30 & 100 & 99.56 \\
& 16 & 97.48 & 97.02 \\
& & 97.19 & 96.77 \\
\hline
\end{tabular}




\section{Chart 3.4.1}

\section{Impulse Response Function}

\section{Snake 1973.03-1979.03}

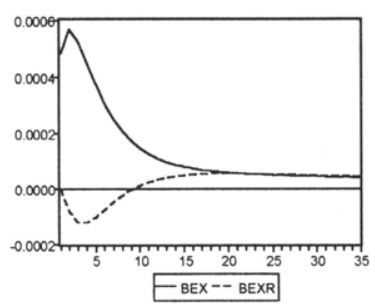

Response of BEX to One S.D. Innovation

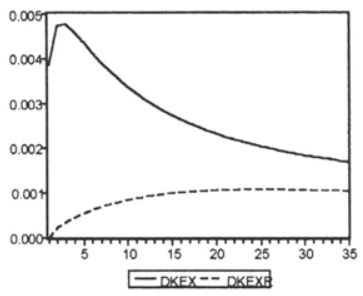

Response of DKEX to One S.D. Innovation

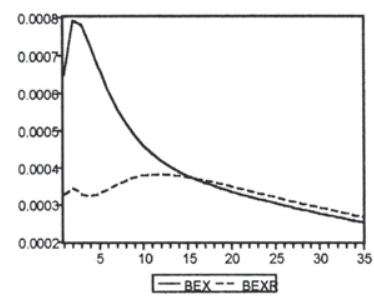

Response of BEXR to One S.D. Innovation

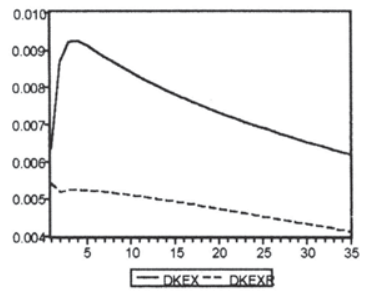

Response of DKEXR to One S.D. Innovation 


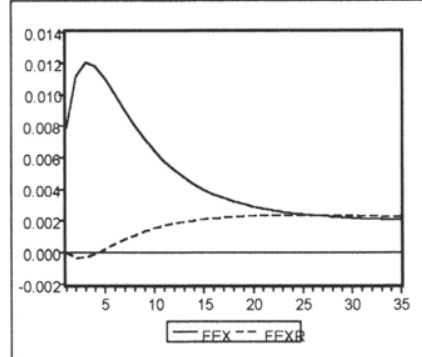

Response of FEX to One S.D. Innovation

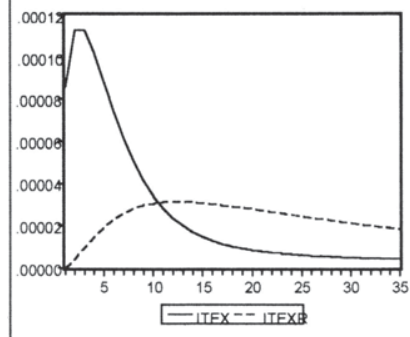

Response of ITEX to One S.D. Innovation

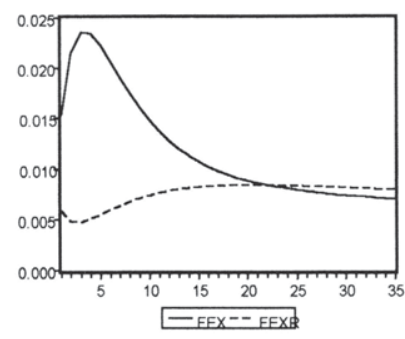

Response of FEXR to One S.D. Innovation

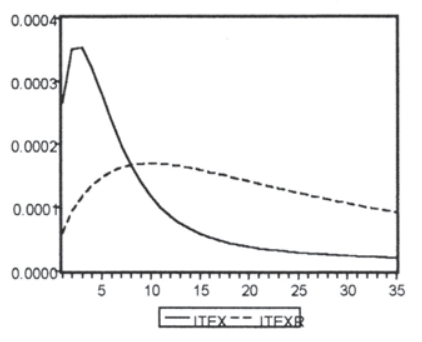

Response of ITEXR to One S.D. Innovation 


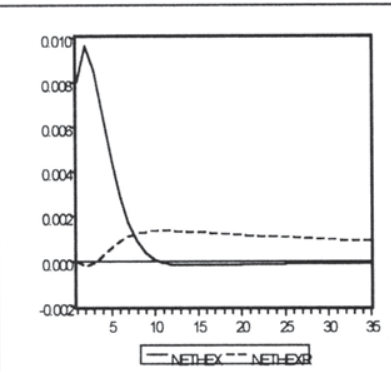

Response of NETHEX to One S.D. Imovations

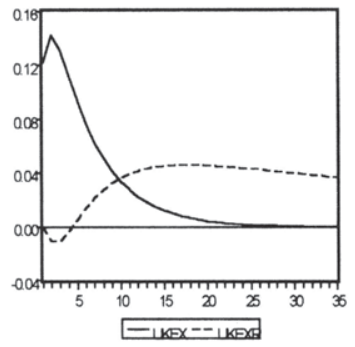

Response of UKEX to One S.D. Imnovations

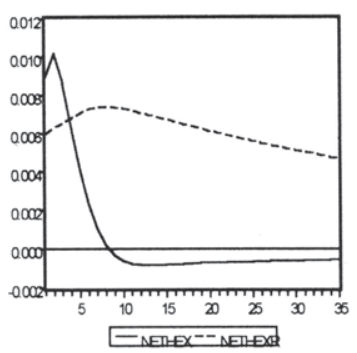

Response of NETHEXR to One S.D. Imovations

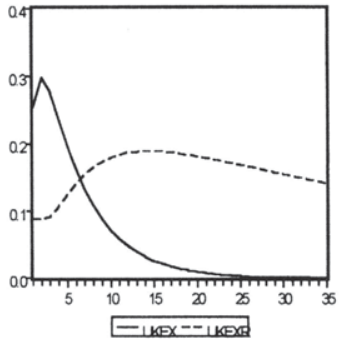

Response of UKEXR to One S.D. Imovations

\section{Chart 3.4.2}

\section{Impulse Response Function}

Hard EMS 1987.03-1992.09

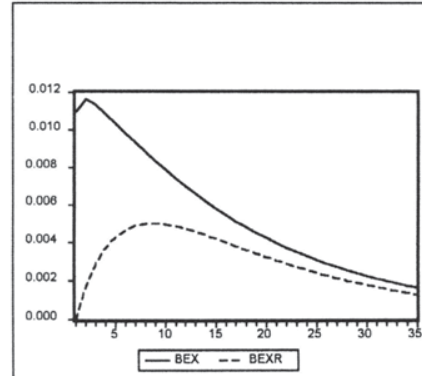

Response of BEX to One S.D. Innovation

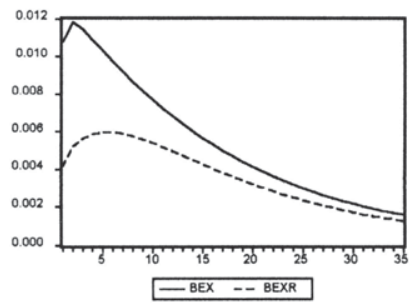

Response of BEXR to One S.D. Innovation 


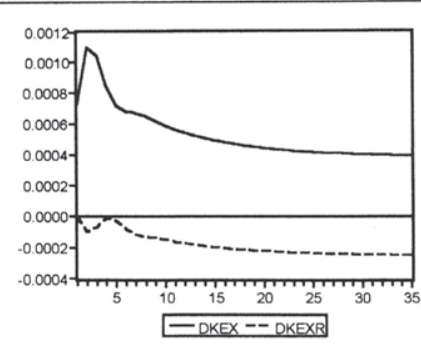

Response of DKEX to One S.D. Innovation

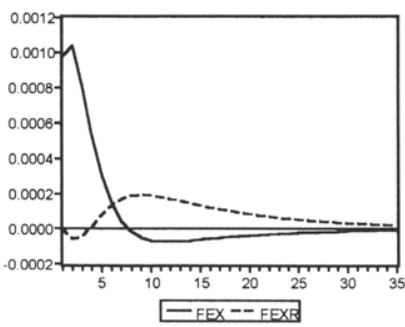

Response of FEX to One S.D. Innovation

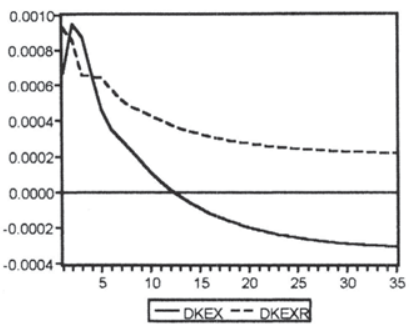

Response of DKEXR to One S.D. Innovation

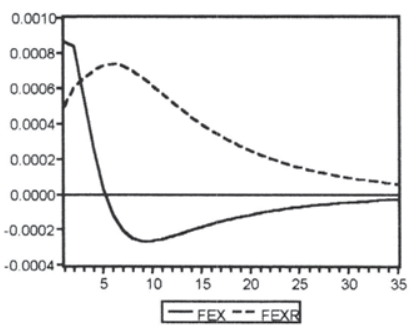

Response of FEXR to One S.D. Innovation 


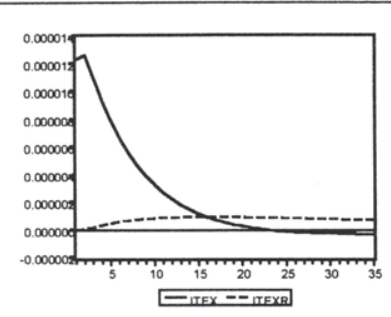

Response of ITEX to One S.D. Innovation

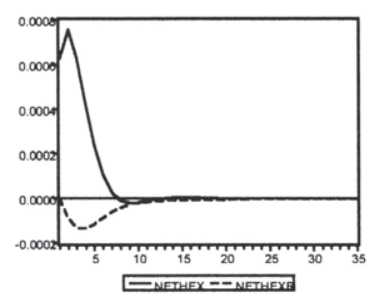

Response of NETHEX to One S.D. Innovation

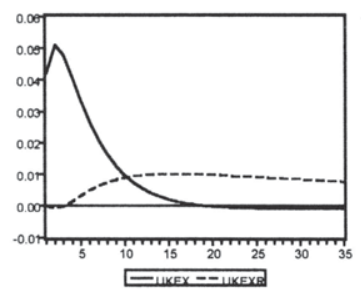

Response of UKEX to One S.D. Innovation

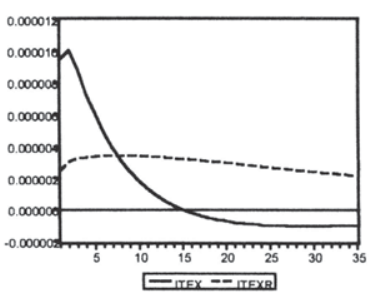

Response of ITEXR to One S.D. Innovation

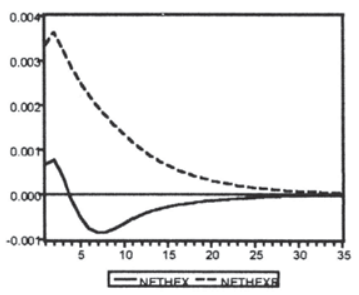

Response of NETHEXR to One S.D. Innovation

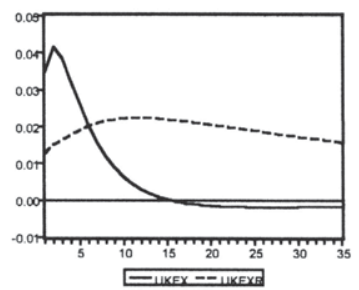

Response of UKEXR to One S.D. Innovation 
Chart 3.4.3

Impulse Response Function

EMS wide bands

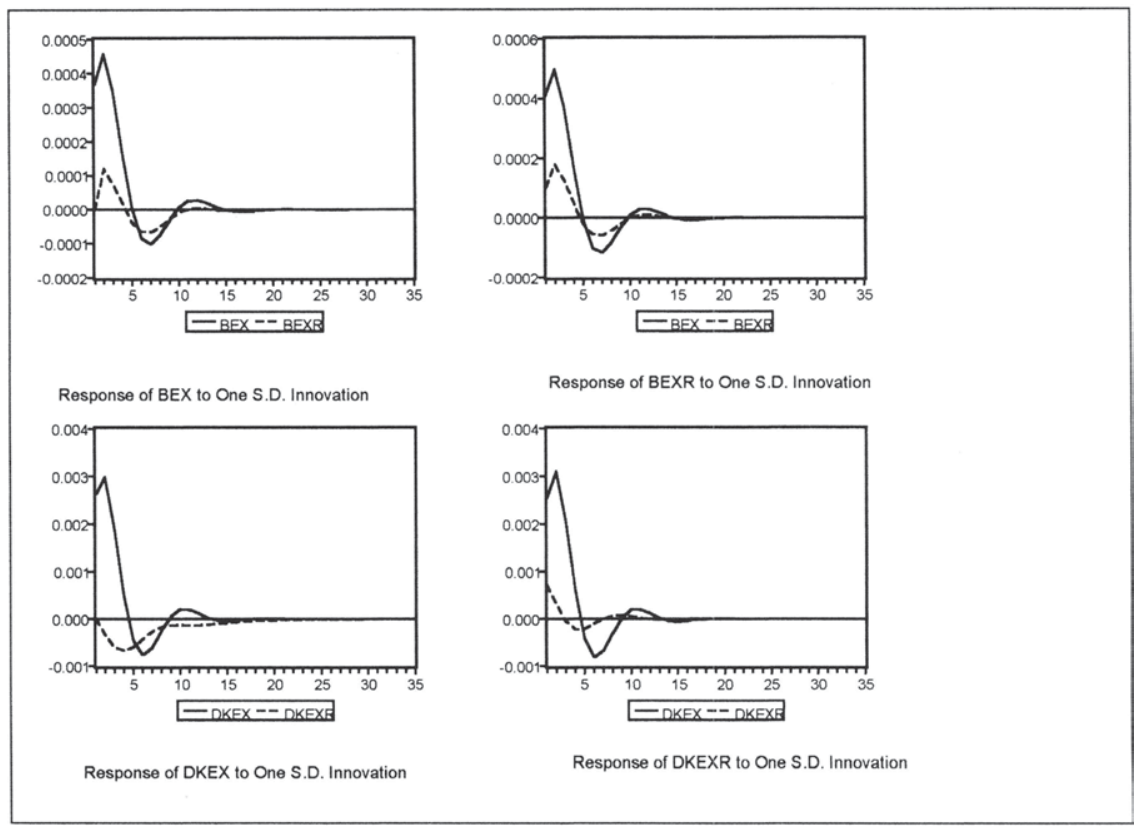




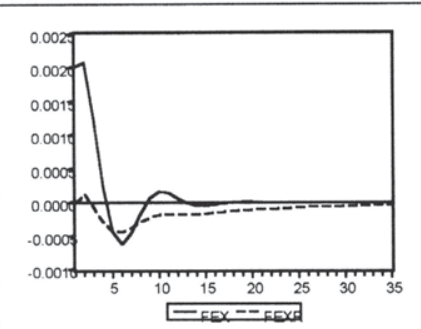

Response of FEX to One S.D. Innovation

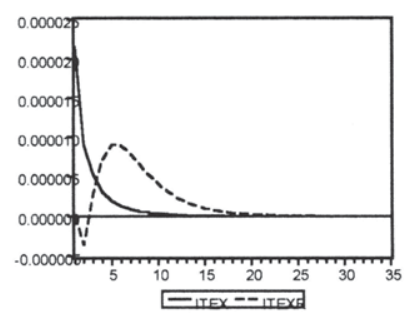

Response of ITEX to One S.D. Innovation

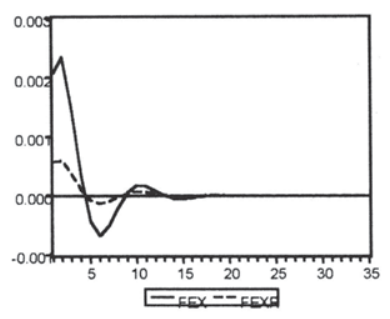

Response of FEXR to One S.D. Innovation

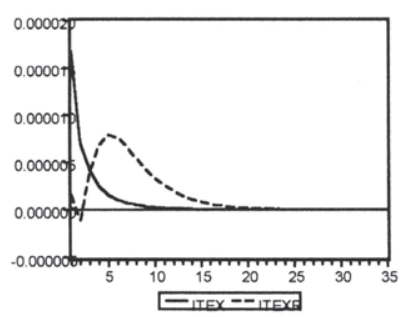

Response of ITEXR to One S.D. Innovation 


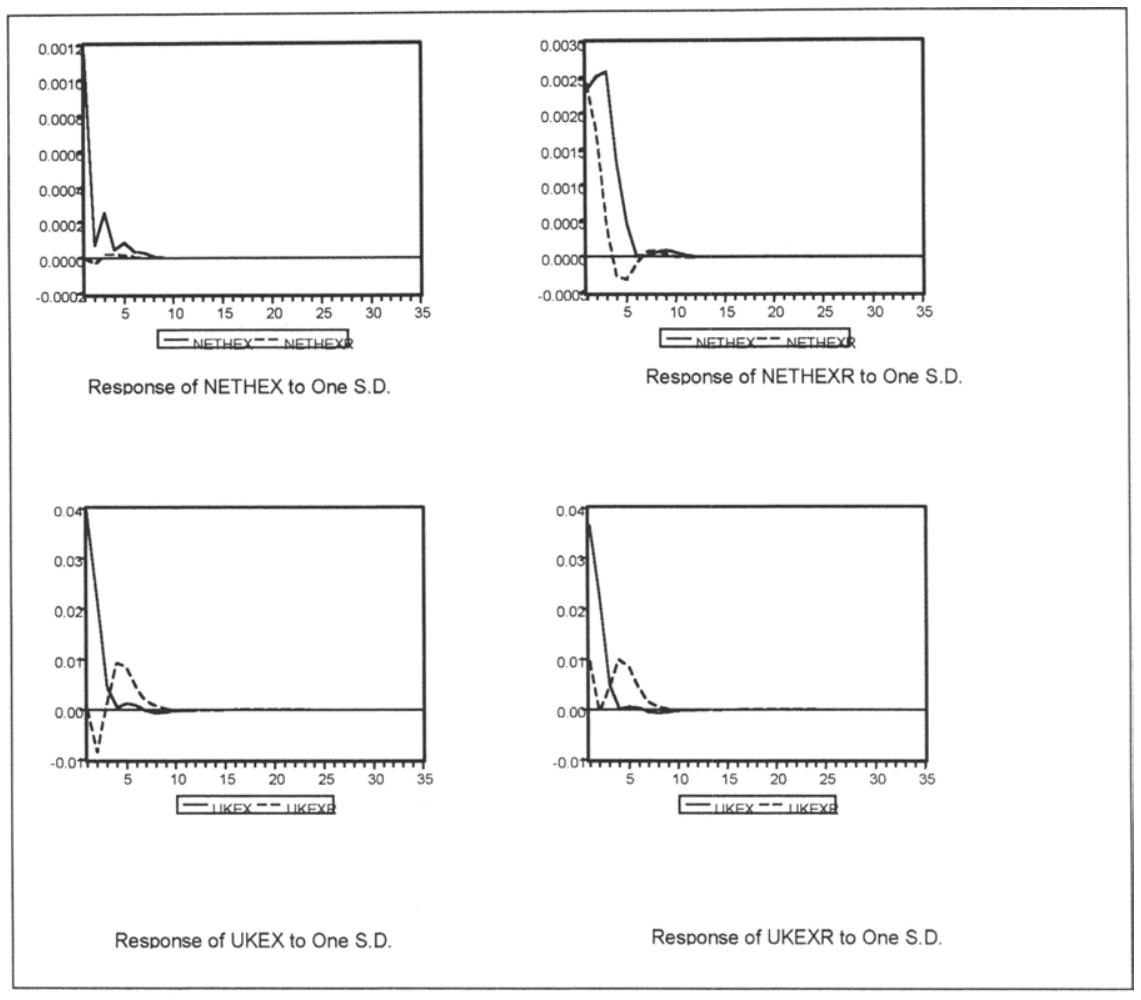




\section{Appendix 3.1}

\section{ECU Composition}

(According to the recalculation from November 1992)

\begin{tabular}{|l|l|l|}
\hline Currency & As \% of ECU & $\begin{array}{l}\text { Composition of the ECU } \\
\text { in National Currencies }\end{array}$ \\
\hline German mark & 31.69 & 1.96992 \\
\hline French franc & 20.16 & 6.60683 \\
\hline British pound & 10.90 & 0.805748 \\
\hline Dutch guilder & 9.90 & 2.21958 \\
\hline Italian lira & 8.89 & 0.735334 \\
\hline Belgian franc & 8.44 & 40.63304 \\
\hline Spanish peseta & 4.80 & 143.386 \\
\hline Danish crown & 2.63 & 7.51410 \\
\hline Irish punt & 1.16 & 0.7353334 \\
\hline Portuguese escudo & 0.76 & 182.194 \\
\hline Greek drachma & 0.57 & 254.254 \\
\hline
\end{tabular}

The redefinition of ECU was made by using the following formula:

$\mathrm{P}_{1}=\mathrm{Q}_{1} \mathrm{C}_{1}$

Where:

$\mathrm{P}_{1}=$ weight of currency

$\mathrm{Q}_{1}=$ fixed quantity of currency

$\mathrm{C}_{1}=\mathrm{ECU}$ exchange rate of currency per ECU 


\section{Appendix 3.2 \\ The Events of 1992 and the Future of Economic and Monetary Union The Maastricht Treaty}

Following the Delors proposal for Economic and Monetary Union made in 1990, the Maastricht Treaty on European Union, agreed upon by the EU heads of Governments in December of 1991, was signed on 7th February 1992.

The Treaty concentrated on the responsibility for the monetary policy. According to the Maastricht treaty, the second stage of the EMU should begin in 1994 and if by the end of 1997, the date for the final phase, has not been agreed then it will start on January 1999.

In the Treaty were defined the convergence criteria that countries should meet in order to qualify for EMU:

1. Government deficit spending should not exceed 3 per cent of GDP.

2. Government debt should not exceed 60 per cent of GDP.

3. Inflation of a country over one year before examination should not exceed by more than 1.5 per cent that of the three best performing member states in terms of price stability.

4. A country must be a member of the ERM and must not have experienced serious upheavals in the two preceding years.

5. In the preceding year a member state should have had an average nominal long term interest rate which does not exceed by more than $2 \%$ the best three best performing member states of price stability.

In the treaty was agreed the creation of an European Central Bank ECB. The ECB and the national central banks together will make up the European System of Central Banks which in turn will be governed by the Council and the Executive Board. Both the ECB and the national central banks are expected to be totally independent of the Community and the governments of the members countries. 


\section{Chapter 4}

\section{The Latin American Experience}

\subsection{Introduction}

Three decades have elapsed since several Latin American countries established their first schemes to promote mutual cooperation and regional integration. Although initial efforts raised great expectations, none of the introduced schemes was able to reach its goals. Despite official commitments by Latin American leaders and governments, economic integration continued disappointingly. There was only modest progress towards the desired objectives of regional and subregional integration of national markets, free circulation of goods and services, joint industrial development, and the coordination of external economic relations ${ }^{194}$

The regional integration process was based more on passionate rhetoric than on economics. This lead to a long history of failures and frustration, and induced the mistrust of economic agents in respect of the possibility of using economic integration schemes as an instrument to achieve development and economic growth. ${ }^{195}$ Deadlines for the removal of barriers to intraregional trade were often postponed, the majority of the liberalization schemes were limited in terms of product coverage and preferences given, implementation of the agreements was generally partial, and initial liberalization was followed by delays, reversals and impasses. In other words, the results fell considerably short of initial expectations and during the 1970s and 1980s all integration schemes in Latin America stagnated after facing several crises.

The difficulties confronted by Latin American integration in the past were due to deficiencies in institutional factors related to the conception of integration schemes ${ }^{195}$ ${ }^{196}$ and profound internal economic and political problems suffered by almost of all the countries in the region.

In the light of this early evolution, there are grounds to believe that even in a more favorable internal and external environment, the regional schemes established during the 1960s would not have fulfilled their promises because the principal problem was that they were conceived within a framework of an import-substitution policy and impregnated by the inward oriented development philosophy 197

\footnotetext{
${ }^{194}$ See Edwards (1994), Cardenas (1992), van Klaveren (1990).

195 The dependency theory, which was very popular in the developing world in the $1960 \mathrm{~s}$, sought to explain why Latin American countries have failed to become industrial societies on the model of the United States and Western Europe. It was alleged that foreign governments, multinational corporations and international financial institutions had taken capital out of Latin America, distorted development patterns and undermined governments and other groups that tried to limit their power. This theory is close to Marxist thought. For details see Haggard and Kaufman (1992), Cardoso and Falleto (1979), Evans (1979.

196 The initial integration schemes were based mainly on the industrial structure of the COMECON agreement.

197 See Lion (1994), Edwards (1992), Beckerman (1994), Castro Escudero (1994).
} 
Regional and subregional integration arrangements are now attracting renewed interest among Latin American countries, with some existing schemes being revisited and new groupings are being formed. The integration process that has probably attracted most attention among non-Latin American countries is MERCOSUR (the Common Market of the South) which consists of Argentina, Brazil, Uruguay and Paraguay and was created in March 1991. This new integration process differs significantly from previous agreements not only in its institutional structure, but also in its underlying philosophy. In contrast with the policies pursued by the region during the 1960s there is now a clearly pro-international attitude based on outward-oriented development models. These new efforts for regional integration are taking place after a decade of economic adjustment and reform. Perhaps one of the most important elements is the existence of a new consensus in Latin America, known as the as "Washington consensus"198, which has replaced the old protectionist policies. There is now some agreement among economists from quite different theoretical backgrounds about basic principles. Most economists in Latin America now recognize the importance of market oriented policies and economic stability in achieving economic growth.

This revitalization of regional cooperation and integration is shown not only through new trade agreements, but also by the development of new forms of cooperation in diverse areas; for example, investment in physical infrastructure, the utilization of shared natural resources, technological development, and nuclear energy. Thus, the establishment of MERCOSUR originating in the bilateral integration agreements adopted by Argentina and Brazil in the 1980s (Hirst 1992) was facilitated by the desire of both countries to overcome traditional perceptions of mutual political and military rivalry. ${ }^{199}$

This chapter will perform several functions. Firstly, a brief historical review of previous experiences of Latin American integration agreements is presented, providing an analysis of the institutional characteristics of these early attempts and the reasons for their failure. Secondly, there is a review of the new integration approach that started during the 1980s, involving the cooperation process between Argentina and Brazil and the later inclusion of the smaller countries of Uruguay and Paraguay, which gave finally birth to the Common Market of the South. Within this is a discussion of the institutional framework put in place by MERCOSUR and the new economic consensus, which have induced a huge shift in the economy policy of most Latin American countries, specifically the members of MERCOSUR. This constitutes a break in the economic history of these countries and dominates the political economic scene of the 1990s. Thirdly, stylized facts are presented, allowing a comparative analysis of the macroeconomic structure and the performance over the last few years of the MERCOSUR countries. This is especially relevant in any design for the optimal exchange rate arrangement for MERCOSUR, as this must take into account the peculiarities of the individual member countries.

\footnotetext{
198 The concept of the "Washington consensus" was coined by John Williamson (1991) to label the new economic policies undertaken by the Latin American countries, such as opening up the economy, the liberalization of trade, stabilization, and austerity in fiscal policy. He used the term Washington consensus because these policies were recommended and sometimes even imposed by international organizations like the IMF and the World Bank.

199 See Van Klaveren (1990), Sargmeister (1994).
} 
The last section comprises of a discussion of the experiences of MERCOSUR countries with fixed exchange rate agreements. Fixed exchange rates are being used as important instruments within stabilization programs and constitute the nominal anchor in orthodox and heterodox plans. After discussing the common elements of previous stabilizing attempts there is finally a detailed analysis of the two most recent experiences, the Currency Board adopted by Argentina and the Real Plan introduced by Brazil. This explores the ingenuous monetary mechanisms they have constructed to cope with dollarization and indexation respectively. They have been reasonably successful in bringing down inflation and returning their economies to a growth path. Therefore, any feasible exchange rate arrangement to be introduced into the region must take into account these two experiences. In addition, politically, no exchange rate policy will be able to be introduced within MERCOSUR without the consensus of Argentina and Brazil and neither of these countries will be prepared to give up their internal achievements. However, this is not necessarily a negative factor, as it offers a "window of opportunity" that can allow them to surmount the weaknesses of their monetary policies and help to design a new framework that satisfies the objectives of both countries.

\subsection{Review of Economic integration in Latin America from Import Substitution to the Washington Consensus.}

\subsubsection{Regional Integration within a Protectionist Framework}

\section{LAFTA200}

During the Second World War, the Latin American industrialization process, based on an import-substitution policy, began ${ }^{201}$. This strategy of development became very popular in most developing countries but especially in Latin America during the period 1940-1970202. Although it initially appeared successful as some Latin American countries reached a stage of industrialization whereby imports of intermediate goods increased very rapidly, there was no parallel increase in exports of these new industrial goods. Thus, most countries faced serious balance of payment problems; a weakness which became evident by the end of the 1950s. Therefore this strategy of development based on the import-substitution policy faced serious problems, partly due to the relatively small size of domestic markets, which were the only receptors of the produced

200 Also called ALALC (Asociación Latinamericana de Libre Comercio).

201 The theoretical foundation of the import-substitution approach was developed by R. Prebisch (1949). He wrote a theory about the deteriorating terms of trade in developing or periphery countries (as Prebisch labeled them). In the first stage, countries should substitute final consumer imported goods with similar, nationally produced goods. Because this national production was much more expensive than that imported, high tariffs were imposed in order to avoid competition. this first stage was reached by most Latin American countries. However, the second stage, which implied the production of capital goods was very difficult to achieve. For additional details see Bruton (1989), Baer (1962), Lal (1985).

202 Latin American became the intellectual center for scientific research on this area. See Baer (1962). 
goods. In addition, Latin American countries were not able to develop the necessary investment to reach the second stage of this strategy, so they were not in a situation of producing capital goods and intermediate goods (see Solís 1988). However, Latin American countries saw a possible solution to overcome this problem through integration schemes and there was a movement towards export increases within a regional scope ${ }^{203}$ The creation of the European Community in 1957 was also perceived as a threat which would close the external markets for the traditional Latin American exports. ${ }^{204}$ As Latin American industries produced few and expensive goods, they had little opportunity to insert themselves into international markets. Therefore, economic integration appeared to be the most appealing alternative in overcoming the limits of the domestic markets by taking advantage of the economies of scale, and forcing domestic industries to a certain level of competence, which would not be as damaging as international competition. In addition, economic integration would strengthen the position of Latin American countries and allow them to win a larger negotiating power. In this sense, economic integration was seen as a channel for continuing the importsubstitution industrialization policy on a wider scale. The Latin American countries did not intend to open up their protected markets to international competition, but rather to expand the regional market among countries with similar economic structures (Hirst, 1992, Ferrer 1996).

By 1956 a project was presented, as a suggestion of the Trade Committee of the Economic Commission for Latin America of the United Nations (ECLA), ${ }^{205}$ studying the possibility of establishing an economic area across the region. Four years later, through the Montevideo Treaty, a free trade area was created among seven Latin American countries, which was called the Latin American Free Trade Association (LAFTA) (see Finch, 1982). LAFTA initially included the three largest economies of the region (Argentina, Brazil, and Mexico) as well as Chile, Paraguay, Peru and Uruguay. ${ }^{206}$ In the following years other Latin American countries joined this free trade area, until it finally comprised the whole of the South America continent and Mexico with the exceptions of Guyana, Surinam and French Guyana.

Although in the early years the LAFTA arrangement appeared to function relatively well, by 1967 the scheme had entered a period of stagnation and crisis that it was never able to overcome. In 1969, the deadline for achievement of regional free trade was extended and at the same time a group of member countries initiated a more ambitious program of sub-regional integration called the Andean Pact (AP). ${ }^{207}$ Successive attempts to renegotiate the Treaty of Montevideo failed, and finally in 1980 LAFTA expired and was replaced by the LAIA ${ }^{208}$ (Latin American Integration Association) ${ }^{209}$.

\footnotetext{
203 A structuralist explanation on the benefits of Latin American integration can be found in Prebisch (1959).

204 The introduction of the Common Agricultural Policy among European countries was seen as especially dangerous for Latin American countries whose exports were based mainly on agricultural goods.

205 CEPAL (Comisión Económica para América Latina) or ECLA (in English).

206 Columbia and Ecuador joined in 1961, Venezuela in 1966, and Bolivia in 1967.

207 For details see Cardenas (1992), Edwards (1994).

208 ALADI (Asociación Latinoamericana de Integration).

${ }^{209}$ For details see FIEL (1991).
} 
The main objective of LAFTA was the gradual elimination of trade barriers and the progressive reduction of tariffs affecting intra-regional trade flows. The Treaty assumed that a transition period of twelve years ${ }^{210}$ would prevail. Over this period, all quantitative and non-quantitative trade restrictions among member states should have been eliminated. The agreement contemplated a process of gradual liberalization of intra-regional flows through periodical negotiations, the results of which should have been included in the national and common lists. These national and common lists were the main instruments of LAFTA. The former included all the tariff reductions that the countries allowed to the rest of the Latin American countries. However, if a country faced temporary economic problems it was possible to eliminate some goods from the list of tariff reductions by inducing a compensation of equivalent effect. In contrast, the common list included all the goods that would remain free of tariffs and could not be excluded from this list in the future. Items included in national lists were those for which each country agreed to reduce nominal tariffs by at least eight per cent per annum. Total tariff reduction was intended to reach 96 per cent of goods for all participant members ${ }^{211}$ and during the first eight conferences a cumulative reduction of 64 percent was reached. However, in the following conferences no new reductions were able to be introduced. One of the main problems originated in the institutional arrangement itself. Thus, the negotiation was considered on tariffs, whose specifications differed from country to country. In 1967 through the Caracas Treaty, the annual tariff reduction was reduced to 2.9 per cent. All countries agreed to include in the common list every three years some products that represented 25 per cent of the intrazonal trade. Therefore, over a 12 year period, all products should have been included for tariff reductions. ${ }^{212}$

From the beginning this attempt at economic integration faced serious problems. The 12 year liberalization schedule was postponed and finally extended until 1980. The total number of tariff concessions granted by LAFTA members on their "national lists" more than doubled between 1962 and 1968, but almost stagnated from then on and the common list performed even worse. Only one list was approved in 1964, but it never became effective. The arrangements for industrial complementation covered very few sectors, most of which were dominated by multinational corporations located in the three larger countries (Argentina, Brazil and Mexico).

During the first 5 years of LAFTA the intra-trade grew from 322 to 700 billion dollars (FIEL, 1991), which represented only 9 per cent of member countries total trade. After a couple of years, the process was stopped and it was no longer possible to follow the agreement signed in 1960.

The Montevideo Treaty was an inappropriate scheme to achieve trade liberalization and economic integration and therefore to promote development. The failure of the negotiation mechanism became clear through the sluggish evolution of the intra-regional volume of trade. LAFTA's exports directed to the regional market only increased from 7.5 to 11.4 per cent between 1962-1964 and 1971-1972. The ratio then remained stable at less than $14 \%$ until the dissolution of LAFTA in 1980.213

210 The transition period was extended to 20 years through the Caracas Protocol (1969).

211 For details see FIEL (1991), INTAL (1980).

212 See Finch (1982), FIEL (1991).

213 See FIEL (1991), Ferrer (1996), Tussie (1987), Mace (1988). 
There are several explanations for the failure of LAFTA and probably all of them have in some way contributed to the delay in the integration process. Firstly, there were some political inconsistencies in the initial proposal. There were, in fact, two projects under negotiation in the late 1950 s whose objectives and methods were not wholly compatible. The treaty of economic integration had to take into account the membership to GATT of some of the participating countries, the opposition of the IMF to a proposed scheme of regional payments and the initial hostility of the US government to the emergence of an exclusive Latin American trading system. (Finch, 1982). Secondly, the type of products for which tariff concessions were granted generated several problems. Most were either primary products (whose intra-regional trade had been traditionally based) or commodities that had never been produced within the region. Thirdly, most of the larger member countries showed a high degree of macroeconomic instability, which reduced their willingness to move towards an intra-regional trade reform. ${ }^{214}$ The agreement did not provide any mechanism to coordinate the economic policies of member countries. In this sense, the slow acceleration in the volume of intra-regional trade was the consequence of encouraging an intensification of traditional patterns of trade within the region. The mechanisms of tariff reduction based on a discussion product by product was extremely bureaucratic and did not encourage dynamic trade. Finally, the project was probably too ambitious and not very realistic, as it did not take into account the huge heterogeneity between the economic structures of the eleven member nations and the lack of an adequate infrastructure.

\section{New attempt at integration: LAIA}

The failure of LAFTA induced Latin American countries to formulate a new and less ambitious institutional framework to allow economic integration and in 1980 the Latin American Integration Association (LAIA) ${ }^{215}$ was created. This new arrangement replaced the original and ambitious goal of establishing a free trade area in the whole of Latin America with the much more pragmatic objective of facilitating bilateral negotiations on commercial agreements that might be generalized to other countries in the region. The basic functions of this new association included the promotion and regulation of reciprocal trade, the achievement of economic implementation and the development of an economic cooperation that could contribute to market expansion. 216

The basic instruments envisaged were bilateral tariff negotiations and the granting of regional tariff preferences by each of the member countries. These tariff preferences, however, were not subject to any predetermined schedule and were not intended to be part of a common external tariff for the region. In order to execute the basic function of LAIA, member countries defined an area of economic preferences that would comprise of tariff preference agreements of regional scope (PAR) and agreements of partial

214 The system of payment provided by LAFTA, inspired by the COMECON agreement, attempted to allow Latin American countries to save foreign reserves by compensating for bilateral trade imbalances in goods. Because larger countries enjoyed chronic trade surpluses and the smaller ones deficits, the larger countries were no longer willing to trade with smaller countries.

215 LAIA or in Spanish ALADI (Asociación Latinoamericana de Libre Comercio).

216 See Finch (1982), Cardenas (1992), INTAL (1992). 
scope (AAR). The first included not only commercial agreements but also trade promotion measures and all the member countries participated. However, only two or three member states participated in the PAR, and benefits were not automatically extended to other countries. A number of exemptions were also established, taking into account that some sectors were highly vulnerable in some member countries. As in the previous agreement, it was also contemplated that the less developed countries could reduce their tariffs at a slower rate. 217

Since its foundation, the results of LAIA have been very modest. In general, it has been limited to renegotiating agreements inherited from the previous LAFTA with no significant increase of trade across the region being observed.

The poor performance of both the LAFTA and LAIA trade agreements can be explained by several significant factors. The Latin American countries were themselves very heterogeneous; they had reached different stages of development and their economies showed relatively low complementation. There were three categories of economies; those with a relatively developed industry (Brazil, Argentina, Chile, Venezuela), intermediate (Colombia, Peru, Uruguay, Mexico) and relatively less developed (Bolivia, Ecuador, Paraguay). The agreement, in part, met specific objectives of a Southern cone group of countries by renewing to some extent the traditional trade flows. However, this objective and indeed a more extensive process of trade liberalization did not meet the aspirations of the smaller and less developed member countries. The infrastructure of transport and telecommunications was not very well developed and constituted a constraint to trade increase and no important effort was made to achieve any improvements in this area. Political factors also did not favor integration. During the 1970s Latin American countries showed a high degree of political instability with several military coups, which contributed to an increase in old rivalries between neighboring countries. 218 External factors also played an important role. The debt burden faced by most Latin American countries during the 1980s induced additional financing problems and pushed all of them to expand their trade surpluses simultaneously, consequently reducing intra-regional imports. In particular, it was the larger countries of the region, such as Argentina and Brazil, who were facing the most serious problems. During the 1980s the intra LAIA imports fell from 10500 to 7500 billion dollars, and the LAIA imports to the rest of world fell from 75300 to 43600 billion dollars between 1980 and $1985 .{ }^{219}$ The debt crisis proved to be not only a restriction to trade, but also increased the already high macroeconomic instability. Although foreign debt was undertaken partially by the private sector, governments were the legal guarantors and therefore were obliged to obtain the necessary resources to meet external payments (Fanelli, Frenkel and Rozenwurzel, 1990). This situation provided an inflationary environment with an important fall in domestic consumption and investment which, in turn, further reduced imports from other Latin American countries.

Unlike the example of the European countries, the Latin American states started the economic integration process without a previous period of cooperation. However,

217 See CEPAL (1992), ALADI (1993).

218 In almost all Latin American countries the borders with their neighbor countries are not well defined. Argentina has border problems with Chile and Brazil, Peru with Chile, Ecuador with Peru, and Venezuela with Columbia.

219 See CEPAL (several issues), FIEL 1991. 
while the institutional design of the LAFTA scheme and the disparity of its membership may be regarded as the primary factor responsible for its failure, it should also be taken into account that regional trade had occupied only a marginal place in the total foreign trade of the region before 1960 and held no place at all in the prevailing import-substitution strategies of the post 1940 period. In addition, the philosophy of development based on the import substitution strategy was itself anti-trade biased and could not help to increase trade flows. The integration rhetoric was based more on politics than on economics; in academia the integration philosophy was in itself close to "dependency thought" 220 showing a scarce relationship with a realistic trade strategy that could have improved trade flows and facilitated growth.

\section{Other Free Trade Agreements between Latin American Countries}

The failure of the previous integrationist attempts of LAFTA and LAIA induced the Latin American countries to undertake subregional agreements through the grouping of countries with similar economic structures. This new approach of integration led to the formation of the Andean $\mathrm{Pact}^{221}$ and CARICOM${ }^{222}$.

\section{The Andean Pact}

In 1969 Bolivia, Colombia, Chile, Ecuador and Peru signed the Cartagena Agreement creating the so-called Andean Pact. It had as an explicit goal the avoidance of the inconsistencies and poor performance of LAFTA. Optimistic expectations were formed based on the relative economic homogeneity of the member countries and a shared belief in an industrial planning strategy as the prerequisite of a successful integration process. 223

The main objectives of the Andean Pact were (1) a progressive liberalization of intraregional trade, (2) the gradual achievement of a common external tariff, (3) the design of regional investment programs, and (4) the establishment of a code for the common treatment of foreign direct investment ${ }^{224}$

The member countries agreed to carry out an automatic yearly reduction of their average tariff level of approximately seven per cent from the initial tariff structure in order to achieve a complete liberalization by 1980.225

Although this automatic liberalization schedule contrasted with the inefficient product by product strategy adopted by LAFTA the Andean Group scheme did several times issue exemptions from the proposed tariff reduction. In discussing the level of the

220 See footnote 2 of this chapter.

221 The Andean Pact is also known as the Andean Group.

222 Chile and Mexico are the only two countries that adopted a different approach. Chile chose an unilateral liberalization, withdrawing from the Andean Pact and declining an invitation to join MERCOSUR. Mexico on the other hand joined the two North American countries in the framework of NAFTA.

${ }^{223}$ Edwards (1992), Ocampo and Esguerra (1994).

224 Garay (1981).

225 The deadline was however not achieved in 1980 and was postponed to 1983 . 
common external tariff most member countries favored a high tariff as a way to protect the Andean Pact nations from foreign competition.

Throughout the 1970s Andean trade grew vigorously (Garay, 1981). However, this dynamism was only partly related to institutional developments. ${ }^{226}$ Indeed, neither the liberalization program nor the institutional framework of the Andean Pact functioned well. The common external tariff was never approved, liberalization for competitive goods was systematically postponed, and industrial development programs were designed only for a few sectors and proved unmanageable and operationally deficient, particularly due to the political criteria used to allocate new activities. Moreover, governments gradually abandoned the principles that initially inspired these agreements. This period coincided with favorable external factors, particularly the Venezuelan and Ecuadorian oil booms, and the simultaneous Colombian coffee bonanza, which generated rapid income growth in most Andean countries.

In contrast, during the 1980 s intraregional trade experienced a prolonged crisis as a consequence of commodity and debt crises which affected the Andean nations (including Colombia, although to a lesser extent) ${ }^{227}$. In order to correct their balance of payment deficits, all the member countries devaluated their currencies during this period and imposed trade restrictions. By the end of the decade the Andean Pact had virtually collapsed due to a widespread transgression of the liberalization program by member countries and the total breakdown of the industrial programs.

In an attempt to avoid the dissolution of the regional scheme flexibility was introduced, inducing the postponement of existing obligations and the creation of provisions such as administered trade and industrial complementary agreements.

The results obtained by the Andean Pact were more satisfactory than those achieved by LAFTA but much less than expected.

The proportion of Andean Group exports traded in the regional market increased from 1.7 per cent in 1970 to 4.5 per cent in 1979 and then remained stable at around 4 per cent. ${ }^{228}$

The main factors contributing to this poor achievement were the serious difficulties faced by members in designing the common external tariff, and the inconsistency between regional industrial planning strategy and the particular trade regime prevailing in each individual member state. In addition, differences in the level and dispersion of the protective structure of the Andean Group members generated divergent positions regarding the appropriate timing and the optimal level of the common external tariff. The problem was exacerbated by the overvaluation of most of the member's real exchange rate and essentially because of the existence of several different exchange rate practices within the region that made it even more difficult to measure the effective protection rate received by any activity in any particular country. 229

By 1985 the Andean Pact had became completely paralyzed. After 1989 there were new political stimuli which removed the original import substitution elements, and emphasis was placed on inter-regional trade liberalization, the elimination of restrictive provisions regarding direct investment and intellectual property rights. Through

226 For details see Ocampo and Esguerra (1994).

227 See Junta de Acuerdo de Cartagena (1986).

228 See CEPAL (1985).

229 See Morales de Marega (1983). 
the presidential meeting at Galapagos Islands (1989) the heads of state of the Andean countries decided that most restrictive provisions would be phased out and that a free trade zone would be implemented by December 1993 (1995 for Bolivia and Ecuador). The 1990 Meeting in La Paz accelerated these commitments with a decision to consolidate the free trade zone by December 1991 for all members, and establish a customs union by December 1993. Whether this new integrating effort will survive is still open to question. The volume of intraregional trade has not increased considerably and some countries, including Bolivia, have presented applications for membership of MERCOSUR.

\section{Economic Integration in Central America}

Central American economies have also developed some agreements for commercial integration, their first attempts dating from the mid-1960s (CARIFTA) ${ }^{230}$

The gains from this integration process were strongly biased in favor of the most developed countries of the agreement. As a result, the less developed countries exerted pressure for broadening the scope of integration (Rodriguez, 1994). This situation led to the creation of the Caribbean Community (CARICOM) in August 1973. Its objectives went further than commercial integration ${ }^{231}$ and involved the harmonization of monetary and fiscal policies and the establishment of a common external tariff for imports from non-member countries.

During the early mid-1980s, as a result of the international debt crisis, the Central American Common Market broke down, and most countries in the area responded to the debt crisis by imposing massive non tariff barriers including multiple exchange rates.

In July of 1991 and after several years of independently undertaking trade adjustments, the governments of the Central American nations decided to revitalize the Central American Common Market. The main differences from the previous agreements are that the external tariff represents a clear movement towards trade liberalization and that the countries have adopted an export promotion philosophy instead of promoting an inefficient and forced industrialization. ${ }^{232}$

The following table summarizes the current situation of regional integration among the Latin American countries.

230 CARIFTA was initially subscribed to by Antigua, Barbados and Guyana. the agreement was ratified by the other Caribbean countries.

231

232 For details see Hirst (1992) 
Table 4.2.1

Latin American Current Regional Integration Schemes

\begin{tabular}{|c|c|c|}
\hline Name & Countries & Objectives \\
\hline Group of three & $\begin{array}{l}\text { Columbia } \\
\text { Mexico } \\
\text { Venezuela }\end{array}$ & $\begin{array}{l}\text { Elimination of tariffs } \\
\text { Reciprocal co-operation }\end{array}$ \\
\hline Chile-Mexico & & $\begin{array}{l}\text { Elimination of tariffs } \\
\text { Deregulation of transport }\end{array}$ \\
\hline Andean Group & $\begin{array}{l}\text { Bolivia, Columbia, } \\
\text { Ecuador } \\
\text { Peru, Venezuela }\end{array}$ & $\begin{array}{l}\text { Elimination of tariff with some } \\
\text { exceptions } \\
\text { Common external Tariff } \\
\text { Capital mobility } \\
\text { Harmonization of domestic } \\
\text { policies } \\
\text { Transport deregulation } \\
\text { Promotion of foreign direct } \\
\text { investment }\end{array}$ \\
\hline $\begin{array}{l}\text { Common Market of } \\
\text { Central America }\end{array}$ & \begin{tabular}{|l|} 
Costa Rica, El Salva- \\
dor, Guatemala, \\
Honduras, Nicaragua, \\
Panama
\end{tabular} & $\begin{array}{l}\text { Tariff reduction } \\
\text { Liberalization of common ag- } \\
\text { ricultural trade } \\
\text { Common external tariff } \\
\text { Harmonization of internal } \\
\text { policies }\end{array}$ \\
\hline MERCOSUR & $\begin{array}{l}\text { Argentina, Brazil, } \\
\text { Uruguay, Paraguay }\end{array}$ & $\begin{array}{l}\text { Common external tariff } \\
\text { Elimination of trade tariffs } \\
\text { Harmonization of domestic } \\
\text { policies }\end{array}$ \\
\hline $\begin{array}{l}\text { Economic Carib- } \\
\text { bean Community }\end{array}$ & 15 countries & $\begin{array}{l}\text { Common external tariff } \\
\text { Common external policy } \\
\text { Monetary harmonization }\end{array}$ \\
\hline
\end{tabular}

Source: FIEL (1991)

\subsubsection{The New Integration Approach}

During the 1980s, integration gained new impetus in Latin America and previous arrangements such as the Central American Common Market (CACM), the Andean Pact, and the Caribbean Community (CARICOM) have been given new life. Other new bilateral and multilateral arrangements have also flourished ${ }^{233}$, among others NAFTA, MERCOSUR and the Free Trade area of Chile-Mexico. This new integration wave contrasts sharply with past experiences, reflecting dramatic transformations in the development strategies on which they are based. Integration schemes are now considered as part of an offensive strategy that can reinforce the insertion of the region into the world economy. The new approach is directed towards outward-looking, extroverted

233 See Bouzas and Ross (1994) for details. 
integration schemes (Fischer 1994, von Klaveren 1995) based on market oriented resource allocation, which in turn stimulates competitiveness. These new preferential trade arrangements link for the first time, either in the rhetorieal or actual negotiations, countries from the North and South along the lines of reciprocal arrangements ${ }^{234}$ (Borrmann, 1996).

In contrast to previous experiences which were strongly based on import-substitution policies, integration is now being accompanied by unilateral trade liberalization, the opening of national economies, and important overall macroeconomic reforms 235 The previously slow and erratic movement towards trade has turned into a massive change of direction that relies on the export imperative originating in the financial constraint that the debt crisis of the 1980s posed to most Latin American countries ${ }^{236}$. The new integration strategy constitutes part of the answer in response to the dramatic problem originating in the debt burden, the macroeconomic disorder economic stagnation and the deterioration of social conditions (Bouzas and Lustig, 1992). General economic strategy experienced radical changes in most of the countries in the region. New international circumstances and the influence of creditors forced the countries to undertake stabilization policies and structural adjustments based on the opening up of the internal market, privatization and the deregulation of economic activity, flexibilization of labor markets and on fiscal austerity (Ferrer 1996). Currently, radical structural reforms are taking place across the Latin American economies. Most Latin American countries have launched severe stabilization processes, public finances are being forced under control, public enterprises are being privatized, and goods and labor markets are being deregulated. In general, the Latin American countries are undergoing a transformation process to develop a more investment friendly environment This new wave of integration has been motivated by a number of factors including a general awareness about the weakening of Latin America's position in international trade and financial markets This is aggravated by a growing concern that the world trade system may be gravitating towards regional trading blocs aligned around the European Community, NAFTA, and Japan.

Regionalism is thus viewed as a precondition for securing effective competitiveness and increased negotiating capacity in global markets (Hurrel 1992). In additional, Latin American national markets are too small, and integration allows member states to take advantage of economies of scale. Widened markets are also more attractive to foreign partners and become effective instruments for competing for goods, services and capital in world markets (Peña 1992).

The new wave of regionalism in Latin America is also strongly linked to political factors with an overall democratization process occurring in the region. Transitions to democracy coincide with the quest for integration ${ }^{237}$. Thus, the new integration

${ }^{234}$ For example NAFTA, and the "Initiative for the Americas", which will be a free trade area covering from Alaska to Usuahia and starting in 2005. The agreement between MERCOSUR and the EU, MERCOSUR and NAFTA, etc.

235 See for details Hirst (1992), Astori (1991), Kesman (1992), Sargmeister (1994).

${ }^{236}$ Latin American countries were forced to achieve a current account surplus in order to fulfill foreign debt services.

237 The new integration process is based on the assumption that membership is restricted to democratic governments. 
schemes are rooted in an accelerated trade liberalization process, which includes reciprocity in the concession of preferences, and the simultaneous search for special trade relations with other countries or blocks. Even more, the integrationist process has received a bigger impetus with the almost generalized renovation of governments across the region between 1989 and $1990^{238}$ The new institutional framework is much more flexible and dynamic than in the past, formed by collective leadership from participating governments rather than by autonomous technical secretariats ${ }^{239}$. In contrast to previous integration attempts, it is the first time that entrepreneurial sectors support the process and even participate actively in the initiative, introducing a new ingredient of competitiveness and adding dynamism to the process (Hirst, 1992). ${ }^{240}$

In summary, the new environment that dominates the international scene of the 1990s explains the high speed of the generalized abandonment of import-substitution industrialization and its translation into a far reaching liberalization of trade regimes that sharply contrasts with the old goal of expanding protected domestic markets to benefit from economies of scale and specialization. The new integration process focuses on improving and securing market access to facilitate industrial restructuring and on the generation of an environment more attractive to foreign direct investment ${ }^{241}$.

\section{The Integration between Argentina and Brazil}

The drive towards integration between Argentina and Brazil began in the mid-1980s with the signing of several agreements of economic cooperation ${ }^{242}$ The momentum arose from two significant changes experienced by these two countries; political evolution towards the consolidation of democratic institutions $\mathrm{s}^{243}$ and a shift towards free market policies. The first agreement between these two countries was the so-called "Integration Act" (Acta de Integracion) 244 signed in 1986 and the "Treaty of develop-

238 Presidential changes in Latin America between 1988 and 1992: MERCOSUR members Argentina (July 1989), Uruguay (March 1990), Paraguay (May 1989). Andean Group members: Bolivia (July 1989), Ecuador (July 1988), Colombia (July 1990), Peru (July 1990), Venezuela (February 1989). Central American Common Market: El Salvador (July 1989), Guatemala (January 1991), Honduras (November 1989), Panama (May 1990), Nicaragua (February 1990), Costa Rica (February 1990), and Mexico (November 1988).

239 For details see Ondarts (1992), Gratius (1994).

240 Hirst (1992) supports the idea that the integrating tendency is not an isolated process but covers the whole region, although in a fragmentary way. in this sense there are several small integrating initiatives; the Andean Pact, the Group of Three, Agreement Chile-Mexico, Agreement Argentina-Chile, Agreement Venezuela-Argentina. She suggests that a process prevails in which many initiatives coexist simultaneously and strive to achieve integration and cooperation among small groups of countries and these also reinforce the associative impulse with selective criteria.

241 See Gratius (1994), Weber von (1995), Ferrer (1996).

242 There were movements towards a close economic integration between Argentina and brazil during the Alfonsin-Sarney era. The former was the Argentinean president from 1983-89 and Sarney was president of Brazil from 1985-1990.

243 For the analysis in respect of the evolution of the democratic process within MERCOSUR countries see Alimonda (1993).

244 For detail see Acta para la Integración Argentino-Brasileña (29/7/86). 
ment and cooperation" signed in 1989245. The bilateral integration efforts between Argentina and Brazil started with the Declaration of Iguazú in November 1985 and the Declaration of Integration in 1986. In November 1988 both countries signed the final Integration Treaty, which came into force on 24 August 1988.

The Treaty provided the road towards integration over a period of ten years and agreed some basic principles: gradualism, flexibility, equilibrium and symmetry. These principles were designed in order to allow the progressive adaptation of the economic sectors of each country to the new enlarged conditions of competition. This also demonstrated the concern of different sectors within both countries about the existing asymmetries between their respective systems and economic structures. ${ }^{246}$

Initially, these bilateral agreements were conceived within the general framework of LAIA and based on traditional industrial and trade policies with an inward-looking strategy. Nevertheless, a big change in the design of the new regional integration policy came immediately after the presidential changes of Menem, in Argentina and Collor, in Brazil (Edwards, 1993). The democratization process of both countries has induced some relaxation in the political tensions between them, which had been especially exacerbated during military regimes. This improvement in bilateral political relations induced a substantial increase in bilateral trade, although it was quite unbalanced in favor of Brazil due to the unilateral liberalization and stabilization program launched by Argentina and the corresponding overvaluation of the Argentine currency. The initial instrument of this new integration process was the Iguazu declaration (1985) that showed the desire of both countries to undergo closer cooperation policies. The following year the Mixt Commission (Comision Mixta) was created, which was formed by the governments and private sectors of both countries. In June 1986, the Act of Integration Argentina-Brazil was signed establishing the program of economic integration and cooperation between both nations (Mayoral, 1992). This program attempted to accelerate technological modernization and to achieve a better resource allocation between both economies by taking advantages of economies of scale. The basic instruments used were the protocols that defined the rules and general strategies of the integration process. A total of 24 protocols was signed in six government meetings (see Appendix 4.1).

The Argentina-Brazil relationship demonstrated an extraordinary ability to overcome huge political and economic changes, including the presidential changes in both countries, a hyperinflationary process which led to a large fluctuation in national output and domestic demand, dramatic changes in the parities of domestic currencies ${ }^{247}$ and even the shift in the initial strategy of integration ${ }^{248}$. In 1990 Brazil started the unilateral full

\footnotetext{
245 See Perez del Castillo (1993), Naum (1993), Gosner (1995).

246 This concern about asymmetries relates to the different cost structures faced by the industries of each country. These were not related to their own individual efficiency but instead to external factors, such as different taxes, energy and other service costs, labor and social security laws, exchange rates and credit regimes.

247 Inflation was 5,000 per cent in 1991 and 2,5000 per cent in Brazil in 1993. 'This situation induced a change of parity of the domestic currency of over 40 per cent in 1992 in respect to 1986

248 Seitenfus (1993) analyzes in detail the initial objectives of MERCOSUR based on a gradual process and its later shift towards an accelerated liberalization program.
} 
trade liberalization process that overhauled the existing integration agreement. The initially selective opening of markets on a product by product basis was replaced by automatic tariff reductions and aimed at establishing a Customs Union by January 1995 thereby providing the basis for MERCOSUR. ${ }^{249}$ This bilaterally managed liberalization induced not only a large expansion in the trade of both countries but there was also an important change in the structure of the exports with a clear shift towards a larger proportion of manufactured goods of industrial origin. ${ }^{250}$

Due to this experience trade between Argentina and Brazil has grown much more than other Latin American trade flows. Between 1985 and 1994 the former increased six times and the latter only three (Ferrer, 1996). Whilst in 1985 trade flows between Argentina, Brazil, Paraguay and Uruguay represented 28 per cent of the total LAIA trade, in 1994 it reached more than 43 per cent. Intra-MERCOSUR trade in the service sector, banks, transport, insurance and private investment, and joint ventures are much more intense in the Southern cone than in the rest of the Latin American region. There exist some additional reasons that explain a bigger dynamic among the MERCOSUR countries. In comparison with previous arrangements, this time it concentrated on the two larger countries, Argentina and Brazil, which are the most diversified and industrialized economies of I atin America (Ferrer 1991). Despite the deindustrialization process experienced by Argentina during the last two decades, the country still has a respectable industrial base and a relatively diversified export manufacturing sector. The natural integration forces are much stronger the more diversified the economic structure of the participant countries. Geographical proximity is an insufficient incentive if the social and productive structure of member states has little interaction and consequently provides only a weak space for intra-industry trade specialization. ${ }^{251}$ The higher the initial level of development previous to the integrating agreements, the larger are the possibilities of a division of labor based on the intra-industry trade. 252 Consequently, the higher dynamism of MERCOSUR with relation to other Latin American agreements is explained by the axis Buenos Aires-Sao Paulo, which is one of the most developed and industrialized regions in South America.

249 The Agreement was formalised through the Act of Buenos Aires in 1990.

250 Initially the trade between both countries was based on agricultural goods and industrial goods of agricultural origin, where income elasticity is relatively low.

251 This lacking of an industrial base was the reason for failure in some African and Central American agreements.

252 Among the most successful trade agreements are the European Union and the bilateral agreement of USA-Canada. In all these cases, previous to the signing of the agreements there was already an important economic interdependence. 


\section{The Enlargement of the Agreement to Paraguay and Uruguay}

Although the main objective of this new integration approach was to include countries with relatively similar size and economic structure in order that intra-industry trade and trade creation could develop rather than trade diversion ${ }^{253}$, in the Asuncion treaty the Brazilian and Argentinean governments agreed to invite the two smaller countries of Uruguay and Paraguay to participate in MERCOSUR as full members (Bizzozero and Lujan, 1991). ${ }^{254}$ There were several reasons for their inclusion ${ }^{255}$ in the first round of integration, although the most important was probably their geographical proximity to Brazil and Argentina, which induced the idea that they were natural partners. Although the relevance of their individual trade with respect to the total trade of Argentina and Brazil was insignificant, for these two countries the trade with Argentina and Brazil as a proportion of their own total trade was quite significant (over $40 \%$ ). In addition, the Uruguayan economy is strongly influenced by short term developments.in the economies of its neighboring countries, Brazil and Argentina. In the case of Paraguay, Brazil and Argentina showed political interest in maintaining good relations with this country because of their hydroelectric projects: Itaipú, and Yaciretá, respectively. The inclusion of Paraguay was also seen as a symbolic way to ensure and reinforce the continuity of the Paraguayan democratization process 250

\section{MERCOSUR: The Asuncion Treaty}

The Asuncion Treaty signed on March 26, 1991, by the four parties of Argentina, Brazil, Paraguay and Uruguay set the framework for negotiating the establishment of the new common economic area in Latin America, called MERCOSUR. On 29 November, 1991, it was presented to the Latin American Integration Association (LAIA) under the legal framework of the Acuerdo de Complementacion Económica (ACE-18). MERCOSUR, which started on 1 January, 1995, for the first two partners and 1996 for. the smaller two was conceived, at least in the first stage as a customs union 257

The institutional structure is by construction verv flexible. MERCOSUR is open to other Latin American countries that fulfill basic requisites. MERCOSUR countries themselves have signed free trade agreements with third parties, like Chile and Bolivia

253 Viner (1950) pointed out that a move towards free trade by two nations who continue to maintain high tariffs against other countries could leave them worse off rather than better off because trade diversion instead of trade increase would arise.

254 The idea behind this was to create a new free trade area with relatively few players which could then be enlarged in the next future. The purpose was to reedit the experience of the EU when, starting from the cooperation of France and Germany, the process was later extended to other European countries. See Astori (1991).

255 In 1986 it was agreed that Uruguay would be included in the free trade area and in 1990 it was decided that Paraguay would also join.

256 In April 1996 the Paraguayan Army headed by Oviedo initiated a coup attempt with the intention of deposing the democratically elected president, Wasmosy. The unconditional support of Argentina and Brazil towards the democratic authorities was probably the most important factor in overcoming the crisis. see America Financiera (1996).

257 The countries will strengthen the economic relationship in the future towards reaching a common market. 
and with other trade areas, like the EU ${ }^{258}$. There is also a project to sign a free trade agreement with NAFTA and ASEAN.

The importance of the four MERCOSUR countries in the Latin-American subcontinent can be highlighted by pointing out that in 1996 they encompassed $50 \%$ of the region's gross domestic product, $60 \%$ of its population and $40 \%$ of the region's foreign trade ${ }^{259}$ It includes a population of 200 million inhabitants within an area of 11.863 square $\mathrm{km}$ and produces a GDP of 600 billion dollars.

The Asuncion Treaty constituted a change in the initial approach towards economic integration and cooperation between Argentina and Brazil, with the objective of the establishment of a common economic area. However, the original principles of the Brazil-Argentina agreements of gradualism, flexibility, equilibrium and symmetry were maintained in order to facilitate the adjustment of different economic sectors to the new competitive conditions.

The Asuncion Treaty defined the main goals of MERCOSUR (Kesman, 1992) as follows:

a. Free circulation of goods, services and productive factors among member countries and elimination of all tariff and non-tariffs restrictions.

b. Settlement of a common external tariff (AEC) which has to be the consequence of a common external trade policy.

c. Coordination of macro-economic policies among the four countries.

d. The harmonization of internal legislation.

The main challeneses faced by MERCOSUR were the design of the permanent government structure and a reasonable macroeconomic convergence of member states. The design of the common external tariff was the first serious problem faced by member states There was strong resistance due to fears relating to the trade diversion effects that the AEC could originate. The focus of concerns in designing the common external tariffs was linked to the extent of divergence among the tariff structures of member countries (Sargmeister, 1994, Astori, 1991). However, the fact that the MERCOSUR countries had already unilaterally embarked on substantial trade liberalization and greatly simplified their tariff structures helped an agreement to be reached. ${ }^{260}$ The decision concerning the common external tariff was taken in 1992 at the III Council Meeting (CMC). Maximum rates were fixed at 20 per cent, but allowed for exceptions of specific products (which could face reductions over a longer period from 1995 to the beginning of 2001). The maximum tariff offers made by all partners in September 1992 were already below 20 per cent with the exception of some peaks in the Brazilian tariff. These high Brazilian tariffs applied to cars (35 per cent), information goods ( 35 percents), chemicals (30 per cent), consumer electronics ( 30 per cent) and computer-

258 In 200s a free trade area between MERCOSUR and the European Union will begin. In October 1996 the free trade agreement with Chile started and was followed in November 1996 with one in Bolivia. there are also negotiations towards signing an agreement with NAFTA in order to join a free trade area by 2005 .

259 See Fritsch and Tombini (1994).

260 The number of tariff levels is five in Argentina, 4 in Uruguay, 4 in Paraguay and 8 in Brazil. The equivalent figure in the USA and the European Community is 180 and 100 respectively. 
ized machinery (25 per cent) (Fritsch and Tombini 1994). ${ }^{261}$ The second fundamental problem lies in trying to avoid rapid artificial shifts in intrazone competitiveness caused either by the impact of eliminating border distortions (tariff and export subsidies) or by large fluctuations in the bilateral real exchange rate relating to the relative prices of domestic production and competing imports measured in a common currency. The most crucial aspect is how to constrain the large fluctuations in the bilateral real exchange rate since, until now, although the fourth objective of MERCOSUR was to coordinate the macroeconomic policies, no measure has been introduced concerning this issue.

\section{Institutional Aspects of MERCOSUR}

The Asuncion Treaty represented the main organ of MERCOSUR during the transition period, which was scheduled to last until December, 1994. The Treaty itself was designed to be replaced in Ianuary 1995 by the Council of the Common market and the Group of the Common Market (GCM). The former is the political branch and heads the hierarchy of MERCOSUR governing bodies. It consists of the presidents of the four member countries, as well as the ministers of finance and foreign affairs. The Council meets once a year with the presidents of the member countries in attendance, the presidency of the Council is assumed for 6 six months by each member country in rotation (FIEL, 1992). The latter is the executive branch and supervises the implementation of the Asuncion Treaty, enforcing negotiation deadlines and decisions of the Council of the Common Market and also the adoption of necessary measures to comply 262 with the terms of the treaty.

An advisory committee with representatives of the Ministry of Foreign Affairs, Ministry of Finance and the Central Bank forms the national section of the Group of the Common Market. The Treaty recommends the GMC to form Working Subgroups in order to achieve particular objectives In addition, in 1991 the Parliamentary Commission of MERCOSUR was created with the task of analyzing projects and specific agreements negotiated by governments before being sent to the respective countries. Nevertheless, there has not been built yet a permanent supranational institution that allows the enforcement of community rules, and the intergovernmental structure will continue to form the supranational framework of MERCOSUR 263

261 Argentina, Uruguay and Paraguay pressed for faster and more extensive tariff reductions in the producer goods subset (computers, chemicals and machinery) because they are not substantial producers of these goods. There was slight pressure on Brazil to liberalize its car industry tariffs as Argentina is also engaged in car manufacture and still applies quotas.

262 There are actually eleven Subgroups: ST1 Trade Policy, Customs Affairs, ST3 Technical norms, ST4 Fiscal and Monetary policy related to trade, ST5 Transport, ST6 Maritime Transport, ST7 Industrial and Technological Policies, ST8 Agricultural Policies, ST9 Energy Policy, ST10 Coordination of macroeconomic policies, ST11 Labor affairs, employment and social security.

${ }^{263}$ For details of institutional aspects see Revista de Integration, ALADI, Dichiara (1994). 


\section{The Transition Period}

The Asuncion treaty established a short transition period in order to avoid unnecessary damage to any productive sector (Cardenas 1992). Due to different characteristics developed during the process of industrial development, the production structure of the member countries was heterogeneous. Industrial sectors, particularly in Argentina and Brazil, showed complex problems, including industries not being internationally competitive, low productivity rates, low technological innovation, excessive government regulation, inefficient public services, and in Brazil a damaging economic instability at least until 1995.

Therefore, the Asuncion Treaty designed five tools to be used during the transition period to facilitate the road towards the common market. These are:

\section{a. Commercial Liberalization Program}

Annex 1 of the Asuncion Treaty contains a Commercial Liberalization Program whose main purpose was to eliminate all tariff and non-tariff barriers before 31 December, 1994.

The tariff elimination regime contemplated two changes: first a progressive and automatic elimination of all tariffs among all members (see table 4.2.1) and second, a deeper tariff elimination among those members that have already entered into partial scope agreements that do not extend to the other member countries. 
Table 4.2.2

\section{MERCOSUR Reduction Tariffs Program}

(Percentage of Reduction

on the Actual Tariff)

\begin{tabular}{|c|c|c|c|c|c|c|c|c|c|}
\hline $\begin{array}{l}12 \\
1990\end{array}$ & 6.1991 & 6.1991 & $\begin{array}{l}12.199 \\
1\end{array}$ & 6.1992 & $\begin{array}{l}12.199 \\
2\end{array}$ & 6.1993 & $\begin{array}{l}12.199 \\
3\end{array}$ & 6.1994 & $\begin{array}{l}12.199 \\
4\end{array}$ \\
\hline 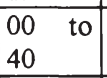 & 40 & 47 & 54 & 61 & 68 & 75 & 82 & 89 & 100 \\
\hline \begin{tabular}{|ll}
41 & to \\
45 & \\
\end{tabular} & 50 & 52 & $\overline{59}$ & 66 & 73 & 80 & 87 & 94 & 100 \\
\hline $\begin{array}{ll}46 & \text { to } \\
50 & \end{array}$ & 50 & 57 & 64 & 71 & 78 & 85 & 92 & 100 & \\
\hline $\begin{array}{|ll|}51 & \text { to } \\
55 & \\
\end{array}$ & 55 & 61 & 67 & 73 & 79 & 86 & 93 & 100 & \\
\hline $\begin{array}{ll}56 & \text { to } \\
60 & \\
\end{array}$ & 60 & 67 & 74 & 81 & 88 & 95 & 100 & & \\
\hline $\begin{array}{|ll|}61 & \text { to } \\
66 & \\
\end{array}$ & \begin{tabular}{|l|}
65 \\
\end{tabular} & 71 & 77 & 83 & 89 & 95 & 100 & & \\
\hline $\begin{array}{|lc|}66 & \text { to } \\
70 & \\
\end{array}$ & 70 & 75 & 80 & 85 & 90 & 95 & 100 & & \\
\hline $\begin{array}{|ll|}71 & \text { to } \\
75 & \end{array}$ & 75 & 80 & 85 & 90 & 95 & 100 & & & \\
\hline $\begin{array}{|ll|}76 & \text { to } \\
80 & \\
\end{array}$ & 80 & 85 & 90 & 95 & 100 & & & & \\
\hline $\begin{array}{|ll|}81 & \text { to } \\
85 & \\
\end{array}$ & 85 & 89 & 93 & 97 & 100 & & & & \\
\hline $\begin{array}{|ll|}86 & \text { to } \\
90 & \\
\end{array}$ & 90 & 95 & 100 & & & & & & \\
\hline $\begin{array}{|ll|}91 & \text { to } \\
95 & \\
\end{array}$ & 95 & 100 & & & & & & & \\
\hline $\begin{array}{ll}96 & \text { to } \\
100 & \end{array}$ & 100 & & & & & & & & \\
\hline
\end{tabular}

Source: Article 3 of the Asuncion Treaty.

\section{b. Rules of Origin}

The rules of origin were one of the central provisions of the Treaty and applied until the common external tariff was enforced. The reason for needing rules on the origin of goods to be traded among the member countries is that whilst tariffs within the common market are being lowered, each country has different tariffs for imports from outside the common market. This could make it especially profitable to import parts and/or goods from a third country with lower tariffs than the ones being applied within the common market and to re- export them or to export the final goods to the common market, thus profiting from the tariff differentials. 


\section{c. System of Settlement of Disputes}

Annex III of the Asuncion Treaty provided a few rules with respect to the settlement of disputes which may arise among the member countries during the transition period.

\section{d. Common Tariff Policies}

The Asuncion Treaty also had provisions relating to the tariff policies of the member countries, designed to prevent the neutralization of the tariff preferences arising from the timetable for automatic tariff liberation.

They made provisions for tariff exemption to always be calculated on the lowest external residual tariff. If one member country raised its tariffs for imports from outside the common market the preference would continue to be applied on the tariff in force at the time the Treaty became effective, and if one of the members reduced its external tariffs, the preference will be applied on the new reduced level.

The provisions also stated that the parties could preserve the tariff preferences agreed upon between themselves and that they could consult among themselves prior to making unilateral reductions in their external tariffs which could then cancel the concessions.

\section{e. The Safeguard Clause}

This clause had the primary purpose of temporarily limiting imports of a product from a member country which would damage national producers of the same product. In the event of this the country affected could request a round of consultations.

This request must be accompanied by explanations and a description of the facts. This is important as such action could eventually give rise to retaliation from other member countries. The consultation must be started within ten days from the request being submitted and a decision must be taken within twenty. During these consultations the countries involved should negotiate an import quota. Annex IV provides for consultations between parties should be a member country consider its economic activities adversely affected by actions which do not necessarily imply or threaten damage to its market. This clause has the purpose of dealing with any other unexpected disruptions. This tool could only be used during the transition period and only once, which means that if the safeguard clause has been already applied to a certain product, once its duration has ended it is not possible to get it reimposed. 


\subsection{Macroeconomic Profile of MERCOSUR Stylized Facts}

Exchange rate systems are not neutral. They have significant effects on output, employment inflation and balance of payments adjustments. They can be applied as an instrument in stabilization processes in order to increase credibility at the cost of reducing flexibility or vice versa. In addition, the choice between different degrees of flexibility constitutes a trade off towards credibility. Therefore, it becomes very important to understand the macroeconomic background of the countries under analysis in order to draw some conclusions towards the design of an exchange rate agreement. Thus, government preferences attached to the objectives of both flexibility and stability are closely related to the overall macroeconomic environment. The purpose of this section is to present a clear picture of the macroeconomic global structure of individual MERCOSUR states, highlighting the asymmetries that MERCOSUR countries face and the overall implications for the introduction of monetary agreements between countries.

\section{Structure and Evolution of Regional GDP}

MERCOSUR comprises a large economy (Brazil), an intermediate economy (Argentina) and two small economies (Uruguay and Paraguay). The two small economies show a much lower degree of economic development than either Brazil or Argentina. Paraguay, the least developed, shows nevertheless, the best macroeconomic performance during the 1980s. Among these countries there exist important differences in productive structure, growth patterns, levels of development, employment rates, foreign trade structures, share of government sector on GDP, foreign indebtedness and degree of coverage of the welfare state. However, all the countries as "dependent economies" have suffered similar external shocks, such as two oil shocks, a lack of liquidity in the international system the debt crisis, the political economic response of the individual countries and their macroeconomic performence was fairly heterogeneous across the last three. Brazil was the only economy in Latin America that achieved a positive, albeit small rate of growth during the 1980s. After the initial recession which originated in the debt crisis, Brazil partially adapted its strategy and achieved a moderate export-led recovery between 1984-1985.

A brief study of MERCOSUR shows that the value added of the manufacturing industry occupies seventh place in the world after the four six principal industrialized countries (excluding the former USSR). The highest percentage of value added is contributed by Brazil, whose dynamism in its industrial sector during the last two decades was only outperformed by the NICS (new industrialized countries) of the South-eastern Asian countries and Japan (see table 4.3.3)

The GDP of the four MERCOSUR countries together represents 49.2 per cent of LAIA GDP, however Brazil. alone represents. 77 per cent of total MERCOSUR GDP, Argentina only 20 per cent, Uruguay 1 per cent and Paraguay 2 per cent. Moreover, the MERCOSUR GDP structure has changed over the last three decades with the growing significance of the Brazilian economy and a declining importance of the 
Argentinean GDP. ${ }^{264}$ In 1970 Brazil contributed 59 per cent of the MERCOSUR GDP while Argentina contributed 37 per cent. (see table 4.3.2)

The growth rates per annum show a heterogeneous pattern across countries. While Brazil and Uruguay show average GDP growth rates of 8.6 and 8.7 respectively for the period 1970-1980, Argentina grew by only 2.6 per cent and Paraguay by 3 per cent over the same time period. During the $1980 \mathrm{~s}^{265}$ GDP growth rates show an important change with a significant slowdown in all the economies. Brazil grew on average by 2.2 per cent, Uruguay by 3.2 per cent, and Paraguay by only 1.7 per cent, whilst Argentina suffered a GDP fall of 1.4 per cent. Since 1990 the growth pattern has changed in favor of Argentina and between 1990 and 1994 Argentina grew on average by 6.2 per cent per annum whilst Brazil grew by only 096 per cent. Uruguay by 3.1 per cent and Paraguay by 3.31 ver cent (see tables 4.3.2 and 4.3.4)

${ }^{264}$ The economic policies introduced in Argentina during the 1970s and 1980s induced a strong deindustrialization process. Although both countries initiated their industrial development through import-substitution policies, once the model showed symptoms of weakness during the 1970s Argentina responded by switching partially to an import led growth model in 1978. The inability to strengthen these reforms caused a return to the old highly protected import substitution model in 1983. In contrast, after the debt crisis in 1982, Brazil managed to adjust the import substitution model during the 1980s and to some extent to transform it into an export led growth model.

${ }^{265}$ The 1980 s was labeled by economists as the lost decade. 
Table 4.3.1

Basic Indicators

\begin{tabular}{|c|c|c|c|c|c|c|c|c|}
\hline & \multicolumn{2}{|c|}{ Argentina } & \multicolumn{2}{|l|}{ Brazil } & \multicolumn{2}{|c|}{ Uruguay } & \multicolumn{2}{|c|}{ Paraguay } \\
\hline $\begin{array}{l}\text { Area } \\
\text { (thousand of } \\
\text { square } \mathrm{km} \text { ) }\end{array}$ & \multicolumn{2}{|l|}{2767} & \multicolumn{2}{|l|}{8512} & \multicolumn{2}{|l|}{177} & \multicolumn{2}{|l|}{407} \\
\hline $\begin{array}{l}\text { Population } \\
\text { (millions } \\
\text { inhabitants) }\end{array}$ & \multicolumn{2}{|l|}{33.1} & \multicolumn{2}{|l|}{153.9} & \multicolumn{2}{|l|}{3.1} & \multicolumn{2}{|l|}{4.5} \\
\hline $\begin{array}{l}\text { GDP per capita } \\
\text { USS } 1994\end{array}$ & \multicolumn{2}{|l|}{8041} & \multicolumn{2}{|l|}{3563} & \multicolumn{2}{|l|}{5599} & \multicolumn{2}{|l|}{1817} \\
\hline $\begin{array}{l}\text { Average } \\
\text { Growth GDP } \\
\text { per-capita } \\
(1980-1992) \text { in } \\
\%\end{array}$ & \multicolumn{2}{|l|}{-0.5} & \multicolumn{2}{|l|}{0.3} & \multicolumn{2}{|l|}{-0.1} & \multicolumn{2}{|l|}{-0.7 . } \\
\hline $\begin{array}{l}\text { Average annual } \\
\text { inflation rate }\end{array}$ & $\begin{array}{l}1970- \\
1980 \\
134.2 \\
\end{array}$ & $\begin{array}{l}1980- \\
1993 \\
374.3\end{array}$ & $\begin{array}{l}1970- \\
1980 \\
38.6\end{array}$ & $\begin{array}{l}1980- \\
1993 \\
423.4\end{array}$ & $\begin{array}{l}1980- \\
1993 \\
63.7\end{array}$ & $\begin{array}{l}1980- \\
1993 \\
66.7\end{array}$ & $\begin{array}{l}1970- \\
1980 \\
12.7\end{array}$ & $\begin{array}{l}1980- \\
1993 \\
25\end{array}$ \\
\hline $\begin{array}{l}\text { Life expect. at } \\
\text { birth } \\
1993\end{array}$ & 72 & & 67 & & 73 & & 67 & \\
\hline $\begin{array}{l}\text { Adult illiteracy } \\
\text { in \% } \\
1993\end{array}$ & 5 & & 20 & & 4 & & 12 & \\
\hline
\end{tabular}

Source: World Development Report 1995, World Bank

\section{Table 4.3.2}

Structure and Evolution of the Regional Economies

(in $\%$ at 1980 constant prices)

\begin{tabular}{|l|l|l|l|l|l|l|}
\hline & \multicolumn{3}{|c|}{$\begin{array}{c}\text { Percentage of Total } \\
\text { MERCOSUR members } \\
\text { GDP }\end{array}$} & \multicolumn{3}{c|}{ Growth Rate } \\
\hline & 1970 & 1980 & $1990-95$ & 1970 & 1980 & $1990-95$ \\
\hline Argentina & 37 & 25 & 20 & 2.6 & -1.4 & 6.2 \\
\hline Brazil & 59 & 72 & 77 & 8.6 & 2.2 & 0.96 \\
\hline Uruguay & 1 & 1 & 1 & 8.7 & 3.2 & 3.1 \\
\hline Paraguay & 3 & 2 & 2 & 3 & 1.7 & 3.0 \\
\hline MERCOSUR & 100 & 100 & 100 & 6.6 & 1.4 & 3.31 \\
\hline
\end{tabular}

Source: Anuario Estadístico de América Latina y el Caribe (several issues) CEPAL. 


\section{Manufactured Added Value}

\begin{tabular}{|c|c|c|c|}
\hline & $\begin{array}{lr}1970 & \text { (millions } \\
\text { current } & \text { US } \\
\text { dollars) } & \end{array}$ & \begin{tabular}{|l|}
1991 (millions \\
current \\
dollars)
\end{tabular} & $\%$ increase \\
\hline 121 countries & 722.2 & \begin{tabular}{|l|l|}
3555.3 \\
\end{tabular} & 4.9 \\
\hline USA & 253.9 & 868.2 & 3.4 \\
\hline MERCOSUR & 16.6 & 103.4 & 6.2 \\
\hline Brazil & 10.4 & 78.9 & 7.6 \\
\hline Argentina & 5.7 & 22 & 3.8 \\
\hline Paraguay & na & na & na \\
\hline Uruguay & na & na & na \\
\hline
\end{tabular}

Source: Anuario Estadístico de América Latina y el Caribe, CEPAL and Progreso Económico y Social de América Latina. BID (several issues)

Table 4.3.4

Real Gross Domestic Product (GDP)

Average annual growth rate

\begin{tabular}{|l|l|l|l|l|}
\hline Year & Argentina & Brazil & Uruguay & Paraguay \\
\hline 1985 & -6.6 & 7.8 & 1.5 & 4 \\
\hline 1986 & 7.3 & 7.5 & 8.9 & 0 \\
\hline 1987 & 2.6 & 3.5 & 7.9 & 4.3 \\
\hline 1988 & -1.9 & -0.1 & 0 & 6.4 \\
\hline 1989 & -6.2 & 3.2 & 1.3 & 5.8 \\
\hline 1990 & 0.1 & -4.4 & 0.9 & 3.1 \\
\hline 1991 & 8.9 & 0.2 & 3.2 & 2.5 \\
\hline 1992 & 8.7 & -0.8 & 7.9 & 1.8 \\
\hline 1993 & 6 & 4.1 & 2.5 & 4.1 \\
\hline 1994 & 7.4 & 5.7 & 5.1 & 3.5 \\
\hline
\end{tabular}

Source: Progreso Económico y Social de América Latina. BID (several issues)

By observing the GDP structure (table 4.3.5) the following conclusions are obtained: the industrial sectors in Argentina and Brazil are much more deyeloped than their counterparts in Paraguay and Unuguay. In 1994 the secondary sector represented 30.7 per cent of total GDP in Argentina, 37.3 per cent in Brazil, 23.1 per cent in Paraguay and 28.7 per cent in Uruguay. The service sector, in contrast, represents an important share of GDP at 63.3 per cent in Argentina, 605 per cent in Uruguay 51.9 per cent in Brazil and 52.4 per cent in Paraquay. However, the compositions of these service sectors differ between countries. Basic services represent 17 per cent of GDP in Argentina, 10 per cent in Uruguay and in both Brazil and Paraguay count for less than 8 per cent. In contrast, the financial sector is the main contributor to the service sector in Brazil and Uruguay representing 24 per cent of GDP and 23 per cent respectively. Uruguay introduced important measures to liberalize its financial sector in the late 
1970s for example, by allowing private banks to hold deposits in every foreign currency. Although the Uruguayan government does not guarantee these deposits, no restrictions are imposed.)

This situation has transformed Uruguay into a small "finaneial paradise" and it has become the financial center of the Southern eone, capturing deposits in every foreign currency, especially from nationals of Argentinian and Brazilian origin. 266 The diverging behavior of financial development in Brazil and Argentina can be explained by their responses to hyperinflationary processes. Whilst Brazil allowed the automatic indexation of deposits in domestic currency, Argentina underwent a strong dollarization process. As Arnaudo (1987) explains, indexation in financial operations was introduced in Brazil in 1964 with satisfactory results which led to a growth in the financial assets/output ratio. The Argentinian economy was "de facto" dollarized. Therefore, at least until 1991, the prohibition of foreign bank account holdings and any financial instruments denominated in foreign currency, meant that a large proportion of financial instruments left the official system ${ }^{267}$. Dollarization became legal and official through the introduction of the currency board system in $1991^{268}$ which allowed private banks to lend and borrow in foreign currency and to have foreign currency denominated accounts. Since 1994 even reserve requirements can be held in US dollars, in domestic currencies or a combination of both ${ }^{269}$

The agricultural sector constitutes a large share ( 24.5 per cent) of Paraguayan GDP, which is evidence of a predominantly agricultural economic structure in contrast to the relatively well developed industrial sectors of Argentina and Brazil.

The evolution of these sectors across these three countries between 1980 and 1994 shows a similar pattern. In all these examples the importance of the industrial and agricultural sectors diminished in favor of the services sector.(see table 4.3.5)

266 In February 1995, 90 per cent of the US dollar deposits in Uruguay were owned by nationals of Argentina. See America Financiera (1995). After the Mexican crisis of December 1994 there were important capital inflows into Uruguay which originated in deposits from Argentinean nationals that left the Argentine financial system because of fears that the Argentinean government would abandon the currency board system.

267 This was the origin of the huge capital flights during the 1970s and 1980s. See Mastroberadino (1994).

268 For a description of the Currency Board in Argentina see Canavese (1992).

269 The Currency Board fixed the domestic currency to the US dollar on a ratio of $1: 1$. 
Table 4.3.5

GDP Structure

(as \% of GDP)

\begin{tabular}{|c|c|c|c|c|c|c|c|c|}
\hline Sector & \multicolumn{2}{|c|}{ Argentina } & \multicolumn{2}{|c|}{ Brazil } & \multicolumn{2}{|c|}{ Paraguay } & \multicolumn{2}{|c|}{ Uruguay } \\
\hline & 1980 & 1994 & 1980 & 1994 & 1980 & 1994 & 1980 & 1994 \\
\hline Agriculture & 6.4 & 6 & 11 & 10.8 & 28.6 & 24.5 & 13.5 & 10.8 \\
\hline Industry & 41.2 & 30.7 & 43.8 & 37.3 & 27.4 & 23.1 & 33.7 & 28.7 \\
\hline Services & 52.4 & 63.3 & 45.2 & 51.9 & 43.9 & 52.4 & 52.8 & 60.5 \\
\hline Total & 100 & 100 & 100 & 100 & 100 & 100 & 100 & 100 \\
\hline
\end{tabular}

Source: Anuario Estadístico de América Latina y El Caribe. CEPAL

Table 4.3.6

Distribution of the population

in percents

\begin{tabular}{|l|l|l|l|l|}
\hline \multicolumn{3}{|c}{1970} & \multicolumn{2}{c|}{1995} \\
\hline Country & urban & rural & urban & rural \\
\hline Argentina & 78.4 & 21.6 & 82.6 & 13.8 \\
\hline Brazil & 55.8 & 44.2 & 76.9 & 23.9 \\
\hline Paraguay & 37.2 & 62.9 & 47.5 & 52.5 \\
\hline Uruguay & 82.1 & 17.9 & 90.5 & 9.5 \\
\hline
\end{tabular}

Source: World Development Report, 1996. World Bank

In regard to investment rates, the four countries all show important differences in relation to the developed countries. Whilst in most industrialized countries investment rates reach between 20 and 25 per cent of GDP, and in Japan and the Southern Asian countries this figure is even higher, (only the USA shows a relatively low investment rate at 17 per cent), among MERCOSUR member states there has been an important deterioration in the investment rate during tho 1990s. The share of GDP invested was much lower in 1993 than it was in 1980 (see table 4.3.7). However, the behavior of investment rates is very diverse across the countries and between decades. Paraguay shows a very low starting rate (12.5) in 1970 but its performance was very dynamic in the following two decades, showing the largest investment rate arfong the four countries analyzed. (31.7 in 1980 and 22.5 in 1993). Argentina and Brazll invested similar proportions of their GDP in 1993. In both cases the rates of investment decreased sharply between 1980 and 1993, from 25.3 to 18.4 in Argentina and from 23.3 to 18.2 in Brazil. Uruguay shows the lowest investment rate of all MERCOSUR countries at 17.3 in 1980 and 12.8 in 1992.

Argentina and Uruguay are the worst performers among the four MERCOSUR countries in terms of the evolution of their investment rates. However, both countries show different behavior patterns over time. Uruguay manifested a chronically poor performance for decades, which can be explained by an oversized welfare system. 270 In contrast, Argentina shows a significant fall in the investment rate since 1980. This

${ }^{270}$ The welfare system of Uruguay is the most developed in the region. 
situation is explained by the huge capital flight (Mastroberardino, 1994) that left the country due to macroeconomic instability, in particular through high inflation rates and uncertainty in regard to government behavior towards dcmestic savings in foreign currency 271

In general, the explanation of the poor performance of investment rates in Latin American countries can be found in the highly unstable macroeeonemie environment that has contributed to increased uncertainty. Although many authors, such as Williamson (1995), argue that the main problem of the Latin American countries is the low savings rates (see table 4.3.8), this situation is not entirely true in some cases, particularly as regards Argentina. Although individual saving rates were quite large problems arose due to the high degree of macroeconomic and political instability. Consequently, domestic savings holdings remained out of the financial system (currency substitution) ${ }^{272}$ or were deposited abroad ${ }^{273}$.

Table 4.3.7

Gross Domestic Investment/GDP

\begin{tabular}{|l|l|l|l|l|}
\hline Year & Argentina & Brazil & Paraguay & Uruguay \\
\hline 1970 & 20.5 & 21.5 & 12.5 & 10 \\
\hline 1980 & 25.3 & 23.3 & 31.7 & 17.3 \\
\hline 1985 & 17,8 & 19.2 & 22.5 & 11.4 \\
\hline 1991 & 14,5 & 18.9 & 24.8 & 12.6 \\
\hline 1992 & 16.7 & 17.5 & 23.5 & 12.8 \\
\hline 1993 & 18.4 & 18.2 & 22.5 & - \\
\hline
\end{tabular}

Source: Anuario Estadístico de América Latina y El Caribe. CEPAL

Table 4.3.8

Gross Domestic Savings/GDP

\begin{tabular}{|l|l|l|l|l|}
\hline Year & Argentina & Brazil & Paraguay & Uruguay \\
\hline 1980 & 23.8 & 21.1 & 183 & 11.7 \\
\hline 1985 & 23.1 & 24.4 & 18.9 & 17 \\
\hline 1991 & 16.2 & 20.9 & 158 & 15.8 \\
\hline 1992 & 15.1 & 20.8 & 10.5 & 13 \\
\hline 1993 & 16.5 & 20.2 & 13.5 & na \\
\hline
\end{tabular}

Source: World Development Report, 1995 World Bank

271 During the aftermath of the foreign debt crisis the Argentinean government (Alfonsin) was forced to collect tax in order to face the payment of arrears corresponding to the external debt. Therefore, economic agents had high expectations of exorbitant increases in taxation. In addition, investors were afraid that the government could freeze or even confiscate the dollar deposits of domestic investors. Savings deposits in domestic currency also had a very high devaluation risk. In addition, the highly macroeconomic uncertainty was not a very friendly environment for physical investments.

272 Analyzes of currency substitution are found in Brandt (1993), America Financiera (1993). For the theoretical background see Calvo and Rodriguez (1977).

273 Capital flight. See Mastroberardino (1994). 


\section{Fiscal Sector}

Since 1985 the fiscal finances show an important improvement in all the MERCOSUR countries. This is especially true of Argentina and Brazil, who between 1985 and 1989 held the highest Deficit/ GDP ratios (6 per cent in Argentina for 1988 and 7.4 per cent in Brazil for 1989). Argentina has reversed its chronic deficit (between 4 per cent and 6 per cent of GDP) into a surplus since 1992, although in the last two years the fiscal deficit has reappeared ( 2 per cent of GDP). This improvement has been primarily achieved through reductions in expenditure. Current revenue was much lower (16.8) in 1994 than in 1985 (28.3). ${ }^{274}$ Brazil has also sharply reduced its fiscal deficits since 1991 , reaching a fiscal balance in 1994. However, Uruguay has not introduced any improvements on the fiscal side. However, this has never been a severe problem with the highest rate over the period being only 3.5 per cent. Finally, Paraguay does not show any serious fiscal problems (see Fig. 4.3.3).

Fiscal imbalances would probably be one of the major problems for the MERCOSUR countries if they decided to introduce some form of macroeconomic coordination. Although all the members agree on the importance of reaching balanced fiscal finances, improvement in this area depends on structural reforms, in particular, privatization and the restructure of the central administration. Discussions concerning the adjustment of the fiscal sector have reached different degrees in the MERCOSUR countries. While Argentina has privatized most of its government assets, Brazil is still in the first stages and the process is particularly torturous because of need for amendments in the Brazilian constitution of 1988. The Brazilian constitution does not allow the exploitation by foreign capital of some sectors of the economy (refinery of oil, mining). This situation complicates the privatization process significantly as MERCOSUR relies on foreign capital for large amounts of investment. 275

\section{Monetary Sector}

The monetization ratio considered as M1/GDP is relatively high in Paraguay and Uruguay, while in Brazil and Argentina it is extremely low as a consequence of the inflationary processes suffered by these two countries. (see Figure 4.3.5) Argentina showed the lowest monetization rate in 1989 ( 0.9 percent of GDP) exactly at the time that hyperinflation was taking place. However, the remonetization process has been important since 1991, when the new structural reforms began. In 1994 the ratio reached 5.4 per cent of GDP and was increased over the following years ${ }^{276}$ (See Fig. 4.3.6).

274 Since 1995 the fiscal deficit reappeared again as a problem in Argentina. The output fall suffered through the huge impact imposed by the Mexican crisis of 1994 (known as the "tequila effect") induced an important reduction in tax collection. Although this deficit is not monetized because of the strength of the convertibility law, the Argentinean government has increased its public debt. see America Financiera (1996).

275 Actually, this was the reason why during the 1940s in Argentina and the 1960s in Brazil the state undertook the exploitation of some economic activities.

276 See America Financiera (1996). 
In the case of Brazil, monetization has decreased over time, showing the destructive impact of the inflationary process. Brazil started with structural reform much later than Argentina. Whilst Argentina started in 1991 (Convertibility Plan), Brazil did it four years later (Real Plan).

By analyzing the behavior of prices following the CPI (consumer price index), it is clear that the two largest countries have suffered chronic inflation and hyperinflationary processes (See Fig. 4.3.5).

Argentina suffered a dramatic self-destructing hyperinflationary process in 1989 when yearly CPI reached 3079.9 , although since then inflation has been reduced. Yearly inflation reached 3.9 per cent in 1994 and 1.6 per cent in 1995.

Brazil also suffered a hyperinflationary process $(2937.8$ per cent in 1990). The introduction of a stabilization plan in 1991 reduced it to 440.9 per cent but hyperinflation reappeared again in 1993 and 1994. Recently in 1995, with the introduction of the Real plan inflation per annum was reduced to 16 per cent.(See Fig. 4.3.5)

The interest rates also show the behavior of underlying prices, reaching 17236 per cent in Argentina during 1989 and decreasing to 8 per cent in 1994. In Brazil the nominal interest rate reached the highest ration in 1989 at 2622.9 and decreased in 1994 to 1227.5. In Paraguay and Uruguay interest rates have reached moderated values, however the real interest rates have been mostly negative.(See fig. 4.3.7)

\section{Exchange Rates and Capital Inflows}

The four countries follow very different exchange rate arrangements. The Central Bank of Paraguay follows a free floating exchange rate regime. Since 1991 the economy has suffered the effects of large capital inflows and the monetary authorities were confronted with the dilemma of choosing between holding the real exchange rate steady by accumulating reserves, with the consequent expansion of means of payments, or allowing the currency to appreciate and limiting the inflationary impact. The policy implemented by the Central Bank achieved a degree of balance between the two alternatives, which translated into a real appreciation of the domestic currency (guarani) vis-à-vis the US dollar. The Central Bank frequently stepped into the exchange market and the guarani rose in real terms by approximately 11 per cent in relation to the US dollar. Uruguay applies a crawling exchange rate (vis-à-vis the US dollar) with a band of fluctuation and the exchange rate is applied as an instrument against inflation. The government follows a policy of a 2 per cent per month devaluation, which is lower than the monthly inflation. Abundant capital inflows have maintained the currency at the floor of the floating band, which allows a fluctuation of up to 7 per cent. During 1993 and 1994 capital inflows contributed to a further appreciation of the currency, forcing the central bank to intervene to suppolt the band. Although the Uruguayan peso was appreciated regarding the dollar. the effect on trade was partially offset by the overvaluation of the Brazilian and Argentinean currencies.

After a hyperinflationary process, Brazil introduced a new currency in July 1994, the Real, which was initially pegged to the US dollar. It appreciated substantially after its introduction. In March 1995 the Central bank announced a new exchange rate policy, 
introducing fluctuation bands 277 . The administration has tacitly moved to a crawling exchange rate band policy. Unlike the excessively hasty change in March 1995 the policy adjustment was handled successfully and has contributed to stable exchange rate markets.

Finally Argentina, with the introduction of a currency board system in 1991, shows the most extreme version of a fixed exchange rate system ${ }^{278}$. Since 1991 large capital inflows have caused a strong appreciation of the Argentinean Peso. Fig 4.3.8 shows the evolution of the capital account of the respective countries

In summary, the four countries demonstrate all the possible alternative exchange rates systems from free floating, as in Paraguay to a fixed exchange rate, as in Argentina. Nevertheless all have suffered from the impact of large capital inflows from 1991 and all currencies have been appreciating during recent years. However, because these capital inflows come from third countries this offsets the impact between their currencies.

Nevertheless, the unilateral correction of the nominal parities has caused important shifts in competitiveness. Table 4.3.9 shows the real parities among MERCOSUR currencies. Figure 4.3.10, shows the relationship between bilateral currency parities and trade surplus (deficit) between Argentina and Brazil.

277 The band has been adjusted twice. First on 20 June, 1995 R\$0.91/US\$-R\$0.99/US\$ and then on 20 July, 1995 to between R\$0.928/US\$ and R\$0.932/US\$.

278 The currency board experience is explained in detail in the next section. 
Table 4.3.9

Real Exchange Rate

\begin{tabular}{|l|l|l|l|}
\hline Year & Peso/Real & $\begin{array}{l}\text { Peso/Guara } \\
\text { ni }\end{array}$ & $\begin{array}{l}\text { Peso/Peso } \\
\text { Uruguayo }\end{array}$ \\
\hline 1989.12 & 369.6 & 230.7 & 265.9 \\
\hline 1990.12 & 100 & 100 & 100 \\
\hline 1991.12 & 87.9 & 114.8 & 121.6 \\
\hline 1992.12 & 84.1 & 111 & 109.0 \\
\hline 1993.12 & 80.6 & 107.9 & 120.9 \\
\hline 1994.4 & 104.1 & 115.5 & 130.9 \\
\hline 1994.12 & 79.7 & 113.3 & 122.6 \\
\hline 1994.5 & 79 & 113.9 & 123.6 \\
\hline 1994.6 & 78.9 & 113.8 & 124.2 \\
\hline 1994.7 & 88.2 & 111.3 & 122.1 \\
\hline 1994.8 & 94.3 & 112.9 & 122.5 \\
\hline 1994.9 & 99.8 & 112.7 & 116.1 \\
\hline 1994.10 & 102.0 & 113.3 & 124.9 \\
\hline 1994.11 & 103.6 & 115 & 124.5 \\
\hline 1994.12 & 104.5 & 115.5 & 130.9 \\
\hline 1995.1 & 105.1 & 116.8 & 130.8 \\
\hline
\end{tabular}

Source: Own calculation on the base of CEAL data

\section{Foreign Sector}

The two smaller economies of Paraguay and Unuguay represent the most open economies of the MERCOSUR members. Consequently, in 1993 the relation of total trade to GDP reached 62 per cent for Paraguay, and 43 per cent for Uruguay. Argentina and Brazil, the two larger economies in the region show a relatively low degree of openness, and total trade represents only 15 per cent of GDP for Argentina and 17 per cent for Brazil. All these countries show a movement towards a more open economy, with the exception of Brazu whose economy was more closed in 1993 than it was in 1980 (see table 4.3.10 and 4.3.11).

The participation of MERCOSUR in world trade is not very significant. In a sample of 121 countries the MERCOSUR countries as a whole are in the tenth place. It is in fact the two smaller economies who are in line internationally in terms of the openness of their economies.

Nevertheless, since 1985 the MERCOSUR volume traded has been increasing steadily in absolute terms. The data suggest that the expansion rate of global trade inside MERCOSUR has had a much better performance than that of LAIA. The trade among MERCOSUR countries has grown six times and that of LAIA only three times. The total exported value reached 11.901 millión US dollars in 1994 which reprêsents 18 per cent of the trade in 1993 and 125 per cent of total trade in 1991.

The importance of regional trade can be seen in its relative participation in the total export of the member countries which grew from 12 per cent to 19 per cent in 1991 .

Moreover, the development pattern of the member countries differs from country to country. In Argentina, exports to other MERCOSUR countries grew by 30 per cent 
and in Uruguay by 29 per cent. However, the exports of Brazil only increased by 9.7 per cent and of Paraguay by only 5 per cent. Brazil shows the lowest participation of MERCOSUR export share on total exports although in absolute terms exports 25 per cent more than Argentina. Argentina has increased its participation in MERCOSUR to 30 per cent, while Brazil's participation is stable. It seems important to point out that the share of manufactured goods in total exports is lower than those of the industrialized countries, except in the case of Brazil, where machinery and equipment represent 18 per cent of the manufactured exports. However, by observing the performance of the export products over time, the pattern can be seen to have been changing in the case of Argentina, Brazil and Uruguay shifting towards a larger participation of industrialized products. The total evolution of total Intra-MERCOSUR trade is depicted in Fig.4.3.9 and table 4.3.12, the corresponding to the individual countries.

Table 4.3.10

Openness of the Economy Trade/GDP in percents

\begin{tabular}{|l|l|l|l|l|l|l|}
\hline Year & Argentina & Brazil & Paraguay & Uruguay & $\begin{array}{l}\text { Average } \\
121 \\
\text { countries }\end{array}$ & $\begin{array}{l}\text { Average } \\
\text { OECD } \\
\text { countries }\end{array}$ \\
\hline 1980 & 12 & 20 & 44 & 36 & - & - \\
\hline 1985 & 18 & 19 & 50 & 48 & - & - \\
\hline 1991 & 14 & 15 & 67 & 43 & - & - \\
\hline 1992 & 15 & 17 & 62 & 43 & - & - \\
\hline 1993 & 15 & 17 & 62 & 43 & 31 & 30 \\
\hline
\end{tabular}

Source: World Development Report, 1994. WORLD BANK

Table 4.3.11

\section{Exports of Goods and NFT /GDP}

\begin{tabular}{|l|l|l|l|l|}
\hline Year & Argentina & Brazil & Paraguay & Uruguay \\
\hline 1980 & 5.1 & 9.1 & 15.3 & 15 \\
\hline 1985 & 11.7 & 12.2 & 23.2 & 26.8 \\
\hline 1991 & 7.8 & 8.5 & 28.8 & 23.2 \\
\hline 1992 & 6.6 & 10 & 24.4 & 21.5 \\
\hline 1993 & 6.3 & na & 26.6 & na \\
\hline
\end{tabular}

Source: Progreso Económico y Social de América Latina. BID (several issues) 
Table 4.3.12

Intra-MERCOSUR Countries 279 Exports

\begin{tabular}{|r|r|r|r|r|r|}
\hline Year & \multicolumn{1}{|l|}{ Argentina } & \multicolumn{1}{l|}{ Brazil } & Paraguay & Uruguay & Total \\
\hline 1985 & 667 & 990 & 82 & 212 & 1951 \\
\hline 1986 & 895 & 1170 & 133 & 398 & 2596 \\
\hline 1987 & 767 & 1388 & 127 & 369 & 2651 \\
\hline 1988 & 875 & 1643 & 155 & 451 & 3124 \\
\hline 1989 & 1428 & 1380 & 379 & 701 & 3888 \\
\hline 1990 & 1833 & 1320 & 379 & 712 & 4244 \\
\hline 1991 & 1978 & 2309 & 259 & 679 & 5225 \\
\hline 1992 & 2327 & 4098 & 246 & 689 & 7360 \\
\hline 1993 & 3684 & 5394 & 276 & 1019 & 10373 \\
\hline 1994 & 4740 & 5918 & 377 & 716 & 11751 \\
\hline
\end{tabular}

Source: National sources of the individual countries

Table 4.3.13

Argentina: Impact of MERCOSUR Countries on Imports 1975 - 1994 (per cent)

\begin{tabular}{|l|c|c|c|c|c|}
\hline from & 1975 & 1980 & 1985 & 1990 & 1994 \\
\hline World & 100 & 100 & 100 & 100 & 100 \\
Brazil & 9 & 10 & 16 & 18 & 19 \\
Paraguay & 1 & 1 & 1 & 1 & $-*$ \\
Uruguay & 1 & 1 & 2 & 3 & 4 \\
MERCOSUR & 11 & 12 & 19 & 22 & 23 \\
Third Countries & 89 & 88 & 81 & 78 & 77 \\
* less than 1 per cent & & & & & \\
\hline
\end{tabular}

Source: IMF, Direction of Trade, various issues; Foders (1996)

Table 4.3.14

Brazil: Impact of MERCOSUR Countries on Imports 1975 - 1994 (per cent)

\begin{tabular}{|l|c|c|c|c|c|}
\hline from & 1975 & 1980 & 1985 & 1990 & 1994 \\
\hline World & 100 & 100 & 100 & 100 & 100 \\
Argentina & 2 & 3 & 3 & 7 & 11 \\
Paraguay & $-*$ & $-*$ & 1 & 1 & 1 \\
Uruguay & $-*$ & 1 & 1 & 3 & 1 \\
MERCOSUR & 2 & 4 & 5 & 11 & 13 \\
Third Countries & 98 & 96 & 95 & 89 & 87 \\
$*$ less than 1 per cent & & & & & \\
\hline
\end{tabular}

Source: IMF, Direction of Trade, various issues; Foders (1996)

279 Although MERCOSUR started on 1995, trade already increased in the pre- MERCOSUR period. 
Table 4.3.15

Paraguay: Impact of MERCOSUR Countries on Imports 1975 - 1994 (per cent)

\begin{tabular}{|l|c|c|c|c|c|}
\hline from & 1975 & 1980 & 1985 & 1990 & 1994 \\
\hline World & 100 & 100 & 100 & 100 & 100 \\
Argentina & 19 & 20 & 17 & 12 & 15 \\
Paraguay & 21 & 27 & 36 & 17 & 12 \\
Uruguay & 2 & 3 & 1 & 1 & 1 \\
MERCOSUR & 42 & 50 & 54 & 30 & 28 \\
Third Countries & 58 & 50 & 46 & 70 & 72 \\
\hline
\end{tabular}

Source: IMF, Direction of Trade, various issues; Foders (1996)

Table 4.3.16

Uruguay: Impact of MERCOSUR Countries on Imports 1975-1994 (per cent)

\begin{tabular}{|l|c|c|c|c|c|}
\hline from & 1975 & 1980 & 1985 & 1990 & 1994 \\
\hline World & 100 & 100 & 100 & 100 & 100 \\
Brazil & 8 & 11 & 12 & 17 & 24 \\
Paraguay & 13 & 17 & 18 & 23 & 26 \\
Uruguay & 1 & 1 & 1 & 1 & $-*$ \\
MERCOSUR & 22 & 29 & 31 & 41 & 50 \\
Third Countries & 78 & 71 & 69 & 59 & 50 \\
* less than 1 per cent & & & & & \\
\hline
\end{tabular}

Source: IMF, Direction of Trade, various issues; Foders (1996)

Table 4.3.17

Foreign Debt Position

\begin{tabular}{|l|l|l|l|l|}
\hline Country & \multicolumn{2}{|l|}{$\begin{array}{l}\text { Total External Debt } \\
\text { as per cent of }\end{array}$} & $\begin{array}{l}\text { Total Debt } \\
\text { Services }\end{array}$ & Interest Payments \\
\hline & GDP & Exports & as percent of Exports \\
\hline Argentina & 28.6 & 413.3 & 46 & 25.3 \\
\hline Brazil & 26.3 & 296.0 & 24.4 & 9.2 \\
\hline Paraguay & 20.4 & 73 & 14.9 & 4.6 \\
\hline Uruguay & 54.3 & 243 & 27.7 & 16.5 \\
\hline
\end{tabular}

Source: World Bank, World Development Report 


\subsection{Recent MERCOSUR Relevant Experiences with Fixed Exchange Rates}

In this section, I will initially consider some common factors of the stabilization process based on fixed exchange rates. Secondly, I will concentrate on Argentina's and Brazil's last experiences of fixed exchange rates; the currency board system and the Real plan ${ }^{280}$. Whilst both developed in different ways, with the Argentinian economy dollarizing and the Brazilian economy achieving indexation, both constituted original and ingenious monetary arrangements to overcome high macroeconomic instability. The experiences of Uruguay and Paraguay are not included, as the former applies a quasi-crawling peg system with a band of fluctuations and the latter has introduced a flexible exchange rate regime, although the Paraguayan central bank intervenes into the market (dirty floating). In neither of these cases has macroeconomic instability been as extreme as in the Argentinian and Brazilian cases. The measures launched by these respective governments have had a significant impact on inflation, output, employment and investment. From a political point of view, an exchange rate agreement for MERCOSUR must essentially be supported by both the Brazilian and Argentinian governments due to the weight of both countries within the customs union. Therefore, to some extent it has to encompass both the systems that these countries have developed, individually and unilaterally, or at least has to consider their motivation, incentives and preferences.

\section{Stabilization Plans Anchored on Fixed Exchange Rates}

Since the late 1940s, as with some other Latin American countries ${ }^{281}$, the MSUR states have gone through a rather chronic inflationary process. The inflationary explosion was partly the natural consequence of the application of an import-substitution strategy, facilitated by oversized government sectors, and partly by external shocks, with both oil shocks and the debt crises contributing to common internal problems. Unlike hyperinflation, whose duration is measured in months and exhibits an explosive nature, chronic inflation is relatively stable and may last for decades. ${ }^{282}$ Countries adapt to live with high inflation by developing various indexation mechanisms in financial, labor and goods markets, which by reducing the private costs of inflation, tend to perpetuate the inflationary process. Although large deficits are a common cause of chronic inflation, accommodative monetary and exchange rate policy's widespread indexation is a

\footnotetext{
${ }^{280}$ Respect to previous experiences towards stabilization, Austral, Cruzado etc, there is extensive literature reviewing these experiences. See Heymann (1986), Kieguel (1989), Almansi (1989), Artana (1987), Blejer and Liviatan (1987), Calvo (1988), Canavese and Di Tella (1988), Cardoso (1988), Dornbush (1989), Lopes (1989), Cardoso (1990).

${ }^{281}$ Contrary to the popular mythology, not all Latin American countries have had long inflationary history. For details see Edwards (1994).

${ }^{282}$ The distinction between chronic inflation and hyperinflation goes back to Pazos (1972). Recent analyses are in Bruno (1994), Sachs (1987) and Vegh (1992).
} 
defensive response to living with permanent inflation ${ }^{283}$. Once chronic inflation has been installed in an economy to reduce budget deficits it is not sufficient to eliminate the problem. Thus, sophisticated indexatory defensive mechanisms that the economic agents have learned to develop to survive within an inflationary environment are hard to eradicate. In all cases, destroying chronic inflation has proved to be a difficult task, with the frequent failure of stabilization plans and the reappearance of inflation after a short period of relative stability. ${ }^{284}$ In the late 1970 s and 1980s a number of countries have tried to break these inertial inflationary forces by implementing stabilization programs based on replacing their crawling-peg systems with fixed exchange rates. With few exceptions, most major stabilization programs have fought chronically high inflation by using exchange rates as the main nominal anchor ${ }^{285}{ }^{286}$ The rationale behind this policy is that in an open economy the nominal exchange rate provides an efficient and credible anchor for prices helping to reduce inflation more rapidly and with lower costs than other, alternative anchors. In order for these programs to be successful in moving the economy towards lower inflation. the fixing of the nominal exchange rate has to be accompanied by restrictive credit and fiscal policies. There are, however, reasons why most economies have preferred an exchange rate rather than a monetary anchor, as in high inflationary countries velocity is difficult to predict ${ }^{287}$ (Rebelo and Vegh, 1995, Ahumada, 1989) and due to a high degree of dollarization monetary growth cannot be consistently targeted. ${ }^{288}$ During the last two decades, important stabilization plans have been launched by, among others, Argentina, Brazil and Uruguay. They are usually classified into either "heterodox" or "orthodox" styles. Some stylized facts and theoretical explanations of both kinds of programs have been summarized by Kiguel and Liviatan (1991) ${ }^{289}$ and are presented in Table 4.4.1 with some extensions. Although all of them have used the exchange rate as a nominal anchor, heterodox plans have introduced additional income policy measures, especially price and/or wage con$\operatorname{trols}^{290}$, while orthodox plans have not. However, in the past, orthodox as well as heterodox plans, have shown an inability or unwillingness to control other macroeconomic variables such as fiscal deficits. Therefore, to conclude that the cause of

${ }^{283}$ During the 1960 s and 1970 s there was considerable enthusiasm regarding the potential role of indexation as a way to isolate the real sector from the effects of inflation. See Edwards (1992).

${ }^{284}$ Regularly, it is not very difficult to reduce inflation from high levels to 20 or 30 percent yearly, however a movement toward a much lower inflation rate was hard and sometimes impossible to achieve. See Heymann (1991).

${ }^{285}$ The stabilization plan in Bolivia used the nominal stock of money as an anchor. Morales (1991).

${ }^{286}$ Early evidence is already give by the stabilization of the 1920 's hyperinflation. See Sargent (1982).

${ }^{287} \mathrm{By}$ starting from a high inflationary process and stopping inflation at once, introduces important changes in monetary behavior. In all stabilization plans there are an immediate increase in money demand as response to the new stable situation, however Central banks, although can predict direction cannot predict exactly the degree.

288 For further discussion. See Calvo (1994), Kiguel and Liviatan (1991), Bruno (1991), Calvo and Vegh (1990).

${ }^{289}$ See also Wehringer (1996)

${ }^{290}$ Sometimes there were not effective price controls but price guidelines. 
failure of past stabilizing attempts has been the use of the exchange rate as anchor might be misleading ${ }^{291}$.

Table 4.4.1

\section{Selected Cases of Exchange Rate Based Stabilizations}

\begin{tabular}{|c|c|c|c|c|c|c|}
\hline $\begin{array}{l}\text { Country } \\
\text { Period }\end{array}$ & $\begin{array}{l}\text { Exchange } \\
\text { rate }\end{array}$ & $\begin{array}{l}\text { Income } \\
\text { Policy }\end{array}$ & $\begin{array}{l}\text { Budget } \\
\text { reform }\end{array}$ & $\begin{array}{l}\text { Restrictive } \\
\text { monetary } \\
\text { and/or fiscal } \\
\text { policy }\end{array}$ & $\begin{array}{l}\text { Trade } \\
\text { Policy }\end{array}$ & $\begin{array}{l}\text { Deva- } \\
\text { luation } \\
\text { before }\end{array}$ \\
\hline $\begin{array}{l}\text { Argentina } \\
1959.3-1962.2 \\
1967.2 .197 .03 \\
1973,31975.2 \\
1978.4-1981.1 \\
1985.1-1986.3 \\
\text { Since } 1991.2\end{array}$ & $\begin{array}{l}\text { fixed } \\
\text { fixed } \\
\text { fixed } \\
\text { tablita } \\
\text { fixed } \\
\text { currency } \\
\text { board } \\
\end{array}$ & $\begin{array}{l}\text { no } \\
\text { gradual } \\
\text { yes } \\
\text { no } \\
\text { shock } \\
\text { no }\end{array}$ & $\begin{array}{l}\text { at beginning } \\
\text { yes } \\
\text { no } \\
\text { moderate } \\
\text { at beginning. } \\
\text { yes }\end{array}$ & $\begin{array}{l}\text { yes } \\
\text { no } \\
\text { no } \\
\text { yes } \\
\text { no } \\
\text { yes }\end{array}$ & $\begin{array}{l}\text { inversion } \\
\mathrm{KA}_{3} \\
\text { no } \\
\mathrm{KA}, \mathrm{CA}_{4} \\
\text { no } \\
\mathrm{CA}, \mathrm{KA}_{5}\end{array}$ & $\begin{array}{l}\text { yes } \\
\text { no } \\
\text { no } \\
\text { no } \\
\text { yes } \\
\text { yes }\end{array}$ \\
\hline \begin{tabular}{l|} 
Brazil \\
$1964.2-1968.3$ \\
$1986.1-1986,4$ \\
Since 1994.2
\end{tabular} & $\begin{array}{l}\text { st.dev.6 } \\
\text { fixed } \\
\text { fixed with } \\
\text { bands }\end{array}$ & $\begin{array}{l}\text { gradual } \\
\text { shock } \\
\text { gradual }\end{array}$ & $\begin{array}{l}\text { yes } \\
\text { no } \\
\text { moderate }\end{array}$ & $\begin{array}{l}\text { no } \\
\text { no } \\
\text { no }\end{array}$ & $\begin{array}{l}\text { yes } \\
\text { no } \\
\text { gradual }\end{array}$ & $\begin{array}{l}\text { yes } \\
\text { no } \\
\text { gradual }\end{array}$ \\
\hline \begin{tabular}{l|} 
Uruguay \\
$1968.2-1972.1$ \\
$1978.4-1982.4$ \\
$1985.4-1990$ \\
Since 1991.1
\end{tabular} & $\begin{array}{l}\text { fixed } \\
\text { tablita } \\
\text { float. } \\
\text { crawling } \\
\text { peg }_{7}\end{array}$ & $\begin{array}{l}\text { shock } \\
\text { no } \\
\text { no } \\
\text { no }\end{array}$ & $\begin{array}{l}\text { at beginning } \\
\text { yes } \\
\text { no } \\
\text { partially }\end{array}$ & $\begin{array}{l}\text { no } \\
\text { yes } \\
\text { no } \\
\text { yes }\end{array}$ & $\begin{array}{l}\text { yes } \\
\text { no } \\
\text { yes } \\
\text { yes }\end{array}$ & $\begin{array}{l}\text { yes } \\
\text { no } \\
\text { no } \\
\text { yes }\end{array}$ \\
\hline
\end{tabular}

Source: Kiguel and Liviatan (1992a). Own extensions.

\section{Table 4.4.2}

\section{Alternative Stabilization Plans}

\begin{tabular}{|l|l|l|}
\hline & $\begin{array}{l}\text { Restrictive monetary } \\
\text { and fiscal policy }\end{array}$ & $\begin{array}{l}\text { No Restrictive monetary } \\
\text { and fiscal policy }\end{array}$ \\
\hline Income Policy & Heterodox Plan & Illusionist Plan \\
\hline $\begin{array}{l}\text { Absence of income Pol- } \\
\text { icy }\end{array}$ & Orthodox Plan & No Plan \\
\hline
\end{tabular}

Source: Own design based on Bruno (1991)

${ }^{291}$ The experience of Chile during the 1970s and Israel during the 1980s showed that both orthodox (the first) and (heterodox) the second can succeed in bringing down inflation in a permanent way, if they are followed by a consistent fiscal policy. See Corbo de Melo (1986), Edwards and Cox-Edwards (1991), Edwards (1994), Bruno, Fischer, Helpman (1991). 
Table 4.4.3

Selected Cases of Exchange Rate-Based Stabilizations: Results

\begin{tabular}{|l|c|c|c|c|c|c|c|c|}
\hline \multicolumn{1}{|c|}{$\begin{array}{c}\text { Country } \\
\text { Period }\end{array}$} & $\begin{array}{c}\text { Inflation } \\
\text { rate }_{1}\end{array}$ & $\begin{array}{c}\text { GDP } \\
\text { high }_{2}\end{array}$ & $\begin{array}{c}\text { Cons. } \\
\text { boom }\end{array}$ & $\begin{array}{c}\text { Invst. } \\
\text { boom }\end{array}$ & CA $_{3}$ & $\varepsilon_{4}$ & W/P5 & $\begin{array}{c}\text { BD/ } \\
\text { GDP }_{6}\end{array}$ \\
\hline Argentina & $9,5-1,9$ & 1 & yes & yes & - & - & + &,-+ \\
$1959.3-1962.2$ & $2,5-2,7$ & 2 & yes & yes & - & - & + &,-+ \\
$1967.2-1970.3$ & $5,8-0,8$ & 1 & yes & no &,+- & - &,+- & + \\
$1973.3-1975.2$ & $8,1-8,6$ & 1 & yes & yes & - & - &,+- & + \\
$1978.4-1981.1$ & $24,9-2,6$ & 1 & yes & yes & - & - & - &,-+ \\
$1985.1-1986.3$ & $27-(1)$ & 1 & yes & yes & - & - & + & - \\
Since 1991.2 & & & & & & & & \\
Brazil & $6,4-4,2$ & 4 & n.a. & yes &,+- &,-+ &,-+ & - \\
$1964.2-1968.3$ & $11,1-1,7$ & 1 & yes & n.a. & - & - & + & $=$ \\
$1986.1-1986.4$ & $45,2-(1,6)$ & $(1)$ & yes & n.a. & $(-)$ & $(-)$ & $(+)$ & n.a. \\
Since 1994.2 & & & & & & & & \\
Uruguay & $9,5-1,9$ & 1 & yes & yes &,-+ &,-+ &,+- &,-+ \\
1968.2-1972.1 & $3,4-4,6$ & 1 & yes & no & - & - & - & + \\
$1978.4-1982.4$ & & & & & & & & \\
\hline
\end{tabular}

"n.a." indicates an unclear outcome or data not available; "=" indicate no or insignificant changes of respective variables; information within parenthesis indicate preliminary results.

${ }_{1}$ Monthly percentage change in inflation rates from the starting to the end point of the respective stabilization program.

${ }_{2}$ First year in which GDP grew above trend.

${ }_{3}$ Current account: "+" ... improvement, “_." ... deterioration.

${ }_{4}$ Real exchange rate $\varepsilon$ : “+” ... depreciation, “-“ ... appreciation.

${ }_{5}$ Real wages W/P “+" . . rise, “_“ ... fall.

${ }_{6}$ Budget deficit ratio $\mathrm{BD} / \mathrm{GDP}$ : “+” ... rise, “““ ... fall.

Source: Kiguel/Liviatan (1992). Own extensions. 
Although both kinds of stabilization plans were originated within totally different theoretical frameworks ${ }^{292}$, there are some constants across all the stabilization processes: 1) Slow convergence of inflation and devaluation rate: an exchange rate anchor is preferred because of its immediate effect on the inflation of traded goods, and overall inflation will quickly converge to the rate of devaluation (Rebelo and Vegh, 1995). However, due to some stickiness in non-tradable goods prices, the convergence is slow, and there is some persistence in the indexation of the non-traded goods. ${ }^{293}$

2)Initially an expansion in the economic activity takes place and is followed by a later slowdown. Exchange rate based stabilization develops a form of business cycle and once the exchange rate is fixed, there is initially an output expansion led by the nontraded sector, whose relative prices have experienced an improvement (Kiguel and Liviatan, 1992 b) Exchange based stabilization programs have therefore been very attractive, as instead of showing an initial recession, they induce an initial expansion, although this is followed by a recession Choosing between nominal anchor and exchange rate anchors implies a choice between two sequences; recession- expansion or expansion-recession.

Many of the exchange rate stabilization attempts failed because once the recession was approaching, fiscal measures were relaxed in order to postpone this, which undermined credibility $^{294}$, by implying an abandoning of the plan and a return to an inflationary process.

3)Real exchange rate appreciation is observed as a consequence of price increases in non-traded goods.

4) Wage increases in terms of the foreign currency. As CPI, as the weighted average between traded and non-tradable goods, increases there are claims for wage increases by labor unions.

5)The effect on interest rates has been ambivalent. In general, in most heterodox plans interest rates have increased whereas in orthodox plans they have declined. The theoretical explanation of the lowering effect on the interest rates is given by the assumption that uncovered interest parity holds ${ }^{295}$. Once the devaluation has been credibly stopped then the domestic nominal interest rate has to come down because expected inflation has decreased (Wehringer, 1996).

If the public is not totally convinced that the stabilization plan will succeed the exchange rate expectation, and therefore interest rates, will be high. Part of this credibility is dependent on public perceptions in respect to the maintenance of budget deficit improvements (Agenor, 1994).

6)A rapid remonetization of the economy usually takes place after the implementation of the stabilization plan. The ratio of M1 to GDP has typically increased rapidly in the aftermath of stabilization. In every stabilization plan, there has initially been a sharp price decrease and a correlated important increase in money demand. This first

\footnotetext{
${ }^{292}$ Orthodox plans are mainly supported by neo-liberal while heterodox by neo-keynesian

${ }^{293}$ For the effect of stabilization plans on tradable and non-tradable good see Giovannini (1992).

${ }^{294}$ Regularly once credibility is undermined speculative crises develops. See chapter 2.

${ }^{295}$ For theoretical details see chapter 2.
} 
phase ${ }^{296}$ allows governments to finance budget deficit without major problems because of the double effect; a reduction in the Olivera-Tanzi effect ${ }^{297}$ plus an increase in the money demand. However, this situation is short lived and only allows the government limited time to introduce the "real" fiscal measures. If they are not introduced, or only partially or inconsistently ${ }^{298}$, inflation reappears again with the consequent reduction of real balances.

7)Fiscal adjustment. This constitutes the key condition for the success of stabilization plans. The elimination of a large public sector is clearly a necessary condition for permanent disinflation. Programs where fiscal adjustment has been either temporary or absent have quickly failed (Argentina tablita 1978, Austral, 1985, Brazil, Cruzado 1986). In successful schemes public accounts have been balanced after implementation of the program (Convertibility, 1991 Argentina) In the case of the Real plan it is not clear if the fiscal correction is permanent

8) A boom in the stock market and real estate market. The stock market has regularly boomed in response to the achievement of stabilization. Housing and land properties have also experienced a significant increase.(Roldos, 1991 Morande, 1992). This first positive impact is interpreted as a market support to the introduction of stabilizing measures.

In summary, the underlying assumptions on exchange rate stabilization are based on credibility arguments. Fixed exchange rate systems introduce a constraint to fiscal and monetary policy (Edwards, 1992, Hansson and Sachs, 1994). As a result, under a fixed exchange rate the equilibrium is characterized by lower rates of inflation than under discretionary (and adjustable) exchange rate policies ${ }^{301}$. A fixed exchange rate increases the costs of following expansionary monetary and/or fiscal policies, because at the end a currency crisis will arise ${ }^{302}$. An essential question is whether a nominal fixed exchange rate regime can ex- ante provide an important constrain to fiscal and monetary policy If a country announces unilaterally that it will peg its domestic currency to another hard one, no institutional impediment to alter the exchange rate has been introduced. Under these circumstances, the simple government declaration is no more than an intention. In principle, this announcement will carry little credibility especially

\footnotetext{
${ }^{296}$ This first phase is the "magic phase"which consists in the simple announcement of a new stabilization plan, if is perceived as credible by the public, generates automatic positive effects. See CARTECO (1991).

${ }^{297}$ In high inflationary economies, tax collection suffers a deterioration on its real value because taxes are not automatically indexed. This effect is known in the literature as OliveraTanzi effect. See Sachs and Larrain (1993)..

${ }^{298}$ The Austral Plan introduced among other measures to reduce fiscal deficit to postpone : public purchases, wage increase of public employees, public investment.

${ }^{299}$ The Austral Plan introduced among other measures to reduce fiscal deficit to postpone : public purchases, wage increase of public employees, public investment.

${ }^{300}$ Details on the Convertibility and Real plans are presented in the next section.

${ }^{301}$ IMF documents states that inflation performance of countries that have operated under fixed exchange rate regimes has been, on the whole, superior to that of the group operating under more flexible arrangements. See Aghevli (1991).

${ }^{302}$ However, it is not clear which has been the order of causality, whether the fixed exchange rate have induced lower inflation rates, or countries with low inflation rate have been able to maintain fixed exchange rates.
} 
as when it has been introduced before it has often been abandoned. In this sense, the degree of commitment associated with the adoption of a fixed exchange rate can be increased by implementing legislation that makes an alteration of the parity costly. Argentina provided this type of arrangement in the form of a currency board system, which is explained in detail in section 4.4.1. below. A second type of arrangement that can contribute to increased credibility is given by a system where the authorities enter into a form of multilateral commitment that makes the alteration of the peg costly, for example as in the EMS or the Bretton Woods systems.

\subsubsection{The Argentinian Currency Board System}

After a succession of failed stabilization plans (Austral, Australito, Bunge Born, Rapanelli) ${ }^{303}$ that attempted to bring down chronically high inflation, the Argentinian government faced two destructive hyperinflation processes, with an extremely high demonetization level and currency substitution as the normal way of transaction and important output loses. Previous stabilization experiences were similar in that none of them had succeeded in permanently closing the fiscal gap. They all introduced a transitory correction towards budget deficits, but after a short lived stability inflation reappeared again ${ }^{304}$ The serious difficulties in eliminating fiscal deficits were due to its structural roots. An oversized government sector could not be consistently financed by tax revenues without squeezing the private sector. Inflation was thus the symptom of inherent inconsistencies within the model applied. In this sense, to face the hyperinflation process implied to have reached the frontier of the import-substitution model and therefore a new consensus about a new model could be built up ${ }^{305}$. It must be taken into account that to implement a new development model implies to "change the rules of the game". Therefore in a democratic society this is only possible if to some extent a "new consensus" has been reached. General macroeconomic conditions forced the Argentinian government to introduce important structural reforms in the midst of a chaotic macroeonomic environment.

Under this general background, in April 1991 the "Convertibility plan" was launched which included severe monetary reform by establishing a currency board system. A currency board is a special kind of policy rule for monetary base creation that guarantees a country not to devalue under any circumstance while operating under this system (Zaragoza, 1996). The currency board is in this sense a devaluation proof rule ${ }^{306}$.

\footnotetext{
${ }^{303}$ I will not review the previous experiences towards price stability. There is extensive literature on this topic. See Mastroberardino (1994), Almansi (1989), Canavese and Di Tella (1988) Frenkel and Fanelli (1987), Heymann (1986, 1988, 1994).

${ }^{304}$ There was also some hysteresis process. Initially the government could reduce inflation to a defined floor, 30 percent yearly, however once inflation reappeared again the new stabilization plan could reduce inflation until 60 percent and so on.

${ }^{305}$ In the previous relevant stabilization attempt, the Austral plan, it was clear that important structural measures had to be implemented, however, the lack of social agreement within the society hindered the process.

${ }^{306}$ Currency boards have been widely introduced into British colonies in the $19^{\text {th }}$ century and the idea vanished with the independence of the countries. Apart from Argentina others countries working under currency board systems are : Hong Kong introduced a currency board in 1983, Estonia in 1992, Lithuania 1994. For details see Williamson (1995)
} 
The monetary policy follows a very simple procedure, monetary authority will issue domestic currency only against a defined foreign reserve currency, for example the US dollar ${ }^{307}$. Therefore the monetary base will equal the amount of reserves that the central bank holds, The economic interpretation is that the monetary base is fully backed by the designated foreign reserve currency ${ }^{308}$. The Covertibility Law ${ }^{309}$, was the "key" element of this new stabilization plan, whose objective was, through a "shock therapy", to finish with almost fifty years of inflation rates higher than the international averages, including two explosive hyperinflations ${ }^{310}$. This law has two main objectives, on the one hand, to convince economic agents that to hold domestic currency is exactly the same as to hold US dollars, on the other hand, to force the Treasury not to finance any fiscal deficit through monetary expansion, This system demonstrates some advantages over full dollarization as it allows the government to collect some form of "seignorage". Thus, if economic agents hold domestic currency instead of US dollars, then the currency board can gain interest on the foreign reserve assets. These monetary measures plus the elimination of fiscal deficit allowed the inflation rates to reduce sharply towards the international level. However, this new stabilization plan consisted not only of monetary and fiscal packages to contain inflation, but was part of an overall structural reform whose objective was to reach a more efficient allocation of resources. The plan was based on three main pillars: monetary reform, fiscal reform, including a restructure of debt with domestic and foreign creditors, and a deregulation process. The monetary reform, as previously explained was based on, the so called Covertibility Law (May 1991) and transformed the central bank into a currency board ${ }^{311}$. Therefore, the only feasible source of monetary expansion was the purchase of international reserves. By implication, the central banks are not allowed to finance any fiscal deficit. The fiscal reform was concentrated on three sets of actions: a) a tax reform, b) an expenditure reform and c) the privatization of public enterprises,

a)The tax reform implied an improvement in the tax revenue, through a much broadened and uniform VAT and improvement in the tax administration though the reduction of corruption and tax evasion.

b) The expenditure reform was implemented in March 1990 through civil service reform (Law of economy emergency) which allowed a reduction in public employment.

\footnotetext{
${ }^{307}$ At the time of designing the currency board system the country determines against which currency domestic money will be issued. Estonia for example established a currency board against the DM.

${ }^{308}$ The rationale on why a so strong rule was needed is based on the credibility arguments presented in chapter 2.

${ }^{309}$ The currency board implemented through a law. This law can only be modified by simple majority rule.

${ }^{310}$ For details see Canavese and Gerchunoff (1996).

${ }^{311}$ The Argentinian central bank committed itself by law to maintain a fix parity (1:1) between the domestic currency and the US dollar. As previously explained, this parity is guaranteed by backing 100 percent of the monetary base through foreign reserves.
} 
c) The privatization of public assets was the main source of resources and allowed the government to reach fiscal equilibrium. The restructuring of liabilities with domestic creditors was implemented in December 1989 (BONEX ${ }^{312}$ Plan).

Short term central bank debt within the banking system was converted into ten year Treasury Bonds (BONEX). This measure allowed the elimination of the quasi-fiscal deficit. The restructuring of liabilities with external creditors was reached in June 1990. The Argentinian government restarted partial payment of external debt after having suspended payment since 1988. External debt, which had reached 61 billion US dollars, was allowed to be used in exchange for government assets in the privatization process. In September 1992 a Brady Plan relief was granted to Argentina, and permitted the reduction of external debt by 7 million US dollars and the rescheduling of the external debt into a 30 years repayment scheme. The total amount, including the principal and interest was reduced by 35 percent. The deregulation process was introduced through the so called Deregulation Decree of October 1991, allowing the freeing up of three principle, highly regulated areas: a) domestic industry, b) foreign trade, and c) capital markets. Many regulations referring to trade unions were lifted. For example, since 1991 they were allowed to negotiate wages on a firm by firm basis, instead of industry-wide. Most of the quota restrictions were removed and tax exports were eliminated.

\section{The Effect of the Currency Board on the Argentinian Economy}

The new package of measures undertaken by Argentina allowed the economy to reach a new growth path GDP grew by 30 percent in real terms between 1991 and $1994^{312}$; price stability was reached, and the inflation rate was reduced from over 2500 per cent per annum to 3.5 per cent in 1994 and 1.6 in $1995^{314}$. The reforms introduced into the economy, especially the privatization process, induced profound changes in labor markets. Employment as a proportion of the population has increased by one per cent, with new entries encouraged by new opportunities which have exceeded the increase in the demand for labor. As a result unemployment has risen since 1991, reaching 12 per cent in 1994. The second phenomenon observed following the stabilization measures has been the attraction of a huge amount of portfolio investment, although the gap between the domestic and the foreign interest rate decreased over time. The explanation of this trend can be found not only in the success of macroeconomics reforms ${ }^{315}$ but can also to have been originated in external factors ${ }^{316}$. Although the inflow of

\footnotetext{
${ }^{312} \mathrm{BONEX}$ plan was called the restructure of the domestic debt with the private sector. The holder of government debt titles received a new bond, which was denominated in US dollar (BONEX). Debt holders suffered a capital loss, and in addition the maturity of the bonds was postponed.

${ }^{313}$ This output growth was led by the non-tradable sector.

${ }^{314}$ Notice that Argentina has not reached one digit yearly inflation rate in the last 50 years.

${ }^{315}$ Part of the capital inflows are explained by the extremely low US interest rate, which induced portfolio diversification with a larger participation of investment in developing economies.

${ }^{316}$ Calvo, Reinhart, Leiderman (1992) estimates the effect of external and internal factor as determinants of portfolio capital inflows.
} 
capital is welcomed as a sign of the overall improvement in the macroeconomic situation, they have introduced additional problems into the Argentinian economy. Capital inflows increased the domestic aggregate demand, part of which is directed to nontradable goods and as long as supply of the non-tradable goods is inelastic in the short run, the adjustment process is evident in price increases.

Under a currency board system, which committed the central bank to fix the domestig currency to the US dollar on a 1:1 ratio, the result was a distortion in the relative prices in favor of non-tradable goods and a consequent currency appreciation followed by a current account deficit. In December 1994 the impact of the Mexican devaluation imposed a huge negative shock on the Argentine economy, and the convertibility law was severely tested. The capital account showed a negative result for the first time since March 1991 due to private capital flights, and the deficit in the current account reversed into a surplus without a devaluation taking place. Under the currency board system the consequence of the capital outflows was followed, predictably, by a fall in the international reserves (from 16 million to 10200 million US dollars between January and May 1995) with a consequent reduction in the monetary base. Although the adjustment mechanism implicit in the currency board can be seen to have worked relatively well in the sense that there was a tendency to correct relative prices, the process was extremely painful and output fell by 4.4 per cent and unemployment rose to 16.6 per cent. As the fall in the reserves reduced the liquidity of the system, the impact on the financial and banking system was high and is probably irreversible. From December 1994 to March 1995 approximately 7.4 billion US dollars left the banking system (some 16 per cent of the total of deposits), and M3 fell by some 8.4 billion US dollars (a $15 \%$ reduction) ${ }^{317}$.

Consequently the government, in an attempt to increase liquidity inside of the narrow margin provided by the Convertibility Law reduced the reserve requirements from 43 per cent to $30^{318}$ per cent In addition, Argentina's Convertibillity Law was relaxed and during this period only 80 per cent of reserves backed the money supply, and 20 per cent of reserves could be held in the form of dollar denominated Argentinian sovereign bonds (Powell, 1995). In order to avoid a massive crash, fusion and merger were facilitated. From 205 banks at the end of December, only 167 survived at the end of June 1995. Although the authorities could overcome the crisis, the costs were extremely high in terms of output and employment. 'The experience showed that the currency board was an exceptional instrument to start a new monetary history. However, the absence of an escape clause highlights both its strengths and weakness because it increased credibility but made adjustment extremely painful

\footnotetext{
${ }^{317}$ M3 is in Argentina a broad measure of money demand including both peso and dollar bank deposits.

${ }^{318}$ Central bank estimations showed that the reduction of the reserve requirements injected up to 3.4 bn US dollars into the financial system relative to a total drop in deposits of some $7.4 \mathrm{bn}$ US dollar.
} 


\section{Recent Developments and Evaluation}

The Argentinian government has sought to respond swiftly to the challenges faced through 1994 so as to ensure that the plan could be suitably adjusted to exogenous variables by adhering firmly to convertibility. The government concentrated their efforts on fiscal matters and new measures were announced in $1995^{320}$. Provincial governments were encouraged to balance their finances, even privatizing provincial enterprises and banks. Since the Mexican crisis, foreign accounts have become unpredictable, as represented by the behavior of international capital flows. Due to the importance of winning the confidence of foreign investors the government has sought a closer contact with the IMF ${ }^{321}$. Although the economy was slowly overcoming the recession no prospects for major improvements in employment are present due to both the structural nature of some of the unemployment and the sharp reduction in the size of the public sector. There has however been an important improvement in the export performance although it is too weak to absorb the excess of labor supply originated in the output fall of the non-tradable sector.

Whilst the government relies on the effect of a labor market flexibilization, the scope has been very limited because of the strong opposition of the labor unions. In terms of the public debt, since 1994 it has been steadily increasing and at the same time changing its profile. Helped by favorable market conditions, in March 1993 it enabled Argentinian borrowers to return to the international capital market. However, the terms on which this new public debt was contracted shows that maturity became shorter, until early in 1996 when a 15 year DM bond was issued. Moreover, as the dollar market becomes progressively more saturated the government has begun to take advantage of borrowing conditions in other markets. Seizing the opportunity presented by greater liquidity on the international capital market, Argentina issued bonds worth more than 3.4 billion US dollars in the first quarter of 1996. Liquidity in the Argentinian system returned to pre-Mexico crisis levels and the conditions agreed with the $\mathrm{IMF}^{322}$ allowed the public sector to borrow again on the local market and even in local currency. ${ }^{323324}$ Although the Convertibility Plan has been a success in terms of reducing inflation and initially even in terms of GDP growth, the system is extremely harsh and procyclically biased, thus inducing the expansion of the non tradable sector and causing relative price distortion in times of positive external shocks. However in response to negative external shocks the economy is pushed into a deep recession which implies high output losses and unemployment. This effect is the result of the high vulnerability that the system introduces in the form of unrestricted high capital mobility. Currency boards

\footnotetext{
${ }^{320}$ New fiscal measures were introduced to reach higher revenue collection and to reduce government spending.

${ }^{321}$ For details see Mastroberardino (1996).

322 April 1996 IMF approved stand-by credit for US\$ 1 billion.

${ }^{323}$ The issue of the domestic debt was interrupted after the hyperinflation.

${ }^{324}$ According to official figures, an estimated two billions pesos ( 2 billions US dollars) of credit will be raised this year in the form of LETES (short term paper). See Argentinian Economic Report (1996).
} 
are devaluation-proof instruments, yet they have no control over financial crises ${ }^{324}$. The main problem can be attributed to the fact that in the past the Argentinian authorities have frequently applied escape clauses, and therefore the system needs to be reassured that this time they are absent, in order to generate credibility. Alternatively, in the presence of severe shocks, such as has been the case in the Mexican crisis of December 1994, no instruments at all are available to moderate the impact, making the economy highly vulnerable in response to external shocks. The new challenge consists in how to introduce some flexibility into the system without destroying credibility. In this sense, an external agreement, as for example through MERCOSUR could provide some improvements in this direction.

\subsubsection{The Brazilian Real Plan}

In December 1993, the Brazilian government launched a new stabilization plan. This comprised three stages, starting with a fiscal reform, followed by the introduction of a new unit of account: the Real (hence the name given to the stabilization plan). The Realplan constitutes the most innovative mechanism to break inertia inflation without the use of wage and price controls; instruments that have failed in previous experiences of stabilization. ${ }^{325}$ The basic principle was a phased introduction of a new currency pegged to the US dollar ${ }^{326}$

As one of the channels of price inertia in Brazil had been the backward-looking wage indexation, rather than dollarization as in the Argentinian case ${ }^{327}$, the authorities recognized that any immediate exchange rate stabilization of the cruzeiro would not achieve stability. The Real plan was an astute approach that attempted to destroy the inertial inflation through a super-indexation of the economy There were several reasons for its introduction. Primarily, by linking prices to URV (unity of real value) agents could observe that even as prices rose daily, the pattern of increases would gradually converge towards a single rate in terms of URV. Once relative prices were perceived to have been adjusted and were moving together, the past memory of inflation, perpetuated by indexation would disappear (Sachs and Zini, 1996) ${ }^{328}$. The plan was set in place in three phases. During the first, from January to February 1994, budgetary controls were enhanced through the congressional approval of certain emergency deficit-cutting measures. The second stage, which was the most innovative, began in March 1994. Wages, prices and taxes were re-denominated in a new unit of account the URV (unit of real value). At the same time, the use of indexation in URV wage contracts was prohibited for the following 12 months. In fact, the program in-

\footnotetext{
${ }^{324}$ The Argentinian financial crisis started with the liquidity squeeze of Bank Extrader, a very small bank which was heavily exposed in Mexican bonds securities. When the value of those assets fell in the aftermath of the Mexican devaluation, the bank no longer could cover its short term liabilities. See Mastroberardino (1996).

${ }^{325}$ See Calcagnoto and Fritz (1996)

${ }^{326}$ For an official explanation of the Real Plan see Banco do Brasil (1993).

${ }^{327}$ This is also the reason why the financial sector was more developed in Brazil than in Argentina.

${ }_{328}$ For additional details see Macedo (1996) Baer and Pavia (1996), Boletim Mensal (1996),
} 
duced wage indexation to the contemporaneous exchange rate, rather than to backward-looking inflation. From March 1994 to 1 July, 1994 the URV was in fact the US dollar unit of account, as the URV was fixed close on a one-to -one basis with the dollar. Although all wages and most prices were denominated in URVs by March 1994, prices in URVs could change both before and after the plan, but actual transactions continued to be made in "Cruzeiros Reais", based on the market exchange rate. Inflation in URVs (in dollars) could then be calculated and was around two per cent per month during the period March to May. The third stage (from 1 July 1994) introduced the new currency, the Real, which was pegged to the dollar from the start. All URV prices were to be converted (one-to-one) into Real prices, although some prices increases took place in the days prior to the plan's introduction. Inflation dropped immediately from the cruzeiro of approximately 50 per cent per month (June) to the URV rate of around two per cent per month after September and persisted roughly at that rate in the following year. The Real Plan produced, initially, favorable results within labor markets. Open unemployment fell to a 3.4 per cent average in Brazil's six largest cities, while average real wages of the employed labor force jumped by 4.9 per cent. In addition, as inflation declined production rises became increasingly generalized with an increasing share of output being directed towards low-income groups in response to their growing purchasing power. Within the balance of payments, the increase in domestic demand, coupled with the appreciation of the exchange rate and tariff reductions led to a 33.2 billion US dollar jump in imports. The drop in trade surplus was offset by a decline in the service imbalance, which was attributable to lower net interest payments. The Mexican crisis also imposed serious costs by slowing down economic activity and there were pressures in the exchange rate market. To deal with the decline in external competitiveness, the government introduced fiscal measures in January to abolish the 15 per cent reserve requirement on advances against exporters. Tariffs were also raised on automobiles and other consumer durable goods, which had accounted for a significant share of the rise in imports during 1994.

However, the economy remained overheated and the trade balance recorded a deficit of 1.1 billion US dollars. In response to this deteriorating situation, the authorities announced an important package of measures on 6 March, 1995. The Central Bank announced a new exchange rate policy, including fluctuation bands, and the real was effectively devalued by over 2 per cent over a two week period. Additional new fiscal measures were adopted with the objective of reducing the foreseen fiscal deficit in 1995. Five constitutional reforms relating to oil, natural gas, telecommunications and the abolition of the constitutional distinction between Brazilian and foreign investors were approved $^{329}$. New restrictions were placed on hiring at all levels of government, while public federal banks were ordered to reduce operating costs by 15 per cent. A

\footnotetext{
${ }^{329}$ The Brazilian Constitution of 1988 constitutes the most serious obstacle to break with the import-substitution model and also interferes with the flexibilization of labor markets. It was the product of length and difficult negotiations within the Brazilian society and first of all in the Parliament. The Constitution guarantees the labor unionization by category instead of a firm basis, the right to strike, the right that civil servant cannot be fired. It discriminates between Brazilian and foreign investors as a basis for state support and establishes that certain areas can only be exploited by Brazilian capital. The Brazilian constitution is similar as the one introduced by Peron in Argentina in 1952.
} 
new plan was announced to privatize financial institutions and one of the nations largest mining companies.

\section{Recent Developments}

Although there was a change of government during the aftermath of the implementation of the Real Plan, the new administration that came into office ${ }^{330}$ coincided with the achievement of consolidating the price stability that had been behind the Plan real. Thereafter, continued price stability could set the stage for sustained growth through sweeping fiscal reforms, economic liberalization and more rapid privatization. In order to achieve these objectives important key amendments to the 1988 Constitution are needed ${ }^{331}$. With fiscal reforms progressing slowly the focus of macroeconomic management remained on a tight monetary policy with high interest rates and careful credit management within the economy. Although the policy of gradual devaluation of the currency tends to avoid further overvaluation and maintain balanced the external accounts, the main risks to the economy are a further deterioration in the fiscal balanca a failure to pass reforms as well as reappearing inflation due to wage pressures, During 1996 only modest progress was observed with respect to the fiscal policy ${ }^{332}$. Although inflation has been brought under control and indexation seems to be eliminated, there are some signs that reindexation may be re-entering the system ${ }^{333}$.. The new exchange rate policy of a quasi-crawling peg system can in itself be dangerous. $O$ On the one hand, it assures the sustainment of the exchange rate, avoiding overvaluation, while on the other hand it can become the element that fuels inflation and restores indexation ${ }^{334}$ In Brazil it has taken a much longer time for society to recognize the necessity of starting with structural reform than has been the case in Argentina, and this is primarily due to the fact that it was the import-substitution model in Brazil which allowed the country to reach growth, and even during the debt crisis the Brazilian authorities could to some extent introduce some changes into the model. Whilst the Brazilian exchange rate policy grants some flexibility, as the central parity can be devalued, the degree of credibility is much lower than that of the currency board introduced by Argentina. Furthermore, fiscal austerity measures have been announced but the system does not provide for their enforcement.

\footnotetext{
${ }^{330}$ The Real Plan was launched by Collor, whose political situation was extremely weak. Cardoso was elected president in 1994.

${ }^{331}$ See Conjunctura Economica (1996) Boletim Mensal (1996), Mastroberardino (1996).

${ }^{332}$ See Boletim Economico (1996).

${ }^{333}$ There are some indications that indexation is taking place in part of the economy (informal rentals contracts). Additionally, the decision of a labor court of granting in 1996 an increase of $25 \%$ to Banco do Brazil staff set a bad precedent for other state companies.

${ }^{334}$ It takes a long time to eliminate the psychological effect of inflation. Backward looking adjustment is still present in mind of economic agents.
} 


\subsection{Summary and Conclusions}

In this chapter, first I reviewed the previous agreements towards Latin American integration introduced during the past three decades. The integrationalist process in Latin America which dates from the 1960s, has seen several agreements enacted, (LAFTA, LAIA, Andean Group, and CARICOM) without success. None of them could reach the goal of significantly increasing trade and competition across the region. This has caused widespread skepticism towards the relevance of such agreements. Three decades have lapsed and new attempts now flourish, which have also attracted a great deal of interest outside of Latin America, MERCOSUR among them. This new integrationalist approach contrasts sharply with previous attempts not only as regards the institutional arrangements, but also in relation to political and economic factors. The underlying economic policies of both integrationalist processes are based on opposite development models. While the first attempt was part of an inward-oriented development strategy based on a structuralist development model, the import-substitution model, the new one is an example of an outward-oriented economic policy based on a neo-liberal model, "the so called Washington consensus" model. The debt crisis that started in 1982 constituted the inflection point between both models, by forcing Latin American countries to abandon the old structuralist model and to look for some alternative solutions to overcome the crisis. The results have been surprisingly optimistic; countries introduced important stabilization plans in order to reach price stability, but within the context of overall structural reform. Governments opened up their economies to foreign trade, privatized public sectors and introduced important measures in order to make labor markets more flexible and to maintain budget discipline. Growth rates were reversed from the years of stagnation and large capital inflows were attracted, an important part of them being foreign direct investment. Moreover, the most important challenge faced by these countries has been how to sustain the macroeconomic stabilization and the structural reforms in the long term. In this sense, the MERCOSUR agreement offers a new "window of opportunity". In the real side it allows for the "conclusive" dismantling of the high level of tariff and non-tariff barriers introduced during the last decades. On the monetary side, it permits the countries to move towards further reforms in fiscal, monetary and exchange rate policies. Latin American countries need to rebuild credibility within their financial markets and in this sense an external agreement can act as a coordinating and enforcement policy instrument. Although, one of the explicit objectives of the MERCOSUR agreement is to "coordinate macroeconomic policies" among member countries, no concrete measure has been introduced concerning this issue. Furthermore. it is exactly in this area where most of the effort must be invested. While all the countries agree with respect to general principles, there are important differences in the management of budget deficits, monetary policy, size of the current accounts and real exchange rates. With the exception of Paraguay, one of the constant pressures on the MERCOSUR countries has been high inflation.

All the countries, in particular Argentina and Brazil, have attempted fighting inflation using the nominal exchange rate as an anchor within stabilization plans. Although there is a conformity across MERCOSUR countries with respect to the underlying rational behind the adoption of the exchange rate which relies on the credibility argument, no coordination among members has been introduced. In this sense, a movement 
towards a fixed exchange rate linking member states would help to coordinate policy between them and could then act as an additional enforcement. I have also reviewed the last antinflationary experiences of Brazil and Argentina. Whilst the first adopted a fixed exchange rate with a band of fluctuation, Argentina introduced a currency board. The fixed exchange rate of Brazil does not introduce enough enforcement on the fiscal side because the central parity can always be readjusted. In fact, in response to the Mexican crisis, the Brazilian government introduced a small exchange rate correction. While the Brazilian exchange rate system allows sufficient flexibility, it does not introduce any constraint towards fiscal policies. On the other hand, the Argentinian system is extremely inflexible towards unexpected external shocks although it does provide a high level of credibility. Therefore both systems contain strengths and weaknesses. As a result, the design of a new system for the MERCOSUR region offers the opportunity of constructing a better system by introducing some flexibility while maintaining a high degree of credibility. 
Figure 4.3.1

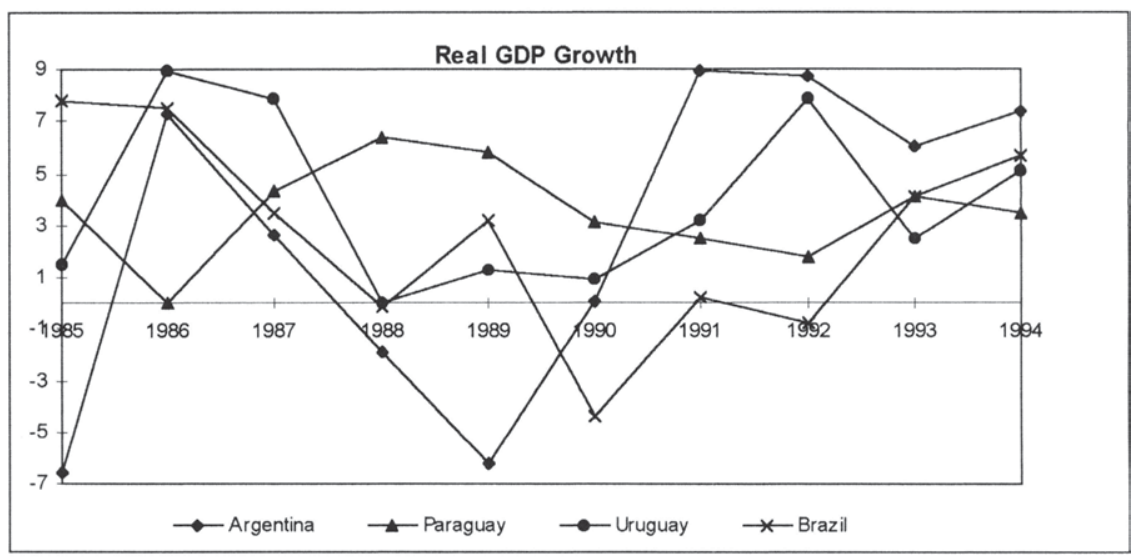

Source: Anuario Estadístico de América Latina y El Caribe, 1995. CEPAL

Figure 4.3.2

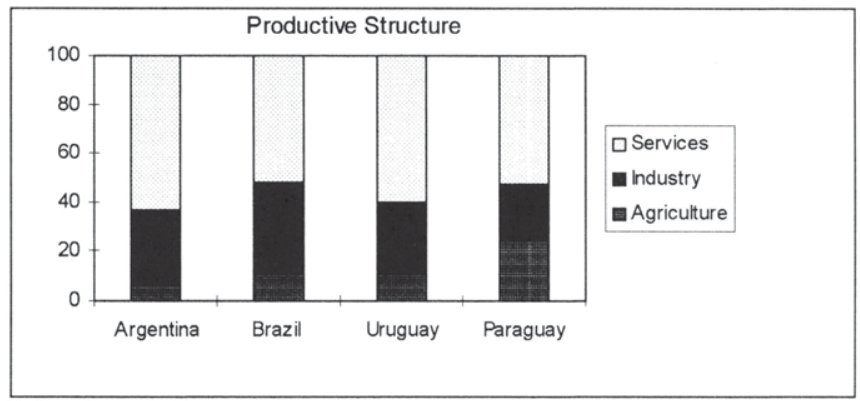

Source: Anuario Estadístico de América Latina y El Caribe, 1995. CEPAL 
Figure 4.3.3

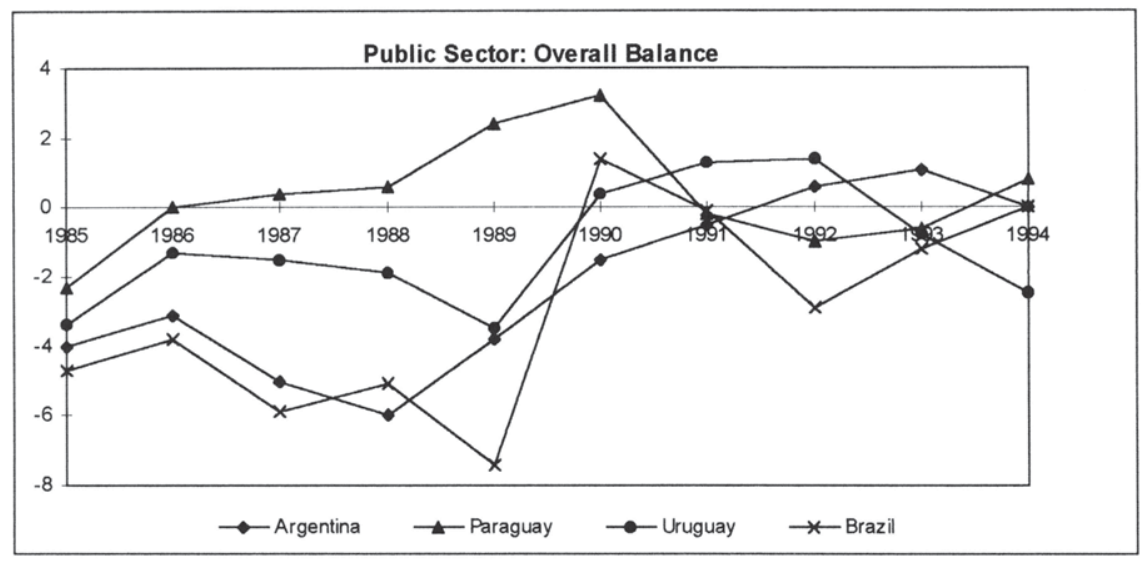

Source: Anuario Estadístico de América Latina y El Caribe, 1995. CEPAL

Figure 4.3.4

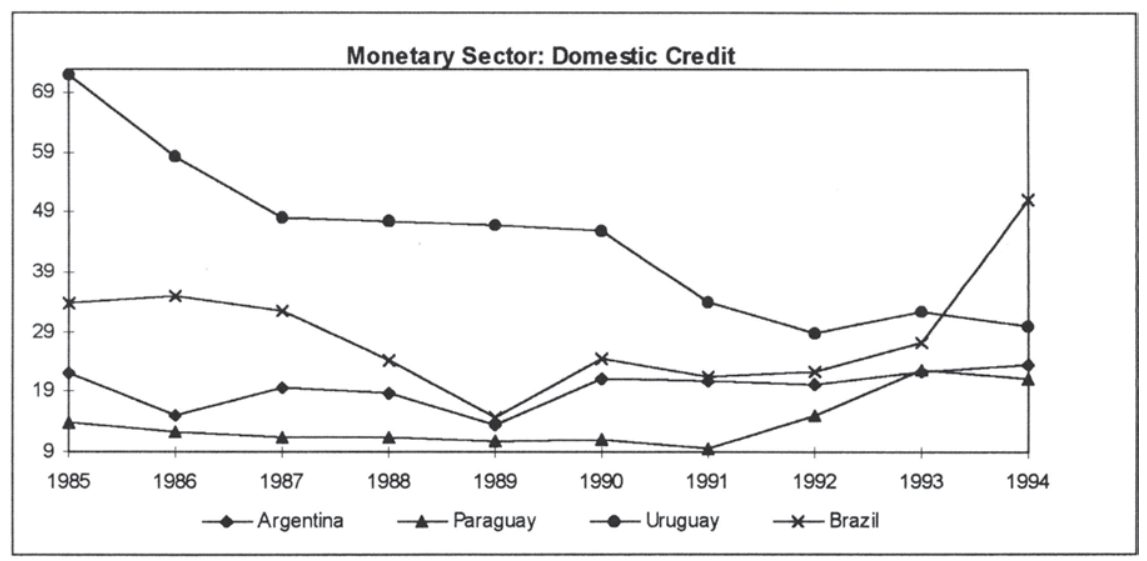

Source: Anuario Estadístico de América Latina y El Caribe, 1995. CEPAL 
Figure 4.3.5

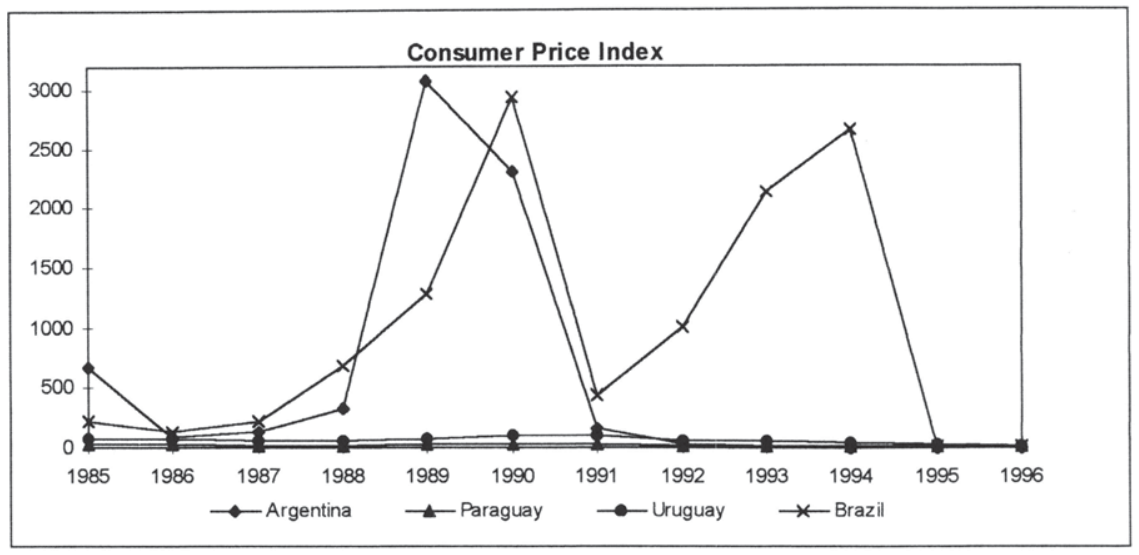

Source: Anuario Estadístico de América Latina y El Caribe, 1995. CEPAL

\section{Figure 4.3.6}

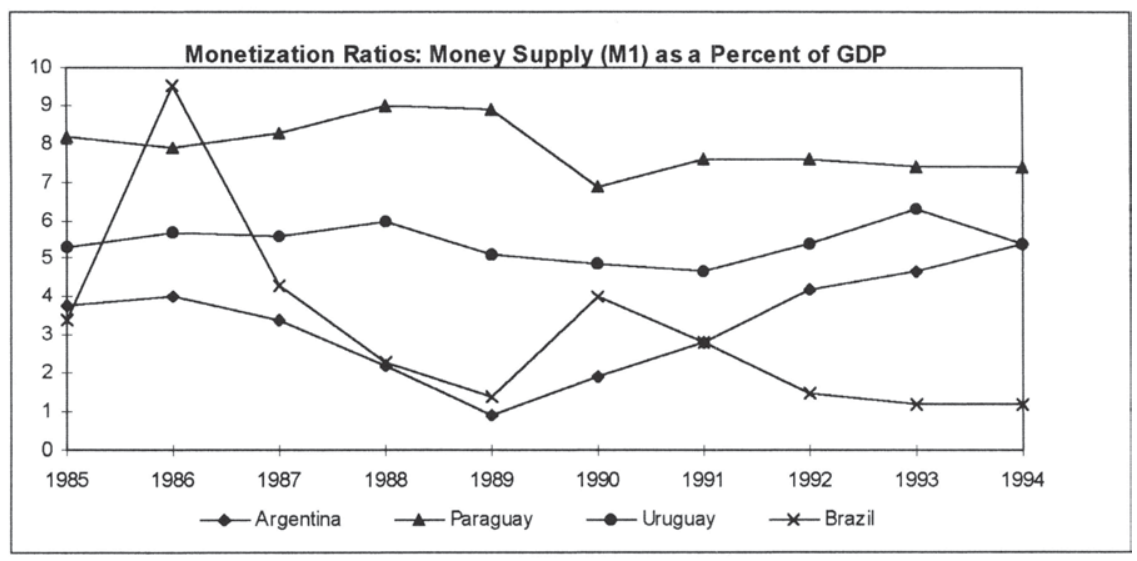

Source: Anuario Estadístico de América Latina y El Caribe, 1995. CEPAL 
Figure 4.3.7

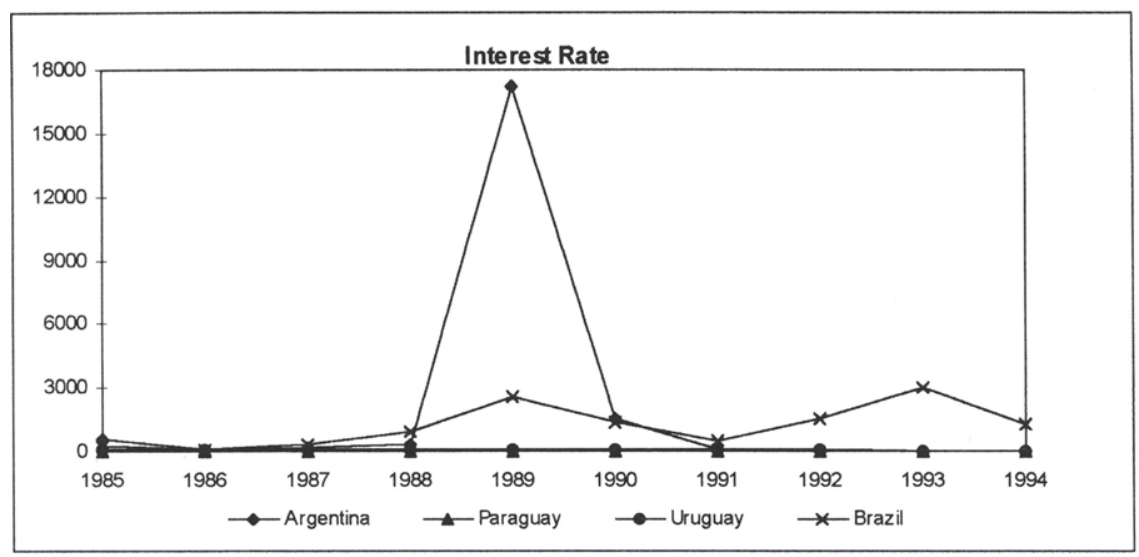

Source: Anuario Estadístico de América Latina y El Caribe, 1995. CEPAL

Figure 4.3.8

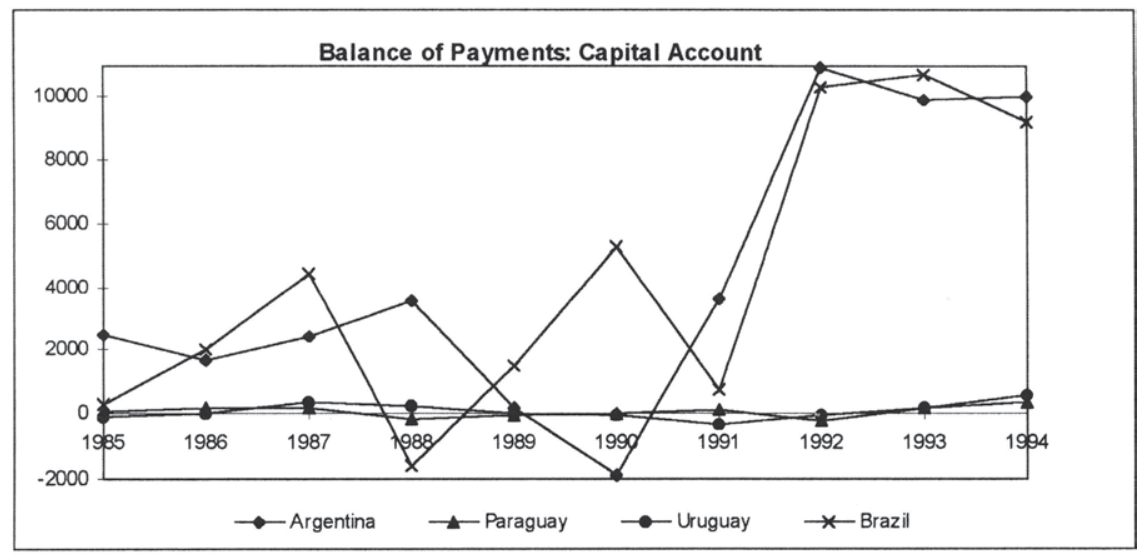

Source: Progreso Económico y Social de América Latina. BID (several issues) 
Figure 4.3.9

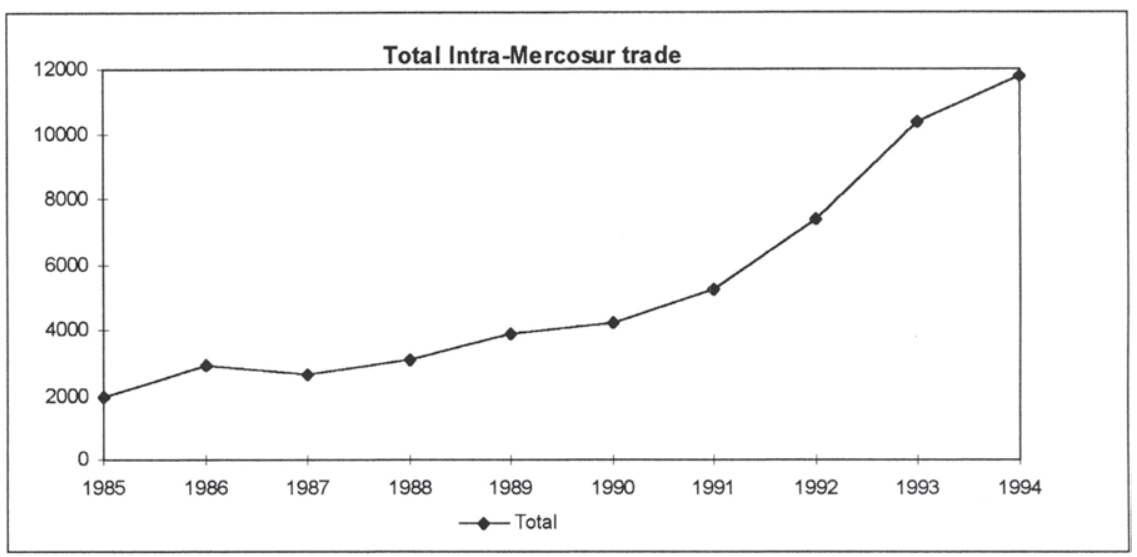

Source: Anuario Estadístico de América Latina y El Caribe, 1995. CEPAL

Figure 4.3.10

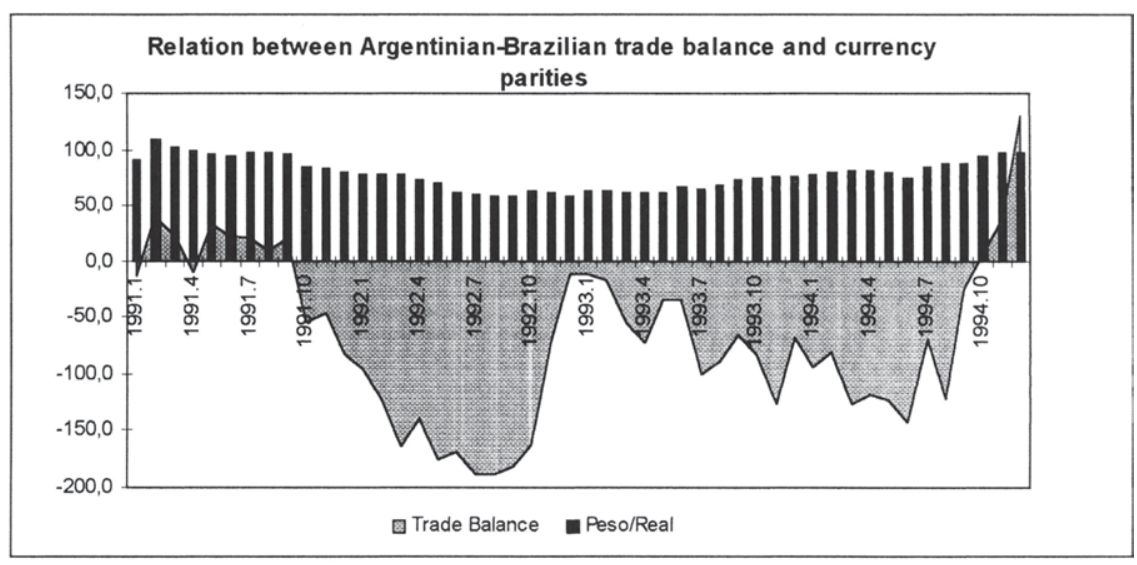

Source: Anuario Estadístico de América Latina y El Caribe, 1995. CEPAL 


\section{Appendix \\ Protocols}

a) 29 July 1988

1-Good of capital

2-Wheat

3-Cooperation for food shortage

4-Trade expansion

5-Binational enterprises

6-Financial affairs

7-Investment Funds

8-Energy

9-Biotechnology

10-Economic Studies

11-Nuclear assistance and radiological emergencies

12- Aeronautic cooperation

b) 10 December 1986

13-Iron and Steel industry

14-Transport

15-Maritime transport

16-Communications

17-Nuclear cooperation

c) 15-17 July 1986

18-Cultural

19-Public Administration

20-Currency

d) 7 April 1988

21-Automobile Industry

22-Food Industry

e) 29 November 1988

23-Common Frontier

f) 23 August 1989

24- Economic and Social Planning 


\section{Chapter 5}

\section{Conclusions and Economic Policy Recommendations}

MERCOSUR, the common market of the South, was created through the signing of the Treaty of Asuncion in 1991 and went into effect in January 1995 for Argentina and Brazil and in the following year for Uruguay and Paraguay. It produces 40 percent of Latin American GDP and comprises two of the most industrialized countries of the region, Argentina and Brazil. Despite the initial turmoil regarding macroeconomics imbalances, trade and intra-industrial relationships have been growing strongly. This new integration scheme has also attracted interest among non-Latin American countries, with new free trade association agreements having been signed with other economic areas such as the European Union, NAFTA and ASEAN. After two years of the agreement's full functioning, many Latin American countries have shown growing interest in participating in it and have presented application for full membership; and Chile (although initially it had rejected an invitation to join it) and Bolivia both have joined the club as associated partners. The objective of the MERCOSUR agreement consists of the free mobility of goods and productive factors and the establishment of a common external tariff. Experience has demonstrated that the implementation of agreements on commercial policy is not in itself sufficient to reap the full benefits of integration if it is not followed by coordination on exchange rate policies. Competitive devaluations implemented unilaterally by the member countries are very dangerous and can provoke the failure of the agreement. In this sense, the European Union provides a good example on this matter. Although the difficulties implied by the coordination of exchange rate policies have been recognized, it has proceeded in this direction, through the introduction of the EMS, and it is ready to move further towards monetary union.

Violent shifts in currency parities between Argentina and Brazil during recent years have induced sharp changes in trade balances among member countries and have delayed the process of eliminating all tariff and non-tariff barriers among them. It thus becomes imperative to analyze what kind of exchange rate agreement would be appropriate for the MERCOSUR case. The aim of this study is to seek some answers to the question: what would be the optimal exchange rate policy for the MERCOSUR countries? My study approached that question from three different though related angles: a theoretical analysis, a review of the European experience with exchange rate agreements, and finally a review of the Latin American experience.

Chapter 2 introduced the theoretical analysis. First, within a two-country MundellFleming-Dornbusch model, I compared the effects of monetary and fiscal shocks in the short and in the long run and the dynamic adjustments of two opposite exchange rate systems, fixed and flexible. I concluded that in both cases spill- over effects from one country to another are observed. Additionally, I found that fixed exchange rates reduced nominal and real exchange rate variability. However, the adoption of a fixed exchange rate system implies completely relinquishing an autonomous domestic monetary policy, with the monetary base thus becoming fully endogenous. Second, I introduced a time inconsistency approach, which suggests the convenience of adopting 
strict rules regarding monetary policy: such strict rules permit the time inconsistency problem to be overcome. Furthermore, a fixed exchange rate regime represents a "monetary rule" and thus could be a desirable arrangement. However, an extremely rigid rule may induce serious problems in the presence of severe shocks, and in extreme situations it might even force the authorities to abandon the adopted rule. Hence some degree of flexibility as an escape clause should be available. Yet escape clauses could present some problems in that, if policymakers have used them extensively in the past, credibility could be reduced.

In Chapter 3, I reviewed the European experience with monetary agreements. I analyzed in what context the discussion about exchange rates agreements arose. I observed that, after the breakdown of the Bretton Woods system, the European integration process was accompanied by strong fears about exchange rate variability and thus the European countries devoted significant effort to designing monetary agreements that could moderate such variability. The debate concentrated on two issues across the years: initially, exchange rate variability constituted the main issue of concern; then, during the 1980s, the discussion shifted much more towards price stability. The European Union has implemented several exchange rate agreements, first the Snake, which allowed relatively high variability, and later the EMS. The EMS constitutes a fixed exchange rate regime with escape clauses under which a band of fluctuation was allowed, as well as realignments. My analysis therefore focused on the ability of the EMS to achieve price and exchange rate stability. The simple observation of descriptive statistics reveals that the EMS has been able to achieve some convergence among European prices towards lower inflation, although the costs in terms of unemployment have been significantly high. Afterwards, I performed an econometric analysis in order to study the dynamic behavior of exchange rate variability in response to nominal and real shocks. I observed that the EMS has reduced the responses of both nominal and real exchange rates concerning monetary shocks. Moreover, no significant influence with relation to fiscal shocks has been observed.

In chapter 4, I focused on the Latin American experience towards integration. After several decades of import-substitution policies and budgetary inconsistencies that led to high inflation, all MERCOSUR countries agreed upon the need to introduce price stability and austerity measures. At least during the last years, efforts have been made in this direction and countries have observed important improvements in GDP growth rates. The MERCOSUR agreement has thus played an important role in this transformation process. It constitutes an instrument not only to achieve integration among the countries themselves, but also into world markets. However, violent movements in the exchange rates of the MERCOSUR countries introduce high uncertainty and affect exports and investment rates. Unilateral exchange rates policies lead to beggar my neighbor effects. I reviewed the use of a fixed exchange rate as an anchor in stabilization plans, as it has been in constant use in MERCOSUR countries with the objective of coordinating expectations and generating sufficient credibility in the system. However, a fixed exchange rate regime can neither substitute for the introduction of austerity measures necessary to correct fiscal imbalances nor can it obviate the implementation of global structural measures such as privatization, opening up the market to world trade, and flexibilization for goods and labor markets. The experience of Argentina and Brazil showed that both countries have used the exchange rate to anchor their stabilization plans, although in different degrees. While Argentina chose an extreme case of 
the fixed exchange rate, a "currency board", Brazil followed a relatively more flexible version: a fixed exchange rate with bands. The choice was based on the respective historical experiences of the two countries. While Argentina has undergone an hyperinflationary process, Brazil had suffered chronically high inflation and this constitutes an important difference as it defines different preferences of policymakers towards credibility and flexibility. Thus, every hyperinflationary process introduces a break in history and destroys the former preferences of economic agents and policymakers as well. ${ }^{336}$ Nevertheless, all exchange rate arrangements that MERCOSUR countries established have been related to the US dollar and no relationship between their own currencies has been explicitly established. This constitutes a problem because, so long as trade flows among MERCOSUR countries increase, the variability of exchange rate becomes a matter of concern. Violent shifts of exchange rate parities introduce "noises" within the markets, distorting competitive advantages. Additionally, at least the two main members of MERCOSUR, Argentina and Brazil, have experienced destructive inflationary processes and there is some kind of consensus as to the necessity to achieve price stability in order to achieve economic growth. In this sense, once all MERCOSUR countries agree upon the introduction of stabilization programs anchored on fixed exchange rates, the natural question is whether it would be convenient to coordinate stabilization plans among them. An important difference from the European case is that none of the MERCOSUR currency can work as an anchor and thus an external hard currency must be chosen for this purpose.

MERCOSUR states can discover in the agreement a "window of opportunity". Its member countries are, on the one hand, unilaterally seeking enforcement commitments that allow them to achieve price stability, and to regenerate a friendly environment towards investment. On the other hand, especially Argentina fears the trade balance effect of unilateral devaluation introduced by the Brazilian government. A global agreement could help to achieve intra-MERCOSUR exchange rate stability and at the same time could work as an external commitment with enforcement power that would contribute to overcome time inconsistency problems.

Summarizing, the three approaches utilized in the analysis lead to the following conclusions: first, some kind of fixed exchange rate agreement is highly desirable. Second, there are several kinds of fixed exchange rate agreements and different degrees of flexibility and there exists a trade-off between credibility and flexibility: the greater is the fixity of an exchange rate agreement, the larger will be the effect on price stability, and the less will be the flexibility that is permitted in response to shocks. Taking into account all these elements of analysis, the economic policy recommendation are as follows:

a)A Currency board for the MERCOSUR region. In chapter 3, I demonstrated that the Argentinian experience with the currency board has been quite successful not only in the monetary but also in the fiscal sphere, because it also compels fiscal discipline to be pursued. Thus, in a currency board system the central bank is not allowed to finance any budget deficit. Because countries have in the past abused monetary policy, it becomes important to introduce institutional constraints that act as an obstacle to-

\footnotetext{
${ }^{336} \mathrm{~A}$ similar effect is observed in Europe in the case of Germany. Germany constitutes the only member country that has suffered a hyperinflationary process and therefore it reveals a much stronger aversion towards inflation than other European countries such as France or Italy.
} 
wards discretionary policies. Governments themselves design strongly institutional arrangements because, in adverse economic conditions, they have more power than a simple commitment by individual governments to keep their promises. Governments can abandon institutional arrangements, but this becomes more costly. In this sense, an international monetary agreement reinforces the commitment since the costs of leaving the club once it has been formed become too high.

With respect to the design, since none of the MERCOSUR currencies can behave as an anchor currency, all currencies must be fixed to an external hard currency such as, for example, the US dollar. The central banks of the individual countries will remain in existence and thus act as individual currency boards, and no central MERCOSUR monetary authority would be needed. Furthermore, this alternative is, in my view, the first best towards credibility, although it implies high costs in the presence of negative shocks because it is an extremely rigid rule and will therefore probably generate some resistance from other MERCOSUR countries. Especially from Brazil, whose demand for credibility is probably not as high as that of Argentina.

b)A fixed exchange rate with a band of fluctuation, which could be initially relatively large ( +-10 per cent) and would be reduced over time. Member states would fix their national currencies to the US dollar, and thus cross-rates between them will be indirectly fixed. This system presents the advantage of being compatible with the currency board working in Argentina as well as the real plan working in Brazil. The currencies could fluctuate inside the band but interventions must be compulsory once currencies have reached the upper and lower limits of the band. Although this system has some similarity to the EMS, each central bank must intervene unilaterally. Since all the countries are fixing to the US dollar, the system presents some peculiarities, i.e. that none of them has an unlimited amount of the hard currency (the US dollar).

Realignments will be possible but they should not be made unilaterally, but in a coordinated way with the agreement of all member countries. This constitutes the main difference with the present unilateral fixing of the nominal exchange rate by the individual countries, and it permits beggar my neighbor policies to be eliminated.

Moreover, because a fixed exchange rate only can allow monetary policies to be coordinated, some additional measures should be introduced with respect to fiscal policies. The MERCOSUR countries should agree not to exceed some limits upon fiscal deficits and government debt ratios. In this sense some punishment procedure should be introduced in case some of the countries do not fulfill this condition. It could work like the European "stability pact" (The Economist, 1996). Member countries would agree to maintain low budget deficits and debt ratios, and those countries which did not follow the rule would be penalized and be forced to pay some fines.

c) A fixed exchange rate to a basket currency with a band of fluctuation. This represents a variant of the previous case, where instead of the US dollar being the anchor currency, a basket of hard currencies would be introduced, e.g. the US dollar, the Yen and the Euro. Taking into account that in 1999 the EMU will start (with a larger or a smaller group of member countries) and that an important part of the extraMERCOSUR trade is orientated towards the European countries, it becomes an attractive alternative to define the basket according to the average of trade proportion of the individual countries.

This alternative has the advantage that it lessens dependency upon the monetary policy of a third country, since it is not very probable that the monetary policy conducted by 
the European Central Bank, the Federal Reserve and the Bank of Japan will move in exactly the same direction at the same time. Thus, this policy will soften the impact of external monetary policies. Concerning the rules for intervention, realignments and a common central bank, they remain as previously presented in the alternative $b$. 
Silvia Marengo - 978-3-631-75137-4

Downloaded from PubFactory at 01/11/2019 07:53:19AM

via free access 


\section{References}

ADEBA (1993) MERCOSUR, Estructura Orgánica, Toma de Decisiones y Atribuciones de Representación Externa. Consejo Argentino Para las Relaciones Internacionales. Asociación de Bancos Argentinos, Buenos Aires, Ed. Fraterna.

Agel, J. Calmfors, L. Jonsson, G. (1996) Fiscal Policy when Monetary Policy is Tied to the Mast. European Economic Review, 1413-1440.

Agenor, P. (1994) The Behavior of Real Interest Rates in Exchange Rate Stabilization Programs. (Mimeo). IMF Washington D. C.

Aghevli, B. (1991) Exchange Rate Policy in Developing Countries: Some Analytical Issues. (Mimeo) IMF Washington D. C.

America Financiera, CEAL (several issues).

Ahumada, H. (1989) Saldos Monetarios Reales e Inflación. Test de Asimetría Usando Métodos de Cointegragión. Argentina 1971-1988. BCRA-CEMYB, Buenos Aires.

ALADI (1993) Articulación de Esquemas Subregionales y Bilaterales de Integración ALADI/SEC/Estudio 75 01/10/93.

Alesina, A. (1988) Macroeconomics and Politics. NBER Macroeconomics Annual 3.

Alesina, A. Summers, L. (1993) Central Bank Independence and Macroeconomic Performance. Journal of Money Credit and Banking, 151-162.

Alesina, A. Tabellini, G. (1989) External Debt, Capital Flight and Political Risk. Journal of International Economics, 568-615.

Almansi, A. (1989) Bi-monetarismo and Inflación en Argentina. Working Paper. Instituto Torcuato Di Tella, Buenos Aires.

Aoki, M. (1981) Dynamic Analisis of Open Economies, New York.

Arce, H. (1995) Bimonetarismo de la Ley de Convertibilidad Argentina de 1991. Monetaria, 78-110.

Argy, V. (1994) International Macroeconomics. Theory and Policy. Ed. Routledge, New York.

Argy, V. Salop, J. (1979) Price and Output Effects of Monetary and Fiscal Policy under Flexible Exchange Rates. IMF Staff Papers, 224-256. 
Amaudo, A. (1987) Cincuenta Años de Política Financiera Argentina (1934-1983), El Ateneo, Buenos Aires.

Arnaudo, A. (1994) La Política Monetaria Argentina Desde la Convertibilidad Monetaria, 315-336

Artana, D. (1989) Incentivos Fiscales a la Inversión Industrial. Working Paper Instituto Torcuato Di Tella, Buenos Aires.

Artis, M. (1987) The European Monetary System: An Evaluation. Journal of Policy Making, 175-198.

Artis, M. Nachane, D. (1990) Wages and Prices in Europe: A Test of the German Leadership Thesis. Weltwirtschaftliches Archiv, 59-76.

Artis, M. Taylor, M. (1988) Exchange Rates, Interest Rates, Capital Controls and the European Monetary System: the Track Record. In Giavazzi, F. Micossi, S. and Miller, M. The European Monetary System, Cambridge University Press.

Atkin, C. (1989) Latin America in the International Political System. 2nd Ed. Boulder Colo. Westview.

Astori, D. (1991) MERCOSUR: Situación y Perspectivas. Realidad Económica. Buenos Aires, No 101.

Avesani, R. Gallo, G. Salmon, M. (1993) On the Nature of Commitment in Flexible Target Zones and the Crisis of 1993. In Hördes, C. Girardin, E. Melitz, J. European Currency Crisis and After. Manchester Univ. Press.

Bacha, E. (1964) An Interpretation of Unequal Exchange from Prebisch Singer to Emmanuel. Journal of Economics, 319-325.

Backus, D. Driffill, J. (1985) Rational Expectations and Policy Credibility Following a Change in Regime. Review of Economic Studies, 211-221.

Bade, R. Parkin, M. Central Banks Laws and Inflation A. (1982) Comparative Analysis. Mimeo. University of Ontario.

Baer, G. Padoa-Schioppa, T. (1989) The Werner Report Revisited, In Collection of Papers Annexed to Report on Economic and Monetary Union.

Baer, W. (1962) The Economics of Prebisch at ECLA. Economic Development and Cultural Change, 169-170.

Bailey, M. Tavlas, G. (1988) Trade and Investment Performance under Floating Exchange Rates: the U.S. Experience. International Monetary Fund, Washington D.C. 1988. IMF Working Papers, 37. 
Bailey, M. Tavlas, G. Ulam, M. (1986) Exchange Rate Variability and Trade Performance: Evidence for the Big Seven Industrial Countries. Weltwirtschaftliches Archiv, 466-477.

Balassa, B. (1961) The theory of Economic Integration. Homehood III Richard Irwin.

Banco Central do Brasil, Boletim Mensal. (Several issues).

Barborosa, R. (1992) Mercado Comun do Soul Balanco do Primeiro Ano. Revista de Industria. Sao Paulo, 55-107.

Barrell, R. (1990) European Currency Union and the EMS. National Institute of Economic Review. 59-66.

Barro, R. (1977) Rational Expectations and the Role of Monetary Policy. Journal of Monetary Economics, 1-32.

Barro, R. Gordon, D. (1983) A Positive Theory of Monetary Policy in a Natural Rate Model. Journal of Political Economy, 589-610.

Barro, R. Grilli, V. (1994) European Macroeconomics. MacMillan Press. London.

Baxter, M. Stockman, A. (1989) Business Cycles and the Exchange Rate Regime: Some International Evidence. Journal of Monetary Economics, 377-400.

Bayoumi, T. (1991) The Effect of the ERM on Participating Economies. IMF Working Papers, 86.

Bayoumi, T. Eichengreen; B. (1994) Macroeconomic Adjustment under Bretton Woods and the Post Bretton Woods Float, NBER Working Papers, 1169.

Begg, D. (1982) The Rational Expectations Revolution in Macroeconomics: Theories and Evidence. Allan, Oxford.

Bekerman, M. (1994) La Integración en el Cono Sur y sus Ventajas Potenciales Para la Economía Brasileña. El Trimestre Económico, 281-308.

Bernal, R. (1994) CARICOM: Externally Vulnerable Regional Economic Integration. In Bouzas, R. Ros, J. Economic Integration in the Western Hemisphere. University of Notre Dame Press.

Bhandari, J. Turvonsky, S. (1982) Alternative Monetary Policies in an Inflationary Equilibrium Model of the Open Economy. Weltwirtschaftliches Archiv, 1-18.

Bhandari, J. Driskill, R. Frenkel, J. (1984) Capital Mobiliy and Exchange Rate Overshooting. European Economic Review. 309-320. 
Bhandari, J. Putman, B. (1983) Economic Interdependence and Flexible Exchange Rates. Cambridge Univ. Press. Massachusetts.

BID-INTAL (1996) El Proceso de Integracion en América Latina, Annual Report.

BID, Progreso Económico y Social en América Latina. Washington D.C. (Several issues).

Bizzozero, L. Lujan, C. (1991) MERCOSUR: Una Opción de Integración Asimétrica? Convergencia de Actores Nacionales y Negociación Subregional, SUMA 6, Buenos Aires.

Blackburn, K. Christensen, M. (1989) Monetary Policy and Policy Credibility. Journal of Economic Literature, 271-245.

Blanchard, O. Quah, D. (1989) The Dynamic Effects of Aggregate Demand and Supply Disturbances. The American Economic Review, 655-673.

Blejer, M. and Liviatan, N. (1987) Fighting Hyperinflation: Stabilization Strategies in Argentina and Israel. (1985-1986) IMF Working Papers, 45.

Bordo, M. (1992) The Bretton Woods International Monetary System. A Historical Overview. In Bordo, M. Eichengreen, B. A Retrospective on the Bretton Woods System. Chicago. University Chicago Press.

Bordo, M. Schwarz, A. (1996) Why Crashes Between Internal and External Stability Goals End in Currency Crisis 1797-1994 Open Economies Review, 431-436

Borrmann, A.(1996) Erfolgsbedingungen interregionaler Freihandelsabkommen HWWA. (Unpublished manuscript).

Bouzas, R. Lustig, N. (1992) Apertura Económica, Integración Regional y la Iniciativa para las Américas. FLACSO, Argentina Documentos e Informes de Investigación, 1-51.

Bouzas, R. Ros, J. (1994) The North South Variety of Economic Integration. Issues and Prospects for Latin America. In Bouzas, R. Ros, J. Economic Integration in the Western Hemisphere. University of Notre Dame Press.

Bovenberg, A. Kremers, J. Masson, P. (1991) Economic and Monetary Union in Europe and Constraints on National Budgetary Policies. IMF Staff Papers, 374398.

Boyer, R. (1978) Optimal Foreign Exchange Market Intervention. Journal of Political Economy, 1045-1056.

Branson, W. (1989) Macroeconomic Theory and Policy. New York, Harper \& Row. 
Branson, W. (1988) International Adjustment and the Dollar: Policy Illusions and Economic Constraints. In Guth, W. Economic Policy Coordination, Conference Organized by the International Monetary Fund in Co-operation with HWWA, Hamburg.

Branson, W. Buiter, W. (1983) Monetary and Fiscal Policy with Flexible Exchange Rates. In Bhandari, J. Putman, B. Economic Interdependence and Flexible Exchange Rates. MIT Press Cambridge, Massachusetts.

Bruno, M. (1991) High Inflation and the Nominal Anchors. Princeton Essays on International Finance. Princeton University Press.

Bruton, H. (1989) Import-Substitution, In Chenery, H. Handbook of Development Economics, Vol 2, North Holland.

Bruno, M. Fischer, S. Helpman, C. (1991) Lessons of Economic Stabilization and its Aftermath, MIT Press Cambridge, Massachusetts.

Bruno, M. (1993) Crisis, Stabilization and Economic Reform: Therapy by Consensus, Oxford University Press.

Buiter, W. (1986) Macroeconomic Policy Design in an Interdependent World Economy. An Analysis of Three Contingencies, IMF Staff Papers, 541-582.

Buiter, W. Eaton, J.(1983) International Balance of Payments, Financing and Adjustment, NBER Working Papers No. 1120.

Buiter, W. Eaton, J. (1986) Policy Decentralization and Exchange Rate Management in Interdependent Economies. In Bahndari, J. Putman, B. Economic Interdependence and Flexible Exchange Rates. MIT Press, Cambridge, Massachusetts.

Buiter, W. Miller, M. (1981) Monetary Policy and International Competitiveness: The Problem of Adjustment. Oxford Economic Papers, 143-175.

Buiter, W. Purvis, D. (1983) Oil Disinflation and Export Competitiveness a Model of the Dutch Decease. In Bahndari, J. Putman, B. Economic Interdependence and Flexible Exchange Rates. MIT Press Cambridge, Massachussets.

Buiter, W. Corsetti, G. Pesenti, P. (1996) Financial Markets and International Monetary Cooperation. The Lessons of the 92-93 ERM Crisis. Princeton University. (Unpublished manuscript).

Calcagnoto, G. Fritz, B. (1996) Inflation und Stabilisierung in Brasilien: Probleme einer Gesellschaft im Wandel. Institut für Iberoamerikakunde. Vervuert, Frankfurt. 
Calvo, G. (1978) On the Time Inconsistency of Optimal Policy in a Monetary Economy. Econometrica, 1411-1428.

Calvo, G. (1988) Servicing the Public Debt: The Role of Expectations. The American Economic Review, 647-661.

Calvo, G. Rodriguez, C. (1977) A Model of Exchange Rate Determination under Currency Substitution and Rational Expectations. Journal of Political Economy, 261278.

Calvo, G. Vegh, C (1990) Credibility and the Dynamics of Stabilization Policy. A Basic Framework. IMF, Washington D.C. (Unpublished manuscript).

Calvo, G., Reinhart, C. Vegh, C. (1994) Targeting the Real Exchange Rate: Theory and Evidence, IMF Working Papers No. 22.

Calvo, G. Reinhart, C. Leiderman, L. (1992) Capital Inflows and Real Exchange Rate Appreciation in Latin America. IMF Working Papers No. 18.

Canavese, A. Di Tella, G. (1988) Inflation Stabilization or Hyperinflation Avoidance? The case of the Austral Plan in Argentina. 1985-1987. In Bruno, M., Dornbusch, R., Fischer, S. Inflation and Stabilization: The Experience of Israel, Argentina, Brazil, Bolivia and México, MIT University Press.

Canavese, A. Gerchunoff, P. (1996) Reformas Estructurales, Productividad y Tipo de Cambio. Desarrollo Económico, 7-22.

Canzoneri, M. (1981) Exchange Rate Intervention Policy in a Multiple Country World. International Finance Discussion Papers. No 174. Federal Reserve Board Washington.

Canzoneri, M. Henderson, D. Rogoff, D. (1981) The Information Content of the Interest Rate and Optimal Monetary Policy. International Finance Discussion Papers. 192, Federal Reserve, Board Washington.

Canzoneri, M. Henderson, D. (1988) Is Sovereign Policymaking Bad? Carnegie Rochester Conference Series on Public Policy.

Cardenas, E. (1992) The Treaty of Asunción: a Southern Cone Common Market begins to take Shape. In World Competition. Geneva. No. 4.

Cardoso, F. Hernrique, E. Falleto E. (1979) Dependency and Development in Latin America, University of California Press.

Cardoso, E. (1988) Seignorage and Repression Monetary Rhythms in Latin America. Revista Brasileira de Economia. Oct-Dec. 
Castro Escudero, A.(1994) El MERCOSUR contra Viento y Marea. Comercio Exterior, 990-1000.

CARTECO, Carta Económica Estudio Broda y Asociados. (Several issues).

Cavallo, D. Mondino, G. (1995) From Hyperinflation to Sustained Growth. Annual World Bank Conference on Development Economics. Washington D.C. 11-22.

CEPAL (1992) Convergencia de los Esquemas de Integración. LC/R 1192.

Charemza, W. Deadman, D. (1992) New Direction in Econometric Practice. Edward Elgar Publishing Ltd.

Chari, V. Kehoe, P. Prescott, E. (1989) Time Consistency and Policy. In: Barro, R. Modern Business Cycle Theory, Harvard University Press.

Chiang, A. (1984) Fundamental Methods of Mathematical Economics. Mc Graw Hill, New York.

Christensen, M. (1987) Disinflation, Credibility and Price Inertia: A Danish Exposition. Applied Economics, 1356-1366.

Choudri, T (1996) Real Stock Prices and the Long-Run Money Demand Function: Evidence From Canada and the USA. Journal of International Money and Finance, 1-17.

Clarida, R. Gali, J. (1994) Sources of Real Exchange-Rate Fluctuations: How Important are Nominal Shocks? Carnegie Rochester Conference Series on Public Policy.

Classen, E. (1980) Grundlagen der Geldtheorie. Springer Verlag.

Clausen, V. Willms, M.(1993) Unabhängigkeit der Zentralbank. Wirtschaftswissenschaftliches Studium, 605-610.

Coffey, P. (1993) The European Monetary System and Economic and Monetary Union. In Coffey Main Economic Policy Areas of the EC after 1992. Luwer Academic Publishers. Netherlands.

Collins, S. (1988) Inflation and the European Monetary System. In Giavazzi, F. Micossi, S. and Miller, M. The European Monetary System, Banca d'Italia, Centro Interuniversitario di Studi Teorici per la Politica Economica and Centre for Economic Policy Research, Cambridge University Press.

Collins, S.(1992) The Expected Timing of EMS Realignments: 1979-83: NBER Working Papers No.4068. 
Corbo, V. de Melo, J. (1986) What Went Wrong in the Southern Cone. Economic Development and Cultural Change, 323-338.

Corden, W. (1986) Fiscal Policies, Current Accounts and Real Exchange Rates: In Search of a Logic of International Policy Coordination. Weltwirtschaftliches Archiv. 289-310.

Crawford, V. (1983) International Lending, Long Term Credit Relationships and Dynamic Contract Theory. Mimeo. University of California, San Diego.

Cukierman, A. Meltzer, A. (1986) A Theory of Ambiguity, Credibility and Inflation under Discretion and Asymmetric Information. Econometrica, 1099-1128.

Cukierman, A. Webb, S. Neyapti, B. (1992) Measuring the Independence of Central Banks and Its Effect on Policy Outcomes. World Bank. Economic Review, 353398.

Da Motta Veiga, P. (1992) Siete Hipótesis sobre los Procesos de Regionalización y la Integración del Cono Sur. Integracion Latinoamericana. January-February.

Dandeker, R. (1993) The Rose Garden Agreement, is MERCOSUR the Next Step to a Hemispheric Free Trade Zone?, Policy in International Business. Washington D. C.

De Grauwe, P. (1989a) International Money Post-War Trends and Theories. Clarendon Press, Oxford.

De Grauwe, P. (1989b) The Cost of Disinflation and the European Monetary System. CEPR Discussion Papers No 326.

De Grauwe, P. (1989c) Disinflation in the EMS and in the Non-EMS Countries, What have we Learned? CES Discussion Papers. Unversity of Lueven.

De Grauwe, P (1994) The Economics of Monetary Integration. Oxford Univ. Press.

De Grauwe, P. de Bellefroid, D. (1987) Long Run Exchange Rate Variability and International Trade. In Arnd, S. and Richardson, D. Real Financial Linkages among Open Economies. MIT Press Cambridge, Massachusetts.

De Kock, G. Grilli, V. (1993) Fiscal Policies and the Choice of Exchange Rate Regime. Economic Journal, 347-358.

Denburg, T. (1989) Global Macroeconomics. New York.

Deutsche Bundesbank (1992) Die Beschlüsse von Maastricht zur Europäischen Wirtschafts- und Währungsunion. Monatsberichte der Deutschen Bundesbank. Februar $45-54$ 
Deutsche Bundesbank. Monatsberichte der Deutschen Bundesbank. (Several issues)

Deutsche-Südamerikanische Bank, Kurzbericht über Lateinamerika. (Several issues).

Dichiara, R. (1994) Wirtschaftsintegration in Lateinamerika: der MERCOSUR. Integration, Bonn, 234-244.

Díaz Alejandro, C. (1976) Foreign Trade Regimes and Economic Development. Columbia University Press, New York.

Dickey, D. and Fuller, W. (1979) Distribution of the Estimates for Autoregressive Time Series with Unit Root. Journal of American Statistical Association, 427431.

Dickey, D. Fuller, A. (1981) Likelihood Ratio Statistics for Autoregressive Time Series. Journal of the American Statistical Association, 335-367.

Dickey, D. Jansen, D. Thornton, D. (1991) A Primer on Cointegration with an Application to Money and Income. Review, Federal Reserve Bank of St. Louis.73, 5878.

Diebold, F. Nerlove, M. (1990) Unit Roots in Economics Time Series: A Selective Survey. In Fomby, T. and Rhodes, G., Advances in Econometrics, Vol. 8 Greenwich, Conn. JAI Press.

Dolado, J. Griffiths, M. Padilla, A. (1994) Delegation in International Monetary Policy Games. European Economic Review, 1056-1070.

Dornbusch, R. (1976) Expectations and Exchange Rate Dynamics, In: Journal of Political Economy, 1161-1176.

Dornbusch, R. (1980) Open Economy Macroeconomics. New York.

Dornbusch, R. (1995) Progress Report on Argentina. Reform, Recovery and Growth. Chicago. 223-228.

Dornbusch, R. De Pablo, J. (1988) Foreign Debt and Macroeconomic Instability in Argentina. Ed. Sudamericana.

Dornbusch, R. (1989) Irelands Disinflation, Credibility, Debt and Unemployment: Ireland failed Stabilization. Economic Policy, 174-209.

Dornbusch; R. Fischer, S. (1994) Macroeconomics, New York, McGraw Hill.

Eastwood, R. Venables, A. (1982) The Macroeconomic Implication of a Resource Discovery in an Open Economy. The Economic Journal, 285-299. 
Edwards, S. (1992) Exchange Rates as Nominal Anchors. NBER Working Papers, No. 4246.

Edwards, S. (1993) Latin American Economic Integration a New Perspective on an Old Dream. The World Economy, 317-338.

Edwards, S. (1994) Exchange Rates, Inflation and Disinflation: Latin American Experience. In Edwards, S. Capital Controls, Exchange Rates and Monetary Policy in the World Economy. Cambridge University Press.

Edwards, S. Cox-Edwards, A. (1991) Monerarism and Liberalization. The Chilean Experiment. Chicago. University Press Chicago.

Edwards, S Tabellini, G. (1991) Explaining Inflation and Fiscal Deficits in Developing Countries. Journal of International Monetary and Finance, 281-302.

Eichengreen, B. (1990) One Money for Europe. Lessons from the US Currency Union. Economic Policy, 118-166.

Eichengreen, B. (1992) History of the International Monetary System: Implications for Research in International Macroeconomics and Finance. In van der Ploeg, F. Handbook of International Macroeconomics, Chicago. University Chicago Press.

Eichengreen, B. Wyplosz, C. (1993) The Unstable EMS, CEPR Discussion Papers No. 817

El Agraa, A. (1994) The Economics of the European Community. Harvester Wheatheaf.

El Economista (Several issues).

Emerson, M. Gros, D. Pisani-Ferry, Italiener, A. and Reichenbach, H. (1991) One market, one money, Oxford University Press. Oxford.

Emerson, M. Huhne, C. (1991) The ECU Report. The Single Currency and What it Means to You. Pan Books, London.

Engle, R. Granger, C. (1987) Co-Integration and Error Correction Representation, Estimation and Testing. Econometrica, 251-276.

Esguerra, P. (1986) El Papel de las Ventajas Comparativa en el Comercio Andino de Manufacturas. Coyuntura Económica, Buenos Aires.

Evans, P. (1979) Dependent Development. Princeton University Press.

Fanelli, J. Fenkel, R. Rozenwurzel, G. (1990) Growth and Structural Reform in Latin America: Where do we Stand? CEDES, Buenos Aires. 
Fernadez, R. Rodrik, D. Why is Trade Reform so Unpopular? CEPR Working Papers. No 391 .

Ferguson, F. (1984) Cooperation in Latin America: The Politics of Regional Integration. In The Dynamic of Latin American Foreign Policies. In Smith, P. The Challenge of Integration Europe and the Americas. Transaction Publishers.

Ferrer, A. (1996) Reflexiones Acerca de la Política de Estabilización en Argentina $E l$ Trimestre Económico, 353-369.

FIEL (1991) Argentina y el Mercosur. Una Respuesta a la Iniciativa para las Americas y Europa 1992, Ed. Manantial.

FIEL (1992) Las Corrientes Aperturistas Latinoamericans y la Economía International, Ed. Manantial

FIEL, (1993) El Comercio Administrado de los 90: Argentina y sus Socios, Ed. Manantial.

Finch, M. (1982) The Latin American Free Trade Association. In El Agraa, A. International Economic Integration, Macmillan, London.

Fischer, S. (1987) Recent Developments in Macroeconomics. MIT Press Cambridge, Massachusetts.

Fischer, S. (1988) Rules Versus Discretion in Monetary Policy MIT. Press Cambridge, Massachusetts.

Fischer, S. (1988) International Coordination: A Survey. In Feldstein, M. International Economic Cooperation. Chicago University Press.

Fisher, S. (1988) Rules versus Discretion in Monetary Policy. NBER Working Papers No. 2418.

Fischer, S. (1995) Modern Approach to Central Banking, NBER Working Papers No. 5064 .

Fischer, B. (1994) Regionaltendenzen in Amerika, Erscheinungsformen, Ursachen, Bewertung, Außenwirtschaft, 536-548.

Fleming, J. (1962) Domestic Financial Policies under Fixed and under Floating Exchange Rates. IMF Staff Papers, 369-379.

Flood, R. Kramer, C. (1996) Economic Models of Speculative Attacks and the Drachma Crisis of May 1994. Open Economies Review, 7 ,431-436 
Flood, R. Garber, P. (1984) Collapsing Exchange Rates Regimes Some Linear Examples. Journal of International Economics, 1-13.

Flood, R. (1982) The Transmission of Disturbances under Alternative Exchange Rate Regimes with Optimal Indexing. Quarterly Journal of Economics, 43-66.

Foders, F. (1996) Mercosur: A New Approach to Regional Integration? Kiel Working Papers. No.746.

Fratianni, M. von Hagen, J. (1990) The European Monetary System Ten Years After. Carnegie Rochester Conference Series on Public Policy.

Fratianni, M. von Hagen, J. (1992) The European Monetary System and European Monetary Union. Boulder, Colo. Westview Press.

Frenkel, J. Aizenman, J. (1984) Shocks, Wage Indexation and Monetary Accommodation. NBER Working Papers No. 748

Frenkel, J. Goldstein, M. (1986) A Guide to Target Zones. IMF Staff Papers, 633-670.

Frenkel, J. Mussa, M. (1985) Asset Markets, Exchange Rates and the Balance of Payments. In Jones, R. Kenen, P. Handbook of International Economics. Amsterdam North Holland.

Frenkel, J. Razin, A. (1987) The Mundell-Fleming Model: A Quarter Century Later, NBER Working Papers No 2321.

Frenkel, J. Rodriguez,C (1982) Exchange Rate Dynamics and the Overshooting Hypothesis. IMF Staff Papers. 1-30.

Frenkel, R. Fanelli, J. (1987) El Plan Austral un Año Después. El Trimestre Económico, 55-118.

Friedman, M. (1953) The Case for Flexible Exchange Rates. In Essays in Positive Economics, University of Chicago Press, 157-203.

Fritsch, W. Tombini, A. (1994) The Mercosul: An Overview. In Bouzas, R. Ros, J Economic Integration in the Western Hemisphere. University of Notre Dame Press.

Fuller, W. (1976) Introduction to Statistical Time Series. New York, Wiley.

Funke, M. (1995) Europe's Monetary Future: One Market one Money? Centre for Economic Forecasting. Discussion Paper, 1, London Business School.

Fundación Mediterránea, Newsletter, IEERAL. Cordoba. (Several issues) 
Gagnon, J. (1989) Exchange Rate Variability and the Level of International Trade. International Finance Discussion Papers. Board of Governors of the Federal Reserve System.

Gagnon, J. (1990) Pricing to Market in International Trade : Evidence from Panel Data on Automobiles and Total Merchandise. In Gagnon, J. Knetter, M. Washington, DC. Board of Governors of the Federal Reserve System. International Finance Discussion Papers, 389.

Gana, E. (1994) Cooperación Macroeconómica en America Latina. Coordinación, Convergencia y Armonización de Políticas. CEFIR, Montevideo.

Gandolfo, G. (1986) International Economics. Springer Verlag, Berlin.

Garay, J. (1981) El Pacto Andino Creación de un Mercado para Colombia? FEDESARROLLO, Bogotá.

Garriga, M. Sanguinetti, P. (1995) Es el Mercosur un Bloque Natural? Efectos de la Política Comercial y la Geografia sobre el Intercambio Regional Estudios, Cordoba.

Gärtner, M. (1990) Makroökonomik flexibler Wechselkurse. Springer Verlag.

Gärtner, M. (1994) Macroeconomics under flexible exchange rates. Harvester Wheatsheaf, LSE Handbooks in Economics Series.

Gassner, C. Wolf, F. (1995), Der Mercosur: Beispiel für eine erfolgreiche Integration? IFO Schnelldienst.

Genberg, H. (1989) Exchange Rate Management and Macroeconomic Policy a National Perspective. The Scandinavian Journal of Economics, 439-469.

Genberg, H. Salemi, M. Swoboda, A. (1984) The Relative Importance of Foreign and Domestic Disturbances for Aggregate Fluctuations in the Open Economy. Switzerland 1964-1981. Discussion Papers in International Economics. No. 8407. The Graduate Institute of International Studies.

Genberg, H. Swoboda, A. (1985), External Influences on the Swiss Economy under Fixed and Flexible Exchange Rates. Schweizerisches Institut für Außenwirtschafts- Struktur- und Regionalforschung an der Hochschule St. Gallen.

Giavazzi, F (1989) The Exchange Rate Question in Europe. In Bryant, R. Currie, D. Frenkel, J, Masson, P Portes, R, Macroeconomic Policies in and Interdependent World. Washington DC, IMF

Giavazzi, F. Pagano, F. (1988) The Advantages of Tying One's Hands EMS Discipline and Central Bank Credibility. European Economic Review, 1055-1082. 
Giavazzi, F Giovannini, A. (1987) Models of the EMS: Is Europe a Greater Deutschmark Area? Global Macroeconomics: Policy Conflict and Cooperation. New York St. Martin. 237-272.

Giavazzi, F. Giovannini, A. (1988) The Role of the Exchange Rate Regime in a Disinflation: Empirical Evidence of the European Monetary System. In Giavazzi, F. Micossi, S. Miller, M. The European Monetary System. Cambridge University Press.

Giavazzi, F Giovannini, A. (1989) Monetary Policy Interactions under Managed Exchange Rates. Economica, 199-213.

Giavazzi, F. Giovaninni, A. (1989). Limiting Exchange Rate Flexibility: The European Monetary System. MIT Press, Cambridge, Massachusetts.

Giovannini, A. (1988) How do Fixed Exchange Rate Regimes Work: The Evidence From the Gold Standard, Bretton Woods and the EMS, CEPR Discussion Papers No. 282.

Giovannini, A. (1990) The Transition to European Monetary Union. Essays in International Finance, 178 Princeton, N.J. Princeton University, November.

Giovannini, A. De Gregorio, J. (1993) International Evidence on Tradables and Nontradables Inflation. NBER Working Paper Series No 4438.

Girton, L. Roper, D. (1981) Theory and Implications of Currency Substitution. Journal of Money Credit and Banking, 12-30.

Godeaux, J. (1989) The Working of the EMS: A Personal Assessment. In Collection of Papers Annexed to the Delors Report. Office of Publications of the European Communities. Luxemburg. 1991-209.

Goodhart, C. (1990) Economic Perspectives on the EMS. Journal of Monetary Economics, 471-487.

Gosling, P. (1986) The Effects of Exchange Rate Variability on UK Exports. National Economic Development. Office Working Papers.

Gotur, P. (1985) The Effect of Exchange Rate Volatility on Trade: Some Evidence. IMF Staff Papers, 211-231.

Granger, C. (1986) Econometric Modeling with Cointegrated Variables. Oxford Bulletin of Economics and Statistics, 213-228.

Granger, C. (1988) Some Recent Developments in a Concept of Causality, Journal of Econometrics, 199-211. 
Granger, C. Newbold, P. (1976) Spurious Regressions in Econometrics. Journal of Econometrics, 111-120.

Gratius, S. (1993), El Mercosur y la Comunidad Europea: Una Guía Para la Investigación. Madrid. IRELA.

Griffiths, W. Hill, R. Judge, G. (1993) Learning and Practicing Econometrics. John Wiley and Sons Inc, New York.

Grilli, V. Masciandaro, D. Tabellini, G. (1991) Political and Monetary Institutions and Public Financial Policies in the Industrial Countries. Economic Policy, 341-392.

Gros, D. Thygesen, N. (1992) European Monetary Integration. Longman Group UK Limited.

Gros, D. Thygesen, N. (1988) The EMS Achievements, Current Issues and Directions of the Future. CEPS Discussions Papers, No 35.

Grossman, G. Helpman, E. (1994) The Politics of Free Trade Agreements. NBER Working Paper No 4597.

Guerreri, P. Padoan, P.(1988) The Political Economy of International Cooperation. London.

Guerreri, P. Padoan, P (1987) The Political Economy Approach to International Cooperation: A Critical Survey. Economic Notes, 67-88.

Guilkey, D. Schmidt, P. (1989) Extended Tabulations for Dickey-Fuller Tests. Economic Letters, 355-357.

Guitian, M. (1988) The European Monetary System: A Balance Between Rules and Discretion. IMF Occasional Papers, No 61, Washington D.C.

Haggard, S. Kaufmann, R. (1992) Economic Adjustment, Princeton University Press.

Haldane, A. (1991) The exchange Rate Mechanism of the European Monetary System: A Review of the Literature. Bank of England Quarterly Bulletin.

Halm, G. (1970) Approaches to Greater Flexibility of Exchange Rates. The Bürgenstock Papers. Princeton University Press.

Halperin, M. (1992) Instrumentos Básicos de Integración Economica en America Latina y el Caribe. BID INTAL.

Hamada, K. (1985) The Political Economy of International Monetary Interdependence. MIT Press Cambridge, Massachusetts. 
Hansson, A. Sachs, J. (1994) Monetary Institutions and Credible Stabilizations. A Comparison of Experiences of the Baltics. Mimeo, Harvard University.

Harvey, A. (1992) The Econometric Analysis of Time Series. Allan N.Y.

Helpman, E. (1981) An Exploration in the Theory of Exchange Rate Regimes. Journal of Political Economy, 865-890.

Helpman, E. Leiderman, L. (1989) Exchange Rate Systems: Are There New Answers to Old Questions? Working Paper. Tel Aviv University.

Henderson, D. (1984) Exchange Rate Intervention Operations: Their Role in Financial Policy and their Effects, in Bilson, J. Marston, R. Exchange Rate Theory and Practice, NBER. Chicago Univ. Press.

Henderson, J. Quandt, R. (1985) Microeconomic Theory. MacGraw Hill.

Heymann, D. (1986) Tres Ensayos Sobre Inflación y Estabilización. Santiago, Chile, CEPAL.

Heymann, D. (1987) The Austral Plan. The American Economic Review, 284-288.

Hibbs, D. (1987) The American Political Economy: Macroeconomics and Electoral Politics in the United States. MIT Cambridge Massachusetts.

Hildebrandt, P. (1991) The Path to European Monetary Union. Economic Review. Federal Reserve Bank of Kansas City, 35-48.

Hirst, M. (1992) Condiciones y Motivaciones del Proceso de Integración y Fragmentación en América Latina. Integración Latinoamericana, January-February.

Hoffmeister, A. Vegh, C. (1996) Disinflation and the Recession-Now-Versus-Recession-Later Hypothesis: Evidence from Uruguay. IMF Staff Papers. 355-395.

Horne, J. Masson, R. (1987) Internationale Kooperation und Koordination der Wirtschaftspolitiken. Finanzierung und Entwicklung, 28-31.

Horne, J. Masson, R. (1988) Scope and limits of International Economic Cooperation and Policy Coordination. IMF Staff Papers, 259-296.

Hurrel, A. (1992) Regionalism in the Americas. Unpublished manuscript.

IBGE, Mercosur: Sinopse Estatistica.

IERAL-Fundación Mediterranea (1993) Qué es el Mercosur? Estudios. Junio.

IMF, International Financial Statistics. (Several issues). 
Isard, P. (1995) Exchange Rate Economics. Cambridge University Press.

Issing, O. (1993) Einführung in die Geldtheorie. Vahlen Verlag. München.

Jarchow, H.(1994) Eine Asymmetrische Währungsunion im Dornbusch-Modell. IFO Studien, 209-226.

Jarchow, H. Rühmann, P. (1994) Monetäre Außenwirtschaftstheorie. UTB Vandehoeck.

Jensen, H. (1994) Loss of Monetary Discretion in a Simple Dynamic Policy Game. Journal of Economic Dynamics and Control, 763-779.

Johansen, S. (1988) Statistical Analysis of Cointegration Vectors. Journal of Economic Dynamics and Control, 234-254.

Johansen, S. Juselius, K. (1990) Maximum Likelihood Estimation and Inference on Cointegration with Application to the Demand for Money. Oxford Bulletin of Economics and Statistics. 169-210.

Johnson, H. The case for Flexible Exchange Rates, 1969. In Halm, G. Approaches to Greater Flexibility of Exchange Rates. The Bürgenstock Papers. Princeton University Press. Princeton. 91-111.

Jordan, T. (1994) Reale Wechselkurse innerhalb der Schweiz und ausgewählter Nachbarstaaten. Kredit und Kapital, 518-535.

Jordan, T. Lenz, C. (1995). Demand and Supply Shocks in the IS-LM Model: Empirical Findings of 5 countries. (Unpublished manuscript).

Junta de Acuerdo de Cartagena (1982) Análisis del Comercio Andino 1969-1980 .Evolución y Características. Lima. (Unpublished manuscript).

Keating, J. (1992) Structural Approach to Vector Autoregressions. Review, The Federal Reserve Bank of St. Louis. Vol.74.

Kenen, P. (1995) Economic and Monetary Union in Europe. Moving Beyond Maastricht. Cambridge University Press.

Kenen, P. (1996) Analyzing and Managing Exchange Rate Crisis. Open Economies Review, 431-436.

Kesman, K. (1992) MERCOSUR: Intercambio Comercial y Asimetrías. Novedades Económicas. Córdoba No. 139.

Kiguel, M. (1989) Inflation in Argentina. Stop and Go Since the Austral Plan. Working Paper 162, World Bank. 
Kiguel, M. (1988) Ups and Downs in Inflation: Argentina Since the Austral Plan. World Bank, Washington D. C.

Kiguel, M. Liviatan, N. (1991) The Inflation-Stabilization Cycles in Argentina and Brazil. In Bruno, M. Fischer, S. Helpman, E. Lessons of Economic Stabilization and Its Aftermath. MIT Press, Cambridge Massachusetts.

Kiguel, M. Liviatan, N.(1992a) When do Heterodox Stabilization Programs Work? Lessons form Experience. The World Bank Research Observer, 35-57.

Kiguel, M. Liviatan, N.(1992b) The Business Cycle Associated with Exchange Rate Based Stabilizations. World Bank Economic Review, 279-305.

Kydland, F. Prescott, E. (1977), Rules Rather than Discretion: The Inconsistency of Optimal Plans. Journal of Political Economy, 473-491

Kindleberger, C .(1970) The Case for Fixed Exchange Rates. In International Adjustment Mechanism. Proceedings of the Monetary Conference, Melvin Village, NH, Oct 8-10.

King, R. Plosser, C. Stock, J. Watson, M. (1991) Stochastic Trends and Economic Fluctuations, The American Economic Review. 819-839.

Kleinheyer, N. (1987) Der Abweichungsindikator im EWS. Stabilität durch EWS? In Scharrer, H. Wessels, W. Bonn. Europa Union, 331-352.

Kloten, N. (1983) Das Europäische Währungssystem. Europa Archiv, Bonn, 599-608.

Kloten, N. (1980) Germany's Monetary and Financial Policy and the European Community. In Kohl. W. Basevi. G. West Germany A European and Global Power. Lexington Books, D. C. Heath and Co Lexington.

Koray, F. (1987) Government Debt, Economic Activity and Transmission of Economic Disturbances, Journal of Money, Credit and Banking. 361-375.

Kösters, W. (1991) Europäische Zentralbank und Preisniveaustabilität. Hamburger Jahrbuch für Wirtschafts-und Gesellschaftspolitik. 155-167.

Kotlikoff, L. Persson, T. Svensson, L. (1988) Social Contracts as Assets: A Possible Solution to the Time Inconsistency Problem. The American Economic Review, 662-677.

Kremers, R. (1989) Gaining Policy Credibility in the EMS: The Case of Ireland. IMF Working Papers, No 36.

Krugman, P. (1979) A Model of Balance of Payment Crisis. Journal of Money Credit and Banking, 311-325. 
Krugman, P. (1995) Currencies and Crisis. MIT Press Cambridge Massachusetts.

Krugman, P. (1993) What do We Need to Know About the International Monetary System? Essays on International Finance. No. 190 Princeton University.

Kuori, P. (1976) The Exchange Rate and the Balance of Payments in the Short Run and the Long Run: A Monetary Approach. Scandinavian Journal of Economics 78, 280-304.

Laidler, D. (1968) The Permanent Income Concept in a Macroeconomic Model. Oxford Economic Papers, 11-23.

Lal, D. (1985) The Poverty of Development Economics, Harvard University Press.

Lastrapes, W.(1992) Sources of Fluctuation in Real and Nominal Exchange Rates, Review of Economics Statistics, 530-539.

Lavagna, R. (1996) Coordinación Macroeconómica, La Profundización de la Interdependecia y Derivaciones para el MERCOSUR. Desarrollo Económico, 35-42.

Lavagna, R. (1994) Opening a Medium Size Economy. A Case for Regional Agreement Argentina/MERCOSUR. The Center for International Affair, Harvard University, Cambridge.

Lion, E. (1994) Regional Trade Arrangements in the Western Hemisphere. Business America. Washington D. C., 17-21.

Little, I. (1982) Economic Development: Theory, Policy and International Relation, Basic Books.

Lohmann, S. (1992) Optimal Commitment in Monetary Policy: Credibility versus Flexibility, The American Economic Review, 273-211.

Lopes, F. (1984) Inertial Inflation, Hyperinflation and Disinflation. Notes and Conjectures. Rivista Da Anpec, 201-212.

Lopes, F. (1989) O Desafio da Hiperinflacao, em Busca da Moeda Real. Sao Paulo, Campus.

McCallum, B. (1995) Two Fallacies Concerning Central Bank Independence, The American Economic Review, Papers and Proceedings, 207-211.

MacDonald, R. (1988) Floating Exchange Rates. Theories and Evidences. Unwin Hyman, London.

Mace, G. (1988) Regional Integration in Latin America: A Long and Winding Road. International Journal, 404-427. 
McKibbin, W. Sachs, J. (1986) Coordination of Monetary and Fiscal Policies in the OECD, NBER Working Papers No 1800.

McKinnon, R, Oates, W (1966) The Implications of International Economic Integration for Monetary, Fiscal and Exchange Rate Policy. Princeton Studies in International Finance, No.16 Princeton University.

McKinnon, R. (1984) An International Standard for Monetary Stabilization. Policy Analyses in International Ecomomics, No 8. Washington Institute for International Economics.

MacKinnon, J. (1991) Critical Values for Cointegration Tests. In Engle, R. Granger, C., Long-Run Economic Relationships, Oxford University Press, Oxford.

Maddala, G. (1992) Introduction to Econometrics. Macmillan Publishing Company, New York.

Maenning, W. (1992) Internationale Transmission und Koordinierung der Wirtschaftspolitik. Duncker \& Humboldt, Berlin.

Mark, N. (1990) Real and Nominal Exchange Rates in the Long Run: An Empirical Investigation. Journal of International Economics, 115-136.

Marquardt, R. (1994) Vom Europäischen Währungssystem zur Europäischen Wirtschafts- und Währungsunion. Europäische Hochschulschriften. Peter Lang.

Marston, R. (1985) Stabilization Policies in Open Economies, In: Jones, R. Kenen, P. Handbook of International Economics, North Holland.

Masson, P. Taylor, M. (1992) Issues in the Operation of Monetary Unions and Common Currency Areas. In Policy Issues in the Evolving International Monetary System, IMF Occasional Paper No. 96.

Mastroberardino, M. Kapitalflucht: die Erfahrungen Argentinien 1976-1992. Institut für Wirtschaftspolitik an der Universität Köln.

Mastroberardino, M. (1996) Latin American Quarterly. Credit Suisse Research, Zürich.

Mayoral, A. (1992) El Mercosur Sigue Avanzando. Novedades Económicas. Cordoba.

Meese, R. Rogoff, K (1983) Empirical Exchange Rate Models for the Seventies, do They Fit Out of Sample? Journal of International Economics, 3-24.

Melitz, J (1988) Monetary Discipline, Germany and the European Monetary System. Kredit und Kapital, 481-511. 
Ministerio de Economía y Obras y Servicios Públicos (1996) Economic Report. Buenos Aires.

Molle, W. (1990) The Economics of European Integration. Theory, Practice and Policy. Dartmouth, Aldershot

Morales, J. (1991) The Transition from Stabilization to Sustained Growth in Bolivia. In Bruno, M. Fischer, S., Helpman, E. Liviatan, N. Lessons of Stabilization and Its Aftermath. MIT Press, Cambridge Massachusetts.

Morales de Marega, H.(1993) Asimetrías Macroeconómicas en el Mercosur. Boletin Mexico. $\mathrm{Nr} 39$.

Morande, F. Soto, R. (1992) Una Nota Sobre la Construcción de Series de Precios de Activos Reales: Tierra y Casas en Chile. Revista de Análisis Económico. Santiago de Chile.

Mundell, R. (1960) The Monetary Dynamics of International Adjustment Under Fixed and Flexible Rates. Quarterly Journal of Economics, 227-257.

Mundell, R. (1961) Flexible Exchange Rates and Employment Policy. Canadian Journal of Economics and Political Science. 509-517.

Mundell, R. (1961) Optimal Currency Areas. The American Economic Review, 609617.

Mundell, R. (1961) The International Disiquilibrium System. Kyklos, 157-170.

Mundell, R. (1963) Capital Mobility and Stabilization Policy Under Fixed and Flexible Exchange Rates. Canadian Journal of Economic and Political Science, 475485 .

Mundell, R. (1964) A Reply: Capital Mobility and Size. Canadian Journal of Economics and Political Science, 421-431.

Mundell, R. (1968) International Economics. Macmillan, New York.

Mussa, M. (1982). A Model of Exchange Rate Dynamics. Journal of Political Economy, 74-104.

Mussa, M. (1986) Nominal Exchange Rate Regimes and the Behavior of Real Exchange Rates. Evidence and Implications. Carnegie Rochester Conference Series on Public Policy.

Naum, M. (1993) Argentina y el MERCOSUR: un Proceso Complejo. Información Comercial Espanola, Madrid No 2369. 
Nelson, C. Plosser, C. (1982) Trends and Random Walks in Macroeconomic Time Series. Journal of Monetary Economics, 139-162.

Neumann, M. (1988) Theoretische Volkswirtschaftslehre, München.

Obstfeld, M. (1986) Rational and Self-fulfilling Balance of Payment Crises. The American Economic Review. 72-81.

Obstfeld, M. Rogoff, K. (1984) Exchange Rate Dynamics with Sluggish 'Prices under Alternative Price Adjustment Rules. International Economic Review. 358-465.

Obstfeld, M. Stockman, A. (1985) Exchange Rate Dynamics. In Jones, R. Kenen, P. Handbook of International Economics. North Holland.

Ocampo, J. Esguerra, P. (1994) The Andean Group and Latin American Integration. In Bouzas, R. Ros, J. Economic Integration in the Western Hemisphere. University of Notre Dame Press.

OECD, Main Economics Indicators. (Several issues)

Ohr, R. (1996) Europäische Integration. Kohlhammer. Stuttgart

Ondarts, G. (1992) La Nueva Integración. Estudios January-February.

Osterwald-Lenum, M. (1992) A Note with Quantiles of the Asymptotic Distribution of the Maximum Likelihood Cointegration Rank Test Statistics. Four Cases. Oxford Bulletin of Economic and Statistics. 461-472.

Padoa-Schioppa, T. (1987) Efficiency, Stability, and Equity: A Strategy for the Evolution of the Economic System of the European Community. A Report Oxford University Press, Oxford.

Papadopoulou, D. (1993) Makroökonomik der Wechselkursunion. Peter Lang, Frankfurt.

Pastori, A. (1993) Marche Commun du Sud: Mercosur. Revue Du Marche Commun et de l'Union Europeéne. Paris No 372.

Powell, A. (1995) Regulation for a Stable Financial System. Prudential Supervision and Liquidity Management in Argentina. BCRA Buenos Aires.

Pazos, F. (1972) Chronic Inflation in Latin America, New York. Prager Publishers.

Peña, F. (1994) Strategies for Macroeconomic Coordination: Reflections on the Case of MERCOSUR. In Bouzas, R. Ros, J. Economic Integration in the Western Hemisphere. University of Notre Dame Press. 
Perez del Castillo, S.(1993) MERCOSUR: History and Aims. International Labor Review. Geneva Nr. 6, 89-138.

Persson, T. Svensson, L. (1987) Time Consistency of Fiscal and Monetary Policy. Econometrica, 1419-1432.

Persson , T. (1988) Credibility of Macroeconomic Policy: an Introduction and Broad Survey. European Economic Review Papers and Proceedings, 372-376.

Persson, T. Svensson, L. (1986) International Borrowings and Time Consistent Fiscal Policy. Scandinavian Journal of Economics, 273-295.

Persson, T. Svensson, L. (1984) Time Consistency of Fiscal and Monetary Policy. Econometrica, 1419-1432.

Persson, T. Svensson, L. (1984) Time Consistent Fiscal Policy and Government Cash Flow. Journal of Monetary Economics. 365-374.

Persson,T. Tabellini, G. (1993) Designing Institutions for Monetary Stability. Carnegie Rochester Conference Series on Public Policy.

Persson, T. Tabellini, G. (1990) Macroeconomic Policy, Credibility and Politics. Harwood Academic Publishers GmbH.

Phillips, P. (1986) Understanding Spurious Regressions in Econometrics, Journal of Econometrics, 311-340.

Pollard, P. (1993) Central Bank Independence and Economic Performance. Federal Reserve Bank of St. Louis. Review 75, 21-36.

Poloz, S. (1990) Real Exchange Rate Adjustment between Regions in a Common Currency Area. Working Paper, Bank of Canada.

Poole, W. (1970) Optimal Choice of Monetary Policy Instruments in a Simple Stochastic Macro Model. Quarterly Journal of Economics, 197-216.

Posen, A. (1993) Why Central Bank Independence Does not Cause Low Inflation: The Politics behind the Institutional Fix. Unpublished Papers. Harvard University. (November).

Prebisch, R. (1987) Cinco Etapas de Mi Pensamiento Sobre el Desarrollo Comercio Exterior 37, No 5.

Prebisch, R. (1949) El Desarrollo Económico de América Latina y Sus Principales Problemas. El Trimestre Económico. 359-361. 
Prebisch, R. (1959) International Trade in an Era of Coexistence of Commercial Policy in the Underdeveloped Countries. The American Economic Review Papers and Proceedings, 255-257.

Rapoport, A. Chammah, A. (1965) Prisioner's Dilemma. A Case Study in Conflict and Cooperation. Ann Harbor.

Reinhart, C. Vegh, C. (1995) Nominal Interest Rates, Consumption Booms and Lack of Credibility: A Quantitative Examination. Journal of Development Economics, 357-378.

Reither, F. (1992) Nachfrageschocks und Wechselkursvolatilität. Kredit und Kapital, 55-64.

Reither, F. (1996) Geldpolitische Strategien: Geldmengenziel versus Inflationsziel. Universität der Bundeswehr Hamburg, Working Papers, 2.

Rebelo, S. Vegh, C. Real Effects of Exchange Rate-Based Stabilization: An Analysis of Competing Theories. NBER Working Papers No.5197.

Robertson, D. Symons, J. (1992) Output, Inflation and the ERM. Oxford Economics Papers, 373-386.

Rodríguez, E. (1994) Central America: Common Market, Trade Liberalization, and Trade Agreements. In Bouzas, R. Ros, J .Economic Integration in the Western Hemisphere. University of Notre Dame Press.

Rogoff, K. (1985) The Optimal Degree of Commitment to an Intermediate Monetary Target. Quarterly Journal of Economics, 1169-1189.

Rogoff, K. (1987) Reputational Constraint in Monetary Policy. Carnegie Rochester Conference Series on Public Policy.

Roldos, J. (1991) La Crisis Bancaria Uruguaya de los 89. Mimeo. CERES, Uruguay.

Roldos, J. (1995) Supply-Side Effects of Disinflation Programs. IMF Staff Papers 42, 158-184.

Romer, D. (1996) Advanced Macroeconomics. Mc Graw Hill. Advanced Series in Economics. Mc Graw Hill, New York.

Rose, A. (1996) After the Deluge: Do Fixed Exchange Rates Allow Intertemporal Volatility Trade Off? International Journal of Finance and Economics, 47-54.

Russo, M. Tullio, G. (1988) Monetary Coordination Within the European Monetary System; Is There a Rule? IMF Occasional Papers. No 61 Washington D.C. 
Sachs, J. (1987) The Bolivian Hyperinflation and Stabilization. The American Economic Review, 345-439.

Sachs, J. Zini, A. (1996) Brazilian Inflation and the Plano Real. The World Economy, 25-58.

Sachs, J Larrain, F. (1993) Macroeconomics in The Global Economy. Harvester, Wheatsheaf.

Sanguinetti, J. (1994) MERCOSUR: las Alternativas del Diseño Institutuional Definitivo. (Unpublished manuscript).

Sargent, T. (1979) Estimating Vector Autoregressions Using Methods Based on Explicit Economic Theories. Quarterly Review, Federal Reserve Bank of Minneapolis.

Sargent, T. (1982) The Ends of Four Big Inflations. In Hall, R. Inflation, Causes and Effects. Chicago. University of Chicago.

Sargmeister, H. (1992) Mercosur: Stand und Perspektiven der wirtschaftlichen Integration im Cono Sur. Diskussionsschriften 44 Universität Heidelberg. Wirtschaftswissenschaftliche Fakultät. Institut für Wirtschafts- und Sozialstatistik.

Scarth, W. (1988) Macroeconomics: An Introduction to Advanced Methods. Harcourt Brace Jovanovich, Canada Inc.

Schäfer, W. (1990) Binnenmarkt und Wechselkurs, Außenwirtschaft, 353-370.

Schiemann, J (1992) Das Europäische Währungssystem (EWS) Im Zielkonflikt zwischen Stabilität und Konvergenz. Zeitschrift für Wirtschaftspolitik, 269-299.

Schinasi, G. (1989) European Integration, Exchange Rate Management, and Monetary Reform: A Review of the Major Issues. US Federal Reserve System, International Finance Discussion Papers, No 364.

Schotter, A. (1981) The Economic Theory of Social Institutions. Cambridge University Press, Massachusetts.

Seitenfus, R. (1993) Nationalregierungen und MERCOSUR: Ziele und Zeitplan als politisches Instrument. Lateinamerika Nr. 32.

Shapiro, M. Watson, M. (1991), Sources of Business Cycle Fluctuations, NBER Macroeconomics Annual.

Sims, C. (1980) Macroeconomics and Reality. Econometrica. 1-48. 
Solis, L. (1988) Raul Prebisch at ECLA. Years of Creative Intellectual Effort. International Center for Economic Growth. Occasional Papers No. 10.

Stallings, B. (1992) International Influence on Economic Policy: Debt, Stabilization and Structural Reforms. In Haggard, S. and Kaufman, R. The Politics of Economic Adjustment. Princeton University Press.

Stockman, A. (1987). The Equilibrium Approach to Exchange Rates, Federal Reserve Bank of Richmond Economic Review.

Stockman, A. (1988) Real Exchange Rate Variability under Pegged and Floating Nominal Exchange Rate Systems: An Equilibrium Theory Carnegie-Rochester Conference Series on Public Policy.

Swann, D. (1990) The Economics of the Common Market. Penguin Books. London.

Swoboda, A. Dornbusch, R. (1973) Adjustment, Policy and Monetary Equilibrium in a Two Country World, in Conolly, M. Swoboda, A. Simulation of Policy Coordination Under Structural Adjustment: An Estimate of the Economic Impact of the Mayekawa Report. (Unpublished Manuscript), Tokio.

Tabellini, G (1987) Reputational Constraints on Monetary Policy: A Comment Carnegie Rochester Conference Series on Public Policy.

Tavlas, G. (1996) Currency Crisis: Introduction. Open Economies Review, 431-436.

Taylor, J. (1980) Aggregate Dynamics and Staggered Contracts. Journal of Political Economy, 1-24.

Taylor, J. (1979) Staggered Price Setting in a Macro Model. The American Economic Review, 108-113

Taylor, J (1983) Union Wage Settlements During A Disinflation. The American Economic Review, 981-993.

The Economist. (Several issues).

Tobin, J. (1996) A Currency Transactions Tax. Why and How. Open Economies Review, 431-436.

Tucker, D. (1966) Dynamic Income Adjustment to Money Supply Changes. The American Economic Review, 433-449.

Tussie, J (1992) The Less Developed Countries and the World Trading System: A Challenge to the GATT. New York. ST Martin's Press. 
Ungerer, H. Evans, O. Nyborg, P. (1983) The European Monetary System: The Experience 1979-1982. IMF Occasional Papers No. 19.

Ungerer, H. Hauvonen, J- Lopez-Claros, A. Owens. E. Mayer, T. (1990) The European Monetary System : Recent Developments and Perspectives. IMF Occasional Paper No. 73.

Ungerer, H. Owen, E. Mayer, T. Young, P. (1986) The European Monetary System. Recent Developments IMF Occasional Papers No. 48.

Ungerer, H. (1990) The EMS the First Ten Years: Policies Developments, Evolution, EIU Working Papers, No 2, Badia Fiesolana, San Domenico

Ungerer, H. (1993) Die Krise des Europäischen Währungssystems im Herbst 1992. Ursachen, Lehren, Konsequenzen. Diskussionsbeiträge. Institut für Wirtschaftspolitik. Universität der Bundeswehr Hamburg.

van Klaveren, A. (1994) Why Integration Now? Options for Latin America. In Smith P. The Challenge of Integration Europe and the Americas. Transaction Publishers.

Vegh, C (1992) Stopping High Inflation: An Analytical Overview, IMF Staff Papers, 626-695.

Vickers, J. (1986) Signaling in a Model of Monetary Policy with Incomplete Information. Oxford Economic Papers, 443-455.

Vinals, J. (1994) Building a Monetary Union in Europe. Is it Worthwhile. Where Do We Stand, and Where Are We Going? CEPR Occasional Paper No. 15.

Viner J. (1950) The Customs Union Issue, New York. Endowments for International Peace.

Wagner, H. (1992) Stabilitätspolitik. Oldenbourg Verlag München Wien.

Walsh, C. (1995) Optimal Contracts for Central Bankers. The American Economic Review, 150-167.

Walsh, C. (1995) Is New Zealand's Reserve Bank of 1989 an Optimal Central Bank Contract? Journal of Money Credit and Banking, 1179-1191.

Weber, T. Voss, H. (1995) Lateinamerika: Mercosur ein Markt mit Zukunft? Bundesstelle für Außenhandelsinformation.

Weber, A. (1990) EMU and Asymmetries and Adjustment Problems in the EMS: Some Empirical Evidence. CEPR Discussion Papers No. 448. London. 
Weber, A. (1991) EMS Credibility. Economic Policy, 57-102.

Weber, A. (1992) The Role of Policymakers, Reputation in the EMS Disinflations. European Economic Review, 1473-1492.

Wehringer, G. (1996) Are Exchange Rate Based Stabilization Expansionary? Theoretical Considerations and the Brazilian Case. (Unpublished manuscript).

Werner, P. Ansioux, B. Brouwers, G. Clappier, B. Mosca, U. Schlöllhorn, J. Stammti, G (1970) Report to the Council and the Commission on the Realization by Stages of Economic and Monetary Union in the Community. In Supplement to Bulletin II. 1970 of the European Communities, Brussels.

Willgerodt, H. Domsch, A. Hasse, R. Merx, V. (1972) Wege und Irrwege zur Europäischen Währungsunion. Rombach Verlag. Freiburg.

Williamson, J.(1990) Latin American Adjustment: How much has happened? Institute for International Economics, Washington. D. C.

Williamson, J. (1991) The Progress of Policy Reform in Latin America Institute for International Economics. Washington D. C.

World Bank, (1995) World Development Report.

Wyplosz, C. (1986) Capital Controls and Balance of Payments Crisis. Journal of International Money and Finance, 167-179.

Ypersele, J. Koeune, J. (1984) Das europäische Währungssystem. Luxemburg: Amt für amtliche Veröffentlichungen.

Zaragoza, C. (1995) Argentina, México and Currency Boards: Another Case of Rules versus Discretion. Economic Review, Federal Reserve Bank of Dallas. Fourth Quarter. 


\section{SCHRIFTEN ZUR WIRTSCHAFTSTHEORIE UND WIRTSCHAFTSPOLITIK}

Herausgegeben von Rolf Hasse, Wolf Schäfer, Thomas Straubhaar, Klaus W. Zimmermann

Band 1 Lars Bünning: Die Konvergenzkriterien des Maastricht-Vertrages unter besonderer Berücksichtigung ihrer Konsistenz. 1997.

Band 2 Andreas Henning: Beveridge-Kurve, Lohnsetzung und Langzeitarbeitslosigkeit. Eine theoretische Untersuchung unter Berücksichtigung des Insider-Outsider-Ansatzes und der Entwertung des Humankapitals. 1997.

Band 3 Iris Henning: Die Reputation einer Zentralbank. Eine theoretische Untersuchung unter besonderer Berücksichtigung der Europäischen Zentralbank. 1997.

Band 4 Rüdiger Hermann: Ein gemeinsamer Markt für Elektrizität in Europa. Optionen einer Wettbewerbsordnung zwischen Anspruch und Wirklichkeit. 1997.

Band 5 Alexander Tiedtke: Japan und der Vorwurf des Trittbrettfahrerverhaltens in der US-amerikanisch-japanischen Allianz. 1997.

Band 6 Wolfgang Grimme: Ordnungspolitisches Konzept der Regionalpolitik. Darstellung der Defizite und des Reformbedarfs der Regionalpolitik am Beispiel Mecklenburg-Vorpommerns. 1997.

Band 7 Christian Ricken: Determinanten der Effektivität der Umweltpolitik. Der nationale Politikstil im Spannungsfeld von Ökonomie, Politik und Kultur. 1997.

Band 8 Christian Schmidt: Real Convergence in the European Union. An Empirical Analysis. 1997.

Band 9 Silvia Marengo: Exchange Rate Policy for MERCOSUR: Lessons from the European Union. 1998. 
Silvia Marengo - 978-3-631-75137-4

Downloaded from PubFactory at 01/11/2019 07:53:19AM

via free access 